

\section{FICHA TÉCNICA}

\section{TÍTULO}

LIBRETOS

FICTIONNALISER L'ESPACE. APPROCHES THÉMATIQUES ET CRITIQUES

Junho 2017

\section{PROPRIEDADE E EDIÇÃO}

INSTITUTO DE LITERATURA COMPARADA MARGARIDA LOSA

WWW.ILCML.COM |

VIA PANORÂMICA, S/N

4150-564 PORTO

PORTUGAL

E-MAIL: ilc@letras.up.pt

TEL: +351226077100

\section{CONSELHO DE REDACÇÃO DE LIBRETOS}

\section{DIRECTORES}

ANA LUÍSA AMARAL

ANA PAULA COUTINHO

GONCALO VILAS-BOAS

ROSA MARIA MARTELO

ORGANIZADORES DO LIBRETO № 10

JOSÉ DOMINGUES DE ALMEIDA

MARIA DE FÁTIMA OUTEIRINHO

\section{ASSISTENTE EDITORIAL}

LURDES GONÇALVES

\section{CAPA}

Instituto de Literatura Comparada Margarida Losa

PUBLICAÇÃO NÃO PERIÓDICA

\section{VERSÃO ELECTRÓNICA}

ISBN 978-989-99375-6-7

DOI: $10.21747 / 9789899937567 /$ libreto10

OBS: 0 conteúdo dos ensaios é da responsabilidade exclusiva dos seus autores.

(C) INSTITUTO DE LITERATURA COMPARADA MARGARIDA LOSA, 2017

Esta publicação é desenvolvida e financiada por Fundos Nacionais através da FCT - Fundação para a Ciência e a Tecnologia, no âmbito do Programa Estratégico "UID/ELT/00500/2013" e por Fundos FEDER através do Programa Operacional Fatores de Competitividade -COMPETE “POCI-01-0145-FEDER-007339".

\section{$\boldsymbol{X X}$ ILCML :}

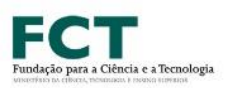

UID/ELT/00500/2013

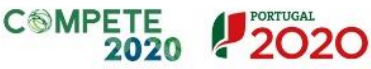

POCI-01-0145-FEDER-007339 


\section{Libretos \#10}

Fictionnaliser l'espace. Approches thématiques et critiques

Orgs. José Domingues de Almeida e

Maria de Fátima Outeirinho

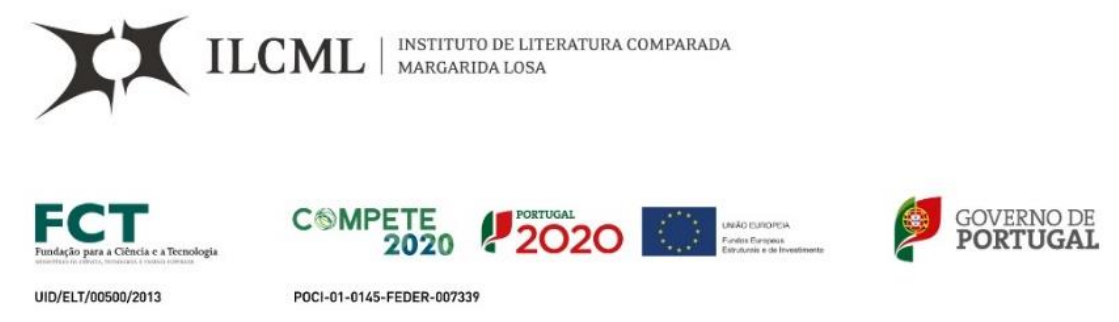





\section{Fictionnaliser l'Espace: Approches Thématiques et Critiques}

Les intersections thématiques - et partant critiques - de la fiction avec son inscription spatiale spécifique s'avèrent un fertile champ d'analyse du texte narratif, et lui assurent un intéressant ancrage renouvelé dans la référentialité. Dans ce paradigme nouveau, la perception du référent spatiotemporel suppose, selon Bertrand Wesphal ${ }^{1}$, que "le discours fictionnel que véhiculent les arts trouve ipso facto une portée originale" (2007: 13). L'approche fictionnelle de l'espace, en tant qu'espace humanisé, espace transformé en lieu (idem: 15), fonde la tâche théorico-méthodologique de la géocritique que Westphal énonce comme suit: "Il s'agira de sonder les espaces humains que les arts mimétiques [dont la fiction narrative] agencent par et dans le texte, par et dans l'image, ainsi que les interactions culturelles qui se nouent sous leur patronage" (idem: 17).

La géocritique est dès lors naturellement interdisciplinaire dans la mesure où elle "prétendra scruter, sans l'entraver, la foncière mobilité des espaces humains [qu'ils soient réels, imaginaires, voire utopiques] et des identités culturelles qu'ils véhiculent" (ibidem) et qu'elle cerne prioritairement "la dimension littéraire des lieux [et] dress[e] une cartographie fictionnelle des espaces humains" (ibidem).

Or, les auteurs du présent ouvrage nous semblent avoir saisi les enjeux critiques et la richesse thématique de cette approche spatiale de la fiction narrative, et ce pour différents écrivains, dans différentes modalités d'écriture et en référence à des espaces variés.

Ainsi, l'étude de Fernando Stefanich analyse, dans trois romans, le processus de sacralisation et de désacralisation du territoire, plus précisément de construction et de déconstruction de Buenos Aires sous l'emprise néolibérale. Toujours en Amérique latine, à partir de l'œuvre de l'écrivain brésilien controversé Rubem Fonseca, Marina 
Silveira de Melo s'attarde, dans une perspective qui se veut comparatiste et intersémiotique, aux représentations et recréations de l'espace réel. Sur le même continent, la mobilité spatiale et imaginaire trouve chez Cecilia Ramírez une lecture stimulante grâce à l'évocation de l'œuvre de l'écrivain uruguayen Juan Carlos Onetti.

Les apories des représentations de l'espace, notamment rural, chez les auteurs ibériques Julio Llamazares y Francesc Serés font l’objet de l'étude de Maria Dasca, alors que, pour Francho Nagore Laín, l'espace mythique de la vallée de Chistau devient le lieu fécond de l'inspiration d'une riche littérature qui s'exprime en aragonais.

Si Olimpia Gargano s'intéresse aux représentations de l'Albanie telle qu'elle apparaît dans la description qu'en donna en 1805 le médecin, savant et diplomate français, François C. H. L. Pouqueville, Atinati Mamatsashvili, de son côté, se propose d'examiner le lieu géographique tel qu'il est appréhendé dans les textes de fiction qui préfigurent d'une manière ou d'une autre la réalité totalitaire nazie et communiste, et ses exemples fictionnels à l'appui.

Florence Troin concentre son approche thématique et critique de l'espace sur la ville de Marseille, à la faveur de la lecture sur plusieurs volets de Sur les pas des Marins perdus de Jean-Claude Izzo, tandis que Fanny Mahy décrit la tension dichotomique entre le " normé " et le " singulier " qui engendre une dialectique particulièrement fertile entre lieux et non-lieux de la consommation dans Palomar et Marcovaldo d'Italo Calvino, et que, dans un tout autre cadre, et en contexte (post)colonial, Juliette Morel revisite, dans une optique foncièrement cartographique, Le cycle de Nedjma de Kateb Yacine.

Par ailleurs, à la question "Quelle place pour l'écrivain dans les portraits de pays photo-illustrés?", Anne Reverseau répond par le nombre non négligeable d'écrivains ayant été sollicités pour rédiger légendes, préfaces, notices, avant-propos et autres textes fictionnels ou documentaires visant à compléter le portrait d'une entité géographique.

Pour Catherine d'Humières, c'est la figure du labyrinthe qui inspire un parcours littéraire à travers quelques œuvres où parcs et jardins se rapprochent de cette figuration spatiale spécifique, alors que Claire Rosset entreprend de relever la part de réel et de fictionnalisation de l'espace dans les Albums de Croquis de l'architecte Albert Laprade. 
Finalement, Minori Noda se penche sur la particularité spatiale et narrative de la mobilité des personnages dans le roman zolien Les Rougon-Macquart alors que, pour Teresa Castela, c'est la Seine dans Épaves de Julien Green qui suscite une lecture géopoétique de Paris et de son fleuve emblématique.

Il résulte de ces différentes contributions que les espaces sont loin de se restreindre à un élément décoratif de la fiction narrative, et du texte littéraire au sens large. Bien au contraire, le lieu, comme espace habité par l'humain, dans ses activités et pratiques les plus diverses, constitue un repère indissociable de la fiction et du personnage, quand il ne s'érige pas lui-même en personnage principal. C'est en cette qualité qu'il assume un intérêt stimulant, voire rafraîchissant pour la critique, et ouvre une imperdable ligne de fuite pour la recherche en littérature.

Maria de Fátima Outeirinho

José Domingues de Almeida

Note

${ }^{1}$ Westphal, Bertrand (2007). La Géocritique. Réel, fiction, espace. Paris: Minuit. 



\title{
La représentation fictive de la Seine dans Épaves, de Julien Green
}

\author{
Teresa Castela \\ École Supérieur d'éducation à Porto
}

Résumé: Le réalisme et l'inertie apparents, qui souvent dominent le début de chaque œuvre romanesque de Green ne constituent qu'un point de départ permettant au lecteur d'accompagner l'évolution que l'écrivain lui propose, vers le malaise et l'assombrissement, puis l'espoir. Dans Épaves, Philippe, vivant à Paris dans la solitude et le vide d'une existence familiale bourgeoise, tente de brise l'ennui de ses journées par des promenades nocturnes ponctuelles au bord de la Seine. Le fleuve emblématique devient alors un élément central de l'œuvre: c'est en grande mesure par lui que la tension narrative se crée et s'intensifie. L'aspect sinistre de la Seine est affirmé par son association fréquente, non seulement à ce même adjectif, mais aussi au gouffre, au piège, à la couleur noire, au sentiment d'horreur, à la peur qu'elle suscite. Mais cette véritable descente aux enfers, provoquée par l'atmosphère fluviale, accompagnée de souffrance et de désespoir, n'est point stérile, car elle seule permet et justifie l'évolution finale du héros, du point de vue de la conscience de soi et de la reconstruction personnelle. Le chemin de l'élévation est alors suggéré, évoquant un lieu intangible: celui de la spiritualité.

Mots-clés: Green, Épaves, Seine, Paris.

Resumo: 0 realismo e a inércia aparente que muitas vezes dominam o início de cada romance de Green são apenas um ponto de partida para o leitor acompanhar a evolução que o escritor lhe dá, rumo ao malestar e desânimo, e depois a esperança. Em Épaves, Philippe, que vive em Paris na solidão e no vazio da vida familiar burguesa, tenta quebrar o tédio dos dias com passeios noturnos ocasionais ao longo do Sena. O rio emblemático torna-se um elemento central da obra: é em grande medida através dele que a tensão narrativa é criada e intensificada. A aparência sinistra do Sena é afirmada por sua associação frequente, não só a esse adjetivo, mas também à armadilha, ao abismo, ao horror, ao medo que desperta. Mas esta descida aos infernos, causada pela atmosfera fluvial, acompanhada por sofrimento e desespero, afigura-se estéril, pois só ela permite e justifica a evolução final do herói, do ponto de vista da autoconsciência e da 
reconstrução pessoal. 0 caminho da elevação é então sugerido ao evocar um lugar intangível: o da espiritualidade.

Palavras-chave: Green, Épaves, Sena, Paris.

Green a souvent été vu comme un écrivain essentiellement attaché au réel, au concret. Toutefois, nous considérons que le réalisme et l'inertie apparents, si présents dans les premières pages des œuvres romanesques de l'auteur, ne constituent qu'un point de départ pour permettre au lecteur d'accompagner l'évolution narrative vers le malaise et l'assombrissement puis, dans certaines œuvres, l'espoir.

Dans Épaves, Philippe, vivant à Paris dans la solitude et le vide d'une existence familiale bourgeoise, tente de brise l'ennui de ses journées par des promenades nocturnes ponctuelles au bord de la Seine. Le fleuve emblématique devient alors un élément central de l'œuvre. En effet, c'est en grande mesure par lui que la tension narrative se crée et s'intensifie. L'aspect sinistre de la Seine est affirmé par son association fréquente, non seulement à ce même adjectif, mais aussi au gouffre, au piège, à la couleur noire, au sentiment d'horreur, à la peur qu'elle suscite. ${ }^{1}$

Mais cette véritable descente aux enfers, provoquée par l'atmosphère fluviale, accompagnée de souffrance et de désespoir, n'est point stérile, car elle seule permet et justifie l'évolution finale du héros, du point de vue de la conscience de soi et de la reconstruction personnelle. Le chemin de l'élévation est alors suggéré, évoquant un lieu intangible: celui de la spiritualité.

\section{1- La descente aux enfers}

Dans Épaves, Green nous plonge dans l'existence ordinaire d'un bourgeois encore jeune, vivant de la fortune héritée de son père, dans un luxueux appartement parisien avec sa femme et sa belle-sœur, l'enfant du couple ayant été mis en pension. Toutefois, pour des raisons diverses, peu de temps après son mariage Philippe se lasse de la présence de ces deux femmes. Ennuyé de se voir mener une existence prédéfinie, qui s'est quasiment imposée à lui et a affaibli son caractère, Philippe est inconsciemment 
porté vers l'extérieur, vers l'inconnu, vers un espace susceptible de lui faire découvrir d'autres dimensions du monde et de lui-même.

Le cadre initial de l'œuvre semble donc évoquer le caractère trivial et médiocre de l'existence, en dépit de la position sociale attribuée aux protagonistes. Mais si le point de départ de la création romanesque greenienne présente, tout d'abord, une telle apparence réaliste, si les lieux et les personnages créés semblent, au premier regard, correspondre à une image commune, cette impression est un leurre car elle est de courte durée. La construction d'aspects apparemment inhérents au réel représente, en quelque sorte, une invitation au voyage adressée au lecteur, vers un univers bien plus cher à Green, celui où dominent l'exagération inquiétante et l'étrangeté et où il est permis à l'écrivain de donner libre cours à ses idées sombres. ${ }^{2}$ Ce n'est donc pas, comme l'a justement remarqué Marie-Françoise Canérot, "par la fuite hors du réel que les premiers romans de Julien Green sont insolites, mais au contraire par une attention si aiguë, si continue, aux réalités les plus communes de l'existence qu'elle en devient insolente et insolite". ${ }^{3}$ La combinaison d'éléments insolites, dont la présence tend à dominer progressivement le récit, avec ceux qui nous rappellent le monde ordinaire, nous plonge dans un univers surréel où toutes les démesures sont permises. C'est par cette technique de la création littéraire, que l'auteur dépasse les limites du vraisemblable pour entrer dans le fantastique.

Les jeux autour des symboles jouent, dans le cadre de la transition entre le monde apparemment réaliste et le monde fantastique, un rôle central. Ainsi, dans Épaves, la Seine, en tant qu'élément aquatique sinistre symbole, dans l'œuvre, d'une féminité maléfique, assume une place marquante. L'image inquiétante que Green créé du fleuve parisien s'appuie sur un parcours développé tout au long de l'œuvre, fortement marqué par la négativité des apparences variables et inquiétantes que prend la Seine sous la plume du romancier.

Malgré les dimensions réelles du fleuve, connues de tous, l'écrivain accentue son image néfaste en lui attribuant, en certaines occasions, la caractéristique de l'immobilité, évoquée entre autres par la référence à sa noirceur et à des sonorités aquatiques sinistres, quasiment imperceptibles. Le fleuve devient alors, par son aspect figé, un lac. 
L'eau bougeait à peine; [Philippe] la voyait se froncer comme une étoffe autour d'une péniche vide amarrée à quelques mètres en aval, mais le clapotis du flot contre la pierre ne s'entendait presque plus. [...] À ses pieds, le fleuve n'était plus qu'un lac noir dont les bords s'effaçaient. (Green 1973: 31)

Nous retrouvons ainsi, chez Green, l'image de l'eau "triste et sombre" évoquée par Bachelard, une eau qui "transmet d'étranges et de funestes murmures", 4 dont l'aspect immobile évoque la perte de ses propriétés purifiantes habituelles et la mort. ${ }^{5}$ L'image du double, rendue par le reflet aquatique devient alors un présage de mort. Bachelard ne manque pas de le signaler: "l'être voué à l'eau est un être en vertige. Il meurt à chaque minute sans cesse quelque chose de sa substance” (Bachelard 1942: 9). Pour Durand, "cette eau noire n'est finalement que le sang, que le mystère du sang qui fuit dans les veines ou s'échappe avec la vie par la blessure dont l'aspect menstruel vient encore surdéterminer la valorisation temporelle. Le sang est redoutable à la fois parce qu'il est maître de la vie et de la mort, mais aussi parce qu'en sa féminité il est la première horloge humaine, le premier signe humain corrélatif du drame lunaire" (Durand 1992: 122). L'eau noire représenterait ainsi la féminité négative, par son association au sang menstruel et au temps.

Toutefois les eaux mouvantes de la Seine, dans Épaves, ne sont pas plus tranquillisantes que les calmes. L'agitation du fleuve acquiert, elle aussi, chez le romancier, une signification dépréciative et sinistre. D’après les propos adressés à son fils la Seine, qui "coule plus vite qu'un homme ne marche" (Green 1973, t. II: 165) est, pour Philippe, la complice des malfaiteurs “Tout ce qu'on lui jette, elle le cache et elle l'emporte. C'est à cause d'elle que ces voleurs se montrent si hardis" (ibidem). Le courant fluvial surgit alors, une fois de plus, sous sa dimension maléfique. Une telle représentation rejoint l'image récurrente des eaux agitées comme symbole du mal, et du désordre (Chevalier/Gheerbrand 1982: 378). L'eau violente "est un des premiers schèmes de la colère universelle" (Bachelard 1942: 239-240), nous rappelle Bachelard.

Les connotations négatives liées à la Seine sont nombreuses et récurrentes dans Épaves, et leur maintien résiste, nous l'avons vu, aux variations d'aspect du fleuve. Mais l'élément aquatique ne se borne pas aux limites définies par l'homme et destinées au cours du fleuve. L'image du pavé humide, du brouillard (Green 1973, t. II: 29) qui finit 
par transformer une "obscure nuit d'automne [...] en une nuit surnaturelle, aussi pâle que l'autre était noire, mais impénétrable" (idem: 39), qui "[gagne] les quais, étouffant peu à peu les lumières" (ibidem), "la forte odeur de l'eau qui [enveloppe le protagoniste]" (idem: 29), son bruit (idem: 27) permettent l'élargissement de l'espace liquide, il finit par s'étendre à la rue et à la ville, accentuant sa proximité face au héros. Le domaine d'intervention de l'élément liquide est ainsi élargi tout comme sa menaçante puissance.

Dans l'atmosphère envoûtante et solitaire savourée par Philippe durant l'une de ses promenades nocturnes, où il se sent tout d'abord porté vers la rêverie, il est conduit vers le lieu où il a vu une femme se faire agresser, qu'il associe à la noyée dont parlent les journaux. Le surgissement soudain, à l'endroit du crime, d'une vieille mendiante sinistre, aux "cheveux d'un gris verdâtre",6 semble nous convier à confondre le fleuve et l'image féminine maléfique. En effet, cette femme, qui retarde le protagoniste d'Épaves, l'attire étrangement vers le bord de la Seine, en une sorte d'invitation à la mort, dont les signes s'inscrivent sur ses propres traits:

La femme leva vers lui une figure aux chairs grises; ses paupières sans cils retombaient lourdement sur des yeux qu'elles cachaient. Il lui manquait trop de dents pour qu'elle pût articuler ses mots. [...] cette créature dont ni la vie ni la mort ne semblaient vouloir, connaissait peut-être de grands bonheurs. (Green 1973: 28)

L'atmosphère qui succède à l'étrange rencontre renforce notre interprétation. Le brouillard, dont le mouvement ascensionnel suggère alors, paradoxalement, l'image du gouffre $^{7}$ et évoque, par conséquent, la négativité du mouvement descendant, finit par emprisonner le héros, il le réduit à l'inaction. La brume meurtrière qui "étouffe peu à peu les lumières" (ibidem), qui "[retire] du monde [...] les lumières, puis les sons" (ibidem), s'empare du protagoniste neutralisant son instinct de survie et l'exposant, par là même, à la mort:

Le sentiment d'être tout à coup prisonnier du brouillard lui donna un malaise sans qu'il eût le désir de s'éloigner. Cet étrange instinct qui nous conseille parfois de nous nuire à nous-mêmes lui commandait de rester là. (Green 1973: 30) 
Le brouillard, en tant qu'extension de l'eau fluviale, rejoint l'image aquatique “superlativement mortuaire”, "substance symbolique de la mort” (Bachelard 1942: 79), que Bachelard identifie dans l'œuvre d'Edgar Poe. L'eau nocturne est ainsi, pour Green comme il en est chez le poète, une invitation au voyage sans retour, à la mort.

Le surgissement d'une figure féminine inquiétante aux pouvoirs mortifères, à proximité de l'endroit où une autre femme avait été noyée par son partenaire, semble suggérer une sorte de métamorphose de la victime en élément maléfique, en conséquence d'une immersion violente causée par une intrigue amoureuse. Par son côté inquiétant, le personnage féminin de Green, émergeant des profondeurs, rappelle donc ces figures qui "depuis les Sirènes antiques représentent, au sens le plus profond du terme, le charme des eaux" (Brunel 2002: 584). Elles attirent les hommes pour les conduire à leur perte.

La pulsion de mort suscitée par le fleuve chez le héros d'Épaves est notable. Philippe est attiré par le bruit de l'eau, ${ }^{8}$ par son odeur, ${ }^{9}$ par le "gouffre", par le "vide" audessus duquel il incline son torse, ${ }^{10}$ il se penche sur l'“eau noire",11 il en vient même à partager avec son fils le sentiment de vertige que la proximité du fleuve éveille en lui12 et à se laisser tenter par l'idée du suicide dont la présence de l'enfant, finalement, le dissuade. ${ }^{13}$ La Seine exerce sur Philippe un charme comparable à celui d'une femme séductrice, dont il se serait inexplicablement épris. Tout comme il en est dans les relations amoureuses greeniennes communes, la proximité de ces curieux amants surgit alors à la fois comme une pulsion et comme un danger mortel:

Toute sa vie, ce fleuve [...] avait attiré [Philippe] sans qu'il pût comprendre pourquoi. Il existait entre eux une sorte de parenté mystérieuse. Ainsi, lorsque Philippe se promenait le long de la Seine, il avait quelquefois l'impression fugitive qu'elle lui parlait et que, de le voir si souvent là, elle avait fini par recueillir ses secrets. Cependant, elle lui faisait peur : il s'inclinait légèrement audessus d'elle et son cœur se serrait aussitôt. (Green 1973: 199)

Quoique la Seine surgisse surtout, dans Épaves, comme un élément négatif, par son côté néfaste que le lien de l'élément aquatique avec la féminité renforce, Green n'annule pas pour autant la valence positive du symbole de l'eau, en tant que double originaire de la conscience, évoquant alors l'élucidation et la connaissance de soi. 


\section{2- Vers l'élévation spirituelle, l'évocation d'une dimension divine}

La signification symbolique de l'eau comme source de vie, moyen de purification et surtout de régénération, des traditions les plus anciennes, ${ }^{14}$ présente dans l'Ancien et le Nouveau Testament, 15 est reprise par l'auteur; quoique l'évolution signalée, porteuse d'espoir, ne surgisse que vers la fin du roman.

La recherche de situations nouvelles, dangereuses, la quête de nouveaux espaces d'exploration externe et interne, menée par des personnages greeniens jeunes, comme Philippe, marqués par la fragilité et la "craintive incertitude"16 de leur être, nous rappellent l'attitude de l'auteur évoquée dans Jeunesse. Green confesse, en effet, se trahir et se retrouver, souvent lorsque, dans ses projections fictives, il se fait passer pour un autre. ${ }^{17}$ Ses romans deviennent, sous cet aspect, le véritable champ d'exploration de soi où le mal fait éclater la vérité, si recherchée par l'auteur.

La confrontation avec le monde extérieur représente ainsi, pour les personnages fragilisés par leurs incertitudes au sujet de leur individualité, tout comme il en a été pour l'écrivain dans ses jeunes années, le chemin vers une véritable conscience de soi. L'élan vers l'eau en particulier, élément réflecteur par nature, semble évoquer, par l'image du double, l'urgence de la rencontre avec soi-même. En somme, il découlerait du désir de rétablir l'équilibre intérieur et de rencontrer, par là même, l'unité première, perdue depuis l'abandon du Paradis que l'enfance représente. ${ }^{18}$

Dans Épaves, l'accomplissement social apparent, n'évite pas le parcours descendant de la destruction progressive de l'être. L'existence du héros est marquée par l'égarement, l'échec, les désillusions consécutives et la dégradation personnelle qui en découle. Toutefois, les épreuves subies s'avèrent indispensables à l'évolution spirituelle de l'individu. Ce point de vue n'est pas sans nous rappeler celui de Nietzsche: "la lutte, le tourment, la destruction des phénomènes nous apparaissent à présent nécessaires, vu la surabondance des formes innombrables qui se pressent et se bousculent dans l'existence, vu la fécondité débordante du vouloir universel. Nous nous sentons transpercés par l'aiguillon furieux de ces maux, à l'instant même où nous pressentons dans l'extase dionysiaque l'éternité indestructible de cette éternité".19 Une fois atteint l'âge où le moi a fait son apparition, pour atteindre Dieu, il est nécessaire de se connaître; or ce sont les différentes expériences de la vie, et surtout ses échecs, qui 
révèlent l'individu à lui-même. La souffrance révèle à l'être sa dimension morale, l'essence de sa personne, la véritable dimension du monde. Chez Green, au chemin descendant de l'existence terrestre correspond ainsi, souvent, un parcours ascendant dont la présence, dans l'œuvre, se révèle discrète mais effective, celui de la progressive connaissance de soi et de la sensibilisation graduelle face à la dimension spirituelle environnante, susceptibles de conduire à des moments de pur bonheur et même au pur Amour, celui que seul Dieu prodigue. Nous rejoignons sur ce point Valérie Catelain qui voit, dans le "mouvement initiatique" suivi par les figures greeniennes "une élévation constante vers la lumière qui s'appuie sur le souvenir de ce qui relie intrinsèquement à l'invisible ou au sacré et peut mener vers la sainteté".20

Notons, toutefois, que la spiritualité présentée par Green demeure indéfinie, car elle représente, avant tout, une expérience personnelle, unique, indescriptible, associée à la recherche du bonheur à travers la connaissance de soi, pouvant conduire à Dieu. Les influences spirituelles de l'auteur sont d'ailleurs multiples. Quoiqu'il ait été essentiellement marqué par le protestantisme et le catholicisme, nous connaissons son intérêt pour l'hindouisme et le bouddhisme. D’autre part l'auteur a clairement exprimé son refus d'écrire des œuvres édifiantes. ${ }^{21}$ Reine-Marie Desnues l'a bien compris: "Les êtres de paroxysme créés par Green ne sont pas des personnages de romanciers psychologues et moralistes mais des êtres animés par un courant de vie intérieure intense qui sont chargés de nous montrer l'homme affronté à son destin mystérieux et inexpliqué. Par ces créatures étranges, insolites, le romancier veut nous faire pénétrer dans un monde plus total qui ne se réduit pas seulement au réel tel que nous le concevons habituellement”. ${ }^{22}$ En effet, Green semble vouloir aller au-delà du tangible, "s'il ressent, comme [Sartre], la 'nausée' du monde réel, et l'angoisse' existentialiste, il a aussi, comme [Bernanos], la certitude triomphante d'une autre vie". 23 Mais l'espoir d'une transcendance, que la spiritualité greenienne intègre, ne prend pas obligatoirement une forme religieuse, comme l'observe Michèle Raclot. ${ }^{24}$ Le mystère, comme indice de la dimension surnaturelle de son œuvre autorise diverses interprétations c'est au lecteur, selon sa sensibilité, de lui attribuer une signification finale dont le sens mystique n'est point exclu. La spiritualité greenienne se révèle ainsi enrichissante, du point de vue romanesque, entre autres parce qu'elle implique une participation active du lecteur. 
L'utilisation de non-dits, de litotes, d'interrogations, provoque l'inquiétude et la curiosité de celui-ci, il finit par se voir appelé à construire le sens du dénouement proposé, ouvrant sur une dimension demeurée indéfinie, nonobstant la suggestion insinuée.

Dans Épaves, comme dans la généralité des romans greeniens, l'espace visible, décrit souvent avec une minutie extrême, comme il en est pour la Seine, représente bien plus qu'un cadre réaliste. C'est la sensibilisation à l'existence d'une dimension distincte de celle dont nous avons la perception immédiate, à travers la vision, qui véritablement intéresse l'auteur. Plus que le réalisme, le détail descriptif vise en effet l'éveil de sensations chez le lecteur, la perception du monde invisible.

Green nous invite en effet, de façon discrète et graduelle, à regarder au-delà des évidences propres à l'univers physique et matériel, apportant ainsi à son œuvre une dimension spirituelle, tout en échappant au danger, qu'il a toujours voulu éviter, de la rendre édifiante.

\section{Bibliographie}

Bachelard, Gaston (1942), L'Eau et les Rêves, Essai sur l'imagination de la matière, Librairie José Corti.

Brodin, Pierre (1963), Julien Green, Éditions Universitaires, coll. Classiques du XXe siècle. Brunel, Pierre (2002), "Mythologie féminine de l'eau", dans Dictionnaire des mythes féminins, dir. Pierre Brunel, Éditions du Rocher.

Canérot, Marie-Françoise (1998), "Les Premiers romans de Julien Green: un réalisme insolent et insolite", dans Julien Green et l'insolite, dir. Marie-Françoise Canérot, Michèle Raclot et Jean-Pierre Piriou, Société Internationale d'Études Greeniennes.

Catelain, Valérie (2006), "Les Voies de la 'renaissance' dans L'Autre", dans Julien Green: visages de l'altérité, dir. Marie-Françoise Canérot et Michèle Raclot, L'Harmattan, coll. Critiques littéraires: 11-29. 
Chevalier, Jean et Gheerbrand, Alain (1982), Dictionnaire des symboles (1969), Éditions Robert Laffont et Éditions Jupiter.

Desnues, Reine-Marie (1961), Chap. “Julien Green”, dans Des auteurs et des hommes, Paul Claudel, André Gide, Marcel Proust, Georges Duhamel, André Maurois, François Mauriac, Henry de Montherlant, Georges Bernanos, Julien Green, Éditions Fleurus.

Durand, Gilbert (1992), Les Structures anthropologiques de l'imaginaire, (1969), Bordas.

Floucat, Yves (1997), Julien Green et Jacques Maritain. L'Amour du vrai et la fidélité du cœur, Éd. Pierre Téqui.

Glaudes, Pierre (1990), “Narcisse au labyrinthe”, Roman 20-50, no 10, “Chaque homme dans sa nuit" de Julien Green, dir. Monique Gosselin.

Green, Julien (1973), Épaves, Gallimard, Bibliothèque de la Pléiade, t. II.

Nietzsche, Friedrich (1949), La Naissance de la tragédie, trad. Geneviève Bianquis, Gallimard.

Petit, Jacques (1973), Notes afférentes à L'Autre, Gallimard, Bibliothèque de la Pléiade, vol. III.

Raclot, Michèle (1988), Le Sens du mystère dans l'œuvre romanesque de Julien Green, Aux amateurs de livres.

Teresa Castela est Enseignante à l'École Supérieure d'Éducation (ESE) de l'Instituto Politécnico de Porto. Docteur en Littérature Comparée (2013) à la suite de la soutenance de sa thèse à l'Université de Paris IV, Sorbonne, intitulée : Sous le signe de Moïra, l'univers féminin dans l'œuvre romanesque de Julien Green. Son domaine de recherche est la littérature française du XXe siècle. 


\section{Notes}

${ }^{1}$ Green, Julien (1973), Épaves, Gallimard, Bibliothèque de la Pléiade, t. II, p. 5, 30, 31, 165... Sauf mention contraire, toutes les références aux œuvres de Julien Green renverront à cette édition. Seul le titre de l'œuvre sera désormais indiqué, suivi du numéro du volume des OEuvres complètes dans lequel il figure, en chiffres romains, et du numéro de la page.

2 Yves Floucat ne manque pas d'évoquer l'inclination du romancier pour les "pensées sombres" qui assaillent l'écrivain dès sa jeunesse (Julien Green cité par Yves Floucat. Floucat, Yves (1997), Julien Green et Jacques Maritain. L’Amour du vrai et la fidélité du cœur, Éd. Pierre Téqui: 17).

3 Canérot, Marie-Françoise (1998), "Les Premiers romans de Julien Green: un réalisme insolent et insolite", dans Julien Green et l'insolite, dir. Marie-Françoise Canérot, Michèle Raclot et Jean-Pierre Piriou, Société Internationale d'Études Greeniennes, 67-79: 68.

${ }^{4}$ Bachelard, Gaston (1942), L'Eau et les Rêves, Essai sur l'imagination de la matière, Librairie José Corti: 66.

${ }^{5}$ Chevalier, Jean et Gheerbrand, Alain (1982), Dictionnaire des symboles (1969), Éditions Robert Laffont et Éditions Jupiter: 381.

6 Ibid. La référence aux cheveux verts nous rappelle l'image des sirènes qui, dans le contexte mythologique, jouent un rôle maléfique. En effet, en faisant usage de leur charme, elles attiraient les marins vers les profondeurs aquatiques, provoquant leur mort. Ici l'image sinistre de la sirène est accentuée par une représentation physique défavorisée de la figure féminine qui l'évoque.

7 “la Seine fumait, envoyant dans les profondeurs du ciel noir un air blanchâtre et opaque” (ibid., p. 30).

${ }^{8}$ Cf. Épaves, II, p. 27, 199.

${ }^{9}$ Ibid., p. 199.

10 Ibid., p. 3.

11 Ibid., p. 23.

12 Ibid., p. 163, 164.

13 Ibid., p. 177.

${ }^{14}$ Chevalier, Jean et Gheerbrand, Alain, op. cit., p. 374.

15 Ibid., p. 376.

16 Jeunesse, V, p. 1303, 1304.

17 “La confession la plus sincère et la plus franche peut devenir le plus impénétrable des masques. C'est souvent quand l'auteur prétend être quelqu'un d'autre qu'il se trahit" (Julien Green, L'Homme et son ombre, texte français et texte anglais en regard, trad. Julien Green, Éditions du Seuil, 1991). 
18 Glaudes, Pierre (1990), "Narcisse au labyrinthe", Roman 20-50, no 10, "Chaque homme dans sa nuit" de Julien Green, dir. Monique Gosselin, p. 101.

${ }^{19}$ Nietzsche, Friedrich (1949), La Naissance de la tragédie, trad. Geneviève Bianquis, Gallimard, p. 112.

${ }^{20}$ Catelain, Valérie (2006), "Les Voies de la "renaissance" dans L'Autre", dans Julien Green: visages de l'altérité, dir. Marie-Françoise Canérot et Michèle Raclot, L'Harmattan, coll. Critiques littéraires, p. 28.

${ }^{21}$ Petit, Jacques (1973), Notes afférentes à L'Autre, Gallimard, Bibliothèque de la Pléiade, vol. III, p. 1712.

22 Desnues, Reine-Marie (1961), Chap. "Julien Green”, dans Des auteurs et des hommes, Paul Claudel, André Gide, Marcel Proust, Georges Duhamel, André Maurois, François Mauriac, Henry de Montherlant, Georges Bernanos, Julien Green, Éditions Fleurus, p. 507.

${ }^{23}$ Brodin, Pierre (1963), Julien Green, Éditions Universitaires, coll. Classiques du XXe siècle, p. 8-9.

${ }^{24}$ Cette idée est indirectement exprimée lorsque Michèle Raclot définit le mystère de Green comme "l'espoir et le signe d'une transcendance, qu'elle prenne ou non une forme religieuse" (Raclot, Michèle (1988), Le Sens du mystère dans l'œuvre romanesque de Julien Green, Aux amateurs de livres, p. 945). 


\section{Una poética del espacio abandonado. El caso de Julio Llamazares y Francesc Serés}

\section{Maria Dasca}

TRILCAT-Universitat Pompeu Fabra (Barcelona)

Résumé: Dans le vaste panorama de la littérature ibérique actuelle, deux romanciers, Julio Llamazares (1955) et Francesc Serés (1972) ont consacré plusieurs romans au sujet de l'abandon des espaces de leur jeunesse. Dans la trilogie De fems i de marbres (2003) et le recueil de récits La pell de la frontera (2014), Serés offre un large portrait des changements produits dans le territoire frontalier entre l'Aragon et la Catalogne. Le centre de son écriture est le rapport entre l'Homme (et sa mémoire) et l'espace (et son histoire). L'idée d'un espace rural appauvri par le dépeuplement et l'érosion est également présent dans les romans La lluvia amarilla (1988) et Escenas de cine mudo (1994) de Julio Llamazares, où il décrit le paysage en déclin d'un village aragonais et d'un hameau léonais. Les deux narrateurs utilisent une prose stylisé et poétique pour préciser les contours d'un espace dégradé, lié à son expérience et à sa participation, en tant que narrateurs, dans la construction imaginaire du territoire. L'objectif de mon étude est d'analyser la mise en fiction de ces deux espaces littéraires (la campagne léonaise et aragonaise) dans l'écriture de Serés et Llamazares. Je vais analyser le rôle de la mémoire dans la construction symbolique d'un territoire imaginaire et historique.

Mots-clés: Serés, Llamazares, géographie, Aragon.

Resumo: No vasto panorama da literatura ibérica atual, dois romancistas, Julio Llamazares (1955) e Francesc Serés (1972) dedicaram vários romances ao tema do abandono dos espaços da juventude. Na trilogia De fems i de marbres (2003) e na coletânea de narrativas La pell de la frontera (2014), Serés proporciona um amplo retrato das mudanças ocorridas no território fronteiriço entre Aragão e a 
Catalunha. 0 centro de sua escrita é a relação entre o Homem (e sua memória) e o espaço (e sua história). A ideia de um espaço rural empobrecido pelo despovoamento e a erosão está também presente nos romances La lluvia amarilla (1988) e Escenas de cine mudo (1994) de Julio Llamazares em que descreve uma paisagem em declínio de uma freguesia aragonesa e de um lugarejo leonês. Ambos os narradores usam uma prosa estilizada e poética para definir os contornos de um espaço degradado, ligado à sua experiência e participação, enquanto narradores, na construção imaginária do território. 0 objetivo do meu estudo é analisar a ficcionalização desses dois espaços literários (o campo leonês e aragonês) na escrita de Serés Llamazares. Analisarei o papel da memória na construção simbólica de um território imaginário e histórico.

Palavras-chave: Serés, Llamazares, geografia, Aragão.

"la gravedad [del mundo] contiene su ligereza" Italo Calvino, Lecciones americanas

\section{Dos imaginarios afines}

La ficción ibérica actual dedicada a la representación del espacio rural testimonia los cambios profundos que, en parte, lo han mantenido al margen de la modernidad artística. Más allá de la posición estéril de determinados planteamientos propios del revival costumbrista, y más allá de la (inoperativa) confrontación entre espacio rural y espacio urbano (Martínez Gil, 1991), escritores como Julio Llamazares (1955) y Francesc Serés (1972) han dedicado una parte significativa de su producción novelística al motivo del abandono del mundo rural. Ambos narradores utilizan una prosa estilizada y poética para ficcionalizar un espacio en cambio constante, que han conocido directamente, en una aproximación, antropológica y epistemológica, que lo moderniza (Resina/Wiestenz, 2012). Sus lugares literarios forman parte de la microhistoria y están poblados por personajes condicionados por las circunstancias, víctimas de las transformaciones materiales y sociales en que se sustentaba su razón de ser y cuya marginación se relaciona con la moral (y la ética) del vencido.

Precisando más, el tema del progresivo despoblamiento y erosión de un pueblo del Pirineo de Huesca, Ainielle, es el punto de partida de la novela La lluvia amarilla (1988) de Llamazares, mientras que los cambios introducidos en las formas de vida de 
Zaidí, una aldea situada en la Franja, el territorio fronterizo de habla catalana entre Cataluña y Aragón, centraliza la trilogía De estiércol y mármol (2003), que recoge los volúmenes El vientre de la tierra, El árbol sin tronco y Una lengua de plomo ${ }^{1}$ de Serés. A través de historias que ponen en relación el individuo con el territorio, el autor modula distintas voces que canalizan una memoria colectiva y dan una dimensión mítica al relato.

Las propuestas narrativas de Llamazares y Serés parten, a la vez, de los principios propios del modelo representacional (respetan la linealidad narrativa, la verosimilitud descriptiva y la identificación empática del texto con el lector) para crear ficciones modernas, cuyo elemento actualizador es justamente el discurso ético y estético que les es implícito.

El objetivo de mi artículo es analizar la ficcionalización de estos dos espacios literarios, situados en dos puntos distintos del campo aragonés, el valle (Zaidí) y la montaña (Ainielle), mediante el estudio de tres elementos compartidos en la escritura de ambos autores: 1) la construcción de una epistemología del paisaje a partir de la ética de los personajes; 2) el recurso a la simbolización de elementos de la naturaleza mediante la subjetivación espacial y la representación visual y sensorial de este imaginario espacial; 3) el uso de una temporización equívoca.

La tensión que se produce en ambos espacios es el resultado del choque entre la vida consuetudinaria y la mutación que supone la progresiva migración al espacio urbano; la autosuficiencia basada en una economía de sustento y el descubrimiento de unas formas de vida que amplían los horizontes vitales tradicionales y, finalmente, la alteración en la rutina que supuso la experiencia traumática de la guerra civil española en el campo aragonés.

Fue el crítico catalán Jordi Marrugat, quien, en su estudio Literatura catalana de la postmodernitat (2014), explicó algunas de las coincidencias entre ambos proyectos novelísticos. Se trata, según Marrugat, de una literatura focalizada en la reconstrucción de un espacio rural de base mítica, que describe minuciosamente los cambios desde la base del discurso de una voz elegíaca: 
En termes generals, la fórmula narrativa d'aquesta trilogia - la recuperació d'un món desaparegut des de la consciència dels canvis individuals i col·lectius que això ha comportat-és sens dubte molt propera a la de l'escriptor espanyol Julio Llamazares. (Marrugat 2014: 173-174)

La modernización de la propuesta recae, sin embargo, en la articulación de un entramado de historias personales en que mezclan distintos tiempos (histórico e individual), marcadas por "l'elegia de la vida individual constantment perduda, les formes de vida col-lectives, els ideals mai assolits" (idem: 178).

\section{La voz ética de los personajes}

La trilogía de Serés comienza con Los vientres de la tierra, cuyos episodios se refieren a una experiencia vital (el embarazo, el trabajo o la vejez) que se relaciona con percepciones sensoriales (los títulos son conceptos como "Sentir", "Mirar", "Ser" o "Beber"); continua (El árbol sin tronco) con la relación de lugares, cosas y personas que un narrador maduro (Assís) hace en el repaso mental de su vida, y se cierra (Una lengua de plomo) con relato épico del final de toda la comunidad: "Aquesta és la descendència, el descens, la decadència dels que viuran pitjor que nosaltres." (p. 377). El discurso se articula a través de unas voces que explican el tipo de relación que tienen con el territorio, articulando, fragmentariamente, un discurso colectivo.

Este uso de distintas voces (la polifonía bakhtiniana) implica un cuestionamiento del universo referido: ya no hay una versión de la historia, sino tantas versiones como voces. Como en la novela posmoderna, se genera un universo de signos sin referentes. En este sentido, la ficción de Serés coincide con algunas de las novelas catalanas más significativas de las tres últimas décadas (como Camino de sirga, 1988, de Jesús Moncada, o Las voces del Pamano, 2004, de Jaume Cabré) cuya modalidad discursiva implicaba el uso de una heteroglosia intradiegética. Con este planteamiento, como reveló un estudio de Neus Carbonell centrado en la novela En el último azul, de Carme Riera, el autor construye una ficción que, sin renunciar a un planteamiento ético, opta por desconstruir la distancia entre la identidad y la alteridad sin apropiarse de esta última, ya que "la multiplicitat de veus, l'heteroglòssia, que caracteritza l'obra fa possible aquesta deconstrucció" (Carbonell 2000: 268). 
Esta opción discursiva y ética difiere de la de La lluvia amarilla. Según ha analizado Gonzalo Navajas, el libro de Llamazares parte de la construcción de un personaje que se autoexcluye de una circunstancia general dominada por la fluidez y la provisionalidad, y se resiste al cambio adoptando una vida lenta, estática y sin movilidad. En contra de lo temporal, impone lo eterno e inmutable. Ya no tenemos polifonía, sino una sola voz cuyo relato se focaliza en el progresivo deterioro del territorio y de quienes lo habitan, a la vez que recupera las voces de los habitantes (o del fantasma en que se convierte el protagonista) que lo ocuparon. Así, la novela constituye una reapropiación de la novela clásica representacional "para configurarla de nuevo a través de la reactualización de formas y figuras arquetípicas del archivo cultural común." (Navajas 1998: 30). Sabedor de un conocimiento que perecerá con su extinción, la actitud de Andrés, el último habitante del pueblo, encarna una resistencia a ultranza. Según Navajas:

[La novela de Llamazares] asume para sí esa función rehabilitadora de las causas perdidas, de un horizonte de expectativas generalizador. Frente a la dispersión y al minimalismo restablece aunque sea de manera provisional e indirecta - la opción del enfrentamiento contra ese statu quo dominador. [...] la opción ética aparece, por consiguiente, en él como un acto estrictamente individual concebido y ejecutado a partir de la desconexión de los nexos civilizadores, del discurso de la ciudad. (idem: 24, 26)

La praxis ética del protagonista se identifica, a la vez, con el posicionamiento de un autor que resiste a aceptar, en su escritura, determinados principios de la novela posmoderna, como la disolución de la continuidad temporal, la desaparición de la opción ética y la legitimidad de la representacionalidad testimonial (idem: 15).

La obra Serés, por su parte, además de prestarse a una lectura en clave ética, incluye personajes que aceptan pasivamente el curso de la historia entendiéndola como un devenir imparable y confundiéndose con la tierra de que forman parte. Su relación con el espacio es dialógica en la medida que incluye la asunción de lo que no les pertenece: el mundo urbano. La trilogía está constituida por capítulos breves, focalizados en personajes distintos, excepto en El árbol de plomo, con un único personaje central: Assís. En la ficción la experiencia migratoria implica la imposibilidad de volver a los orígenes, y esta experiencia es expresada a través del rechazo de la tierra: "els llocs, 
ja ho veus, no deixen tornar" (p. 411). Tomando conciencia de la necesidad de construirse a sí mismos ("només t’heretes a tu mateix", p. 329), los personajes, como en la obra de Llamazares, se abandonan a una inercia y un tempo que ralentiza la acción. Así, la parataxis predomina en unas ficciones donde la naturaleza fatalmente invade el espacio humano: “El parc comença lent allà on acaba l'escola” (p. 228).

\section{El paisaje sensorial y gnoseológico}

Asimismo, la obra de ambos autores parte de la subjetivación del entorno. Esta implica tres procedimientos: 1) el uso de la memoria (las historias se construyen in media res, en un movimiento temporal retrospectivo); 2) la creación de un universo fantasmagórico asociado al recuerdo; y 3) la humanización e identificación con el paisaje.

Unos de los elementos básicos para la construcción del relato es el uso de la memoria. El espacio construido en la obra de Llamazares depende de un tiempo ucrónico y se explica mediante la voluntad de retorno a un origen primordial, el del olvido que es la muerte, que excluye diametralmente el uso del presente y del futuro. Las continuas alusiones a un paisaje decrépito (simbolizado por la lluvia amarilla o el óxido) marcan esta alternancia entre un presente hecho de olvido y un pasado que vuelve:

\footnotetext{
Pero hay hogueras que arden bajo la tierra, grietas de la memoria tan secas y profundas que ni siquiera el diluvio de la vida bastaría tal vez para borrarlas. Uno trata de acostumbrarse a convivir con ellas, amontona silencios y óxido encima del recuerdo y, cuando cree que ya todo lo ha olvidado, basta ya una simple carta, una fotografía, para que salte en mil pedazos la lámina del hielo del olvido. (Llamazares 2014: 51)
}

En la mayoría de casos el pasado invade el presente a través de una nostalgia que "puede penetrar en el cuadro representacional y transfigurarlo de manera que adquiera dimensiones que serían insospechadas sin ella" (Navajas 1998: 22).

Este tipo de literatura, basada en el paradigma épico, se desarrolla paralelamente a los principios, de base mítica, de la literatura de Serés. Ambas literaturas esquivan el hibridismo posmoderno o el revival inherente a la parodia y al pastiche mediante una construcción que enriquece la base clásica (épica y mítica) con el uso del registro 
poético. Este registro crea una tensión emotiva que hace posible el pacto de identificación entre el narrador y el lector. El itinerario físico descrito en el incipit y repetido en el final de La lluvia amarilla es, sin duda, una clara invitación a esta identificación:

\begin{abstract}
Cuando lleguen al alto de Sobrepuerto, estará, seguramente, comenzando a anochecer. Sombras espesas avanzarán como olas por las montañas y el sol, turbio y deshecho, lleno de sangre, se arrastrará ante ellas agarrándose ya sin fuerzas a las aliagas y al montón de ruinas y escombros de lo que, en tiempos fuera (antes de aquel incendio que sorprendió durmiendo a la familia entera y a todos sus animales) la solitaria Casa de Sobrepuerto. (Llamazares 2014: 9)
\end{abstract}

Así como en la obra de Serés esta identificación remite siempre a la tierra en donde se encuentra el origen de las vidas de los protagonistas y del autor, en la obra de Llamazares la remisión implica una naturaleza humanizada. El protagoniza establece una identificación afectiva con el paisaje que conlleva el abandono de la vida social (la renuncia al único hijo vivo, la muerte de Sabina, su mujer, y la huida de Barbusa, expresan esta ruptura). Elementos naturales como la nieve y el frío (asociados a la muerte, principal razón de ser del protagonista) adquieren una importancia fundamental en la medida que se identifican con la unidad perdida a la cual aspira el personaje. El uso de la reiteración incide, justamente, en el carácter repetitivo, e ineluctable, del ciclo natural. En Llamazares además es marcado por la destrucción: "La desaparición [...] no tiene límites ni aun para sí misma; no es un estado, sino su negación." (p. 54)

El espacio literario de Serés, en cambio, es un espacio humanizado fruto del trabajo del hombre. En cierta medida está relacionado con una de las ideas más comunes en la literatura del escritor de Zaidí (que remite a la literatura realista de los años 1960): la necesidad del esfuerzo en la lucha por la supervivencia humana. En la relación material y física con la tierra se percibe un cansancio relacionable con la experiencia: "estic malalt d'experiència" (p. 116), me pesa "la vida dels altres" (p. 117) repite una de las voces de El vientre de la tierra.

En la obra de Serés son frecuentes las escenas en que los personajes se quedan absortos ante la contemplación de un paisaje en declive, que se deteriora 
inexorablemente. El balance final de esta observación meditativa sobre el proceso extintivo es claro: solo la materia - una tierra árida, sin restos biológicos - permanece e iguala unas incipientes diferencias espaciales: "La merda nodreix la ciutat com els fems peixen la terra." (p. 231). El mismo título de la trilogía sintetiza (remitiendo a la antítesis entre lo efímero y lo perenne) lo que acabamos de decir.

En su aproximación casi cartográfica a la descripción física del paisaje, la literatura de Serés se relaciona con la voluntad pictórica de afirmar lo visible propia de la pintura. A diferencia de la experiencia sensorial en Llamazares, que se hace progresivamente sinestésica, la literatura seresiana copia el lenguaje visual a la hora de concretar una apariencia a la vez próxima y etérea, que tiene su medio de expresión en la imagen. Las viejas fotografías (borrosas y con rostros irreconocibles) captan momentos biográficos o históricos, que sintetizan vidas $\mathrm{y}$, con el tiempo, se han convertido en vestigios que no narran: solo son apariencias. Instantáneas mudas en que sustentar una frágil memoria de índole colectiva. 0 imágenes que sitúan los individuos en el curso de un devenir inalterable:

aquesta és l'herència que has rebut, el reconeixement que tota aquesta desferra és solament una aparença, la visió diària que sota el cresp tèrbol dels anys passats, sota el tel volvós d'aquest batibull, hi ha alguna cosa que s'esdevé en el temps travessant des de lluny l'esgavell, quelcom d'una noblesa excessiva que tiba en la mateixa direcció que ho fan els fils que et mouen, que mous, on ets lligat. (Serés 2003: 317)

Como en la obra de W. G. Sebald, la inclusión de imágenes permite crear, a partir del fragmento y de la estructura diaspórica, una unidad. Esta idea recuerda el ensayo de John Berger sobre la relación pintura-realidad en Algunos pasos hacia una pequeña teoría de lo visible (1997). Berger define la pintura como el esfuerzo para afirmar la visibilidad en una composición corpórea y unitaria. La confirmación de una relación, añadirá Berger en el ensayo Mirar (1980), será imposible en los vínculos no establecidos entre humanos. En la ficción de Serés encontramos dos relaciones de este tipo: la primera se establece con los animales - que no confirman la mirada del hombre, pero fascinan -, y la segunda se establece con la imagen (cinematográfica y fotográfica), concebida como un instrumento mágico de apropiación, indicio de una modernidad 
incipiente que filtra el recuerdo sin reconocer el receptor. Todos dos contactos, además, ejemplifican el rechazo que viven muchos personajes seresianos. Una imposibilidad comunicativa que les obliga a tomar conciencia de sí mismos (refiriéndose al espacio) y de marcar (con la voz de la mirada) su posición en el mundo.

Tanto en Serés como en Llamazares solo las voces de los indígenas nos permiten adentrarnos en la realidad del paisaje. Ellas son las depositarias de un pensamiento colectivo, heredado, de interpretación unívoca y previsible:

es tractava de no canviar el sentit que sempre havien tingut la casa i la família vers allò que havia de fer aquí al món, el nom, el món, la paraula, tot plegat constituint una veritable unitat que mai no podria trencar-se, i que més enllà del lloc on jo o els meus descendents fóssim tot s'havia de perpetuar, les coses que passen, passen perquè han de passar, no pot ser d'altra manera (idem: 293)

Enfrente del pensamiento de la tribu, encontramos la realidad fungible de la voz de cada personaje: “Tot l'ordre del començament s'ha desfet en el xerrar” (p. 254). La dimensión colectiva del relato, pero, es cuestionada en Serés cuando el narrador incide en la dimensión radicalmente solitaria de la condición humana, tanto en el campo (donde se practica el familismo amoral) y en la ciudad (donde se produce la anomia). El mismo origen de la comunidad (explicado en "Ser", la narración más antigua, con fecha ficticia de 1893) niega su capacidad unificadora al incluir el incesto en su seno. Abogando por los marginados, la estructura de la obra tiende a acentuar progresivamente el sentimiento de aislamiento del individuo, con numerosas referencias a la tierra abandonada.

\section{Un tempo asociado a la experiencia lectora}

Tanto Llamazares como Serés sitúan la marginación en el centro de una reflexión sobre el destino del hombre y enfatizan el sentimiento de sumisión del individuo frente al espacio y todo aquello (físico - el pueblo y la tierra - y simbólico - modelos de representación y de cohesión) con que esta se identifica. Este planteamiento acerca su obra a un proceso de psicologización de la novela. Sus novelas, además, adoptan una visión posmoderna (ahistórica) de la historia. La historia es ahistórica en el sentido que 
hay un retorno al pensamiento mítico, en un movimiento que pendula entre un presente recurrente y un momento mítico que precede el presente y lo interfiere. La marginalidad de las voces hace que este pensamiento se sitúe en una situación liminar que subraya la llamada "paradoja de la frontera" (Certeau 1990: 186-187), es decir: la idea que todo lo que está separado, está unido al mismo tiempo por lo que lo separa. La soledad de los personajes es acentuada, en este sentido, por su condición de solitarios, que los distingue, por un lado, del colectivo y, por el otro, del proceso de desruralización que, indirectamente, testimonian. En la ficción la secularización resultante es relativa, no incluye desacralización porque los imaginarios de Llamazares y de Serés no tienen dimensión trascendente.

En ambos autores, el material aluvial que, en forma de recuerdos, invade el relato, se dispone a partir de estrategias muy básicas - prefiguración, retrospección, introducción de incidencias organizadas en episodios o escenas.... Predominan los recursos iterativos, al servicio de la creación de una cadencia rítmica, que propicia la consolidación del recuerdo. Esta disposición del material narrativo crea una dinámica específica de lectura, más atenta a la comprensión del relato - y de cómo se relata - que a la acumulación de acciones sucesivas. Centra la atención en la forma - y por eso podemos hablar de una voluntad poética por parte del personaje que relata - e implican, a la vez, un desarrollo dinámico.

A su vez, estos relatos - que presuponen la existencia de un (o unos) homo loquens - crean una determinada sensibilidad, relacionable con la construcción del tiempo narrativo y asociada a la permanencia. Esta formalización del tiempo permite relacionar percepciones múltiples, ordenarlas $\mathrm{y}$, en última instancia, dar unidad al conjunto. Como las pieles de cebolla que separan los capítulos de Una lengua de plomo, sobreponen historias creando espacios narrativos duraderos. Y bellos. 


\section{Bibliografía}

Certeau, Michel de (1990), L'invention du quotidien. 1. Arts de faire, París, Gallimard, 1990.

Carbonell, Neus (2000), "Resistir en la història". En AAVV, El mirall i la màscara. Vint-icinc anys de ficció en l'obra de Carme Riera, Coordinado por Luisa Cotoner, Barcelona, Destino, pp. 261-274.

Llamazares, Julio (2014), La lluvia amarilla, Barcelona, Seix Barral.

Marrugat, Jordi (2014), Narrativa catalana de la postmodernitat. Històries, formes $i$ motius, Barcelona, Publicacions de la Universitat de Barcelona.

Navajas, Gonzalo (1998), “La opción ética en la novela: el caso emblemático de Julio Llamazares". En El Universo de Julio Llamazares, Grand Seminaire, Universidad de Neuchâtel, 26 de mayo 1998, Cuadernos de Narrativa, 3 (diciembre), pp. 13-30.

Resina, Joan Ramon; Wiestenz, William (ed.) (2012), The New Ruralism. An Epistemology of Transformed Space, Madrid, Iberoamericana.

Serés, Francesc (2003), De fems i de marbres, Barcelona, Quaderns Crema.

Maria Dasca est docteur en Philologie Catalane par l'Université de Barcelone (2001) où elle a soutenu une thèse sur la représentation de la folie dans le roman contemporain. Maintenant, elle travaille comme enseignante à l'Université Pompeu Fabra de Barcelone. Ses axes de recherche portent sur le roman contemporain, la traduction littéraire et les échanges culturels.

\section{Notas}

\footnotetext{
${ }^{1}$ Las citas de De estiércol y mármol provienen del original catalán (De fems i de marbres), publicado por Quaderns Crema en 2003. El mismo autor se ha autotraducido al castellano y de sus autotraducciones han sido publicadas por la editorial Alpha Decay. Para más información ver:

http://www.alphadecay.org/autor/francesc-seres
} 



\section{Lorsque parcs et jardins se font labyrinthes}

\section{Catherine d'Humières}

\section{CELIS de Clermont-Ferrand}

Résumé: Parcs et jardins offrent un parfait exemple de rencontre entre nature et culture. Créations humaines destinées à proposer de vivre l'extérieur - la campagne inconnue ou la forêt sauvage - à l'intérieur - dans un espace pensé par et pour l'homme -, elles jouent un rôle protecteur contre ce qui pourrait venir de ce dehors toujours un peu imprévisible, tout en utilisant des éléments que l'on trouve justement au delà de leurs limites. Héritières d'une tradition qui va de la Renaissance au XVIIIe siècle, c'est souvent un désir d'harmonie qui préside à leur organisation et, l'imagination aidant, certains parcs et jardins, réels ou fictionnels, peuvent être conçus et/ou perçus comme de vrais dédales, posant ainsi la question des limites et du désir d'enfermement ou d'évasion de ceux qui s'y promènent. Je propose de me pencher sur quelques œuvres littéraires contemporaines dans lesquelles parcs et jardins peuvent être facilement assimilés à des labyrinthes soit à cause de leur conception même, soit par la perception qu'en ont les personnages qui les parcourent, afin d'envisager comment le rapport entre le dedans et le dehors est mis en scène, et les questions auxquelles aboutit une certaine confusion de leurs limites.

Mots-clés: parcs, jardins, labyrinthe

Resumo: Parques e jardins oferecem um perfeito exemplo de encontro entre natureza e cultura. Criações humanas destinadas a propor viver o exterior - o campo desconhecido ou a floresta selvagem - no interior - num espaço pensado por e para o homem -, elas desempenham um papel protetor face ao que poderia vir desse exterior sempre um pouco imprevísivel, utilizando elementos que encontramos precisamente para além dos seus limites. Herdeiras de uma tradição que vai do Renascimento ao século XVIII, é com frequência um desejo de harmonia que preside à sua organização e, com a ajuda da imaginação, certos parques e jardins, reais ou ficcionais, podem ser concebidos e/ou percebidos como 
verdadeiros dédalos, colocando assim a questão dos limites e do desejo de reclusão ou de evasão para os que se passeiam. Proponho-me debruçar-me sobre algumas obras literárias contemporâneas nas quais parques e jardins podem facilmente ser assimilados a labirintos quer pela sua conceção, quer pela perceção que deles têm as personagens que os percorrem, a fim de pensar como a relação entre o dentro e o fora é posta em cena, e as questões às quais leva uma certa confusão dos seus limites.

Palavras-chave: parques, jardins, labirinto

Parcs et jardins offrent un parfait exemple de rencontre entre nature et culture. Créations humaines destinées à proposer de vivre l'extérieur - la campagne inconnue ou la forêt sauvage - à l'intérieur, dans un espace pensé pour et par l'homme, elles jouent un rôle protecteur contre ce qui pourrait venir de ce dehors un peu imprévisible, tout en utilisant des éléments que l'on trouve justement au delà de leurs limites. C'est souvent un désir d'harmonie qui préside à leur organisation et, l'imagination aidant, certains parcs et jardins peuvent être conçus et perçus eux-mêmes comme de vrais dédales, posant ainsi la question des limites et du désir d'enfermement ou d'évasion de celui qui s'y promène. Nous proposons ici un parcours littéraire à travers quelques œuvres où parcs et jardins se rapprochent du labyrinthe, soit à cause de leur conception même, soit par la perception qu'en ont les personnages qui les parcourent.

La figure du labyrinthe se réfère, avant toute chose, à un espace physique, élaboré avec soin, selon un plan précis. Dans la légende antique, c'est le roi de Crète, Minos, qui commande à l'architecte Dédale une prison secrète destinée à enfermer le Minotaure. Cependant, le flou qui entoure la réalité de l'édifice permettant toutes les fantaisies et toutes les variations sur ce thème, certains artistes ont choisi d'unir la main de l'homme et les éléments naturels pour concevoir le dédale artificiel où ils ont situé l'action de leur récit. D’ailleurs, qui sait si le monstre n'aurait pas été enfermé dans un labyrinthe de haies, dans la mesure où l'architecte et son fils, Icare, emprisonnés à leur tour dans le labyrinthe, s'en échappèrent en fabriquant des ailes et en s'envolant si haut dans le ciel que la cire des ailes d'Icare fondit à la chaleur du soleil? L'enfermement horizontal contraste ainsi avec la trop grande liberté verticale. D’après Janet Bord et Jean-Clarence Lambert, le labyrinthe "est un espace clos, organisé autour d'un centre 
protégé par un plan complexe, comprenant des passages obscurs, des chambres secrètes et des carrefours où certitude et incertitude se croisent" (Bord/Lambert 1977: 13). Cette définition générale convient bien au labyrinthe de jardin dont les confuses limites ont été pensées par l'homme à partir de ce que la nature lui offrait pour se promener, se cacher ou se perdre. Mais là, comme ailleurs, l'enchevêtrement de l'endroit ne suffit pas, c'est l'errance du visiteur qui fonde véritablement le dédale, car celui-ci ne prend sa fonction que lorsque la confusion mentale double la complexité du lieu.

\section{Des limites protectrices}

Nous commencerons cependant par envisager le cas particulier du jardin clos au cœur du labyrinthe, option privilégiée par André Gide dans son roman Thésée, où le Minotaure se tient au centre de l'édifice construit pour l'enfermer, dans un jardin "fleuri de renoncules, d'adonides, de tulipes, de jonquilles et d'œillets" (Gide 1946: 74). Or le jardin clos est chargé de toute une symbolique qui en fait une représentation du paradis terrestre, synonyme de bonheur, de paix et d'abondance. Remémorant éternellement l'époque mythique de la création et du péché originel, l'être humain vit avec, au fond de lui, le regret de ce paradis perdu par sa faute. Comme le souligne Paolo Santarcangeli dans son Livre des labyrinthes - Il libro dei labirinti -, on le retrouve à toutes les époques et en des endroits fort différents: dans les maisons romaines, sur les tapis persans, dans les cloîtres des monastères, dans les jardins mystiques de Chine et du Japon... Dans le roman de Gide, il s'agit d'un endroit voluptueux et plein de charme qui annule par sa douceur et sa sérénité, l'image néfaste et redoutable du monstre de la légende. C'est là que Thésée le trouve endormi et le tue. Des années après, lorsqu'il raconte cet épisode, il a oublié le combat - s'il y en eut un - qui l'opposa au Minotaure, mais l'agrément du jardin est resté gravé dans son esprit. "Je me souviens aussi, comme d’un rêve, du charme de ce jardin, si capiteux que je pensais ne pouvoir m'en distraire" (idem: 75). Il s'agit bien là d'un lieu de délices, fait pour mener une existence oisive et douce, loin de la folie des hommes. C'est pourquoi le lacis de couloirs au cœur duquel il se trouve n'est pas la demeure d'un monstre assoiffé de sang, mais celle d'un être pacifique et sans doute inoffensif. Ce jardin central, par le contraste qu'il forme avec la complexité et l'obscurité du reste du labyrinthe, permet à la fois de mieux mettre en scène le 
dénouement du drame, et de cerner la véritable personnalité de celui qui y réside. En effet, Dédale a élaboré les pièges de cette confuse prison de façon à ce que chacun se perde dans les méandres de ses propres fantasmes. Dans ce contexte, le Minotaure devient une créature dédiée au bonheur et à la vie, et c'est Thésée le monstre assoiffé de sang, venu de l'extérieur pour apporter la mort au sein du labyrinthe.

Si l'on se penche sur l'histoire du jardin, on s'aperçoit qu'elle rencontre celle du dédale jusqu'à fusionner avec elle, et cet amalgame est bien visible à travers la littérature. Si, dans certaines œuvres comme le Thésée de Gide, le jardin clos se trouve au centre du labyrinthe, dans d'autres, c'est un labyrinthe de buis, héritier d'une tradition qui va de la Renaissance au XVIIIe siècle, qui est généralement placé à l'intérieur d'un grand parc, et non d'une habitation. Tracé dans un but ludique, il peut être détourné de sa fonction première pour devenir le lieu du secret, le refuge du monstre. Il en est ainsi dans Le Labyrinthe, de Maurice Sandoz, où le parc d'un château écossais est occupé, en grande partie, par des bois sombres, très anciens, comme une forêt ensorcelée "qu'on retrouvait toujours, la forêt qui menait au labyrinthe" (Sandoz 1949: 126). L'atmosphère qui y règne est loin d'être paradisiaque. La grande demeure et toute la propriété semblent être sous le coup d'une malédiction. Les jeunes gens qui en héritent deviennent taciturnes et moroses, comme s'ils ne pouvaient plus rien attendre de la vie. Et c'est un étrange labyrinthe de verdure, soigneusement clos et caché à tous les regards, qui contient la clef du mystère. En général, la structure du labyrinthe de jardin est assez connue et n'offre guère de surprise: sa forme peut varier, bien entendu, mais il se déroule dans un espace toujours limité. Celui du roman de Sandoz y correspond bien:

\footnotetext{
une allée encadrée de haies [qui] dessinent le plus souvent un quadrilatère régulier à angles droits. Ce carré est encastré [...] dans un second quadrangle; celui-ci s'inscrit dans une troisième allée et ainsi de suite, selon la fantaisie du propriétaire. Il arrive aussi que plusieurs allées soient sans issue; ce sont des attrape-nigauds, une seule conduira le visiteur de l'entrée du labyrinthe au centre des bosquets. (idem: 110)
}

Cet endroit est tellement secret et enchevêtré que seuls quelques initiés y ont leur entrée et leurs repères. Les intrus courent le risque de s'y perdre, comme dans n'importe quel autre labyrinthe. Cependant, son entrée est une allée très large et très 
lisse, qui serait douce même aux pieds nus d'un enfant, et qui "filait en ligne droite entre deux rangées d'ifs portant tous à leur sommet la tête grimaçante d'un animal réel ou monstrueux. Il me sembla voir une rangée de monstres gardiens de je ne sais quel mystère" (idem: 91). À la fois attirant et repoussant, en somme, cet endroit suggère, par son étrange décoration, l'existence d'un monstre, ou tout au moins d'une énigme. En réalité, il s'agit bien d'un labyrinthe de protection contre les regards extérieurs, son centre est une pièce d'eau où une malheureuse créature hybride - une espèce d'hommecrapaud - vient chaque jour chercher un peu de bonheur et d'oubli. Comme celui de Gide, le monstre de Sandoz n'est, en effet, prisonnier que de sa propre monstruosité. Pour tous les deux, le centre du labyrinthe est un hâvre, un refuge, un lieu de douceur au milieu d'une vallée de larmes, le seul endroit où le véritable maître des lieux peut supporter son unicité, et ce sera sa dernière demeure. Chez Sandoz, c'est là qu'il parvient à faire fusionner son hybridité avec "cet accord harmonieux de la végétation, de l'architecture, du calme de l'air, de la musique des eaux" (Brion 1997: 192). Ce dédale aboutit à une image de perfection, et compose pour lui, comme dans le roman de Gide, un micro-paradis au milieu d'un monde de terreur et de violence, et il a la même fonction de refuge et de mise à l'écart. Dans Thésée, cet enfermement n'est pas volontaire, bien entendu, alors que dans Le Labyrinthe, il est voulu par le maître des lieux; et cependant le centre des deux labyrinthes apporte à chacune de ces créatures l'apaisement d'un lieu unique et protecteur, conçu exclusivement pour elle.

Le propre des labyrinthes - n'oublions pas qu'il y est, la plupart du temps, question d'enfermement -, c'est de proposer un parcours entortillé où il est difficile de trouver une issue. Mais, dans certains cas, il est considéré comme un monde clos, réservé à quelques élus pour des raisons parfois très diverses, et l'entrée n'en est pas plus aisée que la sortie car on ne peut y pénétrer qu'après avoir reçu une invitation formelle de son, ou de ses propriétaires. Nous nous pencherons sur Le jardin des FinziContini - Il giardino dei Finzi-Contini -, de Giorgio Bassani où le parc constitue le centre de l'intrigue. Toute l'histoire tourne autour de lui et, pour s'y introduire, il faut avoir été invité officiellement par l'un des membres de la famille Finzi-Contini, eux-mêmes désireux de se maintenir à l'écart, de préserver un mode de vie élégant et raffiné. Malheureusement, cet univers aristocratique ne peut rester indépendant des 
événements dramatiques qui se déroulent dans toute l'Europe, et tous ses habitants en subiront les conséquences. L'isolement de la famille au sein de la communauté juive de Ferrare, volontaire au début par désir de distinction sociale, cessera progressivement, de façon tragique, au fur et à mesure de l'aggravation des lois raciales édictées par le gouvernement de Mussolini. Au début, les Finzi-Contini marquent leur différence en se mettant à l'écart du groupe: ils ont une très grande maison, un parc immense, une tombe majestueuse, l'autorisation d'ouvrir une synagogue particulière pour leurs propres dévotions etc... Il s'agit pour eux de montrer leur supériorité économique et sociale, c'est une vie en marge de leur communauté, voulue et assumée avec fierté. Le roman tout entier balance entre cet orgueil de classe qui les met à part, et la tragédie mondiale qui se profile de façon de plus en plus inquiétante et les emportera finalement. Les juifs de Ferrare se trouvent peu à peu isolés par les lois raciales qui leur interdisent toute activité susceptible de les mélanger aux autres: bibliothèque, tennis, participation aux diverses associations de la ville. Les Finzi-Contini finissent par se retrouver seuls, au milieu d'une communauté isolée elle-même dans son propre pays, et à laquelle ils sont obligés de s'ouvrir. Dans ce contexte dramatique, et à cause de lui, le parc se transforme en un labyrinthe intérieur replié sur lui-même, un monde de rêves et d'illusions où la jeune Micòl entraîne le narrateur dans de longues promenades pendant lesquelles ils sillonnent chemins et sentiers en tous sens, en d'étranges pèlerinages sur les lieux, plus ou moins secrets, qui ont marqué l'enfance de Micòl. Les deux amis tracent ainsi ensemble un double labyrinthe, spatial à travers le parc, et mental à travers les souvenirs partagés, jusqu'au jour où le mauvais temps les pousse dans la remise aux voitures, centre et fin du labyrinthe. L'amour est là qui les attend, mais de façon trop diffuse, trop intuitive: ce ne sera qu'une illusion, Giorgio n'arrivera pas à en prendre conscience à temps. Il n'en ressentira sur le moment qu'une vague impression de malaise, et le magnifique parc à l'anglaise des Finzi-Contini restera à jamais le lieu des occasions manquées. Tout se passe comme si le jardin labyrinthe, conçu pour remplir la fonction de cocon protecteur, n'était en fait que le dérisoire réceptacle d'aventures individuelles face à la monstruosité de l'Histoire des hommes. 


\section{Le franchissement de limites spatio-temporelles}

Tout autre est l'impression qui domine le dédale de Stra où se perdent les protagonistes du Feu - Il fuoco -, de Gabriele d'Annunzio. Marcel Brion l'évoque aussi dans "Réception dans un jardin", en parlant d'un "jardin vénète qui était [...] à lui seul un interminable labyrinthe, infernal et céleste en même temps, qui avait absorbé tous les labyrinthes qu'on y avait construits successivement et qui les digérait avec la placidité d'un monstre repus" (Brion 1987: 152). Le jardin-labyrinthe de sa mémoire prend ainsi, exceptionnellement, une existence propre et maléfique, et se dote d'une faculté d'absorption qui définit généralement le monstrueux habitant plutôt que le lieu enchevêtré. On est loin du jardin-dédale idyllique et protecteur: dans le roman de d'Annunzio, il va s'agir d'un engloutissement temporel plutôt que spatial. Le poète, Stelio, en se perdant dans un labyrinthe de haies, se sent envahi par "une illusion d'antique poésie"1 (d'Annunzio 1995: 213). Peu à peu, il est transporté dans un âge mythique qui devient réel pour lui, le transfigure et l'éloigne de sa maîtresse, la Foscarina. Celle-ci se trouve ainsi doublement perdue dans le dédale, éloignée du monde par le lacis des chemins qu'elle parcourt en vain, et de son ami par une confusion d'époques à laquelle elle ne participe pas. Le labyrinthe remplit là une fonction de porte, car il permet de franchir la barrière qui sépare, d'habitude, les différents temps, les chemins divergents de l'existence; ce faisant, il les rapproche ou les éloigne, et crée une distorsion à l'intérieur même du temps linéaire de chaque individu en y introduisant des éléments étrangers ou étranges.

Le jeune homme se laisse gagner par un désir instinctif par lequel il se projette dans le monde du mythe, alors que la Foscarina, terrorisée par l'atmosphère inquiétante du dédale, finit par perdre le contrôle d'elle-même, comme si elle devait être la proie du Minotaure. Si le jardin-labyrinthe, laissé à l'abandon, a une allure triste et sombre, il reste encore mystérieusement attirant dans la lumière du crépuscule. Son dessin est circulaire et, au centre, se trouve une petite tour d'où l'on peut admirer le parc dans son entier. A la fin, lorsque Stelio atteint enfin ce point central et tente d'arrêter la course affolée de son amie, il voit "le labyrinthe, en dessous de lui, noirâtre de buis et taché de charmes, étroit dans ses interminables enroulements, avec l'aspect d'un édifice démantelé et envahi par les ronces, semblable à une ruine et à un maquis, sauvage et 
lugubre"2 (idem: 216). La forme des labyrinthes de jardin varie mais le principe est toujours le même: une haie taillée, des chemins qui vous égarent et un centre. Extrêmement dépendant de l'homme, peut-être même davantage que les bâtiments euxmêmes qui peuvent presque avoir une vie propre, le labyrinthe de jardin a besoin d'être pensé, élaboré, dessiné et soigné pour vivre. Dans ce roman, la nature, en reprenant ses droits, a rendu le labyrinthe plus enchevêtré encore et, par là-même, plus secret et plus angoissant. Il ne s'agit plus d'un lieu protecteur, idéal et idéalisé, et les personnages finissent par y voir l'écho de leurs préoccupations ou de leurs pensées les plus profondes.

Si Il giardino dei Finzi-Contini, comme on l'a vu précédemment, propose un va-etvient constant entre la réalité quotidienne porteuse de mort, et un lieu, volontairement isolé, où plane l'illusion et le désir, si le protagoniste de Il Fuoco, en se fourvoyant dans l'espace, s'égare dans le temps sans toutefois sortir vraiment de la linéarité impartie à l'existence humaine, la nouvelle, "Réception dans un jardin", de Marcel Brion, va plus loin encore, mettant en scène une interférence temporelle qui transporte le jeune protagoniste jusqu'aux frontières de l'au-delà. Le récit suit les pas d'un jeune peintre, Lissandrino, qui se rend à une réception près d'Albaro, dans une villa qu'il ne connaît pas et s'égare dans un parc mystérieux et compliqué. L'invitation que reçoit le jeune homme, au début de la nouvelle, est bien floue: il ne connaît pas vraiment la personne qui la lui transmet, et on ne sait pas ce qui l'a amené à l'accepter. Curieusement, personne ne l'attend à l'entrée et la grille est ouverte. Il s'introduit ainsi dans un parc immense avec un "étagement de terrasses d'un aspect compliqué [...] grande abondance de pelouses, de parterres fleuris, de cascatelles dégringolant d'escaliers en escaliers jusqu'à un vaste bassin" (Brion 1987: 140); un peu le style des jardins à la française, tout d'abord, mais peu entretenu, comme vaguement laissé à l'abandon. Il se laisse entraîner par le charme de l'endroit et accepte "l'équivoque des chemins en croix proposés par les carrefours, indécis aux fourches insidieuses" (idem: 141). Se détournant momentanément du but de sa présence à l'intérieur du parc, il s'adonne au plaisir de la promenade et adopte, de cette façon le "style de la flânerie: celui du fragmentaire, de la sérialisation, qui prend modèle sur le rythme des pas et les changements de perspective" 
(Montandon 1996: 105). C'est ce nouveau rythme qui le fait passer d'un labyrinthe spatial à un dédale temporel: il finit par perdre

conscience du temps qui s'écoulait, à mesure qu'il avançait plus loin sur de larges avenues, ou revenait sur lui-même perpétuellement poussé dans un jeu malicieux, une sorte de colin-maillard joué les yeux ouverts [...]. Les écheveaux du temps s'effilochaient, s'embrouillaient et se désembrouillaient, suivant leur propre rythme, qui n'est pas le rythme des actions des hommes. (Brion 1987: 142)

Lissandrino, sans s'en rendre compte, se détache d'une réalité sereine, franchit de mystérieuses limites temporelles et s'introduit dans un monde de dissolution et de mélancolie. En effet, en acceptant de jouer à fond le jeu de l'indécision et de la confusion proposé par le parc-labyrinthe, il perd la maîtrise mentale de son itinéraire. Il n'a plus conscience du temps écoulé, et tous les repères s'estompent alors d'eux-mêmes. Il erre au hasard, s'égare un moment dans les allées d'un bois mélancolique, et enfin se trouve devant "une allée ouverte entre des hêtres maladifs hors d'âge [...], une longue succession de degrés de pierre qui évoquait un escalier triomphal" (idem: 143).

Les tours et détours de son interminable itinéraire dans le parc se doublent peu à peu d'un trajet à travers le temps qui le transporte dans le même endroit mais, apparemment, à une autre époque. Il se retrouve errant à travers un lieu dont on ne peut pas dire qu'il soit abandonné car alors la nature y aurait repris ses droits, mais plutôt poussiéreux, fatigué, comme usé par un temps suspendu et interminable. Au terme de son parcours, le jeune homme arrivera bien à une réception - comme le dit le titre de la nouvelle -, mais l'atmosphère en sera insolite, énigmatique, et les personnages comme figés dans une éternité statique et sans espoir. Il se retrouve, finalement, dans une réunion mondaine avec le sentiment de ne pas en faire partie, d'être complètement ignoré des gens qu'il voit, séparé d'eux par une "mince frontière -d'espace ou de temps? -qui le tenait à distance" (idem: 144), comme le protagoniste de L'invention de Morel La invención de Morel - d'Adolfo Bioy Casares. Il n'arrive pas à entrer en contact avec cette énigmatique assemblée de personnes indifférentes, muettes, exténuées par un temps qui semble ne jamais s'écouler. Il devient spectateur de moments oubliés, et ce qui l'étonne le plus, c'est que cet univers fantômatique semble usé, terni, flétri comme 
s'il avait un jour été abandonné par le passage du temps et condamné à une éternité désespérée. Par l'intermédiaire du parc-labyrinthe, le jeune homme aura franchi de mystérieuses limites et trouvé involontairement l'accès à une autre époque, morte et égarée dans une angoissante immobilité. Quand il prend le chemin du retour, le parc a changé d'allure. Tout a vieilli et s'est assoupi dans la décrépitude et la dévastation: il n'y a plus d'eau dans les fontaines noirâtres, plus de feuilles sur les arbres morts, plus de fleurs dans les massifs vides. Tout est à l'image de la réception inerte qu'il a laissé sur la terrasse.

Il n'aurait pas osé, maintenant, pénétrer dans les bosquets pleins de pièges sinistres, franchir des ponts qui n'avaient plus de muscles ni d'os, jeter même un seul coup d'œil sur les fausses ruines qui étaient de vraies ruines, affligeantes avec cet air humilié et ricanant qu'ont les églises sans toit, les colonnades vacillantes, les sous-sols en communication directe avec l'enfer et au delà de l'enfer. (idem: 154)

Il n'y a plus trace du riant labyrinthe dans lequel il s'était engagé avec désinvolture, celui-là est en relation directe avec le monde des morts. Le parc propose, en réalité, une ouverture sur les mystères du temps et de l'au-delà. C'est ce que fuit le jeune peintre en reparcourant les allées devenues sombres et hostiles, anxieux de retrouver un présent devenu aléatoire. Le parc-labyrinthe, clos et replié sur son mystère, ne semble apporter que la mélancolie et la tristesse d'un univers qui n'en finit pas de se détruire.

La nouvelle de Brion se termine dans l'énigme du retour:

L'empressement qu'il aurait dû mettre à prendre congé du subit hiver des arbres du parc était ralenti, gêné par l'inquiétude d'ignorer comment l'accueillerait à son retour le monde qui était, jusqu'à aujourd'hui, le sien et qu'il craignait obscurément de ne pas retrouver tel qu'il l'avait quitté pour aller à la réception. Ou de ne pas du tout retrouver. (idem: 155-156)

Après une nouvelle errance à travers le parc enchanté, Lissandro compte bien reprendre le cours de son existence, mais sort-on vraiment indemne de ce genre d'expérience? Le récit refuse de résoudre l'énigme, et abandonne le lecteur à sa 
perplexité. Brion lui-même, face au tableau d'Alessandro Magnasco ${ }^{3}$ qui lui a inspiré cette nouvelle, s'interroge:

Ce "quelque chose" de superbe et de désespéré que je vois dans le tableau de Gênes inquiète et fait peur. Cette terrasse d'où l'on domine, pétrifiée elle aussi, la région d'Albaro... n'est pas d'ici mais d'ailleurs. Comment ne pas penser à une réunion d'âmes en peine dans les Enfers? (idem: 98)

L'auteur laisse cependant la porte ouverte à bien d'autres suppositions car tout parcours labyrinthique porte en lui plusieurs éventualités. S'il est, bien sûr, possible de retrouver son chemin et de reprendre sa vie là où on l'avait laissée, le plus souvent, néanmoins, l'expérience prend une résonance particulière qui modifie profondément le déroulement futur de l'existence du voyageur. Et il se peut aussi que celui-ci s'égare à tout jamais, condamné à errer dans les méandres de l'espace ou du temps.

Le parcours littéraire que nous avons proposé jusque là montre qu'un parc, ou un jardin, n'est perçu comme un labyrinthe que lorsqu'il est dominé par une volonté de mise à l'écart. Dans ce cas, ses allées mènent au cœur d'un royaume secret qui se referme sur quelque mystère. En outre, on peut distinguer deux façons d'avancer à travers les pistes complexes qui s'ouvrent devant les pas du promeneur: la première consiste à tenter de maîtriser les événements et de choisir consciemment les voies où l'on désire s'engager, au risque de se perdre, la seconde, c'est de se laisser porter par les aléas de la flânerie. D’après Marcel Brion, le labyrinthe est le reflet de l'existence: l'homme, en prenant conscience de la part de hasard qui dirige ses pas, peut en percevoir la saveur et acquérir une certaine sérénité. En fait, il oscille toujours entre ces deux attitudes extrêmes, comme si les décisions humaines constituaient les fils de chaîne sur lesquels la trame du hasard tissait la destinée.

\section{Des enchevêtrements spéculaires}

Il existerait ainsi une étrange correspondance entre le jardin et l'homme. Quoi d'étonnant alors si les enchevêtrements de celui-là font écho à la complexité de celui-ci? Cette correspondance se retrouve clairement dans L'épreuve du labyrinthe - La prueba del laberinto -, de Fernando Sánchez Dragó, mais de façon inversée. Le narrateur, Dionisio, toujours à la recherche de son moi profond, se voit donner un étrange conseil 
au cours de son périple. Un cabaliste lui révèle qu'à l'intérieur de sa tête, il y a un labyrinthe et que c'est à lui de l'explorer.

Parcourez-le et rentrez ensuite dans votre pays, achetez un petit morceau de terrain près d'une rivière [...] et construisez-y, avec des massifs de fleurs, de l'herbe et des arbustes, un autre labyrinthe, cette fois visible et tangible. Faites en sorte qu'il soit une fidèle reproduction de celui que vous avez maintenant dans la tête et parcourez-le souvent, chaque fois que vous le pourrez. ${ }^{4}$ (Sánchez Dragó 1992: 268-269)

Ce serait donc, ici, l'idée déjà présente dans l'esprit qui projetterait ses enchevêtrements dans le jardin. Ce dernier est intéressant à plusieurs titres : tout d'abord parce qu'il préexiste dans la tête de son futur créateur, ensuite parce qu'il sera un miroir mental destiné à acquérir puis à approfondir la connaissance de soi-même et enfin parce qu'il a pour fonction d'enseigner que le secret du bonheur ne peut se trouver que par la méditation et l'intériorité. La fonction première du labyrinthe s'inverse totalement: il n'est plus l'endroit où l'on se perd mais devient l'endroit où l'on se trouve. Son dessin est déjà tracé, il faut, pour qu'il prenne forme, y ajouter le parcours de l'esprit.

Jorge Luis Borges a fort souvent développé le thème de la correspondance entre l'esprit humain et le dédale, notamment dans "Le jardin aux sentiers qui bifurquent" -"El jardín de los senderos que se bifurcan"- dont le narrateur, espion chinois au service de l'Allemagne, fuyant devant la police britannique, s'introduit dans le jardin d'un savant sinologue anglais où il trouvera la révélation d’une énigme familiale jamais élucidée. En effet, ce savant, Stephen Albert, a percé le mystère du livre et du labyrinthe que Ts'ui Pên, arrière grand-père du narrateur lui-même, a laissés à ses héritiers. Le protagoniste ne se perd pas dans son parcours, mais étrangement, il a l'impression d'être passé dans une autre dimension sensorielle.

Sous les arbres anglais je méditai sur ce labyrinthe perdu: je l'imaginai inviolé et parfait sur la cime secrète d'une montagne, je l'imaginai effacé par des rizières ou sous l'eau, je l'imaginai infini, non plus fait de kiosques octogonaux et de sentiers qui reviennent, mais de fleuves et de provinces et de royaumes. ${ }^{5}$ (Borges 1997: 475) 
Le jardin dont il parcourt les voies s'annule dans une vision élargie d'un labyrinthe qui engloberait toute la terre. Il rejoint ainsi, par la pensée, le dessein projeté par son ancêtre de faire un livre total qui engloberait toutes les possibilités de l'imagination. Le narrateur se détache des contingences de sa situation et se laisse prendre par le cours de ses pensées. C'est là qu'il parvient au véritable labyrinthe. “Absorbé par ces images illusoires, j'oubliai mon destin d'homme poursuivi. Je me sentis, pendant un temps indéterminé, envahi par une perception abstraite du monde"6 (ibidem). L'idée du labyrinthe, plutôt que le jardin-dédale lui-même, lui permet d'élever son esprit et d'atteindre une vision globale du monde. Le labyrinthe, dans ce contexte, n'est là ni pour protéger, ni pour montrer la complexité de l'existence humaine; il s'agit plutôt de proposer une certaine façon d'envisager l'univers et de permettre de concevoir pleinement la notion d'infini qui s'applique à lui. Les bifurcations de l'espace et du temps sont à l'image de celles du destin. L'existence humaine se retrouve prisonnière dans un dédale où l'être n'a d'autre solution que de tourner en rond, à l'intérieur d'une vie dont le déroulement se fait au hasard des choix individuels et de circonstances extérieures impossibles à appréhender clairement.

Cette constante recherche, à travers les méandres de ce que les écrits proposent, s'apparente donc en tout point à un parcours labyrinthique, et il est essentiel d'en accepter les risques inhérents, c'est-à-dire la présence toujours possible de fausses pistes ou d'impasses, et l'indispensable éventualité de retours en arrières. Signalons, dans le cas précis du "Jardin aux sentiers qui bifurquent", que la surprise du lecteur est totale à la fin du récit. En effet, pour comprendre le parcours du fuyard, il lui aurait fallu rester dans le jardin et se détourner de la voie suggérée par l'auteur, pour en prendre une autre, tellement différente! Il n'aurait pas dû laisser le livre échapper de la bibliothèque et ainsi, il aurait pu éviter les emboîtements sans se laisser prendre à leur piège car, finalement, il n'est qu'un chemin, une piste, minuscule, ténue, qui se réduit à... un seul mot! Le nom du sinologue -Albert- que l'espion désire indiquer aux Allemands, ses maîtres, pour leur dévoiler celui de la ville à bombarder d'urgence. Comme le dit Bernard Chouvier, "le récit borgésien est labyrinthique, ce qui veut dire qu'il est truffé de pistes qui ne mènent nulle part, de passages en trompe-l'œil ou d'inextricables impasses" (Chouvier 1994: 137). 


\section{Conclusion}

Le labyrinthe de jardin semble ainsi être un des lieux où l'homme se sent intimement mis en cause, où il voit de façon évidente tout un jeu de correspondances entre lui-même et ce qui l'entoure, que ce soit sa vie, son monde ou le cosmos illimité. Dans Un Enfant de la terre et du ciel, de Brion, on peut dégager un passage fort intéressant parce que le jardin-labyrinthe y devient vraiment une allégorie de la vie humaine:

Il se rappelait aussi ce dédale vénète d'un tracé si facile que rien ne semblait plus aisé que d'atteindre l'issue. Mais, après quelques secondes de marche, entre ces murs de branches noires et odorantes, l'entrelacs des allées se referma soudain sur lui, avec la précision monstrueuse des miniatures irlandaises qui nous lancent leurs arabesques comme un filet. [...] Ce jour-là il avait eu peur. Non pas tant de ce danger ridicule qu'il y avait à rester enfermé dans cette prison de buis jusqu'au moment où un gardien viendrait le délivrer, que de ce plaisir aigu et sournois où le jetait ce sentiment d'irresponsabilité, cette abdication de la raison, de la mémoire, même de l'instinct. Cet abandon au pur hasard l'avait rempli tout à coup d'une exaltation panique. Il s'aperçut qu'il ne désirait plus sortir du labyrinthe. Il aimait cette marche brisée, ces recommencements da capo quand une impasse lui barrait la route et lorsque deux chemins exactement semblables se proposaient à lui, la sensation qu'il n'y avait aucun motif pour qu'il choisit l'un plutôt que l'autre.

(Brion 1943: 142-143)

La vie de l'homme étant faite de choix dont on ne sait pas si l'un vaut mieux que l'autre, d'hésitations et de retours en arrière, elle serait comparable à un chemin sur lequel on avance sans repères sérieux, sans savoir vraiment où il mènera. Et surtout, et peut-être est-ce l'aspect le plus intéressant de cette page, l'homme éprouverait une intense jubilation à errer à l'aveuglette dans son propre labyrinthe, à vivre, en un mot. Le labyrinthe s'élargit là de façon infinie jusqu'aux limites de l'univers sensible. Il englobe le ciel, l'air et la terre dans la même ronde, la même danse labyrinthique qui représente bien l'homme.

Ainsi le labyrinthe, alors même qu'il est perçu comme œuvre humaine, échappe aux contingences de la matière pour servir de tremplin au mouvement illimité des interrogations de l'existence de l'homme. La complexité qui domine sa conception en fait une figure variable et mouvante, susceptible d'enrichissements illimités. "Le labyrinthe 
est figure à plusieurs dimensions et, comme telle, c'est seulement dans la multiplication des points de vue posés sur lui qu'il offre son image intégrale" (Forest 1995: 10). Il symbolise la projection de ce que l'homme porte en lui de confus et d'imprécis et son désir de le mettre en forme. C'est pour cela que le parc ou le jardin, création humaine au même titre que l'édifice et que le livre, peuvent se compliquer au point de devenir reflet de l'inextricable lacis de voies qu'on n'en finit jamais de parcourir.

\section{Bibliographie}

D’Annunzio, Gabriele (1995), (1e éd. 1900). Il fuoco, Milano (It.), Mondadori.

Bassani, Giorgio (1989), Il giardino dei Finzi Contini, Milano (It.), Mondadori.

Bord, Janet et Lambert, Jean-Christophe (1977), Labyrinthes et Dédales du Monde, Paris, Les Presses de la Connaissance.

Borges, Jorge Luis (1997), Ficciones (1e éd. 1941) in Obras completas I, Barcelona (Esp.), Emecé.

Brion, Marcel (1943), Un Enfant de la terre et du ciel, Paris, Albin Michel.

Brion, Marcel (1987), Les Ailleurs du temps, Paris, Albin Michel.

Brion, Marcel (1997), Mémoires d'une vie incertaine, Paris, Klincksieck.

Chouvier, Bernard (1994), Jorge Luis Borges, l'homme et le labyrinthe, Presses Univ. de Lyon.

Forest, Philippe (1995), Textes et labyrinthes, Mont de Marsan, Éd. InterUniversitaires. Gide, André (1946), Thésée, Paris, Gallimard.

Montandon, Alain (1996), "Pour une socio-poétique de la flânerie", in Montandon, A. (Coord.), Promenades et écriture, Clermont-Ferrand, Presses Univ. Blaise Pascal, "CRLMC". 
Sánchez Dragó, Fernando (1992), La Prueba del laberinto, Barcelona (Esp.), Planeta.

Sandoz, Maurice (1949), Le Labyrinthe, illustré par Salvador Dalí, Lausanne (CH), Mermod.

Santarcangeli, Paolo (1984), Il Libro dei labirinti, Milano (It.), Frassinelli.

Catherine d'Humières est Associée au CELIS de Clermont-Ferrand. Maître de conférences à la retraite - Université de Cergy-Pontoise. Axes de recherches: Permanence des mythes dans la Littérature de langue romane (XXe- XXIe siècles). Étude des productions pour la jeunesse.

\section{Notes}

1 “Una illusione d'antica poesia." Toutes les traductions ont été faites par nos soins.

2 "Il labirinto sotto di sé nerastro di bussi e maculato di càrpini, angusto nei suoi interminabili avvolgimenti, con l'aspetto di un edifizio smantellato e invaso dagli serpi, simile a una ruina e a una macchia, selvaggio e lugubre."

${ }^{3}$ Alessandro Magnasco, dit il Lissandrino, (1667-1749) est un peintre génois, spécialiste du style rococo. Le tableau auquel il est fait allusion ici, Trattenimento in un giardino di Albaro (1735) se trouve dans les Gallerie du Palazzo Bianco de Gênes (Italie).

4 "Aquí dentro hay un laberinto [...] Recórralo y vuelva luego a su país, compre un trocito de tierra junto a un río [...] y construya en él, con macizos de flores, pasto y arbustos, otro laberinto, esta vez visible y tangible. Procure que sea una fiel reproducción del que ahora tiene en la cabeza y recórralo a menudo, siempre que pueda."

5 "Bajo los árboles ingleses medité en ese laberinto perdido: lo imaginé inviolado y perfecto en la cumbre de una montaña, lo imaginé borrado por arrozales o debajo del agua, lo imaginé infinito, no ya de quioscos ochavados y de sendas que vuelven sino de ríos y provincias y reinos."

6 "Absorto en esas ilusorias imágenes, olvidé mi destino de perseguido. Me sentí, por un tiempo indeterminado, percibidor abstracto del mundo." 


\section{L'espace façonné: l'Albanie fictionnelle de François C. H. L. Pouqueville}

\section{Olimpia Gargano \\ Lycée de Vintimille (Italie)}

Résumé: Alors qu'il publia son Voyage en Morée, à Constantinople, en Albanie (1805), le médecin François C. H. L. Pouqueville n'avait encore mis le pied dans les terres albanaises qu'il décrivit; pourtant, cela ne l'empêcha pas d'en tracer de portraits saisissants, en puisant à foison dans les sources classiques dont il était bien féru.

Son œuvre donna lieu à un effet looping: alors que le géographe Barbié du Bocage s'appuya sur ses descriptions pour dessiner les cartes accompagnant le Voyage de Pouqueville (ce qui aboutit à l'un des nombreux exemplaires de la géographie de cabinet qui à ce temps-là était très pratiquée à l'égard des terres "exotiques"), l'énorme succès de ce voyage "littéraire" déclencha l'écriture de récits à sujet albanais par nombre d'auteurs qui n'avaient jamais visité l'Albanie.

Cette contribution vise à dégager les outils de la représentation par lesquels François C. H. L. Pouqueville créa l'espace albanais, en pavant la voie à une riche production fictionnelle consacrée à ce qui s'avéra être l'un des lieux les plus imaginés parmi les pays méconnus.

Mots-clés: Pouqueville, Albanie, dispositifs de représentation

Resumo: Quando publicou Voyage en Morée, à Constantinople, en Albanie (1805), o médico C. H. L. Pouqueville não tinha posto os pés nas terras albanesas que descrevera; contudo, isso não o impediu de traçar retratos marcantes, baseando-se com abundância nas fontes clássicas de que era um apaixonado.

A sua obra deu lugar a um efeito de looping: enquanto o geógrafo Barbié du Bocage se apoiou sobre essas descrições para desenhar os mapas que acompanham a Voyage de Pouqueville (resultando num dos inúmeros exemplares da geografia de gabinete então muito praticada no que respeita a "terras exóticas"), 
o enorme sucesso desta viagem "literária" provocou a escrita de narrativas de assunto albanês por parte de muitos autores que nunca tinham visitado a Albânia.

Este contributo visa identificar os dispositivos de representação com os quais François CHL Pouqueville criou o espaço albanês, abrindo o caminho para uma rica produção ficcional dedicada ao que acabou por ser um dos lugares mais imaginados dos territórios desconhecidos.

Palavras-chave: Pouqueville, Albânia, dispositivos de representação

L'objet de cette contribution est l'Albanie telle qu'elle apparaît dans la description qu'en donna en 1805 le médecin, savant et diplomate français François C. H. L. Pouqueville. Son œuvre serait l'un des nombreux récits de voyages en terres ottomanes rédigés dans ces années-là, si ce n'était que pour une raison qui la rend particulièrement intéressante à nos yeux, c'est-à-dire le fait que, quand il publia son Voyage en Morée, à Constantinople, en Albanie, Pouqueville n'avait pas encore mis le pied en terre albanaise. ${ }^{1}$ Pourtant, cela ne l'empêcha pas d'en tracer de portraits saisissants, en puisant à foison dans les sources classiques dont il était bien féru. Notre analyse vise justement à dégager les techniques discursives que l'auteur employa pour bâtir, voire "inventer", au sens étymologique du terme, un espace qu'il n'avait jamais parcouru.

\section{Une terra incognita au cour de l'Europe}

Avant de franchir les frontières géo-littéraires de ce petit coin balkanique, il faut tenir compte du fait que, jusqu'à la fin du XIXe siècle, l'espace albanais abordé dans la littérature de voyage comprenait des terres actuellement appartenant à d'autres États, tels que l'actuel Kosovo, le sud-ouest de la Macédoine et la région de Janina, qui fait désormais partie de la Grèce. Si telles en sont les limites spatiaux, il serait bien moins aisé de dégager en peu de mots les coordonnées littéraires qui bornent l'image de l'Albanie, car tout en étant restée longtemps aux marges des études comparatistes ainsi que des savoirs partagés - au cours des siècles elle a été parcourue en tous sens par nombre de savants et d'écrivains - voyageurs qui y consacrèrent leurs œuvres. Néanmoins, comme le note Bertrand Westphal, l'Albanie venait immanquablement d'être découverte. 
L'Albanie est bien la dernière terra incognita d'Europe. Mais, au cours des années qui ont précédé la première guerre mondiale, et en cela qu'elle paraissait aussi vierge que la neige qui couvrait ses montagnes, l'Albanie a fini par faire l'objet d'un étrange paradoxe: elle ne cessait d'être explorée pour la première fois. (Westphal 2001: 239)

En effet, en dépit de l'existence d'une littérature riche et variée à son égard, l'Albanie est demeurée longtemps l'un des pays européens les plus méconnus. Malgré cela (ou peut-être justement en raison de cela), au fil du temps ce pays a fait l'objet d'une production fictionnelle toute particulière, le représentant sous des noms toujours différents et pourtant tous également puisant à des éléments saillants de l'histoire et de la culture albanaise, au point de devenir l'un des lieux les plus imaginés parmi les pays méconnus. $^{2}$

Aux fins de la présente analyse, on se limite à en baliser l'espace imagologique entre deux de ses repères les plus importants, à savoir le sud célébré par Byron, qui la qualifia de "rugged nurse of savage men", "farouche nourrice d'hommes sauvages" (Byron 1812: 79), et la Haute-Albanie, qui juste un siècle après le voyage (1809) qui aboutit au Pèlerinage du jeune Harold fut au cœur de l'une des œuvres les plus passionnantes et passionnées consacrées à un pays balkanique, à savoir High Albania (1909) de Mary Edith Durham, qui la qualifia de "land of the living past", "terre du passé vivant" (Durham 1909: première page non numérotée).

Cela dit, pour mieux recadrer la mise en fiction du lieu que nous allons aborder, il convient de jeter un coup d'œil sur les cartes qui le représentaient.

Cette gravure, qui remonte au tout début du XVII e siècle, est censée être la "première esquisse géographique" (Festa 1993: 102) de l'Albanie. Elle apparaît dans le Voyage du Levant du baron Henry De Beauvau; la carte est munie de repères topographiques numérotés indiquant les emplacements principaux - de la ville de Scutari, à savoir Shkodra, dans le nord du pays, jusqu'à Duraz, soit Durrës, au sud - et s'accompagne de quelques lignes qui en tracent une sommaire esquisse historico-morale. 


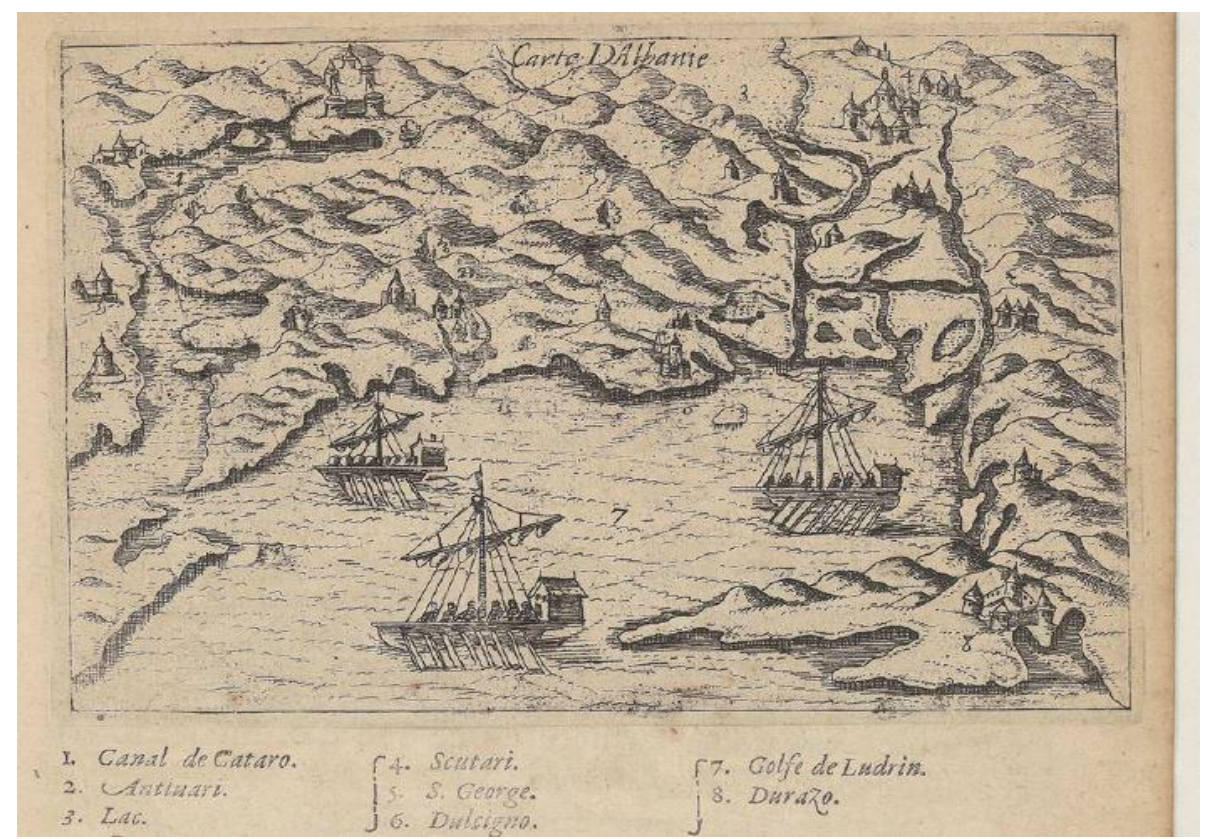

Carte d'Albanie (De Beauvau 1619: 11)

La province d'Albanie est grande \& fertille, principalement vers le Septentrion le peuple en est fort belliqueux ayant montré les principales valeurs sous la conduicte de ce grãd Scanderbeg qui deffit Amurat Empereur des Turcs vingt \& deux fois, en autant de batailles rangées. Leur langue est differente de l'Esclauone \& Grecque: Mais leur façon de faire est semblable a celle des Scythes, desquels ils tirent leurs origine. ${ }^{3}$ Les lieux principaux de cette contrée sont les villes de Duraz [sic] \& Valone. Duraz que les Anciens appelloient Dirrachium [sic] ou Epidaurum estoit fort renommé autre-fois à cause de son port \& pour cela frequenté des Romains. Ciceron en parle en les Epistres côme d'une ville qui luy auoit tesmoigné beaucoup d'amitie pendant son exile. (De Beauvau 1619: 11-12)

Dans ces lignes se distinguent certains des traits marquant de la représentation de l'Albanie dans la littérature de voyage des siècles passés, se polarisant autour de la figure du seigneur Georges Kastriot Scanderbeg, qui au XVe siècle résista longtemps à la conquête ottomane. Au beau milieu de la présentation du pays, exactement à mi-chemin entre le nord et le sud, on y lit un énoncé assez frappant, selon lequel les Albanais dériveraient des Scythes, à savoir l'ancienne population nord-iranienne située à peu près dans les régions comprises entre la mer Noire et la mer Caspienne.

Il n'en va pas autrement dans le Dictionnaire géographique portatif, ou Description de tous les royaumes, provinces, villes... des quatre parties du monde, mieux connu sous le nom de Dictionnaire Vosgien, où, sous l'entrée "Albanie", il est 
catégoriquement affirmé que "[l]es Albanois sont grands, forts, très-courageux, infatigables, bons Cavaliers \& gr. voleurs. Ils suivent la religion des Grecs, et descendent des anciens Scythes" (Vosgien 1749: 13).

Afin d'écarter tout doute, il convient de dire tout de suite qu'à l'état actuel des connaissances, ces affirmations reliant le petit pays balkanique à l'ancienne région du Caucase habitée par les Scythes ne sont censées avoir aucun fondement scientifique. Il reste que cette croyance était tellement répandue et de "longue durée" (au sens braudelien) qu'elle devint un véritable topos géo-littéraire, ou pour mieux dire un $d y s^{-}$ topos, en tant que "lieu" tout à fait dé-placé, voire mal placé.

Les descriptions reliant les Albanais aux Scythes se trouvent dans d'innombrables textes portant sur des différents domaines; en se tenant dans le cadre des œuvres visant à classer les savoirs géographiques, lisons cet extrait du Tableau des peuples européens rédigé par le philologue et historien français Frédéric Schoell, qui relie l'origine des Albanais balkaniques aux Alains, un groupe ethnique inclus dans la famille des Sarmates, qui à leur tour descendraient des Scythes.

C'est un peuple d'une origine inconnue, ${ }^{4}$ peut-être identique avec les Albanois de la mer Noire; ils paraissent être les mêmes que les Alains qui, dans le quatrième siècle, ont envahi l'Europe, et dont une partie peut s'être fixée dans l'ancienne Illyrie. Les Turcs nomment les Albanois Arnaut: euxmêmes s'appellent Skipatar. Ils ont embrassé le rit grec, et n'habitent pas seulement les côtes de la mer Adriatique, mais sont répandus dans tout l'empire turc. (Schoell 1812: 99)

Or, il ne relève pas du sujet de cette analyse d'aborder les questions généalogiques concernant les origines ethniques des Albanais; cependant, il nous paraît approprié d'en exposer les traits essentiels aux fins d'une meilleure compréhension de l'arrière-plan sur lequel elle se déroule. Pour cela faire, lisons les lignes qui suivent, tirées d'un essai concernant la construction identitaire du peuple albanais. Il est intéressant de noter que la théorie de l'origine caucasienne y est mise en relation avec les ouvrages des géographes anciens, ainsi qu'avec le Voyage de Pouqueville:

la recherche moderne reconnaît une forte prépondérance des probabilités en faveur de la possibilité qu'ils [les Albanais] sont effectivement les descendants des anciens Illyriens. La preuve en est surtout d'ordre linguistique; son importance n'est apparue clairement qu'à la suite du 
développement de la moderne ( $\mathrm{XX}^{\mathrm{e}}$ siècle) science de la linguistique historique. Bien avant de cela, cependant, les versions de la théorie "illyrienne" des origines albanaises se développa en concurrence avec d'autres hypothèses, dont la plus influente était celle qui assimilait les UrAlbanais aux habitants d'une région du Caucase, également connue (par les géographes classiques) comme "Albania", et supposait qu'ils avaient émigré de là aux Balkans occidentaux à la fin de l'âge classique, ou au tout début de la période médiévale. Cette théorie caucasienne fut initialement proposée par les humanistes de la Renaissance, qui connaissaient bien les ouvrages des géographes classiques, et ensuite elle fut développée au début du XIX ${ }^{e}$ siècle par le consul et écrivain français François Pouqueville. [...] À la fin du XIXe siècle, cette théorie avait perdu sa crédibilité grâce aux œuvres des linguistes qui avaient démontré que l'albanais était sans aucun doute indo-européen, pas caucasien. (Schwandner-Sievers, Fischer, 2002: 73-74) ${ }^{5}$

Les connaissances au sujet des Scythes sont redevables à Hérodote (Ve siècle av. J. -C.), qui dans ses Histoires les place dans un carré de terre compris entre le Pontus Euxinus (la mer Noire) et le Lacus Maeotis (la mer d'Azov). Par contre, dans sa Géographie Claude Ptolémée (II" siècle après J. -C.) appelle "Scythie" toute l'Asie centrale; dans cette carte, on peut voir (coordonnées 81/45) l'Albania caucasique et les toponymes qui y sont reliés (l’Albanus fl.[umen], la Porta Albaniæ, etc.).

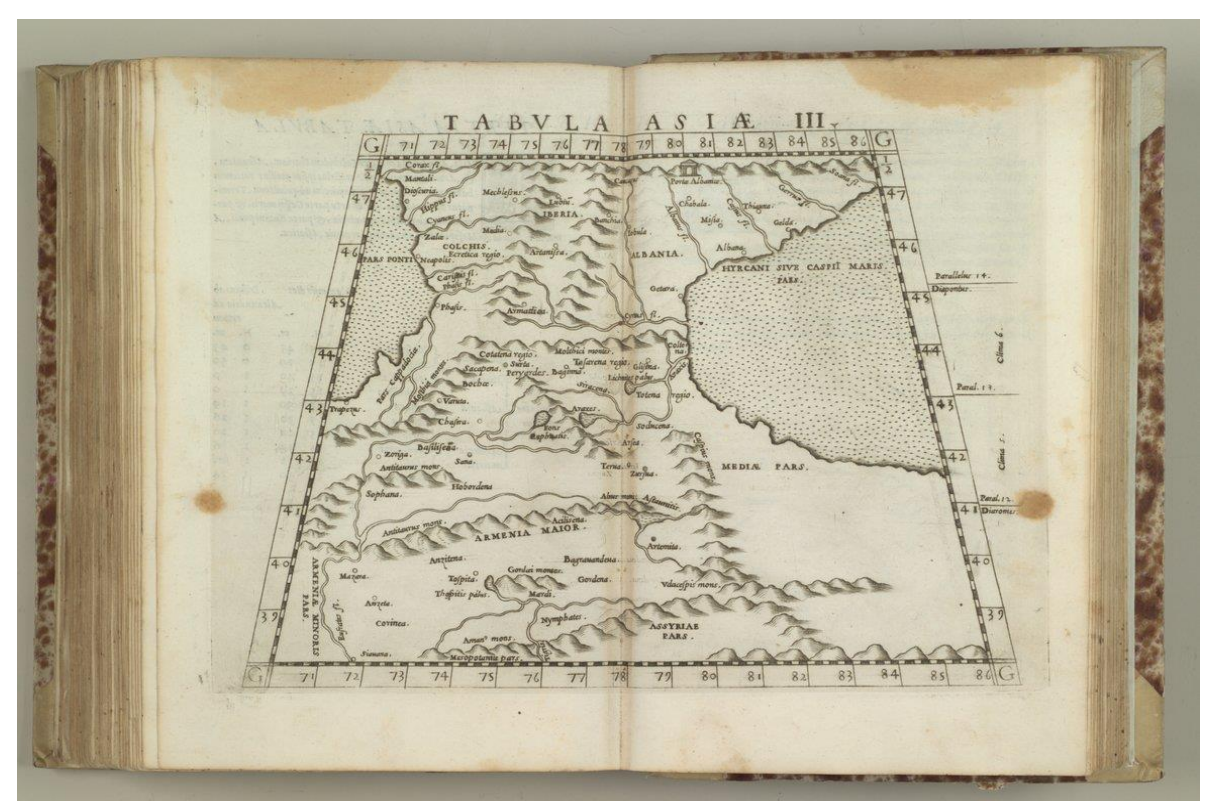

Claudius Ptolemaeus, Tabula Asiae III ${ }^{6}$ 
Bien que fascinant, dégager les étapes du parcours imaginaire qui "déplaça” le peuple scythe du Caucase jusqu'aux rivages de l'Adriatique oriental nous amènerait loin, $\mathrm{au}$ sens spatio-temporel du mot, de l'objet de notre analyse. Dans les limites nécessairement réduits de cette contribution, on peut quand même formuler une hypothèse concernant les origines d'un tel enchevêtrement, qui résiderait sur la base d'une homonymie. Quant à la diffusion de telle idée fausse, il est tout aussi probable que le succès des atlas réalisés pendant la Renaissance contribua à corroborer une telle confusion. Tel pourrait être le cas de la Cosmographia représentée ci-dessous, de l'humaniste allemand Sebastian Münster; dans cette carte, l'Albania s'affiche dans le quadrant inférieur droit.

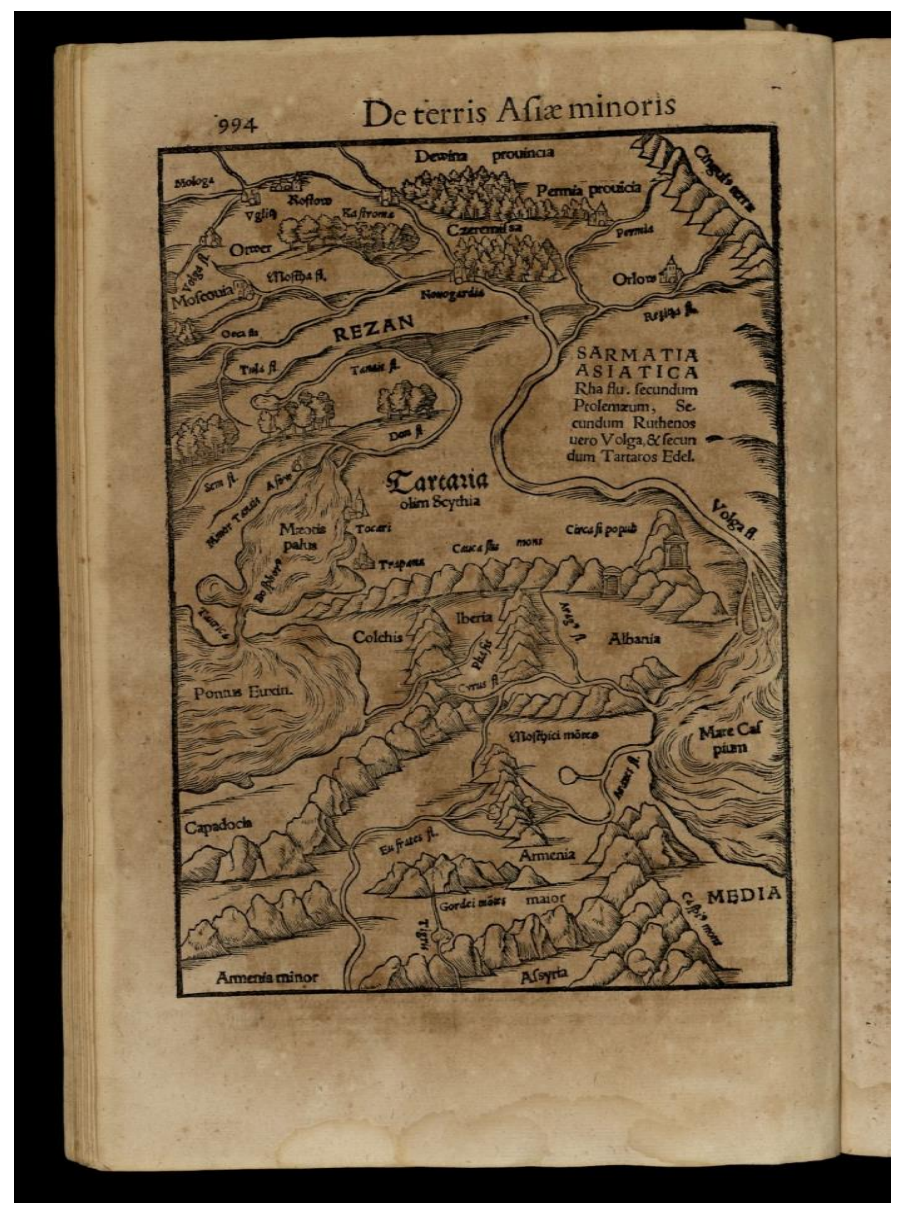

Sebastien Münster, De Terris Asiæ minoris (Münster 1552: 994)7

Publié en cinq langues et 35 éditions entre 1544 et 1628, cet atlas monumental "se tient comme l'un des livres les plus répandus et les plus influents de 
son époque"8 (Nothaft, 2009). La popularité de l'œuvre profita des précieuses gravures sur bois réalisées par, entre autres, Hans Holbein le Jeune. Compte tenu de ces éléments, nous nous demandons si, parmi d'autres données pris en compte par l'analyse imagologique, il ne serait judicieux d'y inclure également la "réception" des travaux cartographiques.

\section{Le récit du jamais vu}

Il est temps d'en venir au Voyage de Pouqueville, en laissant momentanément de côté les Scythes, qu'on retrouvera d'ici peu. Ce texte, qui demeure une étape clé dans la littérature odéporique au sujet de l'Albanie, eut origine à la suite de circonstances rocambolesques: parti en mai 1798 en qualité de médecin à la suite de l'expédition militaire de Napoléon Bonaparte en Égypte, Pouqueville fut forcé en octobre de la même année de quitter le pays, en raison de son mauvais état de santé. La tartane livournaise qui devait le mener en Italie fut arraisonnée par des corsaires, et il fut fait prisonnier par les Turcs avec d'autres membres de l'expédition bonapartienne. Après divers rebondissements, il fut transféré à Constantinople, où il resta emprisonné avec plusieurs fonctionnaires français, alors que d'autres membres de l'expédition furent conduits à Janina et remis au redoutable tyran Ali de Tepelena, qui y avait son siège. Bénéficiant d'un certain degré de liberté en raison de l'exercice de sa profession, Pouqueville put explorer quelques-unes des zones environnant la forteresse de Constantinople. Ce fut dans ce contexte qu'il commença à rédiger le journal qui allait aboutir au Voyage en Morée, à Constantinople, en Albanie, dont le troisième volume (concernant l'Albanie) s'appuie sur les témoignages de ses collègues qui avaient été retenus à Janina. En juillet 1801 il fut libéré; une fois rentré en France, il se consacra à la rédaction de son ouvrage, qui parut en 1805. Il s'ensuit que son "voyage" en Albanie se déroula dans l'intimité de son cabinet, sur la base des cartes, des livres, ainsi que des témoignages d'autrui.

Pourtant, tout en étant rédigé in absentia par rapport aux lieux qui font l'objet de la représentation, le modèle sous-jacent au récit de Pouqueville ne diffère pas trop de celui qui caractérisait nombre de journaux de voyage parsemés de réminiscences classiques qui bien souvent se superposaient à la description. En effet, comme le rappelle Daniel-Henri Pageaux, déjà au XVIIe siècle, lorsqu'il rédigea l'entrée "Voyageur" 
de l'Encyclopédie, le chevalier Louis de Jaucourt se méfiait de la véridicité des relations de voyage, en déclarant que

les voyageurs usent de peu de fidélité. Ils ajoutent presque toujours aux choses qu'ils ont vues, celles qu'ils pouvoient [sic] voir; \& pour ne pas laisser le récit de leurs voyages imparfait, ils rapportent ce qu'ils ont lu dans les auteurs, parce qu'ils sont premièrement trompés, de même qu'ils trompent leurs lecteurs ensuite. (Jaucourt 1751: 477)

Pour sa part, Pageaux renchérit la dose, ajoutant que "l'écrivain-voyageur, par le fait même qu'il écrit, va affabuler" (Pageaux 1994: 31). Par conséquent, il ne serait pas trop aisé que de marquer la différence entre un voyage réel et un voyage imaginaire. Ce qui importe est

de voir selon quelle logique vont se construire ses 'mensonges', même lorsque le texte se présente comme un récit objectif et quels mensonges sont susceptibles de se transformer en matière littéraire (ibidem).

Sur la base de cette prémisse, nous allons franchir le seuil de l'espace albanais "imaginé" par François Pouqueville. C'est justement l'identification de la logique qui commande la construction de ses "mensonges" ce qui nous sert de critère opérationnel dans la déconstruction de ce singulier (et pourtant loin d'être unique) récit du jamais vu.

Dès le début, l'auteur tient à montrer sa confiance dans ses capacités de présenter "convenablement" l'Albanie grâce aux données dont il disposait. Ce sont les fondements de son pacte narratif, visant à assurer les lecteurs de la véracité des faits qu'il va relater.

Réduits en esclavage par un corsaire de Tripoli de Barbarie, on verra ma douloureuse séparation de mon ami Bessières, et comment je profitai de ses observations et de celles du colonel Charbonnel, qui, réunies à de nombreuses données que je possédais, m'ont mis à portée de parler convenablement de l'Albanie: cet objet formera le tome troisième de mon Voyage. [...] (Pouqueville 1805: I, iv-v). 
Si telles sont les orientations générales définies dans la préface, une fois entré dans le cœur du discours, Pouqueville n'échappe pas au topos de la primauté de la découverte:

l'on verra, dans cette relation, l'aspect d'un pays placé aux portes de l'Europe, et inconnu jusqu'à présent, ou sur lequel on n'a publié que des choses vagues et mensongères. ${ }^{9}[. .$.$] En marchant sur$ leurs ${ }^{10}$ traces, on va pénétrer dans un pays nouveau. J'ose me servir de cette expression, puisque le célèbre d'Anville avouait lui-même que le défaut de matériaux et de reconnaissances lui manquaient pour dresser une carte de l'Épire. Peu de voyageurs ont en effet pénétré jusqu'à Ianina, et aucuns n'ont dépassé cette ville, où l'on n'arrive qu'au travers des dangers en voyageant chez un peuple inquiet, que son penchant naturel porte au brigandage, au meurtre et à la cruauté. (Pouqueville 1805: III, 27)

Abstraction faite de l'énoncé attribuant aux habitants d'un pays qu'on n'avait encore parcouru une tendance "naturelle" à commettre les crimes les plus graves, voyons quels sont les dispositifs mis en place au cours de la narration. Dans les lignes qui suivent, l'auteur adapte le Corpus Hippocraticum à ses nécessités, en appliquant aux Albanais des termes qui dans l'œuvre du médecin grec se référaient génériquement aux peuples européens: "Hippocrate semble avoir peint les Albanais, lorsqu'il établit la différence entre l'Asiatique et l'habitant de l'Europe." (Pouqueville 1805: III, 152) Après quoi, en ayant payé sa dette envers le devoir de la véracité grâce à un verbe ayant fonction opinative ("il semble"), il s'est donné le feu vert pour rédiger sa propre description sous l'égide du grand nom qu'il vient d'invoquer.

Le père de la médecine les ${ }^{11}$ caractérise encore plus spécialement par ces paroles, dont l'expérience démontre tous les jours le grand sens: "Tous ceux qui habitent un pays montueux, inégal, élevé et pourvu d'eau, et qui éprouvent des variations considérables dans les saisons, doivent naturellement être d'une haute stature, très propres à l'exercice et au travail, et pleins de courage. Ils sont surtout d'un caractère sauvage et féroce (1). (Pouqueville 1805: III, ...). Les Albanais sont ces hommes des montagnes (1) Traduction de M. Corai. (Pouqueville 1805: III, 153).

Par le biais d'une utilisation astucieuse de la particule pronominale ("les"), l'auteur réussit à adapter le sens du texte primaire à ses propres fins; c'est ainsi qu'il met en œuvre la déduction amplifiante (à savoir, le procédé rhétorique par lequel des 
applications concrètes sont tirés d'un énoncé d'ordre générale du quel on a extrapolées les propriétés), en attribuant à Hippocrate la source de ses jugements dans le but d'en renforcer la validité. D’un seul coup, l'énoncé hippocratique est adapté, voire détourné, en fonction des sujets au cœur de son récit. Cette étape accomplie, il peut continuer en toute sécurité, en intercalant le texte ancien à son propre discours; entre l'un et l'autre, il n'y a que les guillemets qui peuvent révéler la réalisation du collage à un œil attentif.

Une fois établi le lien, il arrive à une conclusion qui se veut incontestable: "[l]es Albanais sont ces hommes des montagnes" (Pouqueville 1805: III, 153), c'est-à-dire qu'ils sont précisément ceux auxquels se référait Hippocrate. Le moule fabriqué, la descriptio peut se déployer en toute liberté.

\footnotetext{
Leur taille commune est de cinq pieds quatre pouces; ils sont fortement musclés; l'angle facial est chez eux généralement droit, et l'ovale du visage allongé; les moustaches sont peu fournies, les joues colorées, l'œil est vif; la bouche, bien proportionnée, laisse voir un double rang de dents parfaitement alignées; le front est étroit, le col est élevé, la poitrine développée, et peu couverte de villosités. Peu chargés d'embonpoint, ils sont en général bien faits, agiles, et ont la jambe fine et peu fournie de mollet. Leur tempérament participe du sanguin et du bilieux. Chez eux le système abdominal est peu développé, et ils ont la constitution la plus propre aux fatigues et aux expéditions lointaines. (ibidem)
}

En quelque sorte, cette démarche ramène à l'esprit un genre littéraire plutôt chéri au Moyen Âge, c'est-à-dire le centon, consistant à découper des phrases tirées d'autres auteurs, de manière à faire correspondre le sens du texte "recomposé" avec ses propres intentions communicatives. Une fois choisis ses auteurs en tant que points de repère dans un terrain "inconnu" (comme l'Albanie l'était par antonomase), on se livrait à en tirer les représentations qui lui convenaient le mieux.

Ensuite, les fils s'imbriquent de plus en plus, au point qu'il ne serait plus possible de distinguer entre l'imagination et l'expérience directe. C'est un véritable voyage sur les cartes, obtenu par "juxtaposition des lieux" (Laboulais-Lesage 2001: 108), d'après la définition utilisée dans une étude consacrée aux géographes français du XVIII siècle. La toile de fond s'élargit à inclure des contrées lointaines, qui ne font nullement partie du terrain au cœur du récit, alors que, en revanche, elles resurgissent du bagage de lectures 
de l'auteur. Il semblerait que, plus les espaces s'élargissent, plus l'imagination prend son envol.

On les trouve aussi, comme je l'ai dit, dans toutes les parties de l'empire, et depuis les rives de l'Euphrate jusqu'à l'embouchure du Drino; ${ }^{12}$ en Égypte et dans les régences barbaresques, les Arnaoutes ou Albanais, sont les soldats par excellence, et les milices les plus renommées. Ils se mêlent également aux phalanges de révoltés qui infestent la Roumilie, ${ }^{13}$ et, sans rougir du métier de brigands, parce qu'il emporte avec lui des dangers, ils racontent hautement leurs coupables prouesses, et ils s'en glorifient. (Pouqueville 1805: III, 154)

Dans les exemples qui suivent se détache le dispositif de la visualisation, qui apparemment est l'un des outils langagiers de prédilection alors que l'auteur souhait corroborer la véridicité de ses propres mots. C'est ainsi que la vision, "vertu cardinale" des écrivains-reporters (Boucharenc 2004: 65), devient acte de vérité de la description: c'est vrai, car on l'a vu de ses propres yeux.

On apperçoit le rivage de la Haute-Albanie dont une partie dépend du pacha de Scutari, duquel je parlerai dans une autre circonstance. Mais si on porte ses regards sur les côtes, depuis la Vallona jusqu'à Butrinto, on ne trouve plus de mouillages sûrs et profonds. (Pouqueville 1805: III, 90)

Quelques lignes plus bas, s'ajoute la présence d'indicateurs déictiques (dans le cas d'espèce, des verbes indiquant l'espace : "s'éloigner", “quitter").

On y voit encore les restes de deux théâtres, d'un stade et de quelques édifices publics, qui sont tous en brique, et on n'y apperçoit [sic] ni sculpture, ni marbre. Quelques fouilles que les Français y pratiquèrent, lorsqu'ils étaient possesseurs de Prévesa, commençaient à récompenser les travaux: (Pouqueville 1805: III, 100). Mais avant de m'éloigner de la Turquie d'Europe, avant de quitter la patrie du roi Glaucias, qui, dit-on, régna dans Scodra, avant enfin de saluer ces rivages célèbres par tant de hauts faits, fixons un dernier regard sur l'ensemble des montagnes de la Turquie d'Europe. La précision, la rapidité de la narration, seront les moyens dont je me servirai pour solliciter l'indulgence, en faveur de la digression à laquelle je me livre. (Pouqueville 1805: III, 264) 


\section{Les Scythes de l'imaginaire européen}

Loin d'être limitées au dernier volume, les références à l'Albanie sont éparpillées tout au long de l'ouvrage. Dans le premier livre, voici que resurgissent les Scythes; ici, le lien entre les deux peuples se tisse par le biais d'une musique "barbare", voire "infernale".

La musique des Grecs de l'Épire, des fiers Albanais, porte un tout autre caractère. Elle est sauvage et barbare comme le peuple qui la chante, et on peut dire qu'elle respire la guerre et le carnage. Elle semble faite pour être répétée par l'écho des cavernes, ou des montagnes affreuses qu'ils habitent. Cette musique, vraiment infernale, n'a pu naitre que chez les Scythes ou chez les Albanais, qui leur ressemblent. (Pouqueville 1805: I, 289)

Mais les similitudes entre les deux peuples ne s'arrêtent pas là.

Les Albanais, qu'on pourrait nommer les Scythes de l'empire d'Orient, ne connaissent que peu de besoins. Ils habitent, en général, des maisons qui n'ont qu'un rez-de-chaussée, et couchent sur des nattes ou sur les épaisses capotes, qui les mettent à couvert des injures de l'air. Peu sensibles aux variations de l'atmosphère, ils mènent une vie également laborieuse dans les différentes saisons de l'année; contents de peu, ils se nourrissent de lait, de fromage, d'olives, de végétaux, de viande mais en petite quantité, de poissons et d'œufs, enfin des poissons salés; tantôt ils font usage de pain, tantôt ils se contentent de blé bouilli ou de maïs. (Pouqueville 1805: III, 149)

Le récit albanais de François Pouqueville lui valut un succès énorme; non seulement le pacha Ali le nomma consul de Janina, mais, ce qui est plus important pour les fins de notre analyse, son œuvre fut immédiatement traduite en plusieurs langues, et déclencha l'écriture de récits à sujet albanais par nombre d'auteurs qui n'avaient jamais visité ce pays. Parmi les ouvrages fictionnels les plus célèbres qui s'en inspirèrent il y eut un récit dumasien consacré au personnage du pacha Ali. Comme c'était souvent le cas, la toile de fond en avait été tracée par le romancier Félicien Mallefille l'un des collaborateurs de Dumas) en puisant à des matériaux d'archive, tels que l'œuvre de Pouqueville (Dumas, et al., 1840: 313). Lisons-en quelques lignes concernant la description du pays. 
L'Albanie était une des provinces les plus difficiles à exploiter. Les habitans [sic] en étaient assez pauvres, très-résolus, et, en outre, naturellement retranchés dans de rudes chaînes de montagnes. Les pachas avaient bien de la peine à y amasser de l'or, parce que chacun avait l'habitude d'y défendre énergiquement son pain. Mahométans ou chrétiens, les Albanais étaient tous soldats. Descendant, les uns des indomptables Scythes, les autres des vieux Macédoniens, jadis maîtres du monde, mélangés d'aventuriers normands qu'avait amenés le grand mouvement des croisades, ils sentaient couler dans leurs veines un vrai sang guerrier: aussi la guerre semblait leur élément. (Dumas, et al., 1840: 311)

Cette représentation de seconde main, voire plus, empruntant à des sources qui elles aussi s'étaient appropriées des images préexistantes, propose une synthèse des traits saillants des Albanais (à savoir, fiers montagnards, brigands au fusil en épaule), ou pour mieux dire de l'“Albanais” hypostatisé, résultant d'un véritable florilège se transmettant à travers les siècles.

Pourtant, si Pouqueville remania ses sources, il n'en allait pas trop différemment de la manière des géographes de son époque, qui dressaient leurs cartes puisant sur les descriptions d'autrui sans presque bouger de leurs cabinets, ce qui d'ailleurs était considéré tout sauf négatif, comme le montre cet éloge de l'une des sources de Pouqueville, à savoir le géographe Jean-Baptiste Bourguignon d'Anville.

Il essayoit de suivre les Phéniciens dans leurs navigations et d'en deviner le secret; [...]Il visitoit avec Scylax de Caryande, les Pays et les Établissemens situés sur une partie des côtes de l'Europe, de l'Asie et de l'Afrique. Il accompagnoit Hérodote dans ses voyages en Grèce, en Italie, en Égypte, en Asie. Il pénétroit jusqu'au-delà de l'Indus avec Alexandre. (Dacier 1834: iii). Les anciens Géographes avoient presque tous voyagé, et parloient très-souvent de ce qu'ils avoient vu. M. d'Anville, au contraire, connoissoit la terre sans l'avoir vue; il n'étoit, pour ainsi dire, jamais sorti de Paris, et ne s'en étoit pas éloigné de plus de 40 lieues. (Dacier 1834: xiii)

Si l'on tient compte que les cartes illustrant le Voyage de Pouqueville furent réalisées par Jean-Denis Barbié du Bocage (qui fut, lui aussi, un géographe de cabinet et l'un des élèves les plus célèbres de D’Anville), il en découle un véritable effet looping, où les éléments de la "narration" (entendue en sens tant verbale que cartographique) se renvoient les uns aux autres. À ce point, on peut fermer la boucle, non sans présenter la carte ci-dessous, où dans le coin inférieur gauche s'affiche une étonnante inscription 
indiquant l'un des espaces les plus mythiques de l'antiquité classique, c'est-à-dire les

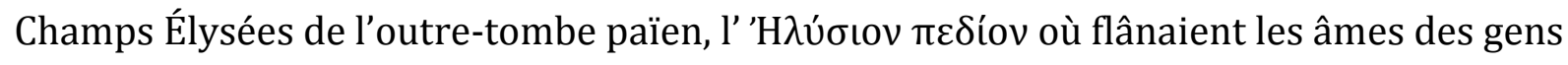
vertueux. À ce qu'en écrivit Pouqueville, il gisait justement dans le sud de l'Albanie.

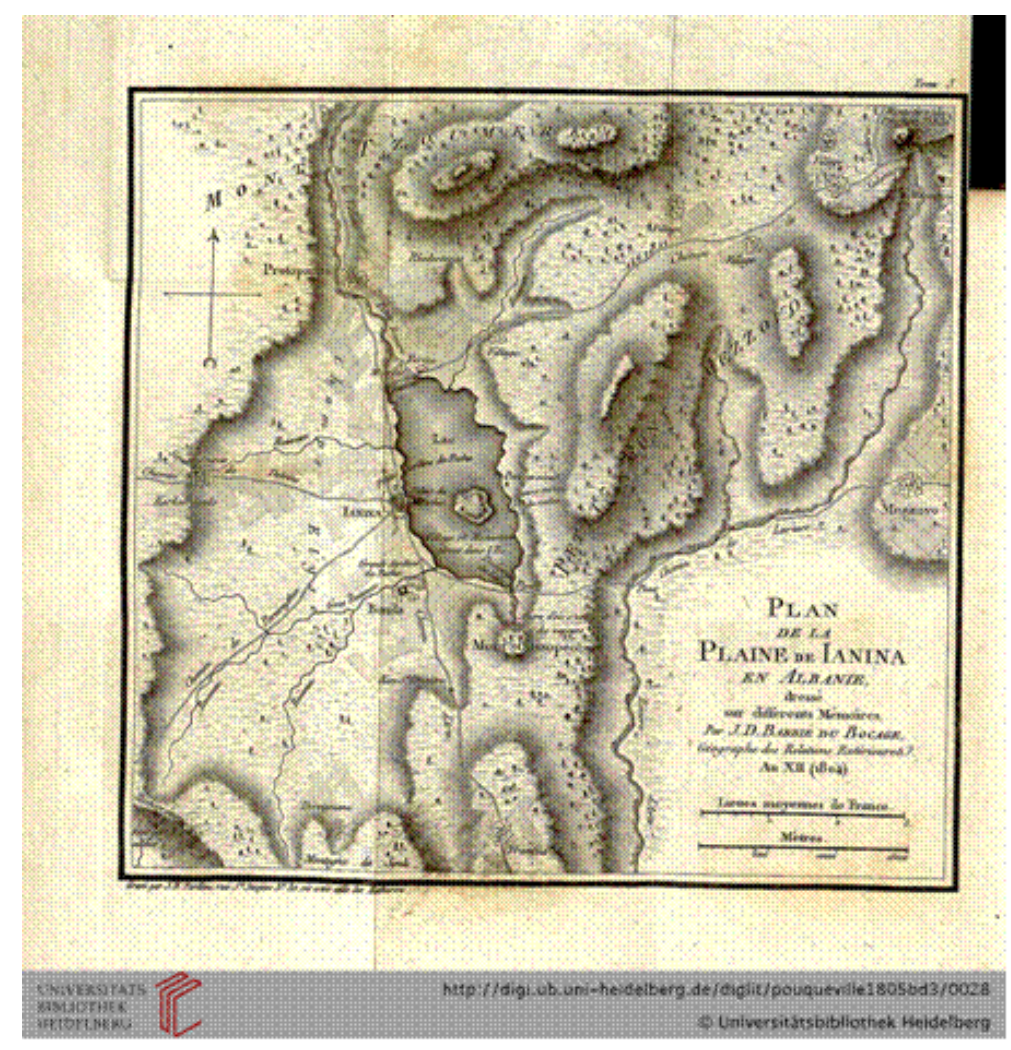

Plaine de Janina dessinée par J. D. Barbié du Bocage d'après le récit de Pouqueville (Pouqueville, 1805: III, page non numérotée suivant la p. xxi) ${ }^{14}$

\section{Conclusions}

À en juger par l'homogénéité des contenus et la fréquence de la représentation, on dirait que, si selon l'hypothèse construite par François Hartog les Scythes d'Hérodote seraient les Scythes imaginaires des Grecs, les Albanais représentés par les écrivainsvoyageurs seraient les Scythes de l'imaginaire européen. Comme la possibilité de ce couplage nous séduit beaucoup, en concluant nos observations rappelons le modèle opérationnel formulé par l'auteur du Miroir d'Herodote.

On peut, [...] à titre d'hypothèse, procéder ainsi: traiter le nom propre Scythes comme un simple signifiant et tracer le parcours de ce signifiant à l'intérieur de l'espace du récit, en repérant tous 
les prédicats qui s'y agrègent et construisent finalement la figure des Scythes: la somme de ces prédicats constituant les Scythes d'Hérodote. (Hartog 1980: 63)

Ainsi, si l'on va repérer à l'intérieur des espaces des récits francophones ${ }^{15}$ des siècles passés les prédicats s'agrégeant à ce signifiant tout particulier constitué par les Albanais en tant que Scythes, la somme de ces prédicats pourrait nous donner d'autres figures qui peuplaient l'imaginaire européen au sujet de l'Albanie.

En définitive, nos considérations sont les suivantes: même si la confusion entre le peuple caucasien et les Albanais découlait de raisons de pure homonymie (en admettant que la variation onomastique puisse être considérée comme complètement "pure", voire dépourvue de toute arrière-pensée), il reste que ce chevauchement des noms entraîne avec lui tout un faisceau d'épithètes qui marquent l'objet de la représentation originaire. Dans d'autres mots, alors que le peuple des Scythes est évoqué dans l'espace balkanique, il y arrive avec toutes les constantes de prédicats qui le marquaient dans ses terres d'appartenance. Par conséquent, alors que l'écrivain-voyageur convoque le peuple caucasien habitant l'Albanie homonyme, il le "transfert" (au sens étymologique du terme, il le "porte", "fert" "de l'autre côté”, "trans") en opérant un découpage qui, tout en étant physique (en tant qu'agissant sur les cartes géographiques), devient en même temps symbolique, en tant qu'il "met ensemble" (du grec ancien symballein), "joint”, et donc "compare" les uns avec les autres. Et cet Autre-là, encore une fois, vient de l'Orient. 


\section{Bibliographie}

Boucharenc, Myriam (2004), L'écrivain-reporter au cœur des années trente, Lille, Presses Universitaires du Septentrion.

Byron, Gordon George (1812), Childe Harold's Pilgrimage. A Romaunt, London, John Murray / Edinburgh, William Blackwood / Dublin, John Cumming.

Dacier, Bon-Joseph (1834), Éloge de M. D'Anville. In: Oeuvres de D’Anville publiées par M. de Manne, Paris, Imprimerie Royale, tome I.

De Beauvau, Henry (1619), Relation Journalière du Voyage du Levant, Nancy, Jacob Garnich.

Dumas, Arnould, Fournier, Fiorentino, Mallefille (1840), Crimes Célèbres, Paris, Administration de Librairie.

Durham, Mary Edith (1909), High Albania, London, Edward Arnold.

Durham, Mary Edith (1914), The Struggle for Scutari, London, Edward Arnold.

Festa, George (1993), "L'Albanie des voyageurs: du Mythe aux Lumières (XVIIe-XVIIIe siècles)", in: Studies on Voltaire and the Eighteenth Century, 311, pp. 101-113.

Hartog, François (1980), Le miroir d'Hérodote. Essai sur la représentation de l'autre, Paris, Gallimard.

Hérodote, Histoires [1889], traduction de Larcher; revue et corrigée par Pessonneaux, Émile, Paris, G. Charpentier,

http://gallica.bnf.fr/ark:/12148/bpt6k5454961c/f328.image.r=scythes.langEN, (consulté le 2. 3. 2015).

Jaucourt, Louis (de) (1751), "Voyageur", in: L'Encyclopédie, tome 17, p. 417. En ligne: http://fr.wikisource.org/wiki/L\%E2\%80\%99Encyclop\%C3\%A9die/1re_\%C3\%A 9dition/VOYAGEUR (consulté le 11. 4. 2015).

Laboulais-Lesage, Isabelle (2001), "Les géographes français de la fin du XVIIIe siècle et le terrain. Recherches sur une paradoxale absence", in: L'Espace géographique 2/2001 (tome 30) En ligne: http://www.cairn.info.proxy.unice.fr/revue-espace-geographique2001-2-page-97.htm (consulté le 15. 4. 2014).

Münster, Sebastien (1552), Cosmographiae uniuersalis Lib[ri] VI [...], Basileae, Henrichum Petri. En ligne: http://purl.pt/13845/3/\#/1074 (consulté le 3. 4. 2015). 
Nothaft, Carl Philipp Emanuel (2009), Compte rendu de: McLean, Matthew. 2007. The Cosmographia of Sebastian Münster. Describing the World in the Reformation, Aldershot, Hampshire (Ashgate Publishing)., VIII-378 p., 30 ill. (St. Andrews Studies in Reformation History). In: Francia-Recensio 2009/3 | Frühe Neuzeit - Revolution - Empire (15001815). En ligne: www.perspectivia.net/content/publikationen/francia/franciarecensio/2009-3/FN/mclean_nothaft (consulté le 3. 3. 2015).

Pageaux, Daniel-Henri (1994), La littérature générale et comparée, Paris, A. Colin.

Pouqueville, François-Charles-Hugues-Laurent (1805), Voyage en Morée, à Constantinople, en Albanie, et dans plusieurs autres parties de l'Empire Ottoman pendant les années 1798, 1799, 1800 et 1801, Paris, Gabon, vol. I ; III.

Ptolemaeus, Claudius [1562], Geographia Cl. Ptolemaei Alexandrini, Venetiis, apud Vincentium Valgrisium. En ligne: http://amshistorica.unibo.it/184 (consulté le 3. 3. 2015).

Schoell, Frédéric (1812), Tableau des peuples qui habitent l'Europe, classés d'après les langues qu'ils parlent, et Tableau des religions qu'ils professent, Paris, F. Schoell.

Schwandner-Sievers, Stephanie, Fischer, Bernd Jürgen (2002), Albanian identities. Myth and History, Bloomington, Indiana University Press.

Vosgien (1749), Dictionnaire géographique portatif, ou Description de tous les royaumes, provinces, villes, patriarchats, évéchés, duchés, comtés, marquisats, villes impériales et anséatiques, ports, forteresses, citadelles, et autres lieux considérables des quatre parties du monde, Paris, Didot.

Olimpia Gargano est enseignante d'Italien et Latin au lycée de Vintimille (Italie). Elle va soutenir (27. 2. 2015) sa thèse de doctorat en Littérature Comparée à l'Université Nice Sophia Antipolis (FR); la thèse porte sur l'image de l'Albanie à partir des récits de voyage des XIXe et XXe siècles, notamment à travers les œuvres d'Edith Durham (High Albania), Jules Degrand (Souvenirs de la Haute Albanie), Ugo Ojetti (L'Albania). 


\section{Notes}

${ }^{1}$ Ce ne fut qu'après la publication du Voyage en Morée que Pouqueville visita en personne l'Albanie, où il demeura jusqu'en 1816.

2 À ce sujet, nous nous permettons de renvoyer à notre article paru à la suite d'un colloque en matière de géocritique organisé en 2011 par l'Université de Naples: GARGANO, Olimpia. 2014. "Illyria, Syldavia, Elbonia e altrove. La re-invenzione narrativa dell'Albania fra spazi immaginari, utopie e distopie", in: DE LuCIA, S., Gallo, C., Marino D. (éd.), Landscapes and Mindscapes. Metodologie di ricerca, percorsi geocentrati e poetiche dello spazio in una prospettiva comparata, Napoli, Marchese, pp. 287-310.

${ }^{3}$ C'est nous qui soulignons.

${ }^{4}$ C'est nous qui soulignons ce qualificatif qui s'avère être l'une des épithètes les plus courants au sujet de ce pays.

${ }^{5}$ Stephanie Schwandner-Sievers, Bernd Jürgen Fischer. 2002. Albanian identities. Myth and History, Bloomington, Indiana University Press: "modern scholarship recognises a strong balance of probabilities in favour of the view that they [the Albanians] are indeed descended from the ancient Illyrians. The evidence for this is primarily linguistic; its significance has become clear only with the development of the modern (twentieth-century) science of historical linguistics. Long before that, however, versions of the 'Illyrian' theory of Albanian origins developed in competition with other hypotheses, of which the most influential was the one that identified the Ur- Albanians with the inhabitants of an area in the Caucasus also known (to classical geographers) as "Albania", and supposed that they had migrated from there to the western Balkans in the late classical or early medieval period. This Caucasian theory was first proposed by Renaissance humanists who were familiar with the works of classical geographers, and later developed by early 19th-century French consul and writer François Pouqueville. [...] By the late nineteenth century this theory was in retreat, thanks to the work of linguists who had demonstrated that Albanian was definitely Indo-European, not Caucasian." (Trad. pers.).

${ }^{6}$ Image tirée de l'édition numérique de l'Université de Bologna.

${ }^{7}$ Image tirée de l'édition numérique de la Biblioteca Nacional de Portugal.

${ }^{8}$ Carl Philipp Emanuel Nothaft, compte rendu de: MCLEAN, Matthew. 2007. The Cosmographia of Sebastian Münster. Describing the World in the Reformation, Aldershot, Hampshire (Ashgate Publishing). "With 35 editions in five languages, published between 1544 and 1628, the monumental 'Cosmographia' from the pen of the German humanist Sebastian Münster stands as one of the most widespread and influential books of the Reformation period." (Trad. pers.).

${ }_{9}^{9}$ François-Charles-Hugues-Laurent Pouqueville, Voyage en Morée, à Constantinople, en Albanie, op. cit., vol. III, p. 2.

10 À savoir, sur les traces des officiers français qui lui avaient rapporté leurs expériences directes.

${ }^{11}$ Ici et dans le cas suivants, c'est nous qui soulignons.

${ }^{12}$ Le fleuve Drin, qui prend sa source dans le nord-est de l'Albanie. 
${ }^{13}$ À savoir la Roumélie, comme à partir du XVe siècle on appelait l'Europe balkanique sous domination ottomane.

14 Image tirée de l'édition numérique de la Bibliothèque Universitaire de Heidelberg. En ligne: http://digi.ub.uni-heidelberg.de/diglit/pouqueville1805bd3/0028 (consulté le 14. 3. 2015).

${ }^{15}$ Dans le cadre de cette analyse on s'est limitée à aborder des œuvres de langue française; pourtant, il y a nombre de cas similaires dans d'autres langues. Pour ne faire qu'un seul exemple, nous rapportons les mots d'Edith Durham qui, en feuilletant des journaux illustrés concernant le siège de Shkodra en 1913, se dit "dégoûtée par la négligence grave qui [avait] permis que des photos même de personnes du Caucase [eussent] été vendues au grand public en tant que sujets des Balkans". Durham, Mary Edith. 1914. The Struggle for Scutari, London, Edward Arnold: "disgusted by the gross carelessness which permitted photographs even of Caucasians to be sold to the public as Balkan subjects". (Trad. pers.). 


\title{
(Non-) lieux de la consommation dans Palomar et Marcovaldo de Italo Calvino
}

\author{
Fanny Mahy \\ Universidade do Porto
}

Résumé: Cet article analyse, par le biais des théories portant sur les lieux et les non-lieux de l'anthropologue Marc Augé, le processus de consommation tel que vécu par les personnages de Palomar et de Marcovaldo. Italo Calvino introduit les deux protagonistes dans des lieux de transaction commerciale ordinaires, codifiés, normés, parallèlement doublés d'un imaginaire de l'intériorité pour le moins singulier. Cette dichotomie entre le "normé" et le "singulier" engendre une dialectique particulièrement fertile pour la compréhension des difficultés rencontrées par l'individu / personnage dans la surmodernité, et notamment dans les relations qu'il entretient à lui-même, aux autres et au monde.

Mots-clés: non lieux, consommation, Italo Calvino, surmodernité, intériorité.

Resumo: Este artigo analisa, mediante as teorias relativas aos lugares e aos não-lugares do antropólogo Marc Augé, o processo de consumo, tal como é vivido pelas personagens de Palomar e de Marcovaldo. Italo Calvino introduz os dois protagonistas em lugares da transação comercial ordinários, codificados, normados, paralelamente desdobrados com um imaginário da interioridade no mínimo singular. Essa dicotomia entre o "normado" e o "singular" gera uma dialética particularmente fértil para a compreensão das dificuldades enfrentadas pelo indivíduo/personagem em sobremodernidade, e nomeadamente nas relações que mantém consigo próprio, com os outros e com e o mundo.

Palavras-chave: não-lugares, consumo, Italo Calvino, sobremodernidade, interioridade. 
A une heure donnée, comme si on avait abaissé un interrupteur, tout le monde laissait tomber la production et, hop! se ruait vers la consommation.

La consommation telle que représentée dans l'œuvre d'Italo Calvino introduit le lecteur dans des lieux de transaction commerciale, un processus banal, codifié, normé, parallèlement doublé d'un imaginaire de l'intériorité pour le moins singulier. Cette dichotomie entre le "normé" et le "singulier" engendre une dialectique particulièrement fertile entre lieux et non-lieux de la consommation. En effet, l'analyse des (non-) lieux dans quelques textes choisis parmi l'œuvre de l'un des plus grands écrivains italiens du $\mathrm{XX}^{\mathrm{e}}$ siècle manifeste, selon nous, dans toute son acuité, une réinscription à la fois poétique, cocasse et sensible, du "jeu brouillé de l'identité et de la relation à soi" (Augé 1992: 101), à l'autre et au monde, ici appréhendé au travers du microcosme de l'instance marchande.

Le recueil intitulé Palomar raconte "les aventures et les mésaventures du regard" de Monsieur Palomar, qui "avait décidé que sa principale activité serait de regarder les choses du dehors" (Calvino 1985: quatrième de couverture). Quatre des vingt-sept nouvelles publiées se déroulent dans un lieu de consommation. Les trois premières investissent les boutiques du marché parisien ; une charcuterie: "Trois livres de graisse d'oie", une fromagerie: "Un musée de fromages" et une boucherie: "Le marbre et le sang". La quatrième, plus exotique, situe l'action dans un bazar de vacances: "La pantoufle dépareillée".

Le petit ouvrage Marcovaldo, du nom de cet homme également sujet aux aventures et aux mésaventures, raconte, quant à lui, l'histoire d'un manœuvre pauvre, chargé de famille, et qui rêve beaucoup à la nature tandis qu'il évolue dans un univers résolument urbain. Comme déclaré sur la quatrième de couverture, "on pourrait dire de Marcovaldo que c'est un Charlot père de famille". Le chapitre seize, intitulé "Marcovaldo au supermarché", complète notre sélection d'un corpus élaboré sur le critère thématique de l'acte de consommation. Pour mener à bien l'analyse de ce corpus, nous procéderons à une mise en relation avec les théories sur les lieux et les non-lieux de l'anthropologue Marc Augé, lesquelles sont développées dans son ouvrage intitulé Non-lieux, Introduction à une anthropologie de la surmodernité. Nous verrons ainsi comment la fiction de Calvino 
parvient à la fois à illustrer, contre-illustrer ou encore à réinventer la dichotomie poreuse entre les lieux et non-lieux et donc, d'une certaine manière, entre modernité et postmodernité, ou encore surmodernité, pour reprendre l'appellation de Marc Augé.

\section{(Non-) lieux identitaires}

Le lieu de consommation, dans une perspective identitaire, apparaît tel un nonlieu où le personnage de Marcovaldo va se soumettre au double processus de désidentification et de jeu de rôle. En effet, selon Marc Augé, le non-lieu délivre l'homme de ses déterminations habituelles (Augé 1992: 129). Dans le non-lieu du supermarché, celui-ci n'a plus conscience de son existence mouvante et fuyante, mais juste de ce qu'il vit ou fait en tant que client de supermarché. L'épaisseur de son identité d'homme se trouve ainsi réduite au statut certes concret, mais provisoire, de consommateur. Cette confiscation de l'entièreté de l'identité par le supermarché implique simultanément un jeu de rôle - celui de consommateur - que le client peut trouver attrayant et plaisant parce qu'il a alors l'impression d'une coïncidence entre sa conscience et lui-même. Si l'existence ne permet pas l'être-en-soi - parce qu'en perpétuelle actualisation -, le rôle social favorise la satisfaction d'être quelque-chose ou quelqu'un, plutôt que rien. Dans le non-lieu de la consommation, le client abolit ainsi l'angoissante liberté de l'homme pour la rassurante illusion d'un être-en-soi, au travers du statut de consommateur. Ce décalage entre la conscience de soi et l'être-en-soi renvoie à la notion de mauvaise foi que développe Sartre dans L'Être et le Néant, notamment au travers de l'exemple du garçon de café. Comme celui-ci, par son comportement stéréotypé, "cherche à se persuader lui-même qu'il se confond si parfaitement avec sa fonction qu'il est sa fonction" (Gazalé 2006: 74), Marcovaldo cherche à se persuader qu'il se confond si parfaitement avec son statut de consommateur qu'il est un consommateur, et cela sans doute d'autant plus qu'il n'a pas les moyens économiques pour effectivement être consommateur. JoAnn Cannon avait déjà explicité les liens entre Palomar et la phénoménologie (voir les choses comme elles nous apparaissent, et comme si c'était la première fois), c'est-à-dire entre philosophie et littérature (Cannon 1985: 191) et il apparaît qu'une telle problématisation de la première par la seconde, voit aussi le jour dans Marcovaldo, cela par l'entremise de la notion sartrienne de mauvaise foi. 
Marcovaldo, en effet, a la particularité de faire semblant d'être un consommateur pour jouir de la conscience d'être quelqu'un, mais cette conscience repose sur une double illusion puisque, d'une part, il joue le jeu sartrien de la mauvaise foi (comme tous les clients du supermarché) et que, d'autre part, il agit "pour de faux" et sait qu'il devra ensuite remettre les articles en rayon à défaut de pouvoir les payer (à la différence des autres clients du supermarché). Le processus de désidentification de Marcovaldo passe par le mimétisme: "chaque fois que l'une ou l'autre [des boniches ou des dames] tendait la main pour prendre un potiron jaune et odorant ou une boîte de crème de gruyère, il faisait de même" (Calvino 1979: 132) mais se voit moduler par la différentiation car tous les actes de consommation ne se valent pas et Marcovaldo, s'il souhaitait juste, au départ, s'offrir le plaisir de balader une boîte de dattes dans son chariot avant de la remettre en place, finit par vouloir se distinguer et "éprouver le plaisir de celui qui sait choisir le produit le meilleur" (Calvino 1979: 132). Le supermarché se présente donc comme un non-lieu en ce qu'il engage le consommateur dans un processus de désidentification, mais le personnage de Marcovaldo complexifie les rapports, d'une part avec sa situation incongrue de consommateur "pour de faux" qui relativise le jeu existentiel de "faire-semblant" au profit d'un jeu plus ancré dans la réalité socioéconomique du supermarché, et d'autre part, avec sa volonté, discrète et touchante, d'une différentiation identitaire en lien direct avec la sélection de produits sélectionnés, auxquels il devra - pauvre Marcovaldo - inéluctablement renoncer...

Le lieu de consommation, dans une perspective identitaire, se rattacherait donc davantage au non-lieu qu'au lieu, même si, nous l'avons vu, certains traits des intrigues ou des personnages de Calvino manifestent une problématisation plus subtile et complexe de la question, appréhendée dans une approche phénoménologique. Ce flottement entre perte et affirmation d'identité reflète celui entre lieux et non-lieux, que Marc Augé appréhende, non comme des entités ou des concepts absolus mais bien comme des "polarités fuyantes : le premier [le lieu] n'est jamais complètement effacé et le second [le non-lieu] ne s'accomplit jamais totalement" (Augé 1992: 101). Ainsi, dans la nouvelle "Le marbre et le sang", l'acte de consommation est pour le client personnage un acte identitaire profondément relié à la culture anthropologique; Palomar est effectivement "conscient du fait que son existence individuelle et la culture à laquelle il 
appartient sont conditionnées par ce lieu" (Calvino 1985: 78). Cette culture, c'est celle de l'homme carnivore et ce lieu, la boucherie, de marbre et de sang, où Palomar se tient "comme dans un temple" (ibidem) et se trouve dans un "état d'âme qui, peut-être, s'exprime pour d'autres dans la prière" (Calvino 1985: 80). Dans cette boucherie, se trouvent des écriteaux, des prix, des noms, ce qui renvoie plutôt aux non-lieux, envahis par des mots ou textes modes d'emploi à valeur prescriptive, prohibitive ou informative (Augé 1992: 121), et pour l'usage indifférencié de n'importe quel passager ou consommateur. Toutefois, dans la perspective de Palomar, les écrits qui participent en principe de l'indifférenciation et de l'usage à répétition des non-lieux se transforment en documents anthropologiques géoculturels et identitaires qui confèrent au temple carnivore la dimension d'un lieu certes marchand, mais aussi authentique et métaphysique:

Sur une pancarte, au mur, le profil d'un bœuf apparaît comme une carte géographique parcourue par des frontières qui délimitent les aires d'intérêt comestible: elles comprennent l'anatomie entière de l'animal, exclusion faites des cornes et des sabots. C'est là une carte de l'habitat humain, non moins que le planisphère du globe terrestre: aussi bien l'une que l'autre sont en somme des protocoles sanctionnant les droits que l'homme s'est attribués, de possession, de partage et de dévoration sans résidus, des continents terrestres comme des lombes du corps animal. (Calvino 1985: 79)

\section{(Non-) lieux relationnels}

Les personnages de Palomar et de Marcovaldo apparaissent dans toute leur humanité et leur sensibilité parce que profondément investis de l'intérieur par la narration. Cette intériorité du personnage bâtit le contraste avec la dimension fonctionnelle, automatique et extériorisée du non-lieu. Le facteur identitaire permet de distinguer les lieux des non-lieux, et nous avons appréhendé l'identité comme le rapport qu'entretient le personnage avec lui-même. Le relationnel, l'interpersonnel est un deuxième facteur permettant d'établir une frontière, perméable et souple, entre les lieux et les non-lieux. Dans la nouvelle "Un musée de fromages", le monde intérieur de Palomar est en butte au monde social, fonctionnel et marchand du petit magasin. Il nous semble que Palomar est comme sorti de ce que l'on pourrait appeler son "pays 
rhétorique". La notion de "pays rhétorique" est empruntée par Marc Augé à Vincent Descombes, auteur d'une analyse de la cosmologie de Combray. Descombes s'est demandé: Où le personnage est-il chez lui? Il a alors découvert qu'il ne s'agissait pas tant de prendre en compte le territoire géographique mais bien plutôt rhétorique. Il définit ainsi ce concept:

Le pays rhétorique d'un personnage s'arrête là où les interlocuteurs ne comprennent plus les raisons qu'il donne de ses faits et gestes, ni les griefs qu'il formule ou les admirations qu'il manifeste. Un trouble de communication rhétorique manifeste le passage d'une frontière, qu'il faut bien sûr se représenter comme une zone frontière, une marche, plutôt que comme une ligne bien tracée. (Augé 1992: 135-136)

Dans "Un musée de fromages", les codes identitaires de l'instance marchande sont très clairs: "trois ou quatre jeunes filles en tablier rose accueillent les clients" (Calvino 1985: 74). Le processus de consommation est également lissé, structuré et routinier: "le client nomme et le plus souvent montre du doigt l'objet de ses appétits précis et compétents, en se déplaçant à travers le magasin" (ibidem). Palomar, lui, n'est pas simplement venu chercher un fromage, mais embrasser de son regard la fromagerie tout entière. Il observe les assortiments proposés, l'enseigne du magasin, les employées, les clients, et son esprit "oscille entre des poussées contrastées" (idem: 75) quant à la connaissance de tous les fromages et le choix absolu de son fromage, dans lequel il doit savoir se reconnaître.

Ces poussées l'emmènent loin dans son monde intérieur et dans un même temps, loin de la visée marchande, fonctionnelle et uniforme de la fromagerie où il se trouve surpris et même complètement décontenancé dans ses rapports aux clients aussi bien qu'aux vendeuses. Occupé de toutes ses pensées, Palomar n'est pas prêt lorsque c'est à son tour d'annoncer ce qu'il aimerait acheter et consommer. Le non-respect du contrat marchand entraîne la réprobation des clients: "tout le monde observe son comportement incongru et secoue la tête de l'air mi-ironique, mi-impatienté, avec lequel les habitants des grandes villes considèrent le nombre toujours croissant des faibles d'esprit qui circulent" (idem: 77). L'ironie des autres clients redouble ou peut-être illustre le rapport ironique établi entre le personnage et le monde qui l'entoure. 
Le personnage tente vainement, ainsi que le note Dana Renga, de réconcilier cette duplicité fondatrice (Renga 2003: 373). Palomar échoue à mener à bien le processus marchand et ne sait pas jouer son rôle de consommateur apprivoisé parce qu'il est sorti de son "pays rhétorique", soit le pays de son intériorité riche d'envies, de pensées et de créativité. L'impossibilité d'exprimer ce pays intérieur entraîne un trouble de communication qui l'oblige à se conformer au pays rhétorique et automatique, de l'autre comme représentant fonctionnel d'une instance marchande:

La commande élaborée et gourmande qu'il avait l'intention de faire échappe à sa mémoire ; il bégaye ; il se replie sur le plus évident, le plus banal, le plus connu par la publicité, comme si les automatismes de la civilisation de masse n'attendaient que ce moment d'incertitude pour le reprendre en leur pouvoir. (Calvino 1985: 77)

Marc Augé définit le lieu comme un endroit identitaire, relationnel ou historique et le non-lieu comme un endroit ni identitaire, ni relationnel, ni historique. Dans la nouvelle "Un musée de fromages", le magasin n'apparaît pas comme un lieu relationnel $\mathrm{du}$ fait que les interactions sont uniquement centrées sur le processus marchand. Toutefois, nous verrons, avec la nouvelle "La pantoufle dépareillée", que le personnage de Palomar est capable de dépasser l'absence relationnelle du processus marchand par le biais de son imaginaire riche et fertile. Pour Marc Augé, la prolifération des non-lieux engendre une forme contemporaine de solitude, laquelle "s'éprouve comme dépassement ou évidement de l'individualité" (Augé 1992: 111). Si dans "Un musée de fromages", les clients et les marchands ont contribué à vider Palomar de son individualité pour le ramener au processus marchand et déshumanisé de la société, Palomar parvient dans "La pantoufle dépareillée”, à dépasser son individualité dans une dimension spatiale aussi bien que temporelle. En effet, alors qu'il voyage dans un pays oriental, Palomar s'arrête dans un bazar et y achète des pantoufles que le vieux vendeur, après des fouilles dans "une avalanche de pantoufles cousues en série" (Calvino 1985: 101), lui a fournies sous forme de paire. Lorsqu'il rentre chez lui, Palomar s'aperçoit que les pantoufles sont dépareillées et se met à imaginer qu'il existe peut-être un autre homme, dans ce pays d'Orient, qui marche, lui aussi, avec deux pantoufles dépareillées. Peut-être pense-t-il à lui. "Le rapport qui nous lie", se dit Palomar, "est plus concret et 
clair qu'une grande partie des relations qui s'établissent entre humains" (idem: 100). Il pense ensuite que l'erreur date peut-être de plusieurs siècles en arrière, et que le vieux vendeur a réparé une erreur commise par l'un de ses ancêtres, et dans ce cas, "la symétrie de leurs pas se répond non seulement de continent à continent, mais à travers les siècles. Monsieur Palomar ne se sent pas pour autant moins solidaire. Il continue à traîner péniblement les pantoufles pour donner à son ombre un soulagement" (idem: 101). Marc Augé expliquait “que c'est l'identité des uns et des autres qui faisait le lieu anthropologique [et que] c'est le non-lieu qui crée l'identité partagée des passagers, de la clientèle ou des conducteurs du dimanche" (Augé 1992: 127). Il s'agit toutefois d'une identité anonyme, provisoire et superficielle alors que ce que nous donne à vivre Italo Calvino au travers de cette petite nouvelle, c'est la transformation du non-lieu d'une consommation en série vers le lieu d'une interaction profonde, permanente, solidaire et cela par-delà l'anonymat.

\section{(Non-) lieux historiques}

Les lieux se distinguent des non-lieux selon les paramètres identitaires, relationnels et historiques. Nous nous sommes arrêtés sur les deux premiers, soit sur la relation du consommateur à lui-même et la relation du consommateur à l'altérité au sein de l'espace marchand. Il convient à présent de porter l'attention sur les rapports spatiotemporels du personnage-client à l'instance marchande elle-même. Dans un premier temps, nous conviendrons du caractère non-historique du supermarché dans lequel évolue Marcovaldo. Il s'agit, bien au contraire, d’un non-lieu inscrit dans l'immédiateté et la précipitation irréfléchie et automatique d'une foule de clients avides de consommer. Pour manifester l'ampleur de ces excès, Calvino use d'une anaphore exclamative:

Consommez! et ils tripotaient la marchandise, la remettaient en place, la reprenaient, se l'arrachaient des mains. Consommez! et ils obligeaient les vendeuses pâlichonnes à étaler des sous-vêtements sur le comptoir. Consommez! et les pelotes de ficelle de couleur tournaient comme des toupies [...] (Calvino 1979: 130) 
Dans ce lieu surchargé des modalités du processus marchand, se créent des embouteillages, mais il faut dire que le "supermarché était grand et aussi enchevêtré qu'un labyrinthe: on pouvait y tourner durant des heures et des heures" (idem: 134). Comme l'a relevé Kerstin Pilz, le motif du labyrinthe parcourt l'œuvre d'Italo Calvino et symbolise à la fois la complexité du monde moderne et l'effort du personnage pour y échapper (Pilz 2003: 229). Il représente aussi, cette fois dans une perspective postmoderne, l'impossibilité pour l'homme d'échapper à sa condition humaine et à l'irréductible multiplicité et complexité rhizomique qui rend désormais toute tentative de contrôle rationnel illusoire (idem: 230). Ce non-lieu labyrinthique est au départ un espace de désir et de plaisir pour Marcovaldo, dont le chariot est “aussi chargé qu'un navire de commerce" (Calvino 1979: 133). Au fur et à mesure que Marcovaldo tourne en rond, le lieu devient labyrinthe et prend une tournure inquiétante, voire même affolante, dès lors que les haut-parleurs annoncent la fermeture imminente du magasin. Le nonlieu de la consommation est désormais menaçant: “de quelque côté qu'elle [la famille de Marcovaldo] se tournât, elle se trouvait devant des passages obligatoires au bout desquels une caissière pointait une caisse-comptable crépitante comme une mitrailleuse contre tous ceux qui faisaient mine de sortir" (Calvino 1979: 135). Le supermarché labyrinthique est désormais perçu comme une prison et la famille de Marcovaldo est comparée à des "bêtes en cage" soit encore des "prisonniers enfermés dans une étincelante prison aux murs faits de panneaux de couleur" (idem: 136).

Si Marcovaldo jouit puis subit les modalités de l'espace labyrinthique et géométrique d'un supermarché accueillant puis menaçant et au final, essentiellement carcéral, Palomar va quant à lui tenter d'établir un rapport identitaire direct avec les produits proposés à la consommation. Ce rapport, dans un (non-) lieu donné, se construit au travers d'une représentation temporelle qui permettrait d'établir la fromagerie comme un lieu certes marchand mais aussi historique. Dès son entrée dans la fromagerie, Palomar remarque l'enseigne: “'Spécialités froumagères', avec son adjectif rare, archaïque ou vernaculaire [qui] prévient qu'est conservé ici l'héritage du savoir accumulé par une civilisation à travers toute son histoire et sa géographie" (idem: 74). Cela n'empêche pas certaines modalités du non-lieu marchand d'être effectives, et le processus, pourrions-nous dire, de procession des clients, apparaît aussi bien réglé que 
celui des aiguilles d'une montre. En effet, au moment où l'une des vendeuses prend en charge un nouveau client, "toute la file avance d'un pas ; et celui qui jusqu'alors avait fait halte près du 'Bleu d'Auvergne' veiné de vert, se retrouve à la hauteur du 'Brin d'amour' (...)" (ibidem). Calvino parle ainsi d"'étapes fortuites" (idem: 75) pour désigner une sorte d'itinéraire obligé dans la fromagerie. Or, ainsi que l'expose Marc Augé, Michel de Certeau conçoit l'itinéraire comme une traversée des lieux, une addition de lieux de passages et donc une négation du lieu: "L'espace comme pratique des lieux et non du lieu procède en effet d'un double déplacement: du voyageur bien sûr, mais aussi, parallèlement, des paysages dont il ne prend jamais que des vues partielles, des 'instantanés', additionnés pêle-mêle dans sa mémoire (...)”' (Augé 1992: 109).

Ainsi, le processus d'achat dans la fromagerie traditionnelle s'apparenterait à un voyage avec itinéraire contrôlé le long d'un cheminement fromager agrémenté de ses variétés. Toutefois, ce paysage de fromages et ses instantanés nous semblent ici participer d'un itinéraire pouvant relever du lieu ou du non-lieu dès lors que cette fonction de passage se transformera potentiellement, chez certains clients, en point de nouveau désir et objectif d'achat ou se cantonnera véritablement, pour d'autres clients, à cette fonction de passage. En effet, certains choisiront d'ajouter un article à leur liste tandis que d'autres ne se laisseront pas distraire de leur objectif et plus encore, "toute suggestion différente sur laquelle ils tombent ne fait que mieux délimiter, par exclusion, le domaine de ce qu'ils veulent avec entêtement" (Calvino 1979: 75). Palomar vit cet itinéraire dans la fromagerie dans une perspective résolument historique puisqu'il considère que "la vraie connaissance réside dans l'expérience des saveurs, faite ellemême de mémoire et d'imagination ensemble" (idem: 76). Comme l'annonce le titre, Palomar perçoit la fromagerie tel un musée, avec des "secrets de travail transmis au long des siècles"; "comme au Louvre, il sent derrière chaque objet exposé la présence de la civilisation qui lui a donné sa forme et qui, de lui, prend forme" (ibidem). Dans la fromagerie, Palomar est spectateur de l'imbrication de l'ancien (les traditions) avec le nouveau (évolutions marchandes), soit le mélange intégré propre à la modernité et qui rattache dès lors la boutique à un lieu à la fois marchand et historique. Le non-lieu propre à la surmodernité s'en distingue du fait qu'il ne parvient pas à intégrer l'ancien 
au nouveau mais "fait de l'ancien (de l'histoire) un spectacle spécifique -comme de tous les exotismes et de tous les particularismes locaux" (Augé 1992: 138).

$\mathrm{Au}$ travers de cette analyse des (non-) lieux identitaires, relationnels et historiques de la consommation dans les recueils Marcovaldo (1979) et Palomar (1985), nous avons mis en relief le passage de la modernité des boutiques parisiennes, lesquelles relèvent, ainsi que l'a constaté Gian-Paolo Biasin, d'une anthropologie culturelle gastronomique (Biasin 1994: 835), vers une instance marchande plus massive et indifférenciée, le supermarché postmoderne, plus précisément surmoderne, dans lequel évoluent Marcovaldo et sa famille. Par une mise en relation des éléments liés aux intrigues et aux personnages de la fiction d'Italo Calvino avec des théories sur les "polarités fuyantes" que sont les lieux et les non-lieux, - lesquelles émanent de Marc Augé -, nous avons voulu donner à goûter tout l'art de Calvino à dire la complexité du monde - ici le microcosme de l'instance marchande- dans une élaboration fictive à la fois simple, efficace et émouvante. ${ }^{1}$ Dans un article sur la "forêt noire" traversée par Palomar, Luisa Guj retient une vision très noire et pessimiste de l'existence du personnage, qui en ressort perdu, puis mort (Guj 1987: 868). La nôtre, au contraire, se fonde sur une vision de l'imaginaire résolument optimiste. En effet, si notre surmodernité laisse périr et fermer bon nombre de lieux et de commerces de proximité au profit des non-lieux démesurés que sont les grands, voire les hyper-marchés, il nous apparaît, avec les personnages de Palomar et de Marcovaldo, que l'imagination et ses fantaisies sont capables d'illustrer, de contre-illustrer et même de réinventer les modalités anthropologiques des lieux et des non-lieux auparavant mises au jour par Marc Augé dans le cadre réaliste et extériorisé de notre société. Après avoir pénétré ces drôles et émouvantes fictions "de l'intériorité", il ne sera désormais plus possible d'entrer au supermarché sans y imaginer un petit Palomar ou Marcovaldo, en proie à la géométrie labyrinthique et tumultueuse de ses venues et allées. Comme de ses pensées... 


\section{Bibliographie}

Augé, Marc (1992), Non-lieux. Introduction à une anthropologie de la surmodernité, Paris, Éditions du Seuil, coll. "La librairie du XXI" siècle".

Biasin, Gian-Paolo (1994), "Other Foods, Other Voices", Comparative Literature, CIX, 5, pp. 831-846.

Calvino, Italo (1985), Palomar, Paris, Éditions du Seuil, coll. "Points".

Calvino, Italo (1979), Marcovaldo, Paris, Julliard, coll. “10 18”.

Cannon, JoAnn (1985), "Calvino's latest challenge to the labyrinth: a reading of Palomar", Italica, LXII, 3, pp. 189-200.

Gazalé, Olivia (2006), "Jean-Paul Sartre et le garçon de café”, Philosophie magazine, 1, 7475.

Guj, Luisa (1987), “The Loss of the Self: 'La selva oscura' of Mr. Palomar”, The Modern Language Review, LXXXII, 4, pp. 862-868.

Lucente, Gregory L. (1985), “An Interview with Italo Calvino”, Contemporary Literature, XXVI, 3, pp. 245-253.

Pilz, Kerstin (2003), "Reconceptualising thought and Space: Labyrinths and Cities in Calvino's Fictions", LXXX, 2, p. 229-242.

Renga, Dana (2003), “Calvino's Vision of the "Economic Miracle”", Italica, LXXX, 3, pp. 371-388.

Sartre, Jean-Paul (1943), L'Être et le Néant, Paris, Gallimard, coll. "Bibliothèque des idées". 
Fanny Mahy travaille actuellement au remaniement de sa thèse doctorale portant sur l'écriture du fait divers criminel dans la littérature contemporaine française et exerce, depuis l'automne 2014, les fonctions de Lectrice Français Langue Etrangère a l’Université de Porto.

\section{Notes}

${ }^{1}$ Il s'agit d'un objectif poursuivi par Italo Calvino; il le confie lui-même lors d'un entretien: "I try to deepen the contrast between sentences that are apparently linear, classical, and a reality that is undeniably complex." (Lucente 1985: 253) 



\title{
Le lieu géographique entre réalité et fiction dans le récit d'anticipation: Zamiatine, Orwell, Thiry
}

\author{
Atinati Mamatsashvili \\ Université d'État Ilia \\ Institut de littérature comparée (Tbilissi, Géorgie)
}

Résumé: Nous proposons d'examiner le lieu géographique tel qu'il est appréhendé dans les textes de fiction qui préfigurent d'une manière ou d'une autre la réalité totalitaire nazie et communiste. La répartition du lieu imaginaire chez Evguéni Zamiatine (Nous autres, 1921) se déploie sur trois axes: le lieu géographique dans lequel est ancrée la narration et qui s'apparente à l'espace soviétique, le lieu purement imaginaire des habitants d'autres planètes auxquels s'adresse le récit, et enfin - le lieu interdit et prohibé du Monde ancien qui est sujet à disparition. Cette suppression du lieu s'apparente à l'effacement de l'Histoire, de l'archive chez George Orwell (1984, inspiré par le roman de Zamiatine et publié en 1949) et à ce que Hannah Arendt aurait appelé l'abolition de la "véracité de fait". En même temps, l'interchangeabilité du lieu dans l'espace et le temps peut provoquer la disparition des êtres humains non seulement du présent, mais aussi du passé: arrachés à l'Histoire, ils s'absentent de tout lieu fictionnel ou réel, comme le relate l'uchronie de Marcel Thiry (l'Échec au temps, composé en 1938 et publié en 1945) en dénonçant des crimes nazis. Dans les trois romans susmentionnés que nous envisageons d’analyser, le lieu fictionnel créé par le texte littéraire concourt à restituer le lieu géographique concret (l’Union soviétique, l'Allemagne nazie, la Belgique occupée) et de révéler le danger de la disparition humaine préfiguré par la disparition du lieu.

Mots-clés: uchronie, lieu, fiction, disparition.

Resumo: Propomo-nos examinar o lugar geográfico, uma vez que é apreendido em textos ficcionais que prefiguram de uma ou de outra forma, a realidade totalitária nazista e comunista. A distribuição do lugar imaginário em Evgueni Zamiatine (Nous autres, 1921) se desenrola em três eixos: o lugar geográfico em que está ancorada a narrativa e que se assemelha ao espacial soviético, lugar meramente imaginário dos 
habitantes de outros planetas a que se dirige a narrativa e, por fim - o lugar interdito e proibido do mundo antigo votado a desaparecer. Esta supressão do lugar assemelha-se ao apagamento da História, do arquivo em George Orwell (1984, inspirado no romance Zamiatine e publicado em 1949), o que Hannah Arendt teria designado por abolição da "verdade de facto". Simultaneamente, a permutabilidade do lugar no espaço e no tempo pode causar o desaparecimento dos seres humanos não só do presente, mas também do passado: arrebatados à História, ausentam-se de todo o lugar ficcional ou real, como narra a ucronia de Marcel Thiry (l'Échec au temps, composta em 1938 e publicado em 1945) ao denunciar os crimes nazis. Nos três romances referidos supra pretendemos analisar, o lugar ficcional criado pelo texto literário ajuda a restaurar o lugar geográfica concreto (a União Soviética, a Alemanha nazi, a Bélgica ocupada) e revelar o perigo de desaparecimento humano prefigurado pelo desaparecimento do lugar.

Palavras-chave: ucronia, lugar, ficção, desaparecimento.

Nous proposons d'examiner le lieu géographique tel qu'il est appréhendé dans les textes de fiction qui préfigurent d'une manière ou d'une autre la réalité totalitaire nazie et communiste.

La répartition du lieu imaginaire chez Evguéni Zamiatine (Nous autres, 1921) se déploie sur trois axes: le lieu géographique dans lequel est encrée la narration et qui s'apparente à l'espace soviétique, le lieu purement imaginaire pour les habitants d'autres planètes auxquels s'adresse le récit, et enfin - le lieu interdit et prohibé du Monde ancien qui est sujet à disparition. Cette suppression du lieu s'apparente à l'effacement de l'Histoire, de l'archive chez George Orwell (1984, inspiré par le roman de Zamiatine et publié en 1949) et à ce que Hannah Arendt aurait appelé l'abolition de la "vérité factuelle" (factual truth) (Arendt, 1993). En même temps, l'interchangeabilité du lieu dans l'espace et le temps peut provoquer la disparition des êtres humains non seulement dans le présent, mais aussi dans le passé: arrachés à l'Histoire, ils s'absentent de tout lieu fictionnel ou réel, comme le relate l'uchronie de Marcel Thiry (l'Échec au temps, composé en 1938 et publié en 1945) en dénonçant des crimes nazis.

Dans les trois romans susmentionnés que nous envisageons d'analyser, le lieu fictionnel créé par le texte littéraire concourt à restituer le lieu géographique concret (l'Union soviétique, l’Allemagne nazie, la Belgique) et de révéler le danger de la disparition humaine préfigurée par la disparition du lieu. 


\section{L'harmonie du lieu fictionnel versus la disharmonie du lieu réel}

L'organisation du lieu géographique, correspondant à l'État Unique chez Zamiatine qui n'est autre que la représentation fictionnelle de l'État totalitaire à venir, se fonde sur une sorte d"“harmonie carrée" qui régit l'organisation extérieure et intérieure de ce même lieu. L'anti-utopie de Zamiatine Nous autres (My), écrit en 1920-1921 à Saint-Pétersbourg, aussitôt considéré comme "contrerévolutionnaire", a été interdit de publication. ${ }^{1}$ Le roman, "exterritorialisé" - si nous empruntons ici le terme à Charles Racine, - bien avant son auteur qui quitte le pays avec un passeport soviétique en octobre 1931,2 revient de l'exil seulement sept décennies plus tard. La première publication en Russie aura lieu dans les années de la Perestroïka (Znamja 1988, n 4-5).3 La sphère terrestre est réduite donc dans le roman à ce que l'auteur appelle l'État Unique, une sorte de pouvoir unique incarné dans la personne du Bienfaiteur. Toutefois, la maîtrise de la terre ne suffit pas et la construction de l'Intégral, "formidable appareil électrique en verre et crachant le feu" (Zamiatine 2010: 6), qui est sur le point d'être achevé au moment où se déroulent les événements dans le roman, a pour but de se soumettre tout l'espace: “Oui, il s'agit d'intégrer la grandiose équation de l'univers; il s'agit de dénouer la courbe sauvage, de la redresser suivant une tangente, suivant l'asymptote, suivant une droite. Et ce, parce que la ligne de l'État Unique, c'est la droite. La droite est grande, précise, sage, c'est la plus sage des lignes" (idem: 7). En effet, la droiture s'avère correspondre au concept primordial qui détermine toute l'organisation $\mathrm{du}$ lieu, mais aussi de l'espace-temps, du pouvoir, des relations interhumaines. La ligne droite est ce qui s'oppose d'emblée à la courbe sauvage, à l'irrationnel, à une déviation quelle que soit sa nature.

Les rues de ce lieu fictionnel sont également "impeccablement droites" (idem: 12), à l'instar des "divins parallélépipèdes des habitations transparentes" (ibidem). Mais la question se pose: s'agit-il d'un pur lieu imaginaire sans référent réel ou est-ce que le référent existe et l'auteur s'en rapporte à une réalité tangible qu'il fait reconstruire? En réalité, "le héros de Zamjatin emploie à rebours le discours de l'avant-garde artistique" (Heller 1981: 140). L'organisation de l'espace et du globe terrestre correspond dans le roman presque mot pour mot à celle développée dans la pensée urbaniste et architecturale moderniste de l'époque. ${ }^{4}$ La "géométrisation de l'espace" (ibidem: 140), 
l'utilisation des matériaux nouveaux (comme l'acier, le verre), l'industrialisation de l'architecture, se répercutent avec l'environnement du roman. Cependant, cette nouvelle pensée esthétique et notamment utilisée par l'auteur dans un sens inverse, "à rebours", qui fonctionne en parallèle avec les théories mathématiques ou la philosophie utilitariste et redonde, en fin de compte, avec la machinisation et l'automatisation de l'époque moderne.

Leonid Heller se penche notamment sur l'analyse de l'anti-utopie zamiatinienne dans l'optique historique et réfléchit sur "le lien du roman avec son époque", à l'encontre notamment de ceux qui considèrent qu'il "ne visait jamais spécifiquement la Russie soviétique" (idem: 137). En se basant sur cette réflexion, notons d'emblée que le nom de Taylor, évoqué à plusieurs reprises dans le roman, peut donner lieu à deux lectures différentes dont l'un se lie avec le célèbre mathématicien du XVIIIe siècle, Brook Taylor (1685-1731). Les opérations qui définissent la vie de l’état Unique, se fondent notamment sur une organisation mathématique précise qui s'oppose au nombre irrationnel de la racine carrée de moins un. Une autre lecture se rapporte à Frederick Winslow Taylor, l'inventeur du Scientifique management, de l'“organisation scientifique du travail", ayant influencé à part entière le monde moderne. L'homonymie, comme l'indique Leonid Heller, permet à l'auteur de mettre en parallèle la méthode du calcul mathématique abstrait et la méthode d'organisation qui régit la réalité entière du roman (idem: 144).

Dans cette optique, les références dans le texte au projet du philosophe utilitariste et réformateur Jeremy Bentham (1748-1832), le Panopticon, ${ }^{5}$ qui prévoyait "une transformation des fainéants en gens honnêtes et travailleurs" peuvent en fin de compte être vues comme une préfiguration (très lointaine certes) à ce que la fainéantise ou le "parasitisme” (“тунеядство”) allait s'apparenter quelques décennies plus tard en union soviétique, notamment lorsque la profession "poète" allait s'égaler à la fainéantise et être suivie de condamnation (le cas le plus célèbre avec le procès de Joseph Brodsky).

De nombreux travaux sont consacrés à la question de l'influence que le taylorisme a exercée sur la Russie soviétique. Le taylorisme, qui "donne l'illusion" à l'homme de pouvoir dominer à l'aide de la machine le monde matériel et construire réellement une utopie, sa répercussion s'avère bien concrète. Après la Révolution, 
Lénine appelle à la "taylorisation" de l'économie. Des sections NOT (Organisation scientifique du travail) apparaissent dans des entreprises. Les travaux de Taylor, Gilbert etc. vont être traduits, alors que la biographie de Henry Ford deviendra un bestseller en Russie dans les années 1924-1925. Comme le note Leonid Heller, en se référant luimême à Jean Querzola, "pour Lénine, il n'existe au fond qu'une seule méthode de travail possible au pays des soviets, qu'il s'agisse de l'usine ou de la Tchéka ${ }^{6}$ (police politique), de la production ou de la répression, une méthode qu'il résume lui-même par une formule on ne peut plus Tayloriste: "enregistrement et contrôle" (učet i kontrol'). Dans cette formule, l'usine et la prison (ou l'armée) se trouvent réunies d'une manière qui fait penser au Panopticon de Jeremy Bentham" (idem: 147).

Par conséquent, toute cette structure idéologico-esthétique de l'époque se retrouve réunie dans la structure même de l'anti-utopie zamiatinienne. L'harmonie "droite" se répercute sur les domaines sociaux, culturels ou individuels. Une musique harmonieuse naît au moment où les engins de l'intégral produisent des grincements "merveilleux" (Zamiatine 2010: 10), ou lorsque un appareil récemment inventé, un "musicomètre", permet à chaque numéro-individu, citoyen de l'État Unique, de produire trois sonates par l'heure. Chez Orwell, c'est souvent le télécran, en engin qui surveille les individus et qui est placé dans chaque recoin de leur habitat ou au travail, qui accomplit le rôle de diffuseur de musique. Il s'agit souvent d'une "stridente musique militaire" (Orwell 2004: 12) ou d'une musique "criarde" (idem: 74): "Dans une autre pièce, quelqu'un essayait, à l'aide d'un peigne et d'un bout de papier hygiénique, d'harmoniser son chant avec la musique militaire que continuait à émettre le télécran" (idem: 26). Cette musique "métallique" (idem: 357) ressemble souvent aussi à "l'aboiement sauvage" (idem: 182) qui n'est pas sans rappeler le discours à la radio des protagonistes nazis dans Les Lumières qui s'éteignent d'Erika Mann (Mann 2011).

En revanche, ce qui s'écarte de cette harmonie mathématique du lieu imaginaire chez Zamiatine c'est une boîte noire appelée "piano" autrefois: "Cette musique était sauvage, nerveuse, bigarrée, comme leur vie alors, sans l'ombre de mécanisme rationnel" (Zamiatine 2010: 26). Le référent, le monde réel surgit par le biais des objets, tel que piano chez Zamiatine ou un porte-plume avec une plume chez Orwell et crée dans un même temps un écart topographique et idéologique avec le lieu u-topique. ${ }^{7}$ 
La rationalité fédératrice zamiatinienne, comme fondement organisateur de l'État totalitaire et s'opposant au chiffre irrationnel, se développe en parallèle avec 1984 de George Orwell. Cependant, à la différence de 1984 où c'est le rationnel, le fait concret, l'exactitude mathématique de $2 \times 2=4$ qui se focalise en tant menace à l'organisation de l'état totalitaire, dans Nous autres, c'est le nombre irrationnel ou autrement dit, la "fantaisie" qui joue ce rôle d'opposition. L'État Unique zamiatinien est remplacé chez Orwell par le nom géographique fictionnel Océania, pourtant ce dernier est loin encore d'être le seul maître du globe terrestre, car deux autres lieux - Estasia et Eurasia existent toujours. La présence de ces lieux n'est pas un empêchement, un dérèglement à éliminer, mais au contraire, ceci est nécessaire à la coordination d'Océania pour maintenir "l'état de guerre" permanent. Les alliés changent perpétuellement, c'est soit Eurasia soit Estasia, selon le moment. L'essentiel est qu'au moment de changement d'allié, la réorganisation ne soit ni visible ni existante: Océania doit "toujours" (c'est-àdire simultanément dans le passé) être en guerre avec celui qui est son ennemi au moment actuel (nous reviendrons sur ce point ultérieurement). Si chez Zamiatine, les constructions sont en verre et permettent de la sorte une transparence parfaite de la vie privée, chez Orwell, c'est le télécran qui régit la surveillance de chaque individu qui n'est pas réduit ici au numéro et à l'initial, mais porte encore un nom propre. Pourtant, ce qui réunit le fonctionnement des deux états (État Unique et Océania), c'est l'omniprésence du bonheur forcé: les numéros zamiatiniens vivent dans un bonheur harmonieux où les relations intimes sont règlementées, tout comme le nombre d'enfants et le moment d'en avoir, etc. Le même principe est maintenu dans 1984 où il est plus prudent de prendre "l'expression de tranquille optimisme"8 (Orwell 2004: 9) lorsque les protagonistes se trouvent devant le télécran. ${ }^{9}$

L'harmonie orwelienne topographique repose en fin de compte sur une harmonie qui ne s'étend pas sur l'hégémonie de l'espace entier, mais sur une hégémonie de la réalité des choses où Estasia et Eurasia, non maîtrisés entièrement, représentent seulement des nécessités absolues à l'existence d’Océania. Cette nécessité repose uniquement sur le maintien de l'état de guerre, c'est-à-dire, sur la création de l'image de l'ennemi extérieur permanent. Les trois slogans du Parti - la guerre c'est la paix, la 
liberté c'est l'esclavage, l'ignorance c'est la force - ne servent qu'à maîtriser la réalité (et non nécessairement le lieu) pour la transformer.

Dans l'uchronie de Marcel Thiry, L'Échec au temps, c'est l'agencement du monde réellement réel qui est présenté comme machinisé et méchanisé; la création du monde fictionnel et utopique qui réside dans le changement des événements historiques déjà survenus, afin de réparer les erreurs historiques, s'apparente au début au rêve idyllique qui sera seulement ultérieurement réalisé (à la différence des deux lieux orwellien et zamiatinien qui se posent d'emblée comme projets déjà réalisés). Les protagonistes arrivent à élaborer une machine qui modifie les conséquences de la bataille de Waterloo, c'est-à-dire à instaurer un autre monde possible. Le projet, qui paraît au début tout à fait utopique, est néanmoins une utopie positive qui voudrait, entre le projet initial lié à la bataille de Waterloo et le désir d'innocenter le grand-père de l'inventeur de la machine, ramener en même temps à la vie l'enfant brûlée de Lisa, la voisine de ce dernier. Ce qui se pose donc comme projet négatif, c'est le monde réellement existant, basé sur un calcul machinisé et sur la façon de "subir le Temps" (Thiry 2013: 63) - c'est-à-dire d'une manière successive où la cause est nécessairement suivie de sa conséquence. L'accès à la réalisation du rêve (construction de la machine réparatrice), s'accomplit au moment où le protagoniste, Gustave Dieujeu, "commerçant par inertie" (idem: 28), se trouvant à la gare, interrompe le cours normatif et réglementé de son chemin "régulier" (idem: 38) et prend, de manière irrationnelle, un train qui ne va pas vers Namur (son domicile), mais vers la mer (Ostende), alors qu'il n'a aucune raison de le faire. Troubler le cours de ses déplacements réguliers se dessine comme annonciateur du déséquilibre du mouvement mécanisé dans le monde réellement réel mais aussi dans celui qui est imaginaire.

Ce qui est à souligner, c'est que les trois textes font visualiser, en parallèle avec le monde possible - ou autrement dit le lieu inexistant "dans le monde réellement réel" (Pavel 1988: 75), si l'on emprunte la formule à Thomas Pavel (État Unique, Océania, Waterloo français), - le monde réel ou le référent. Pourtant, dans les trois cas, ce dernier subsiste dans ses décombres appartenant à une histoire soit révolue et interdite (Zamiatine, Orwell), habité (Orwell) ou non (Zamiatine), soit comme l'une des possibilités et sujet à disparition (Thiry). 


\section{Réorganiser l'espace - réorganiser la pensée de l'homme}

Dans les trois fictions, Nous autres, l'Échec au temps et 1984, la trame principale se joue autour de l'idée de conquérir ou de se soumettre le lieu-espace. Chez Orwell, Océania est en permanence en guerre avec l'une des deux autres puissances - Estasia ou Eurasia. Pourtant ici, la maîtrise ne s'étend pas sur celle des lieux (Estasia ou Eurasia), différemment de Nous autres où la construction de l'Intégral a pour but d'assujettir non seulement le globe terrestre, mais aussi des planètes dans l'espace entier. Dans l'Échec au temps le lieu à réorganiser s'applique à la terre, et plus précisément à un lieu plus restreint - l'Europe.

Ce qui nous intéresse, c'est que l'organisation de l'espace-lieu, telle qu'elle se dessine chez Orwell, Thiry ou Zamiatine, est en étroite liaison avec le temps. Chez le premier, à chaque étape du développement narratif, le temps est aléatoire, voire effacé. Le héros qui commence son journal, ne sait pas exactement en quelle année il est né, soit en 1944, soit en 1945. Aucun repère temporel ne se dessine non plus lorsqu'il est arrêté et emprisonné pour être torturé et rééduqué dans le même temps. Il ne sait pas s'il s'agit de dix ans qu'il s'y trouve ou d'un mois. ${ }^{10}$ Le temps effacé est notamment ce qui se rapporte à l'Histoire effacée et constitue la contexture de l'anti-utopie. Winston, protagoniste de 1984, qui travaille dans le Ministère de la Vérité, a pour charge de rectifier le contenu des journaux, c'est-à-dire falsifier un fait historique en concomitance avec les événements du présent.

\footnotetext{
Lorsque toutes les corrections qu'il était nécessaire d'apporter à un numéro spécial du Times avaient été rassemblées et collationnées, le numéro était réimprimé. La copie originale était détruite et remplacée dans la collection par la copie corrigée.

Ce processus de continuelles retouches était appliqué, non seulement aux journaux, mais aux livres, périodiques, pamphlets, affiches, prospectus, films, enregistrements sonores, caricatures, photographies. (Orwell 2004: 48-49)
}

Par conséquent, non seulement "les genres imaginables de littérature" (idem: 49) et la documentation sont réécrits, mais chaque fait historique est rectifié selon les exigences des faits présents. La conception de temporalité se réduit au seul présent. C'est ce dernier qui détermine toute valeur morale ou idéologique. Il représente une constante fixe dans l'état totalitaire et signifie une stabilité invariable. Le lieu se 
répercute avec l'espace-temps, se lie avec ce dernier d'une manière irrévocable dans la mesure où le principe d'invariabilité temporelle, ainsi que spatiale, s'assimile le principe d'immuabilité du lieu. L'espace est considéré ici dans le sens de la "mutabilité" du passé et du futur et de l'immuabilité du présent où le présent contrôle comme le passé, aussi le futur: "Qui commande le passé commande l'avenir; qui commande le présent commande le passé" (idem: 305). Ainsi, la question posée se résume comme suit: est-ce que "le passé a une existence réelle?" (idem: 305). Est-ce que, le passé peut avoir une "vie" tangible en dehors du présent qui le détermine? Ou autrement dit, “[e]st-ce que le passé existe d'une façon concrète, dans l'espace? Y a-t-il quelque part, ou ailleurs, un monde d'objets solides où le passé continue à se manifester?"11 (idem: 306). Ce qui nous intéresse ici, c'est l'interrelation d'une part entre les notions de la réalité et du passé en tant qu'entités historico-temporelles et d'autre part entre l'espace, le temps et le lieu. Le passé, étant doté d'une réalité tangible, est relié à un lieu, ainsi qu'à un laps de temps spécifique qui se réalise dans l'espace englobant une historicité complexe. Dans le cas contraire, il se réduirait à une u-topie dans le sens de non-lieu - qui n'advient pas et ne s'est jamais advenu.

Si chez Orwell, la disparition du passé implique corrélativement la suppression de l'Histoire, chez Thiry, la réorganisation spatiale et temporelle, toujours attachée à celle du lieu, engage la disparition des humains. Ce discours se répercute directement avec le contexte historique contemporain à la rédaction du roman (1938), voire l'avènement du nazisme en Allemagne et les événements concrets qu'y sont liés. Les deux textes se focalisent sur le projet de modification du passé. Néanmoins, dans l'Échec au temps un autre monde une fois accompli, cette réalisation s'accompagne d'une part de la résurrection d'une fille de deux ans tombée, sous les yeux de sa mère, dans une marmite de l'eau chaude et d'autre part de la réparation de l'erreur historique et non de la falsification des faits historiques, comme c'est le cas avec le projet destructeur de Big Brother dans 1984. Dans le même temps, cette modification du passé dans l'Échec, conçoit aussi un point négatif: l'inventeur et le réalisateur du projet, Hervey, a disparu dans cette possibilité créée. Le projet, qui paraît au début tout à fait utopique, est néanmoins une utopie positive qui voudrait, entre le projet initial lié à la bataille de Waterloo et le désir d'innocenter le grand-père, ramener en même temps à la vie l'enfant 
brûlée de Lisa. Mais le texte dévoile au fur et à mesure combien l'utopie s'assimile les traits de l'anti-utopie:

J'avais pour voisine une dame désagréable qui tançait à voix basse deux tristes longues filles jumelles, aux os saillants, au cheveu terne et à la peau grise, par un véritable cauchemar, toutes deux portaient la trace d'un bec-de-lièvre opéré. Le hasard malveillant qui venait de faire passer sous mes yeux, en une ou deux heures, tout un défilé de dégénérés, de ratés, d'ataxiques et de mal fichus achevait par ce doublé d'horreurs ce triste échantillonnage d'humanité. Alors, je me suis réfugié dans notre Anticause. J'ai pensé qu'un jour - quand vous auriez réussi, mon cher Hervey, un homme comme moi, assis comme je l'étais au milieu de ces laideurs, pourrait à son gré les effacer et les refondre"12 (Thiry 2013: 204-205).

Réparer l'Histoire et instaurer la vérité n'implique donc pas seulement l'intention positive, mais se compose entièrement du négatif: dans ce monde possible la laideur pourrait être extirpée, les dégénérés déracinés, les "infirmes supprimés"13 (idem: 207) et les "tarés stérilisés" (idem: 207). Car, en fin de compte, le projet qui consiste dans la suppression du "principe de cause" (idem: 65) et se charge de "changer la condition humaine" (idem: 65), accomplit l'“effacement" non seulement de l'Histoire, mais des hommes. Le discours du texte (rappelons-le, écrit en 1938), comme nous l'avons souligné plus haut, ne fait pas une allusion et ne constitue pas une écriture "entre les lignes", si nous empruntons ici la formule à Leo Strauss (Strauss 1988), mais fait explicitement référence au projet utopique de Hitler, entamé d'abord sur le peuple allemand.

L'espace aménagé zamiatinien fonctionne d'une manière analogue. Pourtant ici, le passé est enclos, emprisonné derrière un Mur Vert qui n'intègre pas l'État Unique et est prohibé pour les numéros-habitants de cet État: "Nous n'avons cessé d'être des sauvages que lorsque nous avons édifié le Mur Vert, lorsque nous avons isolé, à l'aide de celui-ci, nos machines, notre monde parfait, du monde déraisonnable et informe des arbres, des oiseaux, des animaux..." (Zamiatine 2010: 124). Ainsi, l'espace-lieu du Monde Ancien, inhabité, s'offre isolé et interdit. Pourtant, il existe dans sa réalité tangible, avec des objets qui lui appartiennent et qui ne sont plus d'usage dans un nouveau monde constituant "un seul organisme aux millions de cellules" (idem: 180) et un corps d'une "grandiose unanimité" (idem: 181). 
Pourtant, l'espace-lieu du monde ancien se rapporte à une temporalité révolue où ce n'est plus sous forme de l'Histoire effacée qu'il se présente, mais sous forme de mémoire effacée. Nous avons noté que Zamiatine, dans la construction de son antiutopie, utilisait le discours (esthétique et idéologique) de l'époque à rebours, ou de manière inverse. Cette utilisation est sans doute le plus visible dans l'un de ses articles contemporain à la rédaction de l'anti-utopie où il écrit:

La seule arme digne de l'homme - de l'homme de l'avenir - c'est la parole. Avec la parole l'intelligentsia russe, la littérature russe, a combattu durant des décennies pour un glorieux avenir de l'humanité. Et à présent le moment est venu de prendre cette arme. L'homme se meurt. L'Homo sapiens orgueilleux se met à quatre pattes, se couvre de croc et de poil, l'animal remporte la victoire sur l'homme. Le Moyen Âge sauvage est de retour, la vie humaine perd impétueusement de la valeur, une nouvelle vague des pogroms des Juifs arrive. Il n'est plus possible de se taire ${ }^{14}$ (Zamiatine, “Demain”, 2004 [1919]: 115).

Lorsque nous parlons de l'inversement, il s'agit notamment de ce procédé par lequel Zamiatine effectue les remplacements. S'il parle ici du danger qui consiste dans le retour du Moyen Âge et de la transformation de l'homme en animal, en précisant que "sa peau se couvre de poils", dans le roman, c'est notamment l'inverse qui se produit: le recouvrement de poil ou autrement dit, la subsistance du poil hors le lieu de l'ancien monde (c'est-à-dire dans l'État Unique) signifie le contraire. Notamment, le fait que l'homme ne soit pas encore totalement dé-poilé, robotisé ou déshumanisé (comme c'est le cas du narrateur D-503). La déshumanisation présentée comme un retour en arrière, vers le Moyen Âge, est remplacée dans la fiction par la robotisation impliquant le progrès technique et dépoilement ou perte des traits humains. Par conséquent, dans Nous autres, à l'instar de 1984, c'est le passé, dans la conjoncture de l'espace-lieu-temps, qui reste comme seul pilier en ruine confronté à l'espace de l’État Unique.

Si les deux contre-utopies se déploient dans un futur imaginaire (l'action chez Orwell se déroule en 1984 et chez Zamiatine - au XXXIIe siècle), les événements de l'uchronie de Thiry s'orientent vers le passé, notamment vers le moment de la bataille de Waterloo. Changer le passé signifie ici changer simultanément le présent et le futur. Dans les trois cas, la temporalité et l'historicité jouent un rôle primordial. Celui qui contrôle le présent, maîtrise simultanément le passé et l'avenir. Le seul moyen pour que 
“le passé existe d'une manière concrète dans l'espace" (Orwell 2004: 306), s'applique aux documents:

- Où le passé existe-t-il donc, s'il existe?

- Dans les documents. Il est consigné.

- Dans les documents. Et...?

- Dans l'esprit. Dans la mémoire des hommes.

- Dans la mémoire. Très bien. Nous le Parti, nous avons le contrôle de tous les documents et de toutes les mémoires. Nous avons donc le contrôle du passé, n'est-ce pas?

- Mais comment pouvez-vous empêcher les gens de se souvenir? (ibidem)

Le passé, en tant que conception topographique et historique dans un espace considéré ici comme un monde tangible, se situe dans le document (ceux qui sont perpétuellement rectifiés et détruits) et existe par le biais de ce dernier, mais en même temps, dans la mémoire de l'homme. Empêcher de se souvenir, prendre contrôle du souvenir, c'est ce à quoi aspire l'État totalitaire ou autrement dit Oceania, seul lieu existant ("le monde, c'est Oceania", idem: 327). La mémoire, qui se relie principalement chez Orwell avec la réalité factuelle, car c'est son absence qui induit la perte du souvenir et conséquemment, la possibilité de falsification du document, est remplacée dans Nous autres par la fantaisie. La seule chose qui se présente comme menace à l'État Unique, c'est la présence de la fantaisie - celle qui s'oppose d'emblée à l'organisation carrée et rond ${ }^{15}$ de l'espace-lieu. La seule chose qui échappe au contrôle, c'est notamment la faculté de la fantaisie, considérée comme "maladie" et contre laquelle sera inventé, vers la fin du roman, un vaccin. De telle sorte, ceux chez qui se révèle encore cette "maladie", pourront être opérés et définitivement soumis.

L'irrationnel ou autrement dit la fantaisie, qui s'écarte de l'harmonie carrée et ovale et se voit doté de la faculté d'opposition, fait doublement écho à la notion de la poésie, telle qu'elle se déploie dans l'Echec au temps. Etant perçue comme la force dérangeante, opposante au cours normatif du déroulement temporel, la poésie se fixe en tant que seule force étant en mesure de "délivrer l’homme de la loi du passé. La loi [qui] régit chacun de nous instants. [...] Ce sera de rendre le passé aussi accessible, aussi modifiable que le présent; ce sera de le supprimer, puisque le passé accessible et modifiable ne sera plus le passé"16 (Thiry 2013: 92). Ce projet utopique redonde sur 
plusieurs niveaux avec celui du monde orwellien, basé, lui aussi, sur la suppression de ce dernier. Même si le but initial diffère (positif d'un côté et négatif de l'autre), c'est la raison pour laquelle toute utopie porte en soi, comme le montre Rouvillois (Rouvillois 2014), le projet anti-utopique. C'est aussi la raison pour laquelle, il s'agit de l'échec au temps (comme le montre le titre) ou autrement dit, de l'échec à l'utopie. Revenons au texte: le Temps est régit ici par la succession de cause et des conséquences, la cause résidant dans le passé; ce qui “délivrera les hommes” (Thiry 2013: 66), c’est notamment la Poésie, car elle seule n'a pas besoin des causes et se construit à l'encore de la logique. C'est elle qui se place en face de l'organisation spatio-temporelle du monde réel, capable de "fauss[er] la logique des engrenages" et de "dérang[er] la machine" (idem: 67). La poésie apparait donc libératrice du "monde asservi" (ibidem). Pourtant, cette libération impliquant d'emblée, comme on l'a vu, une libération "totalitaire".

Il y a néanmoins encore un point sur lequel, à notre sens, Nous autres paraît anticiper les réalités totalitaires du XXe siècle. C'est le point de vue, avancé dans le roman, du lien direct entre le concept de liberté et celui de fantaisie: par conséquent, ce qui s'oppose à la soumission totale de l'homme, c'est la fantaisie ou autrement dit, l'imagination. ${ }^{17}$ Non pas la ratio, l'intelligence ou encore autre chose, mais l'aptitude de rêver; l'invention de remède contre ce dernier - signifie simultanément d'éradiquer toute autre pensée ou comme l'aurait formulé Orwell, "rendre impossible un autre mode de pensée" (Orwell 2004: 369). Le trait dominant que voit Hannah Arendt chez Eichmann, c'est son absence de personnalité, ce qu'elle appelle une "incapacité à penser" (thoughtlessness) et "manque d'imagination" (lack of imagination) ${ }^{18}$ (Arendt 1964: 134), ce qui pour la philosophe constitue un point central dans le lien de l'exécution de l'ordre et la responsabilité. ${ }^{19}$ La convergence entre "l'incapacité à penser" arendtienne et l'“esprit hérétique”20 (Zamiatine, “J'ai peur”, 2004 [1921]: 123), autrement dit la "fantaisie" zamiantinienne, se dévoile en particulier dans le dialogue entre I-330 et D503 sur la finalité d'un événement, en l'occurrence - la Révolution, qui pour ce dernier a été la dernière possible (il ne peut pas y avoir d'autres révolutions après celle qui a instauré le pouvoir du Bienfaiteur, comme il ne peut y avoir d'autre pensée sauf celle qui est prônée). L'analogie entre l'absence de pensée et l'imagination se retrouve à deux reprises chez Orwell: la première fois dans son article sur Zamiatine où il rapporte 
notamment ledit dialogue entre I-330 et D-503 et souligne son importance; d'autre part dans sa fiction 1984, notamment par le biais de l'introduction de novlangue dans laquelle "arrêtducrime" désigne savoir arrêter et donc contrôler sa propre pensée dangereuse ou ce que Zamiatine aurait appelé une pensée "hérétique", "non-correcte". Il est notoire que chez Orwell une grande importance est attribuée à la disparition de ce que Arendt appelle la "vérité factuelle" ou autrement dit - au fait historique qui falsifié de jour au lendemain, fait anéantir l'Histoire toute entière. À la différence de Zamiatine où la fantaisie apparaît comme source de l'hérésie pour l'État Unique, chez Orwell, c'est le fait réel. Par la disparition de ce dernier, ce n'est pas seulement le présent qui sera manipulé, mais en premier lieu, le passé, ce qui constitue l'un des dangers majeurs des régimes totalitaires. ${ }^{21}$ Opposée à l'imagination, à la fantaisie, le fait historique s'égale chez Orwell à l'abolition du concept de témoin d'une part et de la preuve d'autre part, ce qui annonce le danger que le mensonge remplace de manière irréversible la vérité et non seulement de manière provisoire. La suppression de la preuve, de l'archive, du témoin égale chez lui à la stérilisation de la mémoire et de l'imagination dévoilée chez Zamiatine.

\section{Conclusion}

L'harmonie orwelienne du lieu (Océania) procède du maintien de l'ordre permanent dans la conception de constante historique, temporelle, géographique, mémorielle. Autrement dit, la mémoire n'existe que dans sa fixité du présent dans la mesure où le présent représente une temporalité unique dans l'échelle de la durée: le passé s'anéantit à chaque reprise dans le moment présent et le futur devient par conséquent contrôlable par le biais de l'inchangeabilité du présent.

L'harmonie du monde thiryen, basée sur un modèle inverse (il s'agit de déranger l'ordre de causalité à conséquence), s'établie en fin de compte non comme une constante fixe, mais au contraire sujet à mutabilité où l'harmonie ne consiste pas dans un équilibre spatio-temporel, mais dans la suppression de la "laideur": c'est une harmonie d'où s'absentent les malades mentaux et les estropiés. Tandis que Nous autres fait découvrir une harmonie lisse (carré ou ovale) où l'homme, en tant que parti intégral de l'organisme unique, se développe en consonance avec l'espace-temps qui le régit. 
Dans les trois cas, la suppression du passé, en tant que lieu concret existant dans l'espace-temps, met en cause en même temps l'existence de l'homme: chez Thiry, l'inventeur de la machine disparaît, chez Orwell, on suggère à Winston, qu'il n'avait “jamais existé" (Orwell 2004: 313), chez Zamiatine, D-503 est opéré, sa mémoire étant stérilisée, il se transforme en numéro dé-poilé.

\section{Références bibliographiques}

Arendt, Hannah (1964), Eichmann in Jerusalem, New York, The Viking Press.

-- (1993), Between Past and Future: Eight Exercises in Political Thought, London, Penguin Books.

Heller, Leonid (1981), "Zamjatin: Prophète ou Témoin? "Nous autres" et les réalités de son époque", Cahiers du Monde russe et soviétique, Vol. 22, No. 2/3 (Apr. - Sep.): 137165.

Herzog, Annabel (dir.) (2011), Hannah Arendt. Totalitarisme et banalité du mal, Paris, Presses universitaires de France, coll. "Débats philosophiques".

Kandinsky, Vassily (1991) [1926], Point et ligne sur plan, Paris, Gallimard, coll. "Folio essais".

Leduc-Fayette, D. (1974), "L'espace du futur”, Les Études philosophiques, n. 1, La représentation (Janvier-Mars): 91-96.

Mann, Erika (2011), [Farrar \& Rinehart, Inc., 1940; Rowohlt Verlag GmbH, Reinbek bei Hamburg, 2005]. Quand les lumières s'éteignent, Paris, Grasset, coll. "Livre de poche". 
Mréjen, Aurore (2013), “Absence de pensée et responsabilité chez Hannah Arendt. À propos d'Eichmann", Raison public <http://www.raisonpublique.fr/article606.html\#nb4> [consulté le 1 avril 2015].

Orwell, George (1946), "Review of 'WE' by E. I. Zamyatin” [First published \&bull Tribune.

- GB, London. -], <http://orwell.ru/library/reviews/zamyatin/english/e zamy> [consulté le 4 avril 2015].

-- (2004) [1948], 1984, Édition électronique, "Ebooks libres et gratuits".

Pavel, Thomas (1988), L'Univers de la fiction, Paris, Seuil, coll. "Poétique".

Rouvillois, Frédéric (2014), Crime et utopie. Une nouvelle enquête sur le nazisme, Paris, Flammarion.

Strauss, Leo (1988), Persecution and the Art of Writing, Chicago, The University of Chicago Press.

Thiry, Marcel (2013), Échec au temps, Bruxelles, Labor, coll. "Espace Nord”.

Zamiatine, Eugène (2010) [1920-1921], Édition électronique, "Ebooks libres et gratuits". Zamiatine, Evgeniy (2004) OEuvres, t. 3, Moskva, Russkaia Kniga.

Atinati Mamatsashvili est Professeure associée de littérature comparée à l'Université d'État Ilia (Tbilissi, Géorgie).

Elle a été chercheuse invitée à l'Université de Namur, Belgique (sept. 2012 - août 2014): bourse de l'Académie Universitaire Louvain - FSR Incoming Post-doctoral Fellowship CoFunded by the Marie Curie Actions of the EU.

Mamatsashvili a soutenu sa thèse de doctorat en 2006 (Aix-Marseille université, Aix-enProvence, France). Elle est auteure de l'ouvrage Une couleur dans mes deux vies (2003) et Le dos. La couleur. Vers le dessin (2003). Mamatsashvili travaille actuellement sur la monographie Écrire à l'âge totalitaire et a préparé (avec Anke Bosse) l'ouvrage collectif Littérature et Totalitarisme: écrire pour témoigner (Presses Universitaires de Namur, 2014). 


\section{Notes}

${ }^{1}$ Les œuvres de Zamiatine sont en grande partie interdites vers la fin des années vingt.

${ }^{2}$ La cause de l'exil de Zamiatine réside notamment dans la publication de Nous autres à l'étranger, ce qui a provoqué les réactions virulentes de la part des autorités soviétiques. C'est donc d'abord le roman qui, à l'instar d'autres textes mis à l'index par des régimes totalitaires, connaît l'exil européen: publié la première fois en anglais en 1924 à New York, il est suivi d'une édition tchèque à Prague en 1927 et d'une édition française à Paris en 1929. La publication intégrale de l'ouvrage dans sa langue d'origine paraîtra en 1952, toujours en dehors du pays, à New York.

3 Zamiatine vit d'abord en Allemagne et ensuite, à partir de 1932 - en France. Il meurt à Paris en 1937.

${ }^{4}$ Comme le remarque Robert Klein, il a toujours eu un rapport latent entre "l'urbaniste et l'utopiste", car l'espace urbain influe sur l'organisation des rapports sociaux et sur les individus séparés. L'architecture peut jouer un rôle fonctionnel (Leduc-Fayette 1974: 95).

5 "Le Panopticon devait être un bâtiment de cinq étages en forme d'étoile, dont une moitié allait servir de prison perfectionnée, et l'autre, de fabrique moderne (Jeremy s'inspira pour l'architecture de cet édifice de la fabrique semblable qu'avait conçue son frère Samuel Bentham alors qu'il était au service de la Grande Catherine comme constructeur naval). Le Panopticon devait permettre une transformation des fainéants en gens honnêtes et travailleurs, tout en assurant la production de biens de consommation. L'ordre (la justice) et la productivité (le bien-être), soucis majeurs de Bentham, ne font qu'un dans son esprit. Il propose une solution à un problème ancien, certes, mais qui se pose en termes nouveaux au seuil de l'époque nouvelle". (Heller 1981: 145)

${ }^{6}$ La Tchéka (Commission extraordinaire panrusse pour la répression de la contre-révolution et du sabotage) représente la police politique créée en 1917 pour combattre les ennemis du nouveau régime bolchevik.

${ }^{7}$ Cela peut également être non seulement un objet, mais un "geste" renvoyant au Monde ancien: “[c]e qui en cet instant le transportait d'admiration, c'était le geste avec lequel elle avait rejeté ses vêtements. La grâce négligente de ce geste semblait anéantir toute une culture, tout un système de pensées, comme si Big Brother, le Parti, la Police de la Pensée, pouvaient être rejetés au néant par un unique et splendide mouvement du bras. Cela aussi était un geste de l'ancien temps" (Orwell 2004: 38). Tel qu'un objet, le geste humain peut renvoyer d'une part à une topographie anéantie (l'Ancien Monde), et contenir, d'autre part, toute une pensée idéologique et temporelle précise.

${ }^{8}$ C'est nous qui soulignons.

${ }^{9}$ Un autre point de convergence entre les deux romans : le protagoniste de Nous autres écrit son journal (le texte entier correspond au journal dans lequel le protagoniste, D-503, note ses pensées et les événements) pour des habitants d'autres planètes dans le but de leur apprendre "le bonheur 
mathématique et exact" et de "les forcer à être heureux" (Zamiatine 2010: 6). Le narrateur de 1984 procède de la même manière - il commence à rédiger son journal " pour l'avenir, pour des gens qui n'étaient pas nés" (Orwell 2004: 11).

${ }^{10}$ Un seul indice qu'il peut y avoir, s'applique à son corps. Lorsque le bourreau lui tend à un moment donné le miroir, il y voit un corps étranger ravagé par le temps et la torture: "Une chose courbée, de couleur grise, squelettique, avançait vers lui. L'apparition était effrayante, et pas seulement parce que Winston savait que c'était sa propre image. Il se rapprocha de la glace. Le visage de la créature, à cause de sa stature courbée, semblait projeté en avant. [...]Il était devenu partiellement chauve. Il avait d'abord cru qu'il avait seulement grisonné, mais c'était la peau de son crâne qui était grise. Son corps, à l'exception de ses mains et de son visage, était entièrement gris, d'une poussière ancienne qui ne pouvait se laver" (Orwell 2004: 334). La longue description de l'étranger-vieillard que donne Orwell (et qui n'est pas sans référence à l'expérience concentrationnaire), peut orienter le lecteur vers un laps de temps assez étendu pour que l'homme puisse se transformer en une "créature" aussi immonde. Ici encore, le temps est conçu comme effacé : il existe dans cette transformation même, où il n'y a que l'avant et l'après-torture. Ce qui n'existe pas, c'est le moment de transformation en "étranger", d'où le regard "effrayé".

${ }^{11}$ C'est nous qui soulignons.

${ }^{12}$ C'est nous qui soulignons.

13 Notons au passage que tous les protagonistes des romans de Willems, composés dans le contexte de l'Occupation, sont infirmes.

${ }^{14}$ La traduction de l'extrait est effectuée par l'auteur de l'article. Nous rapportons la version originale : “Единственное оружие, достойное человека - завтрашнего человека,- это слово. Словом, русская интеллигенция, русская литература - десятилетиями подряд боролась за великое человеческое завтра. И теперь время вновь поднять это оружие. Умирает человек. Гордый Homo sapiens становится на четвереньки, обрастает клыками и шерстью, в человеке - побеждает зверь. Возвращается дикое средневековье, стремительно падает ценность человеческой жизни, катится новая волна еврейских погромов. Нельзя больше молчать...” (Zamiatine, “Demain”, 2004 [1919]: 115).

${ }^{15}$ La rondeur s'encadre dans le roman dans la conception de l'harmonie carrée. La protagoniste, 0-90, se diffère sur plusieurs plan de I-330, car "elle a un esprit simple et rond", des "yeux ronds" (Orwell 2004: 50 ) et s'intègre dans la masse des numéros qui forment "les sphères lisses et rondes des têtes flottantes" (idem: 51). Tout comme la sensation du bien-être se traduit par la rondeur: "Tout semble bon et rond" (idem: 93). Tandis que I-330, celle qui se rebelle, qui forme l'opposition à l'État Unique, est dotée des traits qui sont à l'autre pôle de la rondeur: "sourcils sombres relevés vers les tempes formaient un angle pointu et moqueur" (idem: 71), alors que deux rides qui vont du nez au coin de la bouche, en forment un autre. La jointure des deux angles forme en fin de compte un X "désagréable" (idem: 71). Voir, au sujet de la 
juxtaposition des formes géométriques (le carré, l'ovale, le triangle), des couleurs et des concepts auxquels elles se relient: Kandinsky 1991 [1926].

${ }^{16}$ C'est nous qui soulignons.

${ }^{17}$ Ce point est également accentué chez Orwell dans son article sur Zamiatine (Orwell 1946).

18 " [...] he merely, to put the matter colloquially, never realized what he was doing. It was precisely this lack of imagination which enabled him to sit for months on end facing a German Jew who was conducting the police interrogation, pouring out his heart to the man and explaining again and again how it was that he reached only the rank of lieutenant colonel in the S.S. and that it had not been his fault that he was not promoted. In principle he knew quite well what it was all about, and in his final statement to the court he spoke of the "revaluation of values prescribed by the [Nazi] government." He was not stupid. It was sheer thoughtlessness - something by no means identical with stupidity - that predisposed him to become one of the greatest criminals of that period. And if this is "banal" and even funny, if with the best will in the world one cannot extract any diabolical or demonic profundity from Eichmann, that is still far from calling it commonplace". (Arendt 1964: 134)

${ }^{19}$ Pour le lien entre l'absence de pensée et la responsabilité chez Hannah Arendt qui invalide "ainsi l'idée d'une équation entre obéissance aux ordres et déresponsabilisation", voir: Mréjen 2013: http://www.raison-publique.fr/article606.html\#nb4. Voir également: Herzog 2011.

20 " [...] la vraie littérature peut seulement être celle qui est faite non par des fonctionnaires consciencieux et bienpensants, mais par des insensés, des ermites, des hérétiques, des rêveurs, des révoltés, des sceptiques. Et si l'écrivain doit être raisonnable, être très catholique et utile aux temps actuels, s'il ne peut pas fouetter tout le monde comme Swift, ne peut pas sourire de toute chose, comme Anatole France, alors il n'y a pas de littérature de bronze, mais celle de papier, de journal, qu'on lit aujourd'hui et que demain on s'en sert pour emballer du savon d'argile". (Zamiatine, "J'ai peur", 2004 [1921]: 123) La traduction est effectuée par l'auteur de l'article. Version originale: “Главное в том, что настоящая литература может быть только там, где ее делают не исполнительные и благонадежные чиновники, а безумцы, отшельники, еретики, мечтатели, бунтари, скептики. А если писатель должен быть благоразумным, должен быть католически-правоверным, должен быть сегодня полезным, не может хлестать всех, как Свифт, не может улыбаться над всем, как Анатоль Франс,-тогда нет литературы бронзовой, а есть только бумажная, газетная, которую читают сегодня и в которую завтра завертывают глиняное мыло".

21 "- À quoi devons-nous boire, cette fois? dit-il avec toujours la même légère teinte d'ironie. À la confusion de la Police de la Pensée? À la mort de Big Brother? À l’humanité? À l'avenir?

- Au passé, répondit Winston.

- Le passé est plus important, consentit O’Brien gravement" (Orwell 2004: 217). 



\title{
La plume et le pinceau:
}

\section{l'espace hétéropoétique chez Roberto Bolaño, Rubem Fonseca et Jana \& Js}

\author{
Marina Silveira de Melo \\ Instituto Federal de Brasilia (IFB)
}

Résumé: Le raisonnement de l'individu scientifique (selon un concept plus ancien de science) est remplacé par la sensibilité de l'individu subjectif, son astuce, sa vision au-delà de la matière. Pour parler de celui-ci, nous proposons des exemples de la littérature, avec les romans Vastas emoções e pensamentos imperfeitos (Fonseca 1988) et Los detectives salvajes (Bolaño 1998), et aussi de la peinture contemporaine, avec le couple d'artistes globetrotters Jana \& Js (Autrichienne et Français). Ils nous font voir ce que nous appelons la dimension hétéropoétique de l'espace. Du fait métropolitain naissent l'art de la rue, le scénario d'un film, le récit d'une démarche de création artistique... Il s'agit ici non seulement de mettre en scène cette dimension imaginaire de l'espace - intrinsèque aux espaces humains (Bertrand Westphal 2005) -, mais aussi de donner voix à la création humaine à partir de l'ouverture vers l'imaginaire proposée par l'espace. Nous parlons de deux niveaux diégétiques qu'il faut bien distinguer. D’abord, il y a l'artiste - en chair et os - qui représente/crée/recrée l'espace réel, de façon plus ou moins symbolique. Ensuite, il y a le personnage, lui aussi artiste, qui s'empare de l'espace où il vit et s'en sert comme un combustible de sa création. La plume et le pinceau scellent le rapport entre l'artiste et l'espace.

Mots-clés: espace hétéropoétique, Rubem Fonseca, Roberto Bolaño, Jana \& Js, imaginaires urbains

Resumo: 0 raciocínio do indivíduo científico (segundo um conceito mais antigo da ciência) é substituído pela sensibilidade do indivíduo subjetivo, a sua astúcia, a sua visão além da matéria. Para falar sobre isso, propomos exemplos da literatura, com os romances Vastas emoções e pensamentos imperfeitos (Fonseca 1988) e Los detectives salvajes (Bolaño 1998), e também da pintura contemporânea, com o casal de artistas globetrotters Jana \& Js (austríaca e francês). Eles mostram-nos o que chamamos de dimensão heteropoética do espaço. Do facto urbano nasce a arte de rua, o guião de um filme, a narrativa de um 
processo de criação artística... Trata-se não só de pôr em cena esta dimensão imaginária do espaço intrínseca aos espaços humanos (Bertrand Westphal 2005) -, mas ainda de dar voz à criação humana a partir da abertura ao imaginário proposta pelo espaço. Referimo-nos a dois níveis diegéticos que devem ser distinguidos. Primeiro, há o artista - de carne e osso - que representa/ cria/ recria o espaço real, de modo mais ou menos simbólico. Depois, há a personagem, também artista, que aproveita o espaço onde vive e dele se serve como combustível para a sua criação. A caneta e o pincel selam a relação entre o artista e espaço.

Palavras-chave: espaço heteropoético, Rubem Fonseca, Roberto Bolaño, Jana \& Js, imaginaires urbains

\section{Introduction}

Le raisonnement de l'individu scientifique (selon un concept plus ancien de science) est assujetti à l'astuce de l'individu sensible et à sa vision au-delà de la matière. À cela, s'ajoute le fait que le discours à propos d'un élément brut peut, à tout moment, s'investir de touches connotatives. Afin de pouvoir déceler les enjeux de la perception humaine dans la représentation de la ville, nous proposons d'interroger quelques exemples puisés dans la littérature et dans l'art contemporain. Dans un mouvement parallèle, nous cherchons à analyser la force mythique qu'exerce le fait métropolitain sur la création artistique. Nous voyons naître l'art de rue, le scénario d'un film, un récit écrit, pour ne citer que quelques exemples. Il s'agit ici non seulement de mettre en scène cette dimension imaginaire de l'espace - intrinsèque aux espaces humains (Westphal 2005) -, mais aussi de donner voix à la création humaine à partir de l'ouverture à l'imaginaire que propose l'espace.

Pour l'analyse, nous avons choisi deux romans: Vastas emoções e pensamentos imperfeitos, publié en 1988 au Brésil, de l'auteur brésilien controversé Rubem Fonseca; Los detectives salvajes, publié en 1998 au Chili, du non moins polémique écrivain chilien Roberto Bolaño. Le corpus est complété par un parcours à travers quelques œuvres d'un couple d'artistes contemporains: les globetrotters Jana \& Js (elle est Autrichienne et lui, Français). Notre démarche consiste à présenter et analyser chaque pièce artistique séparément. Cette répartition nous paraît nécessaire pour maintenir la clarté et cohérence de l'article, étant donné qu'il s'agit d'auteurs/artistes ainsi que de supports artistiques diverses. 
Pour chaque pièce artistique, nous parlerons de deux niveaux diégétiques qu'il faut distinguer. En premier lieu, il y a celui de l'artiste - en chair et os - qui représente/recrée l'espace réel, de façon plus ou moins symbolique. En deuxième lieu, il y a celui du personnage, lui aussi artiste, qui s'empare de l'espace où il vit et dont il se sert comme combustible dans la création. Nous montrerons comment, à partir d'une perspective de la littérature comparée qui s'ouvre à des études intersémiotiques, la plume et le pinceau scellent le rapport entre l'artiste et l'espace.

\section{Une ouverture vers de vastes émotions}

Rubem Fonseca et littérature urbaine sont deux noms qui vont de pair. Depuis les années 1960, les lecteurs de ses romans et nouvelles commencent à s'habituer à des décors dépeints de façon très réaliste. En 1992, avec la publication de la nouvelle "A arte de andar nas ruas do Rio de Janeiro", Fonseca brille de nouveau dans le panorama du récit urbain. Il présente le caractère indistinct de la ville, parcourue par un flâneur qui a le projet d'écrire à propos de cet espace mystérieux.

Dans Vastas emoções e pensamentos imperfeitos (1988), le protagoniste n'est pas nommé. Le lecteur ne connaît que sa profession. Il s'agit d'un cinéaste qui fait une recherche sur l'écrivain Isaac Bábel, sur lequel il tournera un film. Il mène en parallèle une enquête policière: il élucide les circonstances de l'assassinat d'une femme. Nous avons ici l'exemple d'un individu dont le regard se dédouble: il se tourne vers l'extérieur (lorsqu'il s'intéresse à l'écrivain russe) ainsi que vers l'intérieur (quand il s'engage dans la résolution d'un crime au Brésil). Nous le nommerons "le cinéaste".

Dans ce récit, l'espace apparaît de deux manières: l'espace factuel et l'espace onirique, présent dans les cauchemars assez fréquents du cinéaste. Il définit ce dernier comme "un monde archaïque de vastes émotions et de pensées imparfaites"1 (Fonseca 1988: 32). Néanmoins, ce “monde archaïque” n'est pas si loin de son monde vécu. Durant les jours où il mène des recherches sur l'auteur Bábel, le cinéaste fait un rêve dans lequel les rues d'une ville comportent "des murs remplis de livres"2 (idem: 90). Son espace réel est également une ville-bibliothèque d'où il extrait des informations et dont il s'inspire pour créer. Il avoue qu'il "aimait déambuler à travers les rues afin de voir les gens" (ibidem: 10). Le cinéaste est finalement un miroir de l'écrivain sur qui il mène une 
recherche. Tel Bábel, “[son] seul intérêt, n'importe où, ce sont les gens” (idem: 128). Alors, pour que la création du cinéaste se fasse jour, il lui faut extraire la poésie de la rue.

Tout autant métaphorique que ses rêves, son réel vécu est imprégné de sa créativité. Il observe les scènes de la vie réelle pour lesquelles il imagine des scénarios. Les personnes et espaces prennent alors valeur d'entités fictives, dont les actions et attributs sont présentés au gré de l'imagination de l'artiste. À titre d'exemple, il qualifie le mur de Berlin qu'il regarde du haut d'un gratte-ciel comme un "haut rail sinueux de béton"3 (idem: 124).

Qu'en est-il de l'écrivain Rubem Fonseca, connu pour la description des inframondes miteux, par l'excès de références réelles? Le peintre des villes et le représentant de la littérature urbaine, où sont-ils? Ils sont toujours là, mais rien n'empêche une certaine lassitude lorsqu'il réfléchit à propos de la représentation artistique. Le personnage du cinéaste verbalise ce manque d'enthousiasme: "Depuis La sortie des Usines Lumière, quelle situation n'a pas encore été abordée par le cinéma?"4 (idem: 77). Et nous complétons son questionnement: quel espace (ou quels espaces) n'ont pas encore été abordés par la littérature et les autres arts?

Malgré tout, Fonseca n'abandonne pas totalement ses référents réels et continue de nommer quelques lieux, comme la "Pizzeria Guanabara" et le quartier Leblon. Les bars sont présents, les hôtels aussi. Néanmoins, leurs fonctions opèrent davantage dans le champ du symbolique. Le passage où le cinéaste et son amie se rendent dans un motel fait figure d'exemple. Ils sont enlacés; lui, derrière elle. Quand ils tirent le rideau, le seul paysage extérieur qui s'offre à leur vue est un grand mur en béton (cf. page 188). Est-il question d'une métaphore de la ville-béton, image chère à Fonseca? Ce mur serait-il un écho du mur de Berlin qu'a connu le cinéaste? La contemplation de Fonseca, dans ce roman, semble émaner de la possibilité de voir la matière à travers le filtre sensible de l'artiste. Autrement dit, la matière est présentée dans sa dimension poétique.

Une autre caractéristique que nous tenons à souligner dans le roman Vastas emoções e pensamentos imperfeitos, est le fait que la production artistique et la reproduction de la ville y apparaissent en abîme. En d'autres termes, elles sont présentes à différents niveaux de la représentation. Chaque niveau constitue le miroir de celui qui le précède. Dans ce que nous pouvons appeler premier niveau, nous retrouvons 
le cinéaste qui a tourné un documentaire sur les misérables du centre-ville ( $c f$. page 186) et qui, à présent, développe des recherches à propos de l'écrivain Bábel. Celui-ci, situé au deuxième niveau, avait écrit une nouvelle dont le récit raconte l'histoire d'un peintre nommé Apolek ( $c f$. page 135). Au troisième niveau, le personnage bábelien Apolek - peint des tableaux religieux dans lesquels les modèles sont les personnes en marge de la ville où il vit. Voici la représentation imagière de cette relation spéculaire:

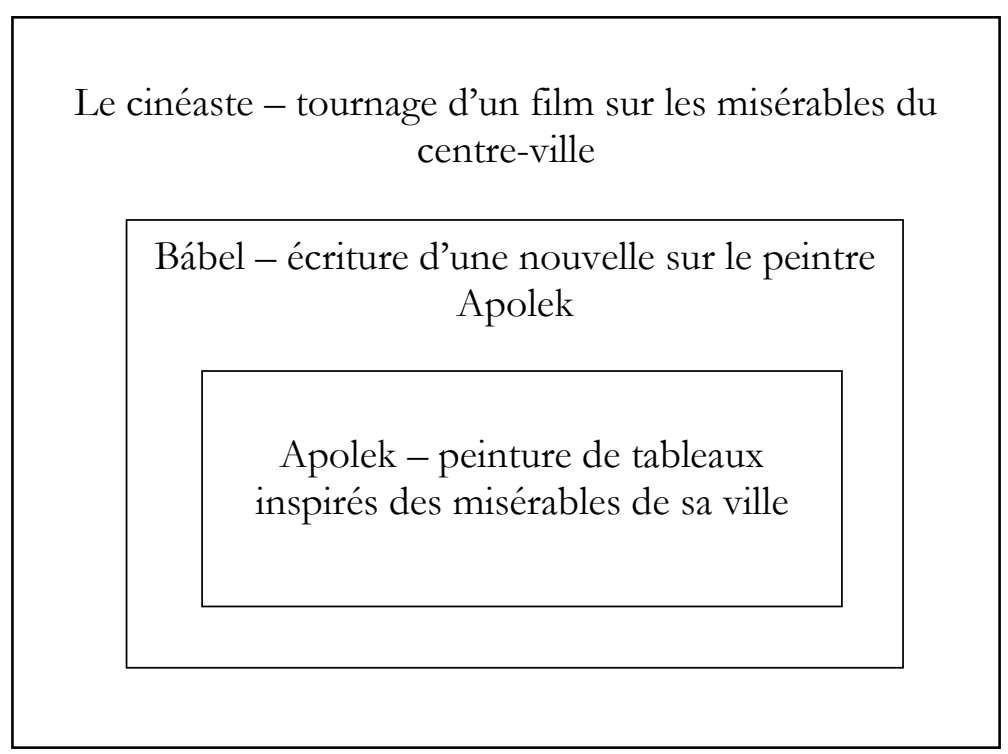

Il est intéressant de remarquer la présence de trois artistes au sein du roman: un cinéaste, un écrivain et un peintre. De plus, parmi eux, deux s'intéressent au même sujet et aux mêmes espaces: les êtres en marge de la société et qui habitent à la même ville que l'artiste. Le lecteur est invité à contempler cet abîme narratif et jouit du vertige qu'il ressent. Dans sa lecture, il se promène au fil des pages comme le cinéaste dans la rue. Celui-ci disait être atteint de la maladie de Menière où les sensations de vertige et nausées pourraient être fréquentes. Les symptômes de maladie qu'il s'invente correspondent d'ailleurs à sa vision concernant son métier de cinéaste. Il ne mâche pas ses mots et se permet l'emprunt de néologismes: "Je veux intranquilliser, troubler, donner des nausées, rendre perplexe, donner des insomnies, faire vomir"5 (idem: 115). Ainsi, le lecteur de Vastas emoções n'est pas insensible et apathique devant l'espace représenté dans ce roman. L'espace, à son tour, n'est pas non plus figé ni unique. Il laisse 
entrevoir sa dimension poétique selon les mouvements et significations qui lui confèrent les points de vue de l'artiste - qu'il soit cinéaste, écrivain ou peintre.

\section{Los detectives salvajes: une "lieuttérature"}

Los detectives salvajes (Bolaño, 1998) est un roman divisé en trois parties datées et nommées: "Mexicains perdus à Mexico (1975)", "Les détectives sauvages (19761996)", “Le désert de Sonora (1976)”.

Le premier indice concernant les personnages qui composent cette œuvre nous est donné par le titre du premier chapitre. Nous apprenons qu'il s'agit ici de Mexicains perdus à Mexico, ce que nous pouvons comprendre de deux façons différentes (parmi d'autres). Soit ils sont perdus dans le sens d'être égarés, d'être errants, probablement dans une ville qui n'est pas la leur; soit leur fortune, leur situation, leur avenir (selon les définitions du dictionnaire Petit Robert) sont atteints. Quoi qu'il en soit, ces personnages ne sont pas dans une situation de confort. Leurs expériences dans l'espace vécu tendent plutôt vers la tension et la difficulté que le bien-être.

Le narrateur et personnage de cette partie s'appelle Juan García Madero: un étudiant en droit, dont la passion est la littérature. Participant à deux ateliers de poésie l'un de Belano, l'autre de Ulisses Lima -, García Madero nourrit des sentiments assez ambigus envers ces poètes. La plupart de ses jours sont dédiés à l'attente de Lima et Belano, dans un bar à Mexico. Néanmoins, ces derniers n'y vont pas assez souvent, ce qui laisse suffisamment de temps à Madero pour les lectures des (mauvais) poèmes de ses camarades et pour l'écriture des siens. C'est surtout dans le bar, cette sorte d'observatoire des passants et de lieu de recul dans la ville, que la poésie se manifeste. Son activité d'écriture, fuyant l'ordinaire des habitués du bar, attire l'attention des gens. Il est le poète dans le bar. Lieu d'éducation poétique pour les uns : la serveuse Rosario commence à s'intéresser à la littérature et lui demande d'écrire un poème pour elle; d'éducation sexuelle pour les autres: c'est dans le bar que Madero aura ses premières expériences du sexe.

Tout au long de la première partie, le lecteur se rend compte que l'atelier d'écriture de Madero s'étend à la rue. Faute de moyens? Certes, mais il aurait pu aller à la bibliothèque de son université. Pourtant c'est la rue qui l'inspire: “Comme je n'avais 
pas d'argent pour entrer dans une cafétéria, je suis resté assis sur un banc de cette même place, à écrire mon journal et à lire un livre de poèmes de Tablada que Pancho m’avait prêté" (Bolaño 2006: 113).

Le bureau-comptoir de Madero finit par être assez présent: "Je me trouvais à l'Encrucijada Veracruzana, appuyé au comptoir, en train d'écrire tantôt mon journal tantôt quelques poèmes [...]" (idem: 137). Ce que nous voulons mettre en exergue ici, c'est que le personnage n'est pas dans n'importe quel bar, il le nomme. Ce même endroit apparaît de nombreuses fois dans le récit, ce qui mène le lecteur à le situer plus précisément dans une sorte de carte mentale des espaces de circulation des personnages de Bolaño. En fin de compte, peu importe si les référents ont vraiment existé ou pas. La pertinence de cette construction est la possibilité de faire exister un DF littéraire, tissé par les mots de cet auteur chilien. En outre, par la récurrence de son apparition, l’Encrucijada devient un lieu-clé dans le récit.

Il existe pour García Madero une interaction avouée entre l'espace et son processus d'écriture, comme nous pouvons remarquer à partir de son commentaire: “[...] au fur et à mesure que je marchais j'ai récupéré sinon l'inspiration (est-ce que ça existe, l'inspiration?), du moins la disposition et l'envie d'écrire" (idem: 138). Nous faisons appel ici à une idée que nous avons développée précédemment dans l'article “Du roman noir au roman autobiographique: variations de la représentation de l'urbain dans la fiction de Rubem Fonseca": solvitur ambulando. Il s'agit d'une expression de Saint Augustin, selon laquelle marcher contribuerait à la résolution des problèmes. Nous avons évoqué ci-dessus une nouvelle de Fonseca (1992) qui s'appelle "A arte de andar nas ruas do Rio de Janeiro". Son narrateur-personnage s'appelle Epifânio et se sert souvent de cette expression latine en ajoutant l'idée selon laquelle l'acte de marcher stimulerait l'imagination. Or, García Madero est ce frère mexicain d'Epifânio et aussi disciple lointain de Saint Augustin. D’après le jeune poète mexicain, avant, il parcourait la ville du nord au sud, en bus ou en métro. Aujourd'hui, il l'arpente à pied, lit, écrit et fait l'amour ( $c f$. page 155). Cela nous renvoie à l'idée de la rue comme lieu d'éducation poétique et sexuelle.

Il est aussi intéressant de noter qu'il existe, dans ce roman, des référentiels spatiaux, plus fréquents que dans celui de Fonseca que nous venons d'analyser. C'est 
surtout dans la deuxième partie, homonyme du titre du roman, que les espaces sont nommés et bien situés dans des rues, quartiers, villes... Le café Quito, rue Bucareli - près de l'Encrucijada; le quartier des putes (avenue Guerrero, Mexico); la faculté de philosophie et de lettres, UNAM, Mexico, décembre 1976; la rue República de Venezuela, à proximité du Palacio de la Inquisición, Mexico, janvier, 1976; la clinique de santé mentale El Reposo, sur la route du Désert de los Lones, environs de Mexico, janvier 1977; le campus d'une université du Middle-West nord-américain, février 1977; la rue Comercio, en face du jardin Morelos, colonia Escandón, Mexico, mars 1977; le bar Céntrico, rue Tallers, Barcelone, mai 1977; la rue des Petites-Écuries, Paris, juillet 1977; l'avenue Marcel-Proust, Paris, août 1977; la rue de Passy, Paris, septembre 1977. Les références ne s'arrêtent pas ici et donnent au lecteur l'impression de lire un document authentique grâce à la quantité d'indices qui sont mis à sa disposition. ${ }^{6}$ Ce roman est à l'image de son auteur: comme les détectives sauvages, Bolaño a parcouru les pays les plus diverses. Il est Chilien de naissance, écrivain au Mexique, habitant en Espagne, "poète-étoile".

A la suite de la présentation d'une littérature qui naît de/dans la rue et de la désignation de nombreux lieux par où voyagent les personnages, la troisième partie continue de présenter des déplacements liés à la création écrite. Cela corrobore également notre thèse concernant l'existence d'une dimension poétique de l'espace. C'est dans cette dernière partie, intitulée “Le désert de Sonora (1976)", que l'espace se fait davantage poésie. Ulises Lima, Arturo Belano et García Madero sont à la recherche d’une poétesse appelée Cesárea, dont les œuvres ils n’ont jamais lu. Il est question d’une sorte d'obsession sur quelqu'un que (presque) personne ne connaît et d'une production littéraire (quasi) imaginaire. Le décor du désert rend cette partie du récit encore plus chimérique. Ce voyage à travers le désert est la recherche d'une poétesse, mais surtout la recherche d'une poésie, de la poésie avec un grand $\mathrm{P}$.

Amadeo Salvatierra, personnage dont les témoignages apparaissent dans la deuxième partie du roman, conserve un poème de Cesárea. Les "jeunes gens" qui arrivent chez lui portaient les clés d'intelligibilité de ce fragment littéraire qu'Amadeo avoue n'avoir jamais saisi. Voici le poème: 


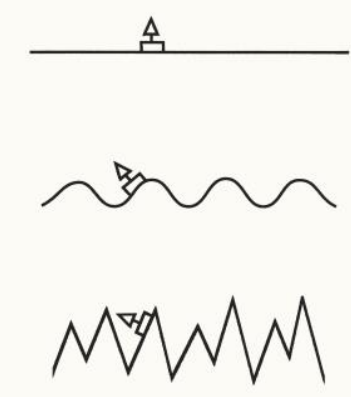

Source : Bolaño 2006: 611.

Après avoir posé plusieurs questions à Amadeo, dans le but de le guider dans la compréhension du poème, les jeunes personnages disent qu'il est plutôt question d'une plaisanterie: "Le titre, Sión, en réalité cache le mot Navegación." (idem: 612). Amadeo, dans un mélange de frustration et soulagement, se dit: “C'était tout ce qui restait de Cesárea, j'ai pensé, un bateau sur une mer calme, un bateau sur une mer agitée, un bateau dans la tempête" (ibidem). Voilà des bribes de la production de cette poétesse mythique, qui apparemment ne se contentait pas des mots pour s'exprimer. Elle envahit l'espace avec trois lignes - droite, ondulée et brisée - et enfouit dans l'océan, sous la tempête, son œuvre, que d'autres vont aller chercher dans le désert. Poème perdu dans le mirage, poème noyé dans l'océan. Comme dans l'ensemble du roman, l'espace et la littérature font corps et deviennent un seul élément, que nous osons nommer "lieuttérature".

\section{Jana \& Js: l'art dans et à propos de la rue}

Changeons maintenant de support artistique et abordons à présent le dernier élément qui compose notre corpus: les œuvres des artistes contemporains Jana \& Js. Nous les avons choisis parce que plus que dédier la plupart de la thématique de leur production à la représentation des villes, Jana \& Js exposent leur art dans la ville. Selon leur page internet, ils “[...] forment un couple d'artistes dont le travail s'inscrit aussi bien dans l'espace urbain que dans des lieux d'expositions fermés. Inspirés par la ville et son architecture en perpétuelle mutation, mais aussi par ceux qui la vivent et l'observent 
[...]". Le street art est l'art dans la rue et, dans le cas de Jana \& Js, il est aussi l'art à propos de la rue.

Une promenade dans le 13ème arrondissement de Paris suffit pour que le passant attentif, mais aussi le distrait, s'aperçoivent de la présence d'images qui fuient l'ordinaire. Parmi plusieurs manifestations du street art présentes dans le quartier, ${ }^{7}$ quelques unes intriguent davantage. En voici un exemple:

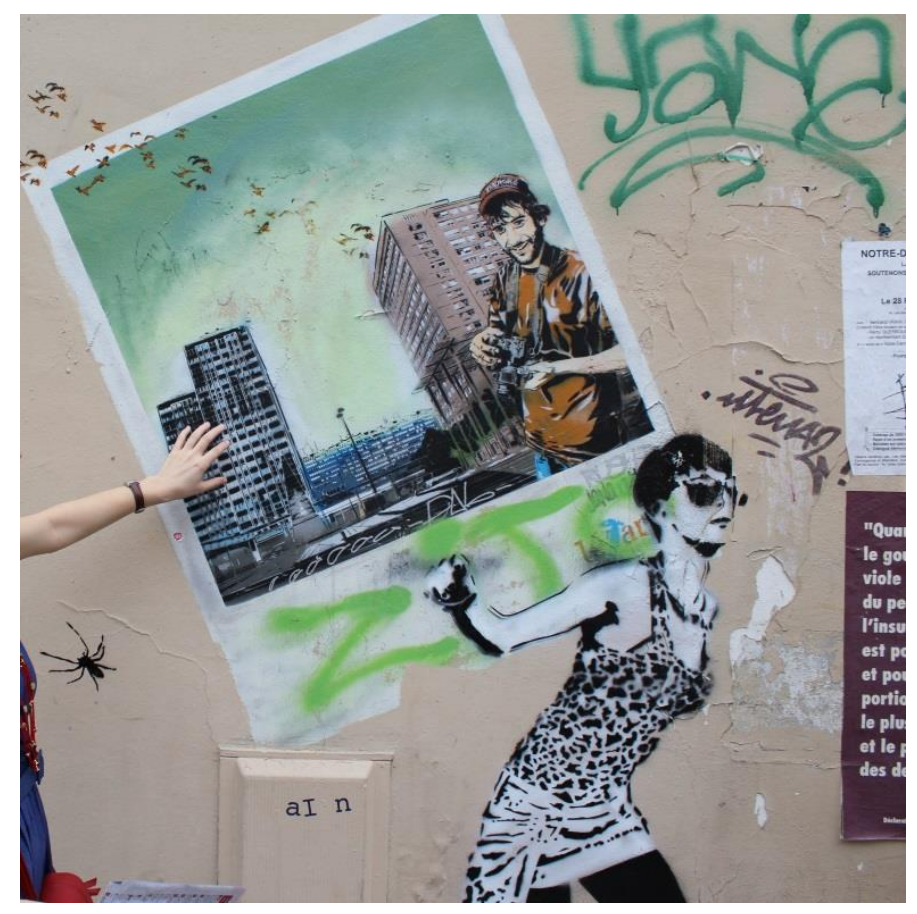

Source : archives personnelles.

La personne qui se promène voit un cliché polaroïd sur le mur. Sur l'image, il y a un homme qui tient dans ses mains un appareil photo et il regarde celui (ou celle) qui le prend en photo; au fond, encore dans le premier plan, nous voyons deux bâtiments; en retrait il y en a d'autres. L'image toute seule ne dérange pas. Pourtant, à l'endroit où elle est exposée, cette photo peut donner matière à réflexion. Elle est dans la rue. Celui qui la regarde est dans la même position que l'homme qui tient l'appareil: arrêté et en train de regarder. De plus, le passant a, lui aussi, la ville autour de lui. Cette image de street art fonctionne donc comme un miroir où le promeneur finit par se voir, même si ce n'est que projeté dans un corps qui n'est pas forcément comme le sien. Il est dans la ville et 
devant elle. Il la regarde avec cette sensation de vertige et de chute dont nous avons déjà parlé.

La mise en abîme des villes se répète dans les œuvres de Jana \& Js. Parmi les images exposées dans leur site professionnel, nous avons choisi celle qui suit:
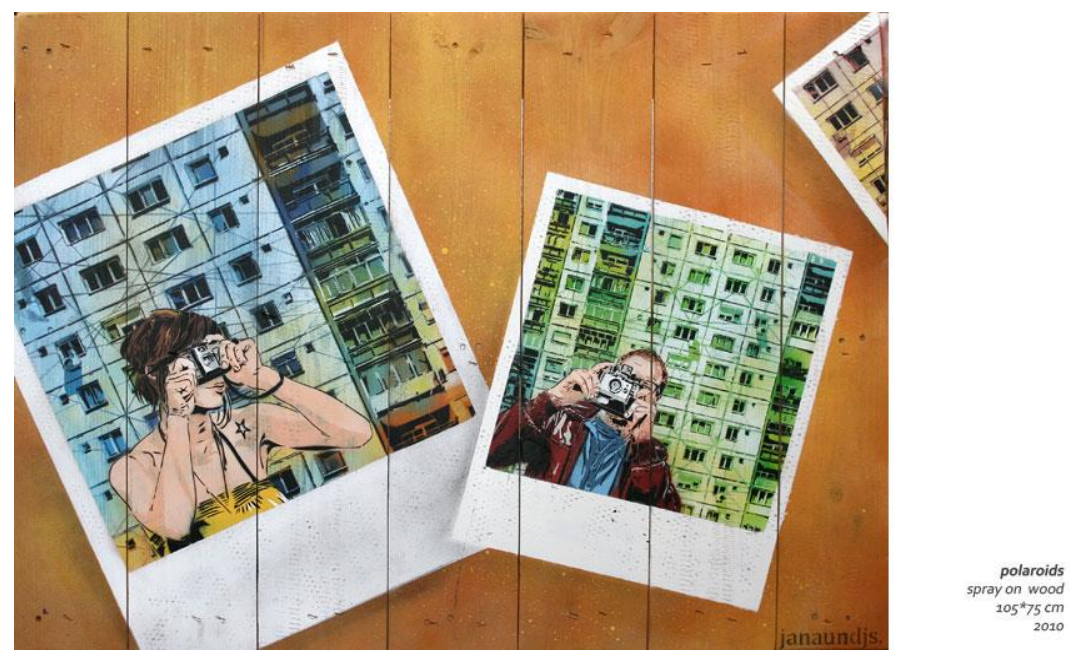

Source : $\underline{\text { http://www.janaundjs.com/francais/toiles.html }}$

A la suite de ce que nous affirmions concernant le roman Les détectives sauvages, il est possible de remarquer ici également la fusion entre l'art et l'espace. Ces deux éléments entrent dans un rapport spéculaire qui finit par accorder du sens tant à l'un quant à l'autre. En d'autres termes, l'image signifie davantage dans son support et son lieu d'exposition; l'espace est re-signifié par l'objet qui nous mène à une réflexion. Encore une fois, le vertige nous prend d'assaut par la vision de la ville (réelle) dans la ville (représentée) et du piéton à l'objectif qui observe le piéton-voyeur.

Comme nous avons remarqué dans Vastas emoções e pensamentos imperfeitos, celui que nous pouvons nommer personnage dans l'image de Jana \& Js est également un artiste. A la différence du peintre, de l'écrivain et du cinéaste, le photographe serait celui qui représente de façon plus réaliste l'espace à travers les images latentes enregistrées par son appareil. Néanmoins, les angles de prise de vue, les types d'objectifs, le contrôle de la distance focale, sont quelques techniques permettant le photographe d'appréhender différemment et de façon poétique la réalité. 
Nous avons intégré ces exemples dans notre analyse car, bien que la peinture ne soit pas une œuvre pluridimensionnelle et que nous n'apercevions pas les formes dans leur ampleur, le mouvement existe à travers cet abîme d'images. De plus, si les livres ont la possibilité d'être diffusés en grande quantité de façon plus rapide qu'une peinture street art, celle-ci a l'avantage de toucher directement un public plus nombreux et diversifié. D’où nous pouvons affirmer que la perte de l'aura de l'art se concrétise dans la rue.

\section{Considérations finales}

Comme nous venons de le remarquer, l'espace - surtout l'urbain - propose une ouverture vers l'imaginaire humain. Les manifestations artistiques véhiculant des imaginaires urbains deviennent de plus en plus fréquentes. Elles sont, bien entendu, tant de l'ordre de la représentation référentielle, que de la représentation symbolique. Ainsi, la littérature et les autres arts s'accaparent de cette particularité émanant de l'espace. Cela nous permet d'affirmer que l'espace comporte une dimension hétéropoétique. La somme des souvenirs et des expériences que nous avons d'un endroit particulier; la fascination que les espaces exercent sur nous; sa dimension symbolique assez représentative... L'espace a assez d'éléments pour pourvoir à la plume et au pinceau de l'artiste.

Dans un sens parallèle, mais complémentaire, nous croyons que les arts et ses diverses modalités nous rendent plus sensibles à la perception de l'espace en tant qu'espace vécu par différentes subjectivités: les passants et les lecteurs. Ils nous permettent de revisiter les lieux de l'ordinaire et du quotidien comme celui qui visite pour la première fois une ville. Être étrangers dans notre propre espace n'est pas une position "péjorative" pour l'individu dans le monde/son monde. Au contraire, il s'agit d'un état d'âme qui révèle plutôt d'une envie d'appropriation sensible et intellectuelle d'un territoire en même temps que du malaise irrémédiable d'y vivre.

Nous ne pousserons pas la réflexion jusqu'à l'affirmation que tous les hommes sont ou pourraient devenir artistes, mais qu'une fenêtre sur l'art leur est ouverte, soit sous forme écrite, peinte ou photographiée. 


\section{Bibliographie}

Benjamin, Walter (1971), L'œuvre d'art à l'époque de sa reproductibilité technique, trad. M. de Gandillac, in Essais 2, Denoël/Gonthier.

Bercoff, Brigitte (2007), "Pratiques de la comparaison dans quelques départements de Lettres en France", in: Baneth-Nouailhetas, Emilienne et Joubert, Claire (dir). Comparer l'étranger. Enjeux du comparatisme en littérature, Rennes, Presses Universitaires de Rennes.

Bolaño, Roberto (2006), Les détectives sauvages, Traduit de l'espagnol (Chili) par Roberto Amutio, Paris, Gallimard. (Première publication au Chili: 1998)

Dallenbach, Lucien (1986), Le récit spéculaire, Essai sur la mise en abyme, Paris, Éditions du Seuil.

Fonseca, Rubem (1992), “A arte de andar nas ruas do Rio de Janeiro”, in Romance negro e outras histórias, Rio de Janeiro, Nova Fronteira.

Fonseca, Rubem (1988), Vastas emoções e pensamentos imperfeitos, São Paulo, Companhia das Letras.

Westphal, Bertrand (2005), Pour une approche géocritique des textes. SFLGC (Vox

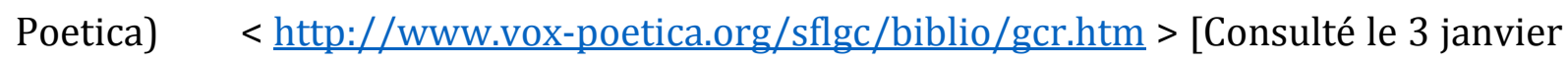
2015].

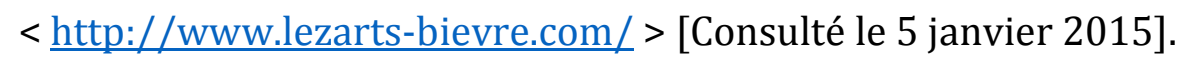

$<$ http://www.janaundjs.com/ > [Consulté le 10 avril 2015].

< https://rutabolanoendf.wordpress.com > [Consulté le 19 avril 2015].

Marina Silveira de Melo est doctorante en Littérature comparée à l'Université Sorbonne Nouvelle Paris 3. Elle a publié notamment:

"De la ville (au) texte: la littérature en tant qu'enquête urbaine et personnelle". Revue Passages de Paris, v. 9, p. 92-101, 2014.

"Un modèle pour la traduction littéraire? Analyse du cas Rubem Fonseca". Atelier de Traduction, v. 20, p. 57, 2013. 


\section{Notes}

1 “[...] um mundo arcaico de vastas emoções e pensamentos imperfeitos.” (Traduction de l'auteure)

2 “[...] paredes cheias de livros." (Traduction de l'auteure)

3 “[...] alto trilho sinuoso de concreto." (Traduction de l'auteure)

4 "Desde La sortie des Usines Lumière, qual a situação que ainda não foi abordada pelo cinema?" (Traduction de l'auteure)

5 "Quero intranqüilizar, causar distúrbios, ânsias, perplexidades, insônias, vômitos." (Traduction de l'auteure)

${ }^{6}$ Les références aux DF dans ce roman de Bolaño sont tellement expressives et travaillent d'une telle sorte l'imaginaire, qu'un itinéraire touristique a été mis au point à partir des endroits cités dans son récit ( $c f$. https://rutabolanoendf.wordpress.com) CEuvre de presque mille pages, sans aucune vocation à figurer parmi les guides dans les étagères des kiosques à journaux, Les détectives sauvages se prête aussi à l'élaboration d'un plan touristique-littéraire du DF.

7 Depuis 2001, l'association Lézarts de la bièvre promeut des activités culturelles et artistiques dans les 5ème et 13ème arrondissements de Paris. Chaque année, un artiste de la scène urbaine est invité pour baliser les parcours de la journée portes ourvertes des ateliers d'artistes. Jana \& Js y ont participé en 2009, mais il est possible de contempler les contributions d'autres artistes au fil de ces quatorze ans de projet. Le résultat est un agréable palimpseste de street art. Pour d'autres informations concernant ce projet, consultez le lien qui suit: http://www.lezarts-bievre.com/ 


\title{
Processus de territorialisation cartographiques
} dans le Cycle de Nedjma de Kateb Yacine

ou comment repenser le territoire et la cartographie à l'usage des revendications anticoloniales?

\author{
Juliette Morel \\ Université Rennes 2, Laboratoire CELLAM / Université Paris-Sorbonne, Laboratoire ENeC
}

Résumé: La cartographie est un vecteur d'appropriation, de domination et de contrôle territorial très puissant pendant les colonisations européennes du XIXe siècle. Elle tient de ce fait un rôle symbolique fort lors des indépendances au XXe siècle, notamment dans les œuvres littéraires des auteurs francophones engagés qui participent à construire les identités nationales des colonies émancipées. Les motifs cartographiques sont récurrents dans l'œuvre fictionnelle de Kateb Yacine et notamment dans le Cycle de Nedjma. L'auteur dessine à travers la figure du "polygone" l'espace politique, le territoire algérien et ses enjeux. Il érige cette figure en concept géopolitique, sur lequel il construit un discours géographique complexe ainsi qu'une critique de la colonisation française et de la gestion politique de l'indépendance algérienne.

Mots-clés: cartographie, territoire, Cycle de Nedjma

Resumo: A cartografia é um vetor de apropriação, dominação e controle territorial muito poderoso durante as colonizações europeias do século XIX. Por esse motivo, tem um papel simbólico importante aquando das independências no século XX., nomedamente nas obras lierárias dos autores francófonos engagés que participam na construção das identidades nacionais das colónias emancipadas. Os motivos cartográficos são recorrentes na obra ficcional de Kateb Yacine e nomeadamente no Ciclo de Nedjma. 0 autor desenha através da figura do "polígono" o espaço político, o território e respetivas questões . Erige 
esta figura em conceito geopolítico sobre o qual constrói um discurso geográfico complexo assim como uma crítica da colonização francesa e da gestão política da independência argelina.

Palavras-chave: cartografia, território, Ciclo de Nedjma

Les littératures qui se développent au $\mathrm{xx}^{\mathrm{e}}$ siècle dans les régions colonisées - encore sous domination ou fraîchement indépendantes - possèdent une dimension politique nécessaire: d'abord parce qu'elles donnent une voix à un peuple qui n'en a habituellement et historiquement pas, dont la parole est opprimée; ensuite parce qu'elles construisent d'autres modèles de langage, de narration, d'imagination, parce qu'elle correspondent à d'autres schémas mentaux, d'autres esthétiques, propres aux peuples colonisés et fruits d'un métissage (Italo Calvino, 1984, Jean-Marc Moura, 1999), qui plus est lorsqu'elles sont écrites dans une langue empruntée ou imposée par le colon. ${ }^{1}$ La colonisation provoque en outre des conditions spatiales individuelles ou de groupe problématiques: usurpation du sol, expropriation des terres, déplacement, immigration, exil. Le discours politique porté par ces littératures acquiert par conséquent une dimension spatiale forte, sur fond de revendications territoriales voire de véritables guerres de (re)conquête sur le terrain; et la problématique territoriale se formule souvent en parallèle de celle de de nation. Mais ces concepts européens modernes apparaissent parfois inadaptés à la liberté rêvée, aux revendications nationalistes teintées d'internationalisme (non-alignés, négritude, créolisation, Relation) et aux États qui en résultent effectivement (souvent composés de plusieurs ethnies et/ou marqués par le plurilinguisme). Dans ce contexte, aborder ces littératures à travers les paradigmes postcolonial et postmoderne permet de mettre en perspective les concepts géopolitiques en jeu. C'est ce que nous proposons de faire dans cet article.

La cartographie est le stéréotype de la conception européenne, hégémonique, "conquérante" dirait Edouard Glissant, et coloniale du territoire selon la perspective postcoloniale. Elle fut effectivement un outil puissant pour découvrir, connaître et soumettre les territoires lors de la colonisation européenne du xixe siècle, puis pour affirmer et imposer l'autorité politique de la métropole sur les colonies (Blais 2014). Or, on retrouve des références à la cartographie dans de nombreux textes francophones de l'Afrique du Nord ou des Caraïbes, comme dans ceux de Kateb Yacine, Rachid Boudjedra, Patrick Chamoiseau ou encore Edouard Glissant. L'étude que nous proposons de mener 
tend à questionner ces références dans le contexte théorique que nous avons exposé plus haut: la cartographie n'est-elle alors convoquée qu'en tant qu'instrument de domination qu'il s'agirait de dénoncer et de déconstruire ou peut-on lire dans ces textes un renouvellement et une réappropriation de l'outil, selon le mouvement de dé/reconstruction caractéristique de la pensée postcoloniale?

Cette étude se focalise plus particulière sur la première partie de l'œuvre de l'auteur Algérien Kateb Yacine (1929-1989) qui a publié en français entre 1956 et 1966 trois textes, Nedjma (1956), Le Cercle des représailles (1959) et Le Polygone étoilé (1966), que la critique a rassemblés sous le terme de "Cycle de Nedjma". Ces trois ouvrages sont complétés par une série de fragments narratifs, poétiques et dramatiques, dont une partie a été publiée en 1986 par Jacqueline Arnaud sous le titre L'œuvre en fragments. Ces œuvres constituent un ensemble partageant un même système de personnages, au centre duquel se place la femme aimée éponyme, Nedjma. Elles ont également en commun leur contexte historique et politique, marqué par la guerre d'indépendance de l'Algérie (1954-1962), et un contexte géographique: l'Algérie, et dans une moindre mesure la France à travers des récits d'immigration. Le choix de ce corpus se justifie de plusieurs manières et notamment parce que l'engagement politique et la perspective géopolitique y sont particulièrement importants: "il s'agissait à l'époque de montrer en français que l'Algérie n'était pas française. C'est ce que j'ai fait dans Nedjma. C'est par là je crois, que les écrivains peuvent redresser les torts commis par les pouvoirs militaires ou politiques", explique Kateb Yacine (Yacine 1994: 97). Dans le contexte de la guerre d'indépendance, et c'est particulièrement vrai pour Kateb Yacine qui est considéré comme l'un des pères de la nation algérienne moderne, l'écriture engagée se fait performative: écrire ce qu'est l'Algérie revient à acter le fait qu'elle n'est pas française, nommer la nation participe à son affirmation.

\section{Système géographique et jeu de construction territoriale chez Kateb Yacine}

S'agissant du traitement de l'espace, Kateb Yacine se fait tout d'abord géographe. De nombreux éléments de géographie régionale sont lisibles dans le Cycle de Nedjma. Ainsi y trouve-t-on tout d'abord l'organisation en gradient Nord-Sud caractéristique de l'espace algérien: une frange littorale au Nord concentrant les villes et la population 
algérienne, une frange de Montagnes, puis le désert recouvrant l'immense partie sud du territoire algérien, symboliquement important chez Kateb Yacine mais présenté comme un tout indistinct. Également, Il est possible de lire la division de l'espace Algérien entre une grande région à l'Ouest, dont il n'est quasiment jamais question, et la Région de l'Est Algérien, où se déroule l'essentiel du Cycle. Enfin, l'espace géographique du Cycle de Nedjma est polarisé par les villes: à l'échelle de l'empire colonial français, Paris, énorme, monstrueuse, point culminant de la quête migratoire; à l'échelle du pays, Alger, la capitale de l'Algérie macrocéphale, attractive, pleine de promesses, mais intimidante (c'est l'aboutissement des migrations de travail internes à l'Algérie, mais aussi le point de départ de l'émigration transméditerranéenne). A une échelle plus grande, la Kabylie est dominée par un couple de villes, Constantine et Bône (Annaba), les "villes-mères" (Yacine 1956: 165), reliées entre elles par "l'express Constantine-Bône", et structurée par un réseau plus dense composé notamment de Sétif et Guelma. Le Cycle est une œuvre citadine s'il en est: face à ces centres urbains la campagne et les villages sont confondus dans une absence de toponyme ou de localisation précise, comme dans une espèce d'indistinction thématique. Par exemple, "la ville de X." où ont grandi Lakhdar et Mustapha se situe dans "des environs de Sétif", sans autre forme de précision (idem: 183), et, à propos de la localisation du chantier où les quatre protagonistes ont enfin trouvé du travail, à la question "Et le nom de l'endroit?", Lakhdar répond: "Tous les villages sont les mêmes", et un peu plus loin lorsque Rachid insiste encore: "- Tu lui as demandé le nom du village? / - Qu'est-ce que ça peut faire?" (idem: 238-239).

Le Cycle de Nedjma fait œuvre de territorialisation en tant que l'écriture, la nomination et la description participent au processus de construction d'une territorialité, c'est-à-dire du "rapport existant entre un acteur [individu ou groupe] et un territoire". La territorialité a une application politique pragmatique dans la nécessité pour les acteurs de contrôler le territoire; mais également, "dépassant le stade de contrôle, cette notion peut être liée au sentiment d'appartenance, et donc à la formation même de l'identité" (Rosière 2008: 283). Les textes de Kateb Yacine participent à ce dernier point en construisant des motifs identitaires symboliquement forts et liés directement à l'espace: par exemple l'association de la femme aimée, Nedjma, et de la nation à travers l'allégorie de la Femme sauvage maitresse du désert dans les Ancêtres 
redoublent de férocité, ou le personnage du Fondateur, "voyageur opprimé, [...] maître du désert, et [...] de la forêt" dans Le Polygone étoilé (Yacine 1966: 13). L'espace référentiel est enfin territorialisé à travers les émotions et les connotations davantage lyriques qui s'y projettent: il est profondément marqué et organisé par la présence, l'absence et les déplacements de Nedjma.

Néanmoins, face à la construction de telles représentations géographiques et géopolitiques qu'on pourrait qualifier de "classiques", le Cycle de Nedjma construit un discours beaucoup plus critique sur le territoire algérien, qui souligne le caractère profondément problématique et insuffisant de telles qualifications pour dire la réalité (post)coloniale du territoire et revendiquer géopoétiquement en même temps que géopolitiquement le "sol usurpé" par la colonisation (Yacine 1959: 29). Pour cela, Kateb Yacine a en fait recours à des processus de schématisation qui s'apparentent à des procédés cartographiques. La géométrie est omniprésente dans l'œuvre de Kateb Yacine (par exemple dans les titres: "Polygone étoilé", "cercle des représailles", "Nedjma" signifiant étoile en arabe) et elle est notamment utilisée dans les textes pour parler de l'espace géographique référentiel. Ainsi est-il possible de comprendre les différentes conditions spatiales expérimentées par les personnages selon les trois implantations cartographiques, le point, la ligne et la surface. On peut qualifier de "points" chez Kateb Yacine les lieux stratégiques de l'action, ceux qui accueillent les moments décisifs de la diégèse, les pauses spatio-temporelles dans le récit, les scènes narratologiques. À différentes échelles, le point est une pièce - par exemple le salon dans lequel sont enfermés Nedjma et Mustapha ou la "chambre nuptiale" où "s'étreignent" Nedjma et Lakhdar (Yacine 1956: 233-235) -, il peut être une maison - "la villa Nedjma" -, un bar dans presque toutes les villes -, une rue - la "rue des Vandales" au début du Cadavre encerclé (Kateb Yacine 1959: 15) -, une place - par exemple la "Place de la Brèche" dans Nedjma qui constitue un point de rencontre clé entre la diégèse (Rachid se fait heurter par une voiture) et l'Histoire coloniale (la place de la Brèche tient son nom d'un épisode décisif de la prise de Constantine par les Français en 1837) -, ou encore un quartier "Beauséjour" à Bône ou le Fondouk de Constantine dans Nedjma, le port d'Alger, "Bab Dzira" dans Le Polygone étoilé (Yacine 1966: 40-45) -, sans oublier les villes dont nous avons parlé plus haut. L'expérience spatiale de la ligne s'oppose au séjour et à la fixation 
spatio-temporelle caractéristiques du point. Le figuré de la ligne peut représenter toutes situations de modalité spatiale. Ce sont des situations plus dynamiques et problématiques d'un point de vue géopolitique chez Kateb: c'est l'exil de Lakhdar dans Le Polygone étoilé, le pèlerinage à la Mecque de Rachid et Si Mokhdar dans Nedjma, l'errance de Rachid entre Constantine et Bône dans Nedjma, de Lakhdar et de Grand père Mahmoud, à Alger ou en France, dans Le Polygone étoilé. Enfin, Kateb Yacine traite en terme de surface les territoires politiques, c'est-à-dire comme des zones circonscrites mais vues dans leur indistincte globalité, comme des ensembles ayant une homogénéité ontologique interne et étant significatifs comme tels. Ce sont des zones sur lesquelles s'exercent ou veut s'exercer une autorité et qui sont définies par et pour celui-ci. Elles correspondent en ce sens à la définition du territoire héritée de la modernité européenne. C'est la Nation, le désert (Yacine 1959: 143 et sq.), la montagne, la forêt (Yacine 1966: 13), la prison, le cimetière ou le camp (idem: 10-12, 94, 130-140). Cette modalité spatiale est schématisée chez Kateb Yacine par le "polygone", terme géométrico-poétique récurrent.

Le "polygone" désigne l'espace politique élémentaire. C'est une schématisation volontairement simpliste qui condense, précisément par son caractère simpliste et grâce à sa dimension ironique, toute la complexité du discours et des revendications géopolitiques portés par l'œuvre. Le fonctionnement de cette métaphore cartographique est typique du processus postcolonial résumé ainsi par Graham Huggan: "la prévalence du topos cartographique dans les textes littéraires postcoloniaux contemporains et la fréquence de son usage ironique et/ou parodique suggèrent un lien entre une lecture dé-/reconstructive des cartes et une révision de l'histoire du colonialisme européen." (Huggan 1994).

\section{Déconstruction de la cartographie dans le cycle de Nedjma de Kateb Yacine: l'exemple du polygone}

Il convient de préciser avant toute chose que le "topos cartographique" chez Kateb Yacine ne consiste pas à faire référence à l'objet carte ni à intégrer au sein du texte des images matérielles de cartes. Kateb Yacine fait davantage usage du processus cartographique comme médium et mode de représentation et d'appréhension de 
l'espace. Cette référence est motivée par la fonction politique de la cartographie, mais aussi par ses propriétés sémiologiques: la cartographie peut utiliser un même symbole pour désigner différents lieux, espaces, phénomènes ou dynamiques géographiques, c'est-à-dire, en terme linguistiques, un même signifiant pour plusieurs signifiés. Comme la métaphore et la polysémie, le symbole cartographique établit de cette façon des liens ontologiques transversaux entre des choses de natures ou d'échelles diverses et offre un vaste potentiel de sens. De la même manière que la figure poétique décrite par Gérard Genette comme un "espace exigu mais vertigineux" (Genette 1966: 221), la figure cartographique, et le polygone en particulier, ouvrent donc un espace de signification immense dans lequel se superposent des couches de sens développées au fil du Cycle.

Le "polygone" est clairement défini dans Les Ancêtres redoublent de férocité, une des pièces composant le recueil dramatique Le Cercle des représailles: "CORYPHÉE (doctoral): tout territoire est un polygone. Tous les pays sont des polygones inscrits dans la sphère terrestre. Il y a des polygones réguliers, des hexagones, comme la France ... et il y a les irréguliers..." (Yacine 1959: 126). Les Ancêtres redoublent de férocité est sans doute un des textes qui développe le discours géopolitique le plus abouti de l'œuvre de Kateb Yacine, et ce passage à la tonalité ironiquement savante (dont atteste la didascalie "doctoral") en est l'exemple le plus édifiant. Ici, les termes "polygone", "hexagone" et l'expression "inscrits sur la sphère terrestre" confirment la motivation cartographique de la métaphore dont l'origine est dévoilée: il est question de "polygone" en référence à la métaphore communément admise qui identifie la France à un hexagone, d'après le dessin schématique de ses frontières à un niveau de généralisation cartographique élevé. A partir de cette figure stéréotypée, l'ordre du processus de désignation sémantique (dans une certaine mesure motivée en cartographie), qui voudrait que la forme effective qu'a un territoire sur la sphère terrestre précède et détermine la forme choisie pour le schématiser sur une carte, est inversé dans le cas de l'Algérie. En effet, peu importe ses limites effectives dans la géographie référentielle (limites qui sont d'ailleurs dans un sens beaucoup plus "régulières" que celles de la France, car rectilignes), l'Algérie est schématisée par un "polygone irrégulier". Cette inversion est d'abord d'ordre rhétorique pour Kateb Yacine et dénonce l'arbitraire et l'indétermination politique de l'Algérie. Cela étant dit, elle correspond également à une 
réalité historique et dénonce ainsi la violence performative de la cartographie pendant la colonisation: l'autorité coloniale (notamment à travers le Ministère du Sahara) définit selon ses propres intérêts la forme géographique du territoire sur lequel elle s'exercerait en traçant des limites rectilignes sur une carte. Hélène Blais dans son ouvrage Mirage de la carte. L'invention de l'Algérie coloniale explique en effet que la fixation des frontières Sud de l'Algérie a été déterminée selon des préoccupations économiques en vue de l'exploitation pétrolière, et elle écrit à ce propos: "La création d'un territoire tracé sur la carte par le souverain en fonction de sa seule volonté est une pratique ancienne en Europe." (Blais 2014: 9). Le dessin cartographique a ainsi précédé et défini la réalité géopolitique, selon le processus que décrit également Mark Monmonier de manière à peine exagérée:

La carte est le symbole parfait de l'état. Supposons que votre grand Duché ou votre zone tribale paraissent fatigués, mal en point et rongés par les bords; vous prenez une feuille de papier, vous placez quelques villes, routes et détails de géographie physique et vous tracez une grande ligne autour du plus grand territoire possible sur lequel vous revendiquez la souveraineté [...] et le miracle s'accomplit! Vous voilà à la tête d'un pays souverain et autonome, flambant neuf et prêt à poser sa candidature aux Nations Unis! Si quelqu'un se permet d'en douter, vous n'avez qu'à indiquer sur la carte d'un doigt péremptoire: votre état est non seulement sur le papier, mais sur une carte, donc il est réel. (Monmonier 1994: 135)

Les termes "hexagone" et "polygone régulier" possèdent une autre dimension polémique dans le contexte de ce qu'était effectivement le territoire français dans les années 1950. Il faut rappeler que l'Algérie acquiert le statut de "département français" en 1848 ce qui implique théoriquement une administration civile et un statut similaire de l'espace français métropolitain et de cet espace "français" ultramarins (Thébault 2012). ${ }^{2}$ Opposer l'“hexagone régulier" de la "France” aux "polygones irréguliers" qui désignent implicitement les colonies revient à nier cette équivalence et rappelle que l'État-nation français cohérent ne peut contenir que le territoire métropolitain selon la logique moderne-même qui le fonde. La rhétorique colonialiste est ainsi, en quelques termes, déconstruite.

Finalement, la figure du polygone vise à signifier la condition territoriale profondément problématique des colonies en général et de l'Algérie en particulier. 
L'indétermination, c'est-à-dire la négation du "droit des peuples à disposer d'euxmêmes" - ou "droit à l'autodétermination" - cher à la période suivant la Deuxième Guerre Mondiale, le caractère usurpé, volé, voilé, aliéné et la crise identitaire sont les caractéristiques premières de ce territoire, d'autant plus que cette figure est pléonastique: le préfixe "poly -" qui porte en lui-même l'idée d'imprécision (le nombre de côtés est inconnu) est confirmé par l'adjectif "irrégulier". Et le potentiel destructeur (car réducteur) mais extrêmement efficace de la cartographie est ainsi, en deux mots, démontré.

La profondeur sémantique, les glissements de sens - entre "hexagone" et "polygone", "régulier" et "irrégulier", forme géométrique et caractéristique politique ainsi que le caractère antithétique voire absurde de cette démonstration "doctorale" l'hexagone n'est en fait pas d'une régularité parfaite, le territoire aux limites rectilignes est irrégulier, etc. - révèlent le fonctionnement ironique de la métaphore du polygone chez Kateb Yacine. Cette figure condense le fonctionnement et la complexité du discours postcolonial qui consiste à déconstruire les concepts coloniaux pour relire à partir des ruines ainsi produites le phénomène colonial sous une autre lumière.

\section{Vers une reconstruction cartographique}

Au-delà de ces quelques lignes, le motif du polygone est repris tout au long du Cycle de Nedjma et subit à chaque fois de légères et régulières dérivations de sens, procédé typiquement katébien. Comme en cartographie, la figure géométrique du polygone représente ainsi chez Kateb plusieurs espaces de natures et d'échelles différentes qui partagent néanmoins, et c'est pour cela qu'ils sont réunis sous la même métaphore, des caractéristiques communes. "La terre, la forêt, la cellule, la France, tout se confond dans la grisaille des aliénés" et dans la figure du polygone (Yacine 1966: 11). Dans la scène qui précède le passage des Ancêtres redoublent de férocité que nous avons longuement commentée plus haut, le Chœur fait l'inventaire des espaces polygonaux:

Coryphée: Ils vont tout droit au polygone.

Chœur: Au polygone?

Coryphée: Oui, c'est là qu'on fusille.

Chœur: polygone, polygone, polygone... 
Coryphée: Ils ont tout mesuré. Ils passent leur temps à prendre des mesures contre nous. Le polygone, en géométrie, ça veut tout dire...

Chœur: il y a au même endroit, là où on fusille, un camp de concentration...

Mustapha (masqué, se détachant du chœur): c'est vrai. J’y étais il y a dix ans.

Coryphée: Nous sommes riches en polygones...

Chœur: Sans compter les cimetières.

Coryphée: Pour ne parler que des terrains vagues. Quant à la prison, c'est un luxe, en prévision de la paix.

Chœur: polygone, polygone, polygone... (Yacine 1959: 126)

Ainsi peut-on constater que le polygone désigne toujours un territoire en crise où la territorialité est problématique parce que marquée par des situations d'incapacité: l'usurpation, l'enferment, l'aliénation ou la mort (Jacqueline Arnaud 1986). Ces espaces sont des territoires en tant qu'ils sont des espaces clos, limités. Mais ce sont des territoires imparfaits, incomplets, indéterminés, irréguliers étant donné qu'ils ne possèdent pas les autres caractéristiques du territoire: la prison, le camp de concentration, le cimetière ou le polygone d'artillerie sont des espaces sur lequel il est impossible, par définition, d'exercer un contrôle ni d'y projeter un sentiment d'appartenance ou une identité (qui ne peut être alors que "vague"). Ce sont des parodies de territoires - et on retrouve ici l'usage postcolonial de la cartographie décrit par Gaham Huggan. L'ironie est enfin palpable à travers les antithèses - "nous sommes riches en polygones", c'est-à-dire en espaces aliénés et vidés; la prison est un "luxe" au regard du reste - et les dérivations de sens des termes "mesure" et "polygone".

\section{Décoloniser la cartographie, ou la construction du polygone étoilé.}

Kateb Yacine ouvre donc un espace de sens immense dans la figure du polygone et c'est ainsi qu'il parvient à déconstruire la fonction réductrice que la cartographie acquiert lorsqu'elle est outil de domination. C'est également de cette manière qu'il s'approprie le polygone et en fait une figure centrale de sa poétique. La figure s'enrichit et s'étend presque à l'infini à travers ses perpétuelles réécritures toute au long de l'œuvre (dont nous n'avons montré là qu'un instantané résumé): "en géométrie, le polygone ça veut tout dire", nous dit le Coryphée...

Graham Huggan explique: 
ethnic writers may focus on the disruptive activity of mapbreaking or on the reconstitutive activity of mapmaking; but they are usually involved to some extent in both: the reconstituted map has altered its terms of reference, not to avoid being subsumed within the dominant cartographic discourse but precisely to resist that avoidance. 'Ethnicity', like 'feminism' and 'regionalism', may thus come to be considered as that set of rhetorical strategies witch activates a slippage of meaning between prescribed (cartographic) definitions. The easy ethnocentric distinction between 'our' territory and 'theirs' is consequently blurred, indicating a fault line between the neat rhetorical divisions inherent in conventional (Western) cartographic discourse. (Huggan 2011: 417) ${ }^{3}$

Il semble que nous retrouvions exactement chez Kateb Yacine ce mouvement de déconstruction puis de reconstruction autour d'une stratégie de glissement de sens et de brouillage par rapport aux différentes fonctions de la cartographie "occidentale", "prescrite" et conventionnelle. Il ne s'agit en effet pas de rejeter en bloc ou de dénoncer le caractère néfaste de la cartographie et de la notion de territoire, typiquement occidentale elle-aussi, dans l'absolu - sinon que faire de leur omniprésence chez Kateb Yacine? -, mais plutôt d'en déconstruire les mésusages et les définitions coloniales afin de les réinvestir de sens selon les perspectives de l'anticolonialisme et de l'émancipation. Dans cette entreprise de reconstruction, tout n'est donc pas à jeter. A l'instar du territoire qu'elle tend à représenter, la cartographie définit des ensembles et des structures closes, circonscrites par des limites géométriques. Cette propriété est conservée par Kateb Yacine qui joue davantage sur l'étendu de l'espace interne ainsi créé, comme les propriétés du polygone katébien en témoignent. Ainsi l'auteur parvientil à construire une figure la fois close dans ses contours et ouverte dans son contenu (car indéfini, c'est-à-dire au potentiel infini). Cette dialectique de l'ouvert et du fermé, du délimité et de l'indéfini trouve son aboutissement voire sa solution dans une autre figure géométrique, le polygone étoilé, également récurrente dans l'univers katébien mais autrement plus globalisante. La transfiguration du polygone en polygone étoilé se pressent par exemple dans la description suivante issue du Polygone étoilé mettant en scène une forme intermédiaire, le "polygone hérissé": 
Il ne manquait pas d'espaces à conquérir, et il faudrait tout exhumer, tout reconstituer, écarter l'hypothèse de ce terrain douteux qui avait attiré soldats et sauterelles, dont le propriétaire avait été tué, dépossédé, mis en prison, et sans doute avait émigré, laissant aux successeurs un vieil acte illisible n'indiquant plus qu'un polygone hérissé de charbons, apparemment inculte et presque inhabité, immense, inaccessible et sans autre limite que les étoiles, les barbelés, la terre nue et le ciel sur ses reins, en souvenir de la fraction rebelle, irréductible en ses replis, et jusqu'à sa racine: la rude humanité prométhéenne, vierge après chaque viol, qui ne devait rien à personne (Yacine $1966: 144)$

Le territoire-polygone problématique évolue ainsi vers un territoire-polygone étoilé qui serait à même de rendre compte du territoire postcolonial en construction, dont les "plans sont chaque fois bouleversés" (Kateb Yacine 1966: 10, 11, 13, 96 et 131). Penser le territoire de l'Algérie émancipée comme un polygone étoilé permet d'intégrer positivement en son sein et dans la construction identitaire nationale en découlant toutes les situations territoriales problématiques que nous avons jusqu'à présent évoquées: l'expropriation et l'exploitation illégitime (voire le pillage) des terres, la mobilité spatiale interne, l'émigration, l'exil (figuré par la structure éclatée du polygone étoilé). L'enchevêtrement des formes polygonales signale la nécessité d'une approche multiscalaire du territoire politique et appelle à réfléchir le nationalisme et la nation non comme des fins en soi mais comme une ouverture vers l'international, au sens marxiste du terme. La métaphore géopolitique résultante est l'image-même de l'hybridation et témoigne de la rencontre culturelle dont est né le postcolonialisme: un tracé géométrique caractéristique de l'art islamique représente une notion géopolitique adaptée à partir d'un héritage conceptuel occidental.

\section{Conclusion}

L'étude de l'usage de la cartographie dans le Cycle de Nedjma de Kateb Yacine illustre parfaitement les enjeux géopolitiques et le mécanisme du discours anticolonial à l'œuvre dans les luttes d'indépendances. Il n'est pas question de rejeter en bloc ou d'ignorer les effets de la colonisation, et la tension vers un retour à un état antécolonisation est impossible, d'un point de vue sociétal comme d'un point de vue conceptuel ou culturel. Le discours sur l'espace politique véhiculé par les métaphores cartographiques katébiennes peut finalement être lu comme un pressentiment de celui 
qui sera plus tard, à partir des années 1970-1980, développé par la postmodernité. Le type de territorialité vers lequel tend le Cycle de Nedjma rappelle en effet le "troisième âge de la territorialité" tel que l'a formalisé Roland Portier. Cet auteur décrit trois âges de la territorialité: le premier âge serait celui de la territorialité biologique, quand la terre était peuplée d'assez peu d'humains pour que les territoires puissent n'être qu'imprécisément délimités; le deuxième âge est celui de la territorialité géométrique, où la surface terrestre est totalement linéarisée et découpée en entités théoriquement cohérentes. C'est la conception de la territorialité “à la française”, moderne, héritée des lumières, en cours pendant la colonisation et très généralement encore aujourd'hui. Enfin, le troisième âge de la territorialité serait celui de la fluidité, de la complexité. Cette conception est capable de prendre en compte "les réseaux, les échelles emboitées (le glocal) [qui] engendrent un lien au territoire hors de la géométrie euclidienne, évoquant des espaces flous", et participe à la postmodernité. Le polygone étoilé de Kateb Yacine, dans sa dimension géopolitique, peut être compris comme la proposition d'une telle territorialité. 


\section{Bibliographie}

Arnaud, Jacqueline (1986), La Littérature Maghrébine de langue française, II: le cas de Kateb Yacine, Paris, Éditions Publisud, "Espaces Méditerranéens”.

Blais, Hélène (2014), Mirage de la carte. L'invention de l'Algérie coloniale, Paris, Fayard, “à l'épreuve de l'histoire".

Genette, Gérard (1966), Figures I, Paris, Éditions du Seuil, coll. “Point essais”.

Huggan, Graham (2011), "First Principles for a Literary Cartography from Territorial Disputes: Maps and mapping strategies in Contemporary Canadian and Australian Fiction", in Dodge Martin, Kitchin Rob, Perkins Chris (eds.), The Map Reader, Oxford, Editions Wiley-Blackwell, pp. 413-421.

Yacine, Kateb (1956), Nedjma, Paris, Seuil, "Point”.

Yacine, Kateb (1959), Le Cercle des représailles, Paris, Seuil, "Point”.

Yacine, Kateb (1966), Le Polygone étoilé, Paris, Seuil, "Point”.

Yacine, Kateb (1994), Le Poète comme un boxeur: entretiens 1958-1989, Paris, Éditions du Seuil.

Monmonier, Mark (1993), Comment faire mentir les cartes ou du mauvaise usage de la géographie, Paris, Flammarion.

Rosière, Stéphane (2008), Dictionnaire de l'espace politique. Géographie politique et géopolitique, Paris, Armand Colin.

Westphal, Bertrand (2011), Le Monde plausible (espace, lieu, carte), Paris, Editions de Minuit. 
Juliette Morel doctorante en littérature et géographie en codirection à l'Université Rennes 2 (CELLAM) et Paris - Sorbonne (ENeC). Elle explore les modalités du dialogue entre cartographie et littérature dans le cadre d'une recherche de doctorat portant sur l'œuvre de l'écrivain francophone algérien Kateb Yacine. Egalement cartographe indépendante, elle a notamment contribué à l'Atlas Itinéraire géopolitique (JeanChristophe Victor, 2011) et au projet de recherche de l'Institut d'Urbanisme Français (Université Paris Est) "Repenser la place des quartiers périphériques dans la métropolisation" (PUCA, 2014 - 2015).

\section{Notes}

1 Nous pensons notamment à la définition du français par Kateb Yacine comme un "butin de guerre" ou l'idée selon laquelle: “Ecrire en français c'est presque, sur un plan beaucoup plus élevé, arracher le fusil de mains d'un parachutiste!" (Yacine [1962], 1994: 56).

${ }^{2}$ Cela étant dit, le statut administratif du territoire algérien colonial est bien plus complexe et hétérogène que sa simple qualification en département français ne le laisse penser. Par exemple, longtemps après 1848 certains territoires restèrent sous administration militaire alors que d'autres étaient passés sous administration civile. Egalement, deux types de communes persistaient en Algérie impliquant deux administrations différentes: les communes de plein droit, proches du fonctionnement des communes métropolitaines, et les communes mixtes, où s'appliquait le code de l'indigénat à la population majoritairement algérienne.

3 "Les écrivains ethniques peuvent se focaliser sur l'activité perturbatrice de la critique de la cartographie ou sur l'activité reconstructive de la production cartographique, mais en général ils sont impliqués dans les deux: la carte reconstruite altère ses termes de référence, non pas pour éviter d'être englobée dans le discours cartographique dominant mais précisément pour résister à cet évitement. L'"ethnicité", comme le "féminisme" et le "régionalisme", peut donc être considéré comme cet ensemble de stratégies rhétoriques qui provoquent un glissement de sens parmi les définitions (cartographiques) prescrites. La simple distinction ethnocentrique entre "notre" territoire et "le leur" devient par conséquent flou, correspondant à une ligne de faille au sein des divisions rhétoriques nettes inhérentes au discours cartographique conventionnel (occidental)." Traduction personnelle. 



\title{
El valle de Chistau como materia en la literatura en aragonés
}

\author{
Francho Nagore Laín \\ Universidad de Zaragoza / Campus de Huesca
}

Resumen: En este estudio analizamos la presencia del valle de Chistau (Sobrarbe, Pirineo Aragonés) en la literatura en aragonés, a través de las obras de Nieus Luzía Dueso Lascorz, Elisa Garzía Dealbert, Santiago Román Ledo y Quino Villa. Para ello utilizamos como bibliografía primaria las obras de estos autores y como bibliografía auxiliar algunos estudios de carácter lingüístico y etnográfico sobre este valle y su variedad diatópica de aragonés (Mott, 1989, 2000, Blas / Romanos, 2008, Lasaosa / Sarasa, 1999). Constatamos que la presencia del valle de Chistau es constante en los escritores oriundos del valle, cuyas obras están escritas en el aragonés local (chistabín). Pero igualmente observamos que algún autor que escribe en aragonés común utiliza también el valle de Chistau como materia literaria. Y tanto en unos como en otros, el valle aparece idealizado o mitificado, como si fuera un paraíso desde el punto de vista del paisaje o, incluso, desde el punto de vista social. Las conclusiones que manejamos como hipótesis de trabajo son: 1) el valle de Chistau es una materia frecuente en la literatura en aragonés; 2) predomina en la literatura en aragonés una visión idealizada del valle, tamizada por el recuerdo o la nostalgia.

Palabras clave: valle de Chistau, literatura en aragonés

Resumo: Neste estudo analisamos a presença do vale de Chistau (Sobrarbe, Pirineo Aragonés) na literatura em aragonés, através das obras de Nieus Luzía Dueso Lascorz, Elisa Garzía Dealbert, Santiago Román Ledo e Quino Villa. Para esse efeito, utilizamos como bibliografía primária as obras destes autores e como bibliografía auxiliar alguns estudos de caráter linguístico e etnográfico sobre este vale e sua variedade diatópica de aragonés (Mott, 1989, 2000, Blas / Romanos, 2008, Lasaosa / Sarasa, 1999). Constatamos que a presença do vale de Chistau é constante nos escritores oriundos do vale, cujas obras estãoescritas em aragonés local (chistabín). Porém também que outros autores existem, e que escrevem em aragonés comum, utilizam o vale de Chistau como materia literaria. Tanto nuns como noutros, o vale surge idealizado ou mitificado, como se fosse um paraíso do ponto de vista da paisagem ou, 
inclusivamente, do ponto de vista social. As conclusões com que lidamos como hipótesis de trabalho são: 1) o vale de Chistau é uma matéria frequente na literatura em aragonês; 2) predomina na literatura em aragonês uma visão idealizada do vale, filtrada pela memória ou pela nostalgia.

Palavras-chave: vale de Chistau, literatura en aragonês

Hay en Aragón territorios que han atraído, más que otros, la atención de los escritores. Así ocurre, por ejemplo, con los Monegros, llanura esteparia que constituye una de las pocas zonas desérticas de la Unión Europea. Ha sido estudiada tanto su visión literaria contemporánea en autores que escriben en castellano (Calvo 2013), como su presencia en la poesía escrita en aragonés (Nabarro 2008-2009).

De forma parecida, nos proponemos analizar aquí la presencia del valle de Chistau (Sobrarbe, Pirineo Aragonés) en la literatura en aragonés, a través de las obras de algunos autores, en las que este valle pirenaico es el escenario de las historias narradas o es el objeto directo de la descripción.

Para ello utilizamos como bibliografía primaria las obras de estos autores y como bibliografía auxiliar trabajos y reseñas sobre la obra de estos, así como algunos estudios de carácter lingüístico y etnográfico sobre este valle y su variedad diatópica de aragonés (Mott, 1989, 2000; Blas/ Romanos, 2008; Lasaosa/ Sarasa, 1999).

El valle de Chistau se sitúa en el alto Pirineo aragonés, al noreste del antiguo condado (hoy comarca) de Sobrarbe. Linda por el oeste con el valle de Bielsa y por el este con el valle de Benás (Benasque), ya en la Alta Ribagorza. Atraviesa el valle el río Zinqueta, afluente del río Zinca. Los pueblos principales del valle son Plan, San Chuan de Plan y Chistén; además, los pueblos de Sin, Señes y Serbeto forman un subvalle -situado entre el valle de Bielsa y la parte principal del valle de Chistau-; frente a estos, al sur y en la ribera del Zinqueta, se encuentra Sarabillo, a la entrada del valle (Lasaosa/ Sarasa, 1999: 17-18; Blas/ Romanos, 2008: 192). Está rodeado por picos que pasan de 3.000 metros de altura: Lardana (3.369 m, oficialmente Posets), Bachimala (3.177), Cotiella (2.912), Punta Suelsa (2.972) o Culfreda (3.043 m), entre los más altos (Lasaosa/ Sarasa 1999: 18). 
En lo lingüístico, el chistabín - variedad local de aragonés - constituye el comienzo del aragonés oriental, de manera que se caracteriza por la frecuente sonorización de oclusivas sordas intervocálicas (frente al aragonés central, que tiende a conservarlas casi siempre, y el aragonés occidental que las conserva muy a menudo) y el uso del perfecto perifrástico (como en el valle de Benás y en Ribagorza, frente al resto del aragonés, que utiliza los perfectos sintéticos). ${ }^{1}$ Coincide con el belsetán (aragonés del valle de Bielsa) en gran parte del vocabulario, así como en el sistema de artículos determinados (el, la, es, las); con el benasqués o altorribagorzano en aspectos fonéticos, como la no pronunciación de la -r final (Nagore 2013a: 170-186).

\section{Autores oriundos del valle}

Primeramente analizaremos la obra de dos autores nacidos en el Valle de Chistau: Nieus Luzía Dueso Lascorz y Quino Villa. Estos son los únicos escritores oriundos del valle que tienen publicada una obra ya relevante y de cierta extensión, ${ }^{2}$ y que escriben en aragonés chistabín, es decir en la modalidad diatópica o dialectal de aragonés propia del valle, si bien con algunas pequeñas diferencias: Luzía Dueso es de Plan; Quino Villa es de Chistén (oficialmente Gistaín). Mientras Luzía Dueso utiliza un tipo de aragonés chistabín que tiene en cuenta todas las modalidades locales habladas en el valle, Quino Villa emplea un tipo de aragonés chistabín más localista, basado exclusivamente en el habla local de su localidad (y aun a veces, en el habla de su casa y de su familia). Por otra parte, Luzía Dueso incluye en sus escritos algunas formas genuinas aragonesas que ya se han perdido en el chistabín (como, por ejemplo: nuei 'noche', dica 'hasta'), mientras que Quino Villa no las admite, prefiriendo utilizar las formas castellanas o adaptadas del castellano (así, por ejemplo: noche, basta 'hasta').

En 1980 veía la luz Al canto'l Zinqueta. Poemas en chistabín, el primer libro redactado íntegramente en la modalidad local de aragonés del valle de Chistau, el chistabín. Y con él irrumpía con fuerza en la literatura en aragonés la voz inconfundible de una poetisa y narradora que desde entonces no cesó en sus aportaciones hasta su fallecimiento: Nieus Luzía Dueso Lascorz (1930-2010), natural de Plan (Bal de Chistau), que ejerció como maestra en diversas localidades del Alto Aragón. ${ }^{3}$ Su libro Al canto'l Zinqueta ('A la orilla del [río] Cinqueta') (Dueso 1980) recoge 25 poemas y supone la 
irrupción del valle de Chistau como materia literaria en la literatura en aragonés. Ya el título del libro nos sitúa en ese valle del noreste de Sobrarbe, que atraviesa el río Zinqueta. Y sus poemas, si bien tocan diversos temas - como tradiciones, leyendas populares y motivos religiosos -, destacan especialmente por la fuerza con que cantan la naturaleza del valle (Nagore 1980).

Entre los poemas que recogen tradiciones y leyendas populares destacan "A Santa Luzia de Señes" (9-13) y "La Orazión de una pastora de Plan" (24-26). En este último observamos varias referencias a microtopónimos del valle, que contribuyen decisivamente a situarnos en esa ubicación geográfica: "Puyalfá, La Selba, es campos de Lisé, / es pinás escurizos del Emprío... / con las güellas, al tarde, ¿tan diré, / si alí no y puedo'stare con el frío...? / Iré ta Pitiligüé, que en el Solano / las reses se me fartan y yo filo" (24).

Entre los que exaltan directamente la naturaleza del valle, destacan "Oda al río Zinqueta" (14-20) y "L'agüerro" (22-23). En ambos la autora hace uso de la prosopopeya: se personifican los elementos naturales, que nos hablan en primera persona, con sentida y remota voz. Son poemas descriptivos, en los que el paisaje es el protagonista indiscutible.

Leyendas de l’Alto Aragón se publicó en una primera edición (Dueso 1985) con 14 leyendas. La segunda edición (Dueso 2003b) incluye tres más. De esas 17 leyendas, 10 tienen como escenario el valle de Chistau y algunas tratan de explicar o justificar el nombre del paraje o del enclave. Así ocurre, por ejemplo, con la "La espluga de Mur Garzía”, "Leyenda del peu de la moncha”, "El Blinco'l Gabacho”, "El puen Pecador" o la "Leyenda de la Basa de la Mora, de Plan", quizá la que contiene más elementos mágicos. Precisamente, comienza con el conocido recurso literario que pone la narración en boca de una abuela tras la pregunta de la nieta:

-Yaya, ¿per qué le dizen a l'Ibón de Plan "La basa de la Mora"? -Una boz de mozeta, nerbiosa, curiosa y espresiba, rompe el silezio d'una bilada d'ibierno. (Dueso 2003b: 7).

La abuela explica que hay que subir al Ibón ${ }^{4}$ de "La Basa de la Mora" antes de que salga el sol, en la madrugada de San Juan, y lavarse la cara con el agua de la laguna: cuando sale el sol se puede ver la imagen reluciente de una mujer que danza sobre el 
agua. Dicen que es el alma de una princesa mora y solo pueden verla, precisamente en la madrugada del día de San Juan, los que tienen el corazón y los ojos limpios.

Marieta (Dueso 1991) es una novela corta que, tomando como excusa una historia de amor entre dos jóvenes del valle, aprovecha para relatar las costumbres y los modos de vida en el valle de Chistau antes de que la carretera lo pusiera en comunicación con la civilización externa. ${ }^{5}$ Incluye algunos poemas. Destaca: -la descripción del comienzo del verano en el valle, con la exuberancia de la vegetación y el corte de la hierba; -la noche de San Juan, con la falla (gran hoguera en la que los mozos de cada casa encienden las teas, que bajan corriendo desde el monte hasta el valle; es sin duda una fiesta de carácter ritual que celebra el solsticio de verano); -la boda, tal como se realizaba tradicionalmente, con todas sus costumbres y tradiciones. Como en otras obras de Dueso, se citan abundantes topónimos del valle: Lisé(r), Plan, Puen de la Suerz, Salitá de San Isteban, el Batán, la Sarra, Güerta de Ruen, Fatarillo, Chesta, San Mamés, San Chuan, Pitiligüé, Fuen de Saila, etc.

La fuen de la Siñora (Dueso 2003a) recuerda una vieja historia de hadas que ocurre en la la Fuen de la Siñora (Plan), de donde toma el título la novela. "Chunto a's dos protagonistas y a la fada, son es costumbres de la Bal y la bida tradizional en ella atros protagonistas importans." (Lerín 2012). Se puede clasificar, pues, en el género costumbrista, ya que se describen con detalle costumbres y tradiciones del valle: $l a$ mataziya del latón ('la matanza del cerdo'), es trucos de san Antón (el repicar de 'las esquilas' para san Antonio, el 17 de enero), el Carnaval, los bailes, la romería de la Birchen de la Plana, el esquileo del ganado, la subida el ganado a los pastos de altura, la siega, la trilla, las fiestas, los achustes ('capitulaciones matrimoniales'), etc., con detalladas descripciones de los vestidos de los novios, la ceremonia, la comida y la entrada de la novia en casa con su ajuar (Ríos 2007: 32-34).

Dios me'n guarde! (Dueso 2007a) es una historia de rivalidad entre dos mozos de Plan, ya que ambos persiguen los favores de la misma muchacha. Como en otras obras suyas, la autora recrea la vida tradicional en el valle de Chistau, aprovechando para destacar algunas labores o actividades propias de cada época. Así, por ejemplo, la fiesta mayor en septiembre (15-16), las coplillas en octubre (25-26). Lo dice expresamente en una nota final: 
Ista yera la bida tradizional en cualsiquier lugar de la montaña dica no fa güeires añadas. [...] L'azión trascurre en Plan, en la Bal de Chistau, perque es nombres de las chens, de las casas y de los puestos son ta yo más familiars,... (Dueso 2007a: 43)

Y en efecto, a lo largo de la obra aparecen referencias a casas como: casa Lorenzia, casa Casasnobas, casa Ruché, casa Buisán, Casa Bris,... A lugares del pueblo: plazeta Moliné, la Corzillada. Y a topónimos como: Es praus de la Suerz, Cásulas, Ruen, Fatarillo, Lasimierre, la Rambla de Turmo, Crabils, las Cometas,... Todos ellos nos sitúan en Plan.

Santamaría (Dueso 2007b) es un cuento costumbrista cuyo hilo conductor es el amor de dos jóvenes protagonistas, Chuaquín y Pilara. La acción transcurre en Plan entre la primavera y el otoño de 1800 (Dueso 2007b: 14). El prado llamado Santamaría es donde se desarrolla la historia y donde los protagonistas se hacen novios. Se hace referencia a muchos topónimos de Plan: l’Artigatiello, Pitarratons, La Corzillada, La Rambla Turmo, La Ribera, Pinantel, Crabils, La Fargueta, Barranco de las Cometas, Barranco d'el Chordonal, La Friolina, Puyalfar, etc. También se nombran algunas casas del pueblo: Camarasa, Sastre, Turmo, Grima, Rafeleta, Puyet, etc. A largo de la novela se mencionan las actividades propias de cada estación: la siembre, la siega de la hierba, la siega del trigo, la malla ('la trilla'): "Toz istos prozesos de a siembra, a siega u a malla son muito bien esplicatos con l'ochetibo de dar a conoxer a bida en a bal en ixos tiempos." (Escartín 2011-2012: 185). Se destacan también las fiestas del pueblo, se describen las comidas, la vida social en la Fuen de la Corzillada, etc. Como se ha indicado:

...con gran mayestría l'autora combina o tema d'o paso d'o tiempo -de primabera dica agüerrocon os temas costumbristas, como as autibidaz d'os cambos en ixas temporada, a bida en o lugar, as fiestas, as comidas, a toponimia, o doble treballo d'as mullers, as relazions entre mesaches e mesachas, emplegando un lenguache senzillo y prosimo a o leutor pa fer-nos beyer a bida en ixos tiempos. [...] A bida en ixos lugars yera e ye difízil, pero ye o suyo remero una miqueta ideyalizato. Antiparti, iste lenguache senzillo con o se fan as descrizions d'ixa naturaleza almirata por l'autora se bale d'imáchens plenas de colors e achetibos que nos dan toda una sensualidá que atresora ista obra. (Escartín 2011-2012: 186) 
La obra termina con este párrafo, que muestra muy bien la importancia que otorga la autora al recuerdo ligado a determinados sitios del valle, así como también ese tratamiento idealizado al que se refería Escartín:

Es dos, cuan podeban, se'n diban ta Santamaría. Aquel prau les trayeba asabelos recuerdos. Es más fondos de la suya bida. Allí se ban fer nobios y se ban querer y ban troballar fendo tantas cosas. La yerba, el rebasto, la siega, la malla, el replegar el trigo y trayer-lo ta casa. Santamaría yera el puesto de Plan an que, cuasi siempre sin querer, eban trasformau la suya bida en un canto a'l probenir que s'ubriba ta ellos en plena chobentú. (Dueso 2007b: 52-53)

Como se ve, todos los libros de Luzía Dueso están relacionados de una manera u otra con el valle de Chistau. No obstante, conviene advertir que también tiene obras, publicadas en revistas, que no tienen relación con el valle. Así, los numerosos poemas de Navidad (valgan como ejemplo Dueso, 1999 y Dueso, 2006) o las crónicas de viajes (sirvan de ejemplo Dueso, 2004-2005 y Dueso, 2007c).

Quino Villa (Joaquín Villa Bruned, Chistén, 1957), maestro, psicólogo y sexólogo, y autor de algunos vídeos etnográficos en aragonés chistabín, ha publicado una novela, Las zagueras trafucas de Marieta (Villa, 2005), de carácter introspectivo y psicológico, cuya acción transcurre en el valle de Chistén a mediados del siglo xix. Narra la historia de una mujer con unos poderes especiales, que a veces se acercan a lo sobrenatural. La historia se va desgranando en capítulos denominados trafucas: son los recuerdos desordenados de la protagonista en su lecho de enferma moribunda. De ahí el título: 'Los últimos extravíos de Marieta'. ${ }^{6}$ En estos recuerdos embarullados se nos van apareciendo fragmentariamente y como entre sueños, episodios de su vida y la magia y belleza del valle de Chistau, donde esta transcurre. Las alusiones a topónimos del valle son continuas: corona d'el Paco (p. 14), es lombardos más altizos de Chesta (18), la cabana de Chiradiello (p. 37), en las Esplanas (p. 116),

También en los nueve cuentos de este autor recogidos en Una tremenera de cuentez [literalmente, 'Una hilera larga de cuentecitos'] (Villa 2009), la acción suele transcurrir habitualmente en la localidad de Chistén, en el valle de Chistau, pues amplifican literariamente hechos o anécdotas ocurridos en este valle. Así, por ejemplo, el primer cuento, "La luceta Chansón" (Villa 2009: 12-43), comienza: "Nos trobán en 
Chistén. Corre la primavera de 1945...". Al comienzo de "El diario Sasé” (idem: 64-107) explica el autor: "Esto no ye mica un cuentet, que va pasare en de veras, a metá d'este siglo zaguere (en es veranos de 1944 y de 1945). [...] Él se diciba Quin, y yera de casa Sasé de Chistén. Quin de Sasé el gritaba la chen". En "Una mina d'incante" leemos: "Hoi mesmo, dimpués de cien años, en el lugare de Chistén encá se sientre la historia de la mina d'incante" (idem: 116). En "Una cheta de luminaria que ta qué" comienza: "Ta la Fiesta Gran de l’año 1914 va allegá la luminaria a Chistén. Aquela va está una feta que mereix un güen sitio en el ricuerdo de la tradición del lugá." (idem: 117). Y en "Un cuartal de mala indole: “Este cuento va pasare en Chistén per alí per l'año 1964, cuan la primera televisión va allegare al lugare, a una casa que feba de tabierna" (idem: 151). Una procesión de personajes locales -denominados por el nombre de pila y el nombre de la casa- van pasando ante nuestros ojos a lo largo de estos cuentos, que retratan a base de prolijos diálogos y en un tipo de lengua hipercoloquial, el ambiente de la vida diaria del pueblo, las anécdotas, las historietas y los hechos relevantes que se siguen recordando en las veladas después de mucho tiempo.

\section{Autores no oriundos del valle}

Aquí podemos incluir a los otros dos autores que estudiamos: Elisa Garzía Dealbert y Santiago Román Ledo. Ninguno de los dos es oriundo del valle, pero tienen relación con él, si bien, como vamos a ver, esa relación es muy distinta en cada caso.

Elisa Garzía Dealbert, nacida en 1964 en un pueblo de la provincia de Barcelona, está asentada en el valle de Chistau desde 1989, en donde ha desarrollado su vocación de escritora, habiendo publicado un único libro, La bal de la bida (1998). Se trata de uno de los pocos casos de escritores no aragoneses que escriben en aragonés. ${ }^{7}$

La bal de la bida ('el valle de la vida') es una novela que podríamos calificar como ecologista-futurista. Escrita en un aragonés chistabín aprendido, y por lo tanto a veces falto de la espontaneidad de quienes lo tienen como lengua familiar desde pequeños, nos sitúa cronológicamente en el año 2000, es decir, en un futuro (fue escrita en los años 90) en que el planeta tierra ha sufrido las consecuencias del efecto invernadero y ha quedado destrozado y convertidas en un yermo irrespirable las zonas más industrializadas y más densamente pobladas. La gente que todavía aguanta en esas 
zonas vive bajo tierra, como las hormigas, con sistemas artificiales de ventilación. No obstante, algunas personas han huido de ese caos y se han afincado en los montes, donde todavía se conserva el aire puro y la vegetación. Allí, trabajando la tierra o desarrollando oficios artesanales, viven en contacto con la naturaleza, siguiendo los ritmos que esta marca a lo largo del año, y construyendo una civilización donde los únicos valores son la convivencia, la solidaridad y el respeto a la vida. Sobreviven, pues, al desastre ecológico, y a partir de los pioneros se crea una raza fuerte y dura, de montañeses trabajadores que no temen al frío ni al calor, ni a la lluvia ni a la nieve.

Aunque la autora no lo dice de forma expresa, se puede deducir que esa tierra nueva de las montañas donde se asientan estos pioneros que huyen del caos lla bal a que se refiere el título) es el valle de Chistau. Y las zonas superpobladas e industrializadas que quedan destrozadas y difícilmente habitables son -se puede deducir- las tierras de Cataluña. Así, pues, el valle de Chistau aparece aquí como una especie de nuevo paraíso que sobrevive a la catástrofe ecológica. Y en ese enclave idílico, que se presenta como último vestigio de la naturaleza primigenia, se habla naturalmente- aragonés chistabín. En ese sentido, se trata de una referencia mítica.

Sin embargo, hay que advertir que en La bal de la bida casi todos los topónimos son inventados: Yoram (una ciudad de fuera del valle), la Casa d'el Caixigo, la Casa d'el Pin, Casa d'el Medico. Como excepción, se nombra la Peña Meyodiya y el Puen Pecador (Garzía Dealbert 1998: 73, 75), referencias inequívocas a la geografía del valle de Chistau. Los nombres de los personajes son también formas inventadas por la autora que suenan a idiomas extraños a nuestro entorno, otorgando un halo de exotismo a la narración: Danko y Ezna (los protagonistas), Trebec, Galena, Ebra, Aba, Nabur, Yorka, Zaco, Abom, Tron, Duan, Daren, Katan, Dalo, Lena, etc.

Santiago Román Ledo (1931-2014), aunque nacido en Ayerbe, pasó su niñez en la ciudad de Huesca. Estudió Magisterio en la Normal de Huesca y posteriormente, ya ejerciendo como maestro, obtuvo la Licenciatura en Filosofía y Letras. Trabajó como maestro en diversas localidades del Alto Aragón (entre otras, Plan, en ell valle de Chistau), en Vilanova i la Geltrú (Barcelona) y en Zaragoza, donde se jubiló. Falleció el 30 de noviembre de 2014 (Estabén 2013-2014: 179). Este autor ha escrito poesía y narrativa, aunque tal vez lo que le caracteriza más es su producción teatral. 
Rolde de broxas en Crenchafosca (Román 1986), que se publicó conjuntamente con No cal que te'n baigas, es una obra de teatro en tres actos basada en un cuento infantil con brujas pirenaicas. Los topónimos que hacen referencia a los lugares donde transcurre la acción son inventados: Crenchafosca (literalmente, 'cresta o loma oscura') puede ser el trasunto de Trasmoz (provincia de Zaragoza) o cualquier otro pueblo que posea un castillo con tradición de brujas. Pero las 17 brujas que componen el círculo (en arag. rolde) se denominan según el lugar de procedencia (en todos los casos, pueblos con tradición brujeril): así, por ejemplo, "Zapatierna d'Espierba”, "Cazcarria de Tella", "Lupera de Bara”, "Paquiza d'Ansó”, "Maut de Biescas”, “Garona de Turbó”, "Casca de Trasmoz" o "Fanchón de Tolosa", en Francia. Una de ellas se llama "Pauleta de Xistau". Y en relación con esto, llama la atención la forma de hablar: la obra está escrita en aragonés común, y las brujas se expresan en aragonés, más o menos matizado, pero Fanchón de Tolosa (de Toulouse) habla en francés y Pauleta de Xistau en aragonés chistabín:

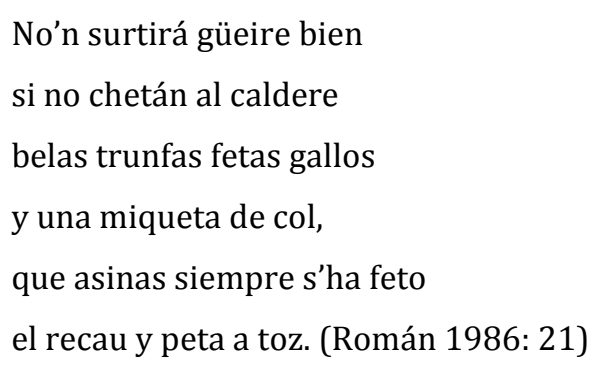

Aquí vemos, como características del aragonés chistabín (Mott, 1989; Nagore, 2013a: 170-186): güeire (frente a guaire), chetán (frente a chitamos), caldere (frente a caldero), belas (frente a bellas), fetas y feto (frente a feitas, feito).

No cal que t'en baigas (Román 1986) lleva por subtítulo Falordia de primabera en tres autos. Es una obra de teatro poético, una versión teatralizada de la narración del mismo título (Román 1983a). Ni en la versión narrativa ni en la teatral hay indicios seguros del escenario geográfico en que se sitúa. Escrita en aragonés común - como la mayoría de las obras de Santiago Román -, los datos lingüísticos no ofrecen ninguna pista. En todo caso, pueden confundir un poco, porque el personaje principal, así como toda su familia, son de "Casa Lo Mallau”, y el artículo lo es propio del aragonés del Valle de Echo, no del valle de Chistau (cf. Mott 1989: 59-60); pero, por otro lado, uno de los 
personajes se llama Mamés, y en el valle de Chistau existe una ermita dedicada a San Mamés. Además, uno de los pocos microtopónimos locales que se citan en la obra es $L a$ Selba: “Toz os días se cala Selba aíntro, me pienso que ta fer leña” (Román 1986: 41). “Pos agora, dende que i ha tornato no piensa qu'en í-se-ne ta la Selba" (idem: 62). No nos dice mucho, ya que La Selba 'El bosque' es un topónimo genérico, común en el Alto Aragón. No obstante, aparece también algún exotopónimo, que puede darnos una pista: “En Bañeras me feba güen estar, anque tasamén m'en daba cuenta” (idem: 42), expresa uno de los personajes femeninos, Petrina, después de estar una temporada trabajando en esa localidad y volver a su pueblo. Bañeras se refiere a Bagnères-de-Luchon, en el Alto Pirineo francés, a donde era tradicional que fueran a trabajar las mozas de los valles de Chistau y de Benasque.

En otra obra de teatro, Como as nabatas que baxaban por o río (Román 1993), tampoco hay referencias concretas al valle de Chistau. Escrita en aragonés común, indica al comienzo: "Semos en bel lugar de l'Alto Aragón". No hay en el texto de la obra otra identificación más exacta; solo podemos apreciar que se trata de un pueblo de alta montaña, pues los medios de vida son la ganadería ("Pronto baxará o bacumen de a montaña": 36) y la madera: dos de los protagonistas son almadieros (en arag. nabaters) y el título hace referencia a las gentes que se van de los pueblos pequeños de la montaña, río abajo como las almadías (en arag. nabatas). Pero la protagonista principal se llama Ardana, y esto puede constituir un dato interesante, ya que Lardana (aquí interpretado como L'Ardana) es el nombre que recibe en el valle de Chistau el monte oficialmente denominado Posets (3.369), segunda cumbre en altura del Pirineo, situado entre los valles de Chistau y de Benás (donde se denomina Llardana, con la característica palatalización ribagorzana de $l$ - inicial).

En las obras de narrativa el objeto directo -implícito o explícito- es el valle de Chistau, por lo que las referencias a este valle son continuas.

Cronicas d'Ardanau (Román 2010a) recoge las memorias escritas por un chico de 10 u 11 años de edad durante el curso escolar 1953-1954. Como nos explica el autor en la Porteta:

Bel nino ye l'autor de Cronicas d'Ardanau. Las escribió en l'añada escolar u curso 1953-1954, en bella traza de parlache aragonés y en bel lugar d'una bal d'o Pirineo. [...] Istas Cronicas no pas son 
de raso fruito d'a imachinazión. Muito de o que i se rezenta acayezió en ixe tiempo. L'autor esistió y encara bibe. [...] Feitos, nombres de personas, lugars, a Bal, tot, cuasit tot, ye en clau, pero ye reyal. Tamién i ha falordia, pero en ye como l'apaño d'un guisau, ta que siga más gustoso (Román 2010a: 7)

Así que el autor nos lo confiesa claramente: casi todo está en clave, pero es real. Ahora bien, esas memorias, salvadas del olvido, han sido enriquecidas con comentarios, realizados casi medio siglo después, en donde el autor contempla el mundo con la perspectiva que le otorgan los años. Vemos, por lo tanto, una confrontación entre un estilo literario infantil y otro más maduro y reflexivo; el contraste entre unas formas de vivir en un valle del Pirineo aragonés a mediados del siglo xx y otras de comienzos del siglo xxi; y, finalmente, que el texto del niño está escrito en aragonés chistabín y el del adulto, en aragonés común. Hay que suponer, por tanto, que el narrador adulto es quien estuvo de maestro en Plan (Bal de Chistau) en 1953-1953 y el narrador infantil, uno de sus alumnos (Nagore 2010b).

El autor nos indica en la introducción:

Iste libret quiere estar, tamién, un omenache a ixas bals d'o Pirineo aragonés e a ixas redoladas oblidatas u lo que ye encara pior, inoratas, que si no i son buedas de tot, amortatas de raso, ban perdendo poblazión e con era o suyo ser, o que las feba ser eras: os suyos costumbres, o suyo dialeuto, ban perdendo a sustanzia mesma... [...] ...bel omenache á puestos e tierras como a Bal de Lierp, a Bal de Bardaxín, La Comuna de Chistau, A Fueba, a Bal de Puertola, a Bal de Bio, A Solana, Sobrepuerto, a Bal de Basa, A Guarguera, A Garzipollera e atros más. (Román 2010a: 8).

Como vemos, las referencias podían ser muchas. Pero sabemos que el autor estuvo de maestro en Plan (Bal de Chistau) entre 1953 y 1956, aproximadamente; el texto del niño está en aragonés chistabín; y finalmente, las referencias toponímicas nos sitúan en ese valle. Comenzando por el título, Ardanau es una creación del autor: se puede explicar a partir de Ardana (Lardana 'pico de Posets', interpretado como L'Ardana), más el sufijo - au tomado del nombre del valle, Chistau < gesta be, una etimología que puede explicarse como 'debajo de Chesta' o 'bajo Chesta', siento Chesta < gesta una gran partida de prado situada entre los pueblos de Plan y de Chistén (oficialmente, Gistaín) y be 'bajo, debajo de’, una voz de origen prerromano vascón. Y a 
lo largo del libro, a pesar de que el autor no quiere desvelar el pueblo al que se refiere, hay referencias a topónimos locales que nos confirman que se trata de Plan. Quizá algunos topónimos son inventados, como Fenegrán 'Prado grande' o San Chulián -que esconde la referencia a San Chuan [de Plan]-8, pero otros son reales, como La Selba, Liser, Peña Medodía, Fueba u San Mamés, como el mismo autor nos confirma después (Román 2014a: 35-36).

Y de ese valle, que podemos identificar con el valle de Chistau, dice el autor: "alí se bibiba como en l'Arcadia feliz" (Román 2010a: 37). Pero el contraste es inmediato: “D’Arcadias ya no en quedan. Puestos, redolatas e lugars olbidatos, sí, beluns masiau olbidatos." (Román 2010a: 38). Más adelante, entre las reflexiones del autor adulto encontramos esta, muy significativa:

Cuan Pepín y Ánchel baxaban dende Ardaniés ta o suyo lugar esen podiu almirar l'ambiesta. Eban de pasar muitos años ta que Pepín, lexos d'o suyo lugar, lexos d'a suya Bal, plegase a tener conzenzia d'a fermosura, grandeza, que'n i ha en ixe gran anque reduziu mundo, mundo espezial entre totas as bals abitatas d'o Pirineo. (Román 2010a: 55).

Como escribíamos con ocasión de la publicación de este libro:

En definitiba, iste libro constituye una singular aportazión literaria: ye un libro de memorias, pero puede capir-se tamién como una mena de nobela, en a que tien muita importanzia a güellada antropolochica enta una reyalidá concreta d'un lugar pirinenco á metá d'o sieglo XX. Escrito con gran senzillez, pero a o mesmo tiempo con gran sensibilidá, dixa una solata de tranquilidá e de reflesión serena, pero tamién de malinconía, como si estase a cronica d'un paradiso perdito que s'entrefila por entre as boiras d'o tiempo. (Nagore 2010b).

Arribo en Chistau. Plan 1953 (Román 2014a) está dedicado explícitamente al valle de Chistau. Como resume Chulia Ara (2015): "Este es un libro que muestra el amor del autor por la Bal de Chistau y el lugar de Plan, donde llegó como maestro en 1953."

La primera parte, "Astí allá de la memoria” ('un poco más allá de la memoria') está escrita en aragonés chistabín y en ella nos trasmite los sentimientos y emociones a su llegada al valle: “Agora querrí manifestar, dezir de bela traza, las sensazions, las emozions, que aquella bal en que remataba d'arribar diban a despertar, yeran despertando, a’l mío esprito." (Román 2014a: 7). 
La segunda parte está redactada en aragonés común: “'Plan 1953' (el capitulo II más lo que sigue) ye feto en aragonés común, en bel intento de que siga más cheneral, ta más aragoneses y ta atra chen que querese leyer-lo, que se interese per Plan y per las luengas neolatinas." (Román 2014a: 12).

He aquí un buen resumen de la temática del libro:

Un choben mayestro plega ta la Bal de Chistau en 1953 ta tomar posesión d'o suyo puesto de treballo. A grandaria d'o paisache, e a polida naturaleza d'a bal l'enluzerna. Ista ye a istoria d'ixa impresión. Ye a memoria de aquers diyas e d'aqueras añadas en una bal paradisiaca. Acordanzas e impresions que se reflexan tanto en as suyas descrizions literarias como en as imáchens: fotografías e pinturas feitas por l'autor e qu'alzan un tiempo que ya no tornará. (Estabén 20132014: 180).

En la segunda parte, titulada "O lugar", realiza una descripición del pueblo de Plan, de sus calles, casas y edificios principales, según los recuerdos de 1953. Incluye un repertorio de nombres de casas (“Oiconimia”) y otro de toponimia. Finalmente, “Ambiestas e intes d'ayer en Chistau” reproduce 23 fotografías, la mayoría realizadas en los años 50, enriquecidas con los comentarios del autor. Tiene, pues, este libro un carácter más documental y menos literario que el anterior. El objeto principal del libro es el pueblo de Plan (Bal de Chistau), tal como estaba en 1953, como si las imágenes se hubieran quedado congeladas en la memoria. Tal como escribe el autor:

M’espresaré en tiempo presén, pero estará un tiempo presén trasladato ta 1953. Gran parti d'o lugar agora ye nueba, e más que más ye diferén a manera d'entender a bida. A chen ya ye atra; beluns quedan d'aquer tiempo, quedamos, pero ya en somos poquez, e biellos (Román 2014a: 16).

La obra poética de Santiago Román Ledo está dispersa en revistas o libros colectivos También en ella resuenan los ecos de la Bal de Chistau: así, en el poema "Fieriza montaña" (Román 1983b), escrito en aragonés chistabín, hace referencia a la casa d'Arián, de Plan; ${ }^{9}$ en otros, a la escritora Luzía Dueso (Román 2010b) o a la mujer chistabina en general (Román 2104b). 


\section{Conclusiones}

Constatamos que la presencia del valle de Chistau es constante en los escritores oriundos del valle (Luzía Dueso, Quino Villa), cuyas obras están escritas en el aragonés local (chistabín). Pero igualmente observamos que autores no nacidos en el valle y que escriben en chistabín (Elisa Garzía) o tanto en chistabín como en aragonés común (Santiago Román) utilizan también el valle de Chistau como materia literaria Y tanto en unos como en otros, el valle aparece idealizado o mitificado, como si fuera un paraíso desde el punto de vista del paisaje o, incluso, desde el punto de vista social. Las conclusiones que podemos explicitar son: 1) el valle de Chistau es una materia frecuente en la literatura en aragonés; 2) predomina una visión idealizada del valle, tamizada por el recuerdo o la nostalgia.

\section{Bibliografía}

Ara Oliván, Chulia (2015), Santiago Román Ledo (Ayerbe, 1931-Zaragoza, 2014). Guía de lectura. Zaragoza, Rolde de Estudios Aragoneses. [Folleto sin ISBN; Depósito Legal: Z252-2015].

Benítez Marco, Ma Pilar (2010a), María Moliner y las primeras estudiosas del aragonés y del catalán de Aragón, Zaragoza, Rolde de Estudios Aragoneses.

-- (2010b), “Nieus Luzía Dueso Lascorz”, Fuellas, 195-196 (chinero-abril 2010): 14-15.

Blas Gabarda, Fernando/ Romanos Hernando, Fernando (2008), Diccionario aragonés: chistabín castellano (Bal de Chistau), Zaragoza, Gara d'Edizions/ Institución "Fernando el Católico". 
Calvo Carilla, José Luis (2013), "Visiones literarias de Los Monegros (imágenes contemporáneas de un mito literario", Archivo de Filología Aragonesa, 69 (2013): 117140.

Dueso Lascorz, Nieus Luzía (1980), Al canto'l Zinqueta, Uesca, Publicazions d'o Consello d'a Fabla Aragonesa.

-- (1985), Leyendas de l'Alto Aragón, Uesca, Publicazions d'o Consello d'a Fabla Aragonesa, col. "Serie cheneral en aragonés".

-- (1991), “Marieta”, Fuellas, 84 (chulio-agosto 1991): 10-24.

-- (1999), “Ya cantan las fuens", Luenga \& fablas, 3 (1999): 123-128.

-- (2003a.), La fuen de la siñora, Uesca, Publicazions d'o Consello d'a Fabla Aragonesa, col. "Serie cheneral en aragonés", 71.

-- (2003b), Leyendas de l'Alto Aragón [Segunda edición ampliada], Uesca, Publicazions d'o Consello d'a Fabla Aragonesa, col. "A tuca".

-- (2004-2005), “Un Biache per Noruega”, Luenga \& fablas, 8-9 (2004-2005): 131-140.

-- (2006), “Zielos de Belén”, Fuellas, 176 (nobiembre-abiento 2006): 34.

-- (2007a), Dios me’n guarde! [Edición bilingüe aragonés-catalán], Uesca, Publicazions d'o Consello d'a Fabla Aragonesa, col. "A tuca”, 7.

-- (2007b), Santamaría. Cuento chistabino [Edición bilingüe aragonés-castellano], Huesca, Instituto de Estudios Altoaragoneses, col. "Letras del Año Nuevo”.

-- (2007c), “Biache a Portugal”, Luenga \& fablas, 11 (2007): 213-222.

Escartín Santolaria, Ana (2011-2012), “Santamaría, de Nieus Luzía Dueso Lascorz”, Luenga \& fablas, 15-16 (2011-2012), pp. 184-186.

Estabén Laguía, Tresa (2013-2014), “A obra narratiba de Santiago Román Ledo. Notas con a enchaquia d'a publicazión de Arribo en Chistau", Luenga \& fablas, 17-18 (20132014), pp. 179-184.

Fuellas. Publicación bimestral en aragonés de cultura, lengua y literatura. Huesca, Consello d'a Fabla Aragonesa, desde 1978. 
Garzía Dealbert, Elisa (1998), La bal de la bida, Zaragoza, Ligallo de Fablans de l'Aragonés, col. "Rampallo".

Lasaosa, Miguel / Sarasa, Juan Carlos (textos) y Ortega, Miguel (ilustraciones) (1999), Chistau en la memoria, Lafortunada (Huesca), Mancomunidad del Valle de Chistau.

Lerín Gabás, Óscar (2012), “La fuen de la Siñora, de Nieus Luzía Dueso”, Fuellas, 210-211 (chulio-otubre 2012), p. 33.

Luenga \& fablas. Publicación anual de estudios y documentación sobre el aragonés y su literatura. Huesca, Consello d'a Fabla Aragonesa, desde 1997.

Mott, Brian (1989), El habla de Gistaín. Huesca, Instituto de Estudios Altoaragoneses.

Mott, Brian (2000), Diccionario etimológico chistabino-castellano / castellano-chistabino. Zaragoza, Institución "Fernando el Católico".

Nabarro, Chusé Inazio (2008-2009), “Os Monegros como tema literario en a poesía en aragonés", Luenga \& fablas, 12-13 (2008-2009), pp. 189-200.

Nagore Laín, Francho (1980), “Reseña de Al canto'l Zinqueta”, Fuellas, 19 (setiembreotubre 1980), pp. 3-4.

Nagore Laín, Francho (2010a), "Nieus Luzía Dueso Lascorz (1930-2010): bellas notas biograficas e amanamiento á una bibliografía d'as suyas obras en aragonés", Fuellas, 195-196 (chinero-abril 2010), pp. 16-19.

Nagore Laín, Francho (2010b), “Cronicas d'Ardanau. de Santiago Román Ledo”, Fuellas, 198-199 (chulio-otubre 2010), p. 28.

Nagore Laín, Francho (2013a), Lingüistica diatopica de l'Alto Aragón. Cómo ye l'aragonés de cada puesto: carauteristicas, bibliografía, testos, mapas. Uesca, Publicazions d'o Consello d'a Fabla Aragonesa, col. "A tefla de cuatro fuellas", 8.

Nagore Laín, Francho (2013b), "Repertorio de publicazions unitarias no periodicas en aragonés (1971-2013)", in López Susín, J. I. (coord.), El aragonés en el siglo XXI. Informe, Zaragoza, Fundación Gaspar Torrente, pp. 89-143.

Ríos Nasarre, Paz (2007), "Antropolochía e costumbrismo en a narratiba autual en aragonés", Luenga \& fablas, 11 (2007), pp. 29-41. 
Román Ledo, Santiago (1983a), “No cal que te’n baigas (Falordia de primabera)”, in II Premio Literario "Val d'Echo" (1983), Uesca, Publicazions d'o Consello d'a Fabla Aragonesa, pp. 33-44.

Román Ledo, Santiago (1983b), "Fieriza montaña", in II Premio Literario "Val d'Echo" (1983), Uesca, Publicazions d'o Consello d'a Fabla Aragonesa, pp. 57-61.

Román Ledo, Santiago (1986), Rolde de broxas en Crenchafosca / No cal que t'en baigas. Uesca, Publicazions d'o Consello d'a Fabla Aragonesa.

Román Ledo, Santiago (1993), Como as nabatas que baxaban por o río. Teruel, Colla de Fablans d'o Sur. [Se publica en el número monográfico de la revista Ruxiada, 16-17].

Román Ledo, Santiago (2010a), Cronicas d'Ardanau. Uesca, Publicazions d'o Consello d'a Fabla Aragonesa, col. "A tuca”, 9.

Román Ledo, Santiago (2010b), “A Luzía (+ 4 marzo 2010)”, Fuellas, 195-196 (chineroabril 2010), pp. 13-14.

Román Ledo, Santiago (2014a), Arribo en Chistau. Plan 1953. Uesca, Publicazions d'o Consello d'a Fabla Aragonesa, col. "A tuca”, 11.

Román Ledo, Santiago (2014b), “Chistabina”, Fuellas, 221-222 (mayo-agosto 2014), p. 23.

Villa, Quino (2005), Las zagueras trafucas de Marieta. Zaragoza, Xordica Editorial, col. "Simién negra", 13.

Villa, Quino (2009), Una tremenera de cuentez. Zaragoza, Xordica Editorial, col. "Simién negra", 19. 
Francho Nagore Laín (Zaragoza, 1951). Doctor en Filología Románica y profesor titular del área de Lengua Española en la Universidad de Zaragoza (Campus de Huesca). Fue presidente del Consello d'a Fabla Aragonesa (1978-2004). Director de las revistas en aragonés Fuellas (desde 1978), Luenga \& fablas (1997), en el campo de la filología; Revista de Gestión Pública y Privada (1996), en el campo de las Ciencias Sociales. Director del área de Lengua y Literatura del Instituto de Estudios Altoaragoneses (19862014). Autor de libros de poesía en aragonés: Sospiros de l'aire (1971), Cutiano agüerro (1977), Purnas en a zenisa (1984), Baxo a molsa (1999). Y de traducciones de poesía al aragonés: Libertá, de Paul Eluard (1977), Triga breu, de Ángel Crespo (1996), O fosal marino, de Paul Valéry (1998), In nuce, de Hèctor Moret (2005). En narrativa: Filorchos d'o zaguer curso en Gabardiés (coordinador y coautor, 2011). Entre sus estudios se pueden destacar los libros: Gramática de la lengua aragonesa (1977; 5aa ed., 1989), El aragonés de Panticosa (1986), Replega de testos en aragonés dialeutal de o sieglo XX (1987), Os territorios lingüisticos en Aragón (2001), El aragonés del siglo XIV según el texto de la Crónica de San Juan de la Peña (2003), Lingüistica diatopica de l'Alto Aragón (2013). Editor, coordinador o director de más de una docena de libros, como: Endize de bocables de l'aragonés (4 tomos, 1999), Luengas menazatas y normalizazión (1999, junto con Pilar Puig), Homenaje a Rafael Andolz (2000), 200 escritors en aragonés en 200 Fuellas (1978-2010) (2011), Diccionario aragonés (anónimo de hacia 1805; conjuntamente con Chesús Bernal). Es desde 2011 Director del Diploma de Especialización en Filología Aragonesa, título propio de la Universidad de Zaragoza que se imparte en la Facultad de Ciencias Humanas y de la Educación (Campus Universitario de Huesca). 


\section{Notas}

1 Precisamente en el valle de Chistau está la divisoria entre las dos zonas: en Sarabillo y los pueblos de La Comuna se usan los perfectos sintéticos, como trobón 'encontraron', fayé 'hice'; en Plan, San Chuan y Chistén se emplean los perfectos perifrásticos, como ban trobá 'encontraron', boi fer 'hice' (Nagore 2013a: $51-55,170)$.

2 Según nuestro repertorio de publicaciones en aragonés (Nagore 2013b), Quino Villa tiene dos libros publicados, mientras que Luzía Dueso aparece en él con seis registros. Se vea también relación de obras de Luzía Dueso en Nagore (2010a).

${ }^{3}$ Sobre la vida y la obra de Nieus Luzía Dueso Lascorz puede verse: Benítez (2010a: 219-228), Benítez (2010b), Nagore (2010a).

${ }^{4}$ Ibón 'laguna de alta montaña' es una voz de origen prerromano, procedente de *ibone, como el vasco ibai 'río' (Mott, 2000: 156). Común en el Pirineo aragonés con este significado, en el Prepirineo y Somontanos, donde no hay lagos de origen glaciar, designa un manantial que brota del suelo.

${ }^{5}$ En 1918 la carretera alcanzó Sarabillo; en 1930 llegó a Plandescún; hasta 1952 no llegó a Plan (Lasaosa / Sarasa 1999: 66).

${ }^{6}$ Blas/Romanos (2008: 500, s.v.) traducen trafuca por 'confusión, lío, desorden'.

7 Otros casos notables son el del valenciano (aunque de familia de orígenes aragoneses) Chusé Carlos Laínez, que tiene cinco libros publicados en aragonés (Nagore 2013b: 118), o el del tarraconense Ferrán Marín i Ramos, que tiene un libro publicado en aragonés (Nagore 2013b: 120).

${ }^{8}$ Escribe el niño en sus memorias: "Como es chuebes de tardes ye fiesta en la escuela eban alcordau con Pepe Luchón y Manolo Chaime dir ta San Chulián, que i guera la feria. D’el nuestro lugar ta San Chulián se'n ban asta las gallinas. Asinas de zerca son es dos lugars.” (Román 2010a: 25). Al respecto, Blas / Romanos (2008: 309, s. v. gallina) recogen el siguiente dicho: “De Plan ta San Juan las gallinas i ban”, con la variante: “De San Juan ta Plan las gallinas se'n ban”. Y hacen el siguiente comentario: “Indica la distancia corta entre estos dos sitios, debido a los escasos 900 metros que separan ambos núcleos de población".

${ }^{9}$ Santiago Román (2014a: 11) recuerda a Luzía Dueso Lascorz, “que aquer diya, el de la mía arribada, me ba acompañar con belatras personas ta tratar de trobar casa, una familia, aón agüespedar-me, que a la fin ba estar casa Arián." 


\title{
Les mouvements des personnages dans Les Rougon-Macquart
}

\author{
Minori Noda \\ Doctrant de l'Université Paris III - Sorbonne Nouvelle
}

Résumé: Dans Les Rougon-Macquart d'Émile Zola, dont les scènes se distribuent entre Paris et les villes régionales, les protagonistes se déplacent d'une ville à l'autre, ou d'un endroit à l'autre dans une ville. Ces déplacements peuvent être considérés non seulement comme phénomènes historiques de la réalité sociale de l'époque, à savoir le Second Empire dans lequel il y eut des mouvements de la population grâce au développement du chemin de fer et à l'urbanisme haussmannien, mais aussi comme une sorte de programme de narration qui nécessite les points de vue des personnages regardant les paysages à la fois urbains et régionaux pour décrire les espaces romanesques.

Ainsi la question du déplacement dans les œuvres romanesques de Zola permet-elle de réfléchir sur la correspondance entre les personnages et les espaces de même que sur la cartographie dans ses œuvres romanesques. De plus, à travers cette réflexion, il s'agit également d'une autre problématique génétique: comment les espaces romanesques sont fabriqués dans ce cycle romanesque? Nous mettrons ici en lumière une relation entre la fiction et l'histoire dans un cas du roman du XIXe siècle, en même temps qu'une possibilité de la géocritique des œuvres zoliennes.

Mots-clés: Zola, géocritique, roman, fiction.

Resumo: Em Les Rougon-Macquart de Émile Zola, cujas cenas se distribuem entre Paris e as cidades regionais, os protagonistas deslocam-se de uma cidade para outra, ou de um lugar para outro numa cidade. Estas deslocações podem ser entendidas não só como fenómenos históricos da realidade social da época, ou seja, o Segundo Império em que houve movimentos da população através do desenvolvimento do caminho de ferro e do urbanismo haussmaniano, mas também como uma espécie de programa de narração que exige que os pontos de vista das personagens observando as paisagens simultaneamente urbanas e regionais para descrever os espaços romanescos. 
Assim, a questão da deslocação nas obras romanescas de Zola permite refletir sobre a correspondência entre as personagens e os espaços, bem como sobre a cartografia das suas obras romanescas. Além disso, através desta reflexão, também se aborda de outra problemática genética: como espaços romanescos são fabricados neste ciclo romanesco? Destacar aqui uma relação entre a ficção e a história num caso de romance do século XIX, bem como uma possibilidade da geocrítica das obras zolianas.

Palavras-chave: Zola, geocrítica, romance, ficção.

\section{Introduction}

Comme la théorie zolienne du roman le montre bien, la correspondance entre l'homme et la nature est un des objets principaux de l'analyse que l'auteur pratique dans ses œuvres romanesques. Dans un article intitulé "Deux définition du roman", Zola définit le roman comme suit: "le roman est un traité d'anatomie morale, une compilation de faits humains, une philosophie expérimentale des passions. Il a pour but, à l'aide d'une action vraisemblable, de peindre les hommes et la nature dans leur vérité" (Zola 2004: 97).

Dans cette définition, qui nous semble bien inspirée de la pensée de Balzac, on peut remarquer que c'est "à l'aide d'une action vraisemblable" que l'écrivain cherche la vérité romanesque dans la représentation de la relation humaine dans la nature.

Ce mot "action", qui signifie à la fois l'intrigue et l'activité physique, nous fait penser que Zola cherche toujours la vraisemblance à travers les mouvements des personnages qu'il met en scène dans ses expériences romanesques.

Ainsi la troupe de noce de Gervaise, l'héroïne de L'Assommoir, et son mari, font une promenade ambulatoire dans la ville de Paris et visitent le musée de Louvre au chapitre III de ce roman:

Puis, la noce se lança dans la longue galerie où sont les écoles italiennes et flamandes. Encore des tableaux, toujours des tableaux, des saints, des hommes et des femmes avec des figures qu'on ne comprenait pas, des paysages tout noirs, des bêtes devenues jaunes, une débandade de gens et de choses dont le violent tapage de couleurs commençait à leur causer un gros mal de tête. M. Madinier ne parlait plus, menait lentement le cortège, qui le suivait en ordre, tous les cous tordus 
et les yeux en l'air. Des siècles d'art passaient devant leur ignorance ahurie, la sécheresse fine des primitifs, les splendeurs des Vénitiens, la vie grasse et belle de lumière des Hollandais. (...) Peu à peu, pourtant, le bruit avait dû se répandre qu'une noce visitait le Louvre; (...) Et la noce, déjà lasse, perdant de son respect, traînait ses souliers à clous, tapait ses talons sur les parquets sonores, avec le piétinement d'un troupeau débandé, lâché au milieu de la propreté nue et recueillie des salles (Zola, 1960-1967: t. II, 445-446).

Dans ce passage assez ironique, puisqu'il décrit l'ignorance de ce cortège, sorti de son quartier populaire pour visiter le musée pour la première fois, on peut imaginer leurs pas assez rapides à travers l'énumération des tableaux qui passent devant les yeux des personnages et la fatigue qui en résulte.

On peut retrouver dans ce passage, d'un côté le mouvement physique, le déplacement des personnages dans le musée, suivi par la promenade dans la ville, et de l'autre côté leur mouvement psychique ou émotionnel.

Dans le système des personnages zoliens, on peut remarquer un effet de mouvement, soit pour l'économie de narration, soit pour la description des paysages représenté dans les romans, avec certains passages dans lesquels les protagonistes se déplacent d'un endroit à l'autre.

Dans ce sens, il est intéressant d'analyser ce phénomène de mouvement dans Les Rougon-Macquart qui se déroule principalement sous le Second Empire. Il est d'autant plus significatif que ce cycle romanesque se base sur la réalité historique et les mœurs de l'époque, dont les sources sont la lecture de documents chez Zola, et les dossiers préparatoires qui en résultent. ${ }^{1}$

Pour réfléchir sur cette problématique, nous allons distinguer les types de lieux dans ce cycle romanesque zolien, et puis démontrer la structure, le mécanisme, et la composition des espaces romanesques de l'écrivain.

\section{Typologie des lieux chez Zola}

Il s'agit tout d'abord de la représentation de Paris dans Les Rougon-Macquart, car la capitale du XIX siècle fait figure de protagoniste essentiel dans ces romans, étant le décor et souvent l'acteur de presque la moitié des principales scènes. Le Paris des Rougon-Macquart est saisi par le romancier à l'époque d'un développement industriel et 
économique inouï: l'inauguration du chemin de fer, la spéculation, l'avènement de la société bourgeoise, l'apparition des classes laborieuses, en sont les principaux aspects, que la fiction romanesque investit. Ces sous-thèmes ne sont pas dissociables du thèmematrice, Paris, la ville moderne. Il n'est donc pas sans intérêt de se demander comment se forme le drame humain dans cet espace privilégié.

Dans cet article nous allons réfléchir tout d'abord sur les mouvements des personnages dans la ville de Paris. Pour cela, il sera intéressant de traiter La Curée et Le Ventre de Paris car, dans ces deux romans, on peut y remarquer et en dégager de nombreux déplacements soit en voiture, soit à pied, ainsi que des promenades sentimentales, émotionnelles, et artistiques, avec les ressentis de l'espace parisien des protagonistes.

\section{L'incipit symbolique de La Curée - la poétique du paysage}

Dans La Curée, deuxième volume des Rougon-Macquart, on peut remarquer dès le début une description du paysage crépusculaire de la ville de Paris. L’héroïne, qui est la jeune épouse d'un spéculateur, est en train de retourner à son hôtel, du côté du parc Monceau du Bois de Boulogne, dans la voiture à cheval avec son beau-fils:

Le soleil se couchait dans un ciel d'octobre, d'un gris clair, strié à l'horizon de minces nuages. Un dernier rayon, qui tombait des massifs lointains de la cascade, enfilait la chaussée, baignant d'une lumière rousse et pâlie la longue suite des voitures devenues immobiles. Les lueurs d'or, les éclaires vifs que jetaient les roues semblaient s'être fixés le long des rechampis jaune paille de la calèche, dont les panneaux gros bleu reflétaient des coins du paysage environnant. Et, plus haut, en plein dans la clarté rousse qui les éclairait par derrière, et qui faisait luire les boutons de cuivre de leurs capotes à demi pliées, retombant du siège, le cocher et le valet de pied, avec leur livrée bleu sombre, leurs culottes mastic et leurs gilets rayés noir et jaune, se tenaient raides, graves et patients, comme des laquais de bonne maison qu'un embarras de voitures ne parvient pas à fâcher. Leurs chapeaux, ornés d'une cocarde noire, avaient une grande dignité. Seuls, les chevaux, un superbe attelage bai, soufflaient d'impatience (Zola 1960-1967: t. I, 319).

Cet incipit du roman, dans un contexte d'haussmannisation et qui raconte la vie bourgeoise et mondaine des protagonistes, s'ouvre par le spectacle du défilé des voitures à cheval. Sous un effet de lumière automnale, ce spectacle est censé être conduit 
par le regard de l'héroïne, à savoir Renée, femme du héros, Aristide Rougon, speculateur parvenu. En effet, les phrases sur les mouvements des yeux de l'héroïne se répètent avant que ne s'introduise une autre description que nous verrons après sept pages de l'édition de la bibliothèque de la Pléiade. ${ }^{2}$

À la fin de cette répétition du mouvement des yeux de l'héroïne, qui est saturée de la vie mondaine et du paysage dans lequel on voit à travers son regard l'embouteillage des voitures qui symbolisent la société bourgeoise du Seconde Empire, on trouve la description du paysage lointain:

\footnotetext{
Au-dessus de ce lac immobile, de ces futaies basses, de ce point de vue si singulièrement plat, le creux du ciel s'ouvrait, infini, plus profond et plus large. Ce grand morceau de ciel sur ce petit coin de nature, avait un frisson, une tristesse vague ; et il tombait de ces hauteurs pâlissantes une telle mélancolie d'automne, une nuit si douce et si navrée, que le Bois, peu à peu enveloppé dans un linceul d'ombre, perdait ses grâces mondaines, agrandi, tout plein du charme puissant des forêts (idem: 326. Nous soulignons).
}

Comme le montre bien la deuxième phrase dans cette citation, on peut remarquer qu'il y a dans cette description une projection sur le paysage regardé des sentiments de l'héroïne, qui est entourée, en haut de ce premier chapitre, de "pétillement des harnais et des roues" et d'“un grondement sourd, continu, rythmé par le trot des attelages" (idem: 321) et des vues des gens du monde qui se trouvent dans les autres voitures autour de la sienne. Renée, l'héroïne de ce roman, qui s'assied dans la voiture avec son beau-fils Maxime, avec qui elle aura une relation amoureuse et incestueuse, s'ennuie de ce spectacle assez mondain qui lui fait pressentir son destin tragique.

En fait, la citation suivante est considérée comme une sublimation poétique des sentiments de l’héroïne qui sera abandonnée non seulement de son mari mais aussi de son amour Maxime:

Renée, dans ses satiétés, éprouva une singulière sensation de désirs inavouables, à voir ce paysage qu'elle ne reconnaissait plus, cette nature si attristement mondaine, et dont la grande nuit frissonnante faisait un bois sacré, une de ces clairières idéales au fond desquelles les anciens dieux cachaient leurs amours géantes, leurs adultères et leurs incestes divins. Et, à mesure que la calèche s'éloignait, il lui semblait que le crépuscule emportait derrière elle, dans ses voiles 
tremblants, la terre du rêve, l'alcôve honteuse et surhumaine où elle eût enfin assouvi son cœur malade, sa chair lassé (ibidem).

Comme on voit bien jusqu'ici, la description du paysage crépusculaire du début de ce deuxième épisode des Rougon-Macquart met en correspondance les sentiments de l'héroïne avec le paysage regardé par celle-ci tout en décrivant le monde et la réalité de la société bourgeoise en tant que le décor de l'histoire. Dans ce processus appartenant à la poétique du roman, au cours duquel sont décrits les mouvements des personnages avec des effets non seulement de la lumière mais aussi du son, trouve donc un exemple topologique à travers une figure féminine de Zola.

\section{La Flânerie dans Les Halles du Ventre de Paris - autour de l'art et de la politique}

Prenons un deuxième exemple de description du paysage urbain dans les Rougon-Macquart, celle des "Halles" faite dans Le Ventre de Paris, troisième œuvre de ce cycle romanesque. Cette construction moderne en fer et verre a attiré l'attention de notre auteur. En fait, pour l'étape préalable à la rédaction du roman, il a fait des enquêtes dans ce lieu central de son histoire, et nous en laissera des manuscrits textuels et cartographiques des Halles. On ne peut pas ignorer que non seulement les "Halles" montrent beaucoup d'aspects qui correspondent à la technique de la description zolienne et à la relation entre les personnages, mais aussi et surtout que la représentation de cet espace moderne se base sur l'enquête, dirait-on, ethnographique de l'auteur. ${ }^{3}$

Ce troisième volume des Rougon-Maqcuart s'ouvre sur l'arrestation par erreur après le coup d'État du 2 décembre 1851, de Florent, le héros du roman, qui vient de s'évader du bagne de Cayenne après sept ans d'épreuves. Il retrouve à Paris son demifrère marié à la belle Lisa Macquart et qui fait prospérer l'opulente charcuterie Quenu Gradelle. Les époux l'accueillent de bon cœur, mais Florent, que le régime du bagne et une évasion au péril de sa vie ont amaigri, se sent dépaysé dans son existence avec les Quenus installés dans la charcuterie, où ils vivent en paix. Bientôt, il accepte une place d'inspecteur à la marée et se charge d'instruire un fils de Louise Méhudin, surnommée "la belle Normande", poissonnière aux Halles et rivale de Lisa. Et alors qu'il se laisse prendre dans la rivalité entre Lisa et la Normande, il se lie avec des membres du groupe 
Gavard, un marchand de volailles des Halles qui regarde Napoléon III comme son ennemi personnel. Florent se prépare à attaquer le Palais-Bourbon et l'Hôtel de Ville, quand, avec la complicité du quartier, on l'arrête. Il est condamné une seconde fois à la déportation.

Dans cette œuvre, le lecteur voit d'abord les Halles selon l'aspect qu'elles offrent au lever du jour.

Quand il déboucha dans la grande rue du milieu, il songea à quelque ville étrange, avec ses quartiers distincts, ses faubourgs, ses villages, ses promenades et ses routes, ses places et ses carrefours, mise tout entière sous un hangar, un jour de pluie, par quelque caprice gigantesque. L'ombre, sommeillant dans les creux des toitures, multipliait la forêt des piliers, élargissait à l'infini les nervures délicates, les galeries découpées, les persiennes transparentes; et c'était, audessus de la ville, jusqu'au fond des ténèbres, toute une végétation, toute une floraison, monstrueux épanouissement de métal, dont les tiges qui montaient en fusée, les branches qui se tordaient et se nouaient, couvraient un monde avec les légèretés de feuillage d'une futaie séculaire (idem: 621.).

Ici, il faut d'abord fixer les yeux sur une division de l'espace des Halles assez nette, qui est fermement établie dès la deuxième ligne de l'extrait. Il semble qu'elle corresponde à l'antagonisme économique entre les commerçants des Halles, et à l'antagonisme politique et existentiel entre le héros républicain et ce grand bâtiment moderne dû à la prospérité du second Empire. En outre, le lieu central du roman est dessiné par des métaphores végétales: "forêt", "végétation", "floraison", "épanouissement", “tiges", "branche”, et "feuillage”, qui se déploient sous les yeux du héros, dont le point de vue fait découvrir au lecteur l'ensemble de l'espace principal de ce récit. Dans Les Rougon-Macquart, on voit souvent les images de la plante appliquées à la description des espaces. Les exemples les plus connus en sont la description de la serre dans la maison de Saccard, dans La Curée, et celle de "Paradou" dans La Faute de l'abbé Mouret, espace isolé, comme une sorte de paradis, où le héros et Albine tombent amoureux. Dans ces œuvres, les métaphores de la plante connotent le sensuel, mais celles du Ventre de Paris ne le font pas, et ne représentent qu'à la frontière qui cerne un monde. Cette description des Halles est généralement réaliste, en ce sens que le texte 
s'efforce de représenter la réalité telle qu'elle est, en transmettant au lecteur la faible lumière de l'aurore, la position spatiale des objets, et la profondeur des espaces.

Arrivé à Paris grâce au sauvetage d'une maraîchère, Mme François, qui se rend vers le Halles pour sa marchandise quotidienne, le héros Florent, jeune homme maigre, s'initie à l'espace principal de ce roman en étant guidé par un peintre et habitant du quartier, Claude Lantier, que la maraîchère lui présente et qui succède à celle-ci dans le rôle d'initiateur. Dans ce premier chapitre, le héros et le peintre flânent tout d'abord autour des Halles, puis à l'intérieur de cet espace moderne, comme on l'a vu la citation précédente. Mais ce qui est intéressant, c'est que les deux protagonistes contrastent au niveau des impressions et des pensées qu'ils subissent devant ces espaces en se promenant à chaque endroit.

Au cours de leur flânerie dans le quartier, ils visitent la rue Pirouette où le frère du héros, Quenu gérait sa charcuterie avec sa femme Lisa. En réalité, cette rue de l'ancien Paris existait à l'époque contemporaine de l'écrivain selon une référence qu'il utilise pour sa création du roman, à savoir: Paris, ses organes, ses fonctions et sa vie dans la seconde moitié $d u$ XIX ${ }^{e}$ siècle de Maxime du Camp, ${ }^{4}$ et qui lie la rue Rambuteau et la rue Mondétour.

Cependant, dans l'histoire, le héros apprend qu'il n'y a plus la charcuterie de son frère dans cette rue, lorsqu'il y arrive guidé par le peintre. Cette mauvaise nouvelle "lui causait une émotion extraordinaire" (idem: 619). En fait, alors qu'il était au bagne, la famille Quenu avait déménagé dans un autre endroit qui se trouve à deux pas de là, dans la rue Rambuteau.

Mais après avoir quitté la rue Pirouette, le héros et le peintre se promènent autour du quartier pour entrer dans les Halles. Ce qui est intéressant dans ce passage, c'est que le héros, qui est traumatisé par son souvenir d'avoir été arrêté par erreur par les gendarmes lors de coup d'État de 1851, s'inquiété cette fois-ci de la deuxième arrestation, sent monter la phobie de la nourriture qui s'entasse dans les Halles, tandis que le peintre observe des tas de légumes, de viandes, et de fleurs avec son grand intérêt pour l'art et le pittoresque:

Et le peintre ravi clignait les yeux, cherchait le point de vue, afin de composer le tableau dans un bon ensemble. Mais cette diablesse de soupe aux choux avait une odeur terrible. Florent tournait 
la tête, gêné par ces tasses pleines, que les consommateurs vidaient sans mot dire, avec un regard de côté d'animaux méfiants (idem: 624).

En s'appuyant sur ce contraste entre les deux protagonistes, l'un est porteur de la mémoire de la politique du Seconde Empire, l'autre n'observe que par un intérêt purement artistique, leur flânerie, dont le but est d'un côté de trouver la charcuterie de Quenu, et de l'autre côté de faire découvrir au lecteur l'espace principal du roman, converge vers un seul et même endroit: la rue Pirouette. Pour le peintre, ce petit coin sauvé de l'haussmannisation est un endroit pittoresque, tandis que pour le héros, il s'agit du son seul lieu familier auquel il puisse se confier. En effet, le peintre invite le héros à voir son tableau de cette rue juste avant qu'ils se séparent.

Ce qui est remarquable encore dans ce premier chapitre, c'est que ce personnage de peintre est aussi une sorte de porte-parole de l'écrivain. Comme l'écrivain Zola pense que "la forme des Hugo, des Lamartine et des Musset est épuisée. Il faut nous séparer violemment de l'école lyrique de 1830, ou du moins la renouveler, la faire nôtre par une nouvelle inspiration" (Zola 2004: 51-52), Claude Lantier qui se trouve devant l'espace dans les Halles, s'efforce de renouveler le romantisme et fonder une nouvelle esthétique:

on en était aux Halles centrales, à ce colosse de fonte, à cette ville nouvelle, si originale. Les imbéciles avaient beau dire, toute l'époque était là. Et Florent ne savait plus s'il condamnait le côté pittoresque ou la bonne chère de Baratte. Puis, Claude déblatéra contre le romantisme ; il préférait ses tas de choux aux guenilles du Moyen Âge. Il finit par s'accuser de son eau-forte de la rue Pirouette comme d'une faiblesse. On devait flanquer les vieilles cambuses par terre et faire du moderne (idem : 624).

Malgré ses efforts pour se retrouver chez son frère, le héros s'égare dans ce quartier accablé d'une faim insupportable après avoir quitté son guide-initiateur Claude. Il regrette de ne pas avoir accepté "l'aumône de Mme François" et d'avoir eu "peur de Claude comme un imbécile" (idem: 632-633). Mais finalement il arrive à trouver par chance une connaissance qui sait que la famille Quenu a déménagé à deux pas de leur précédente résidence.

À travers cette dramatisation dans le processus de l'arrivé chez son frère, puisque le héros est vraiment désespéré, agonisant de faim dans la rue, on peut avoir 
une perspective du récit : l'antagonisme entre le héros et le quartier, la configuration de la politique et de l'art à la fois dans le récit et dans la réalité.

\section{Conclusion}

Selon Zola, la description est "un état du milieu qui détermine et complète l'homme" (Zola 2004: 275). Dans sa pensée, qui est certainement influencée par le positivisme, il y a toujours une sorte de correspondance ente l'espace et les personnages qui s'y trouvent. On peut dire que les mouvements des personnages servent d'un côté à l'économie de la narration, et de l'autre côté à la mise en œuvre de la pensée du romancier. Pour mettre en scène les espaces parisiens, Zola donne des effets de mouvement, soit physique et spatiale, soit psychique et émotionnel à travers des figures de personnages qui se déplacent dans les espaces qui les entourent. À cette étape, l'auteur peut assurer la vraisemblance de ses œuvres romanesques en s'appuyant sur toutes les données qu'il accumule dans le processus des enquêtes, à savoir ses propres expériences ethnologiques. C'est dans ce "sens du réel" (Zola 2004: 188), selon l'auteur lui-même, que le lecteur peut sentir la réalité sociale, artistique, et intime vécue par les personnages zoliens. 


\section{Bibliographie}

Du Camp, Maxime (1875), Paris, ses organes, ses fonctions et sa vie dans la seconde moitié $d u$ XIXe siècle, Paris, Hachette.

Hamon, Philippe (1983), Le personnel du roman, Genève, Librairie Droz S.A.

Lumbroso, Olivier (2004), Zola La Plume et le compas, Paris, Honoré Champion, et 2002.

Les mainuscrits et les dessins de Zola. Note préparatoires et dessins des Rougon-Macquart, Paris, Les Éditions Textuels.

Mitterand, Henri (1980), Le discours du roman, Paris, Presses Universitaires de France, 1987. Le regard et le signe, Paris, Presses Universitaires de France, et 1990. Zola L'histoire et la fiction, Paris, Presses Universitaires de France.

Scarpa, Marie (2000), Le Carnaval des Halles, Paris, CNRS édition.

Seassau, Claude (1989), Émile Zola le réalisme symbolique, Paris, Librairie José Corti.

Zola, Émile 1960-1967, Les Rougon-Macquart, Paris, Gallimard, "Bibliothèque de la Pléiade" et 2004. Écrits sur le roman, Paris, Librairie Générale Française, "Le Livre de Poche".

\section{Notes}

\footnotetext{
${ }^{1}$ Sur la critique générique des Rougon-Macquart, voir, d'Olivier Lumbroso : Zola La Plume et le compas, Honoré Champion, Paris, 2004, et Les mainuscrits et les dessins de Zola. Note préparatoires et dessins des Rougon-Macquart, établie et commentée par le même auteur et Henri Mitterand, 3vol. Les Éditions Textuels, Paris, 2002. et d'Henri Mitterand: “Germinal: La genèse de l'espace romanesque" in Zola L'histoire et la fiction, Paris, Presses Universitaires de France, 1990, et "Modèles et contre-modèles Naissance de l'ouvrier romanesque: L'Assommoir" et " "La bête goulue" " in Le regard et le signe, Presses Universitaires de France, Paris, 1987. Sur la critique sémiologique et narratologique, voir, d'Henri Mitterand: "Chronotopies: la route et la mine" et "Dispositifs optique: L'EEuvre" in Zola L'histoire et la fiction, op.cit., et "Fonction narrative, fonction mimétique, fonction symbolique: Etienne Lantier" in Le discours du roman, Presses Universitaires de France, Paris, 1980, de Philippe Hamon: Le personnel du
} 
roman, Genève, Librairie Droz S.A., 1983, et de Claude Seassau: Émile Zola le réalisme symbolique, Librairie José Corti, Paris, 1989.

2 "Renée se souleva légèrement, cligna les yeux, avec cette moue exquise que lui faisait faire la faiblesse de sa vue."(Émile Zola, Les Rougon-Macquart, Gallimard, "Bibliothèque de la Pléiade”, Paris, 1960-1967, t. I, p.319), "Puis, comme elle voyait mal, elle prit son binocle, ..." (ibidem, p.320), "Renée avait cédé à la secousse légère de la calèche se remettant en marche, et, laissant tomber son binocle,..." (ibidem, p.321), "Renée avait reposé sa tête, les yeux demi-clos, regardant paresseusement des deux côtés de l'allée, sans voir." (ibidem, p.322), "Accoutumée aux grâces savantes de ces points de vue, Renée, reprise par ses lassitudes, avait baissé complètement les paupières, ne regardant plus que ses doigts minces qui enroulaient sur leurs fuseaux les longs poils de la peau d'ours." (idem), "Renée regardait, les yeux fixes, comme si cet agrandissement de l'horizon, ces prairies molles, trempées par l'air du soir, lui eussent fait sentir plus vivement le vide de son être." (ibidem, p.324).

${ }^{3}$ Sur la question géographique, narratologique, et ethnocritque du Ventre de Paris, l'ouvrage de Marie Scarpa: Le Carnaval des Halles (CNRS édition, Paris, 2000) est très intéressant. Et surtout le chapitre III de cet ouvrage intitulé "Zola, ethnologue du quartier des Halles" est consacré au sujet de la géocritique et de la représentation des espaces de ce troisième volume de Rougon-Macquart.

4 "Autour de ce marché central, quelques restes de l'ancien Paris sont cependant encore demeurés debout comme une impuissante protestation du passé; à traverser la rue Pirouette, les rues de la Grande et de la Petite-Truanderie, on s'étonne que l'on ait pu vivre et que l'on vive encore dans de pareils cloaques." (Maxime Du Camp, Paris, ses organes, ses fonctions et sa vie dans la seconde moitié du XIXe siècle, Hachette, Paris, 1875, t. II, p.123). 


\title{
Idas y venidas hacia el centro del universo en Dejemos hablar al viento de Juan Carlos Onetti
}

\author{
Cecilia Ramírez \\ Universidad Blaise Pascal, Clermont-Ferrand - CERHAC
}

Resumen: Abordaremos las novelas Dejemos hablar al viento (1979) de Juan Carlos Onetti y La pesquisa (1994) de Juan José Saer bajo el tema de los desplazamientos que configuran y confirman el imaginario del espacio narrativo de estos autores.

Bien sabemos que tanto Onetti como Saer han concebido un universo narrativo anclado en el espacio más o menos preciso del Río de la Plata. Tanto la mítica e imaginaria "Santa María" del uruguayo como "La zona" del argentino se erigen como centros espaciales de la problematización y el desarrollo de la ficcionalidad.

El exilio y la partida, la vuelta y la visita son movimientos que más allá de sus causas y circunstancias, delinean y descomponen los espacios, los mistifican y los renuevan en una percepción en ocasiones desfasada y pesadillesca de lo real.

Nos proponemos entonces explorar la noción del centro del universo narrativo hacia el cual convergen espacios auxiliares propiciados por desplazamientos realistas, imaginarios y oníricos con el fin de avanzar en el estudio de los mundos ficcionales y su aporte a la literatura en español.

Palabras clave: Juan Carlos Onetti, Juan José Saer, desplaziamentos

Resumo: Abordaremos os romances Dejemos hablar al viento (1979) de Juan Carlos Onetti e La pesquisa (1994) de Juan José Saer no que toca ao tema das deslocações que configuram e confirmam o imaginário do espaço narrativo destes autores. 
Sabemos que tanto Onetti como Saer conceberam um universo narrativo ancorado no espaço mais ou menos preciso do Río de la Plata. Tanto a mítica e imaginária "Santa María" do uruguaio como "La zona" do argentino erigem-se como centros espaciais de problematização e desenvolvimento da ficcionalidade.

O exílio e a partida, a volta e a visita são movimentos que para além das suas causas e circunstâncias, delineiam e decompõem, mistificam e renovam os espaços, numa perceção por vezes desfazada e de pesadelo do real.

Assim, propomo-nos explorar a noção de centro do universo narrativo para o qual convergem espaços auxiliares propiciados por deslocações realistas, imaginárias e oníricas, com o objetivo de avançar no estudo de mundos ficcionais e sua contribuição para a literatura em espanhol.

Palavras-chave: Juan Carlos Onetti, Juan José Saer, deslocações

Fundar, crear un espacio literario es, entre tantas otras cosas, dar forma a un concepto de ficción propio y establecer las bases de una ética narrativa. ${ }^{1}$ Es el gesto fundador que adjudica al imaginario un lugar a la escritura a través del espacio del texto y del o los espacios de lo contado. En la obra del escritor uruguayo Juan Carlos Onetti (1909-1994) su concepto de ficción se ha traducido en una narración anclada y desplegada en universos imaginarios que han franqueado el espacio del libro para devenir un texto único, una saga que se constituye en "un encadenamiento inestable de historias que [...] retornan entre repetición y diferencia, en un deslizamiento o nomadismo que se extiende con modulaciones de recursividad" (Ferro 2010: 47). Quien dice Onetti, dice Santa María, quien dice Santa María, dice Onetti.

En este estudio nos concentraremos en la dinámica que se establece entre aquellos espacios concernidos en la novela Dejemos hablar al viento (1979): la mítica Santa María y Lavanda otra ciudad imaginaria que aparece tímidamente en el imaginario onettiano. A partir de este título veremos cómo el centro del mundo imaginario onettiano entra en un juego de relación e imposición frente al surgimiento de otros lugares, para nosotros satelitales. 


\section{"Santa María"}

Los conocedores de la obra onettiana bien saben que Santa María es una ciudad imaginaria, creada por el personaje Juan María Brausen en La vida Breve (1950). La ciudad, de la que Brausen será considerado su fundador, surge en sus derroteros del pensamiento y de la ensoñación, primero como encargo y necesidad económica, luego como salvación y escapatoria de sus propias miserias y angustias. A partir de La vida breve la escritura de Onetti toma un giro decisivo en lo que concierne a la consideración del espacio de la narración; se produce lo que Roberto Ferro llama una "expansión endógena" de su obra ya que los relatos siguientes a La vida breve ${ }^{2}$ se centran y se desarrollan en y a partir esta ciudad ficcional. La escritura de Santa María se constituye como una "estructura topológica-simbólica"3, que, según Ferro traza

un complejo entramado de reescrituras que se integran y cruzan [...] desde la cita literal, la alusión, el deslizamiento y trastorno de tramas anteriores, la insistencia en la exhibición de artificios imaginativos usuales, la reiteración de sintagmas cristalizados que desencadenan un vasto juego de remisiones figurativas entre las distintas historias y personajes. (Ferro 2011: 26)

La geografía de esta ciudad imaginaria se presenta como genérica, y desde esta apariencia provinciana se alimenta su verosimilitud, su cercanía con el lector: "La creación de un espacio mítico, esa Santa María imaginaria que puede reconocerse por su dimensión provinciana y topográfica como ubicada en el litoral rioplatense" (Martínez 1980: 29)4: el río, el puerto, colonias de inmigrantes, la capital, la configuración del pueblo que luego pasa a ser ciudad con su plaza principal, sus bares y hoteles y su estatua ecuestre son algunos elementos que componen el paisaje sanmariano, el cual, en el ir y venir discontinuo de los relatos, va estableciéndose en el imaginario del paisaje rioplatense. Santa María se asienta con los recursos de la ficción como, "uno de los lugares más familiares de nuestra imaginación" (Muñoz Molina 1994: 18) y diseña desde sus límites vagos y movedizos sus relaciones con el mundo referencial. ${ }^{5}$

Íntimamente ligados a su centro del mundo natal e imaginario los personajes sanmarianos circulan dentro del territorio, van y vienen infringiendo fronteras, permanecen, desaparecen y resucitan, se exilian y retornan, haciendo de este cúmulo de movimientos una dinámica del Ser y con ello un disparador reflexivo sobre las 
posibilidades de representar la realidad, de sobrevivir, de salvarse. Es así como también con el correr de las novelas, cuentos y nouvelles, Santa María se ha vuelto cifra de una subjetividad específica en el acerbo literario hispánico: la de habitar como sinónimo de sufrir un espacio: esta ciudad distópica de contornos litoraleños y/o rioplatenses abriga, acoge y desecha a un grupo humano del que se destaca una clase de "Sísifos" empedernidos.

Con respecto a lo referencial del espacio en la escritura onettiana se ha transformado en un proceso de construcción (por su "fundación imaginada"), desconstrucción (puesto que, por un lado, de ciudad capital pasa al estatus de pueblo, luego al de ciudad; y, por otro lado, el nombre de la ciudad onettiana evoca las primeras palabras que corresponden al nombre primitivo de la ciudad de Buenos Aires: "Santa María de los Buen Aire") ${ }^{6}$ y reconstrucción ${ }^{7}$ (ya que la organización de los diversos espacios cambia entre relato y relato), trasladándose a un territorio imaginario verosímil que permite relacionarse con otros lugares también imaginarios o de referente real.

Es así como, aun si existen relaciones nominales, Santa María ha logrado desligarse de sus lazos referenciales, Buenos Aires y Montevideo a través de lo espacial para convertirse en capital imaginaria del Río de la Plata, en espacio mítico, levitante, intemporal. Baste recordar las palabras de Rodríguez Monegal que dejando de lado la toponimia asociada al universo onettiano, lo posiciona en la geografía impersonal rioplatense:

Llámese Montevideo (como en El pozo) o Buenos Aires (como en Tierra de nadie) o Santa María (como en casi todas las otras novelas), la ciudad que describe Onetti, la ciudad en la que viven y mueren sus personajes, la ciudad con la que él ha estado soñando hasta hacer soñar también a sus lectores, es una ciudad situada a orillas del vasto, barroso, equívoco Río de la Plata. Y es, también, una ciudad de hoy. (Rodríguez Monegal 1970 b: 19) ${ }^{8}$

Producto de una "fundación imaginada", trazada en un mapa-borrador ${ }^{9}$ que delinea en un primer momento su geografía equívoca, Santa María se establece como centro del universo onettiano, "un otro lado que constituye una topología textual en la 
que las ciudades leídas que asedian y de las que hay que emigrar, constituyen una posición complementaria" (Ferro, 2011: 41).

Con respecto a los espacios y topografías que aparecen en el corpus de la saga onettiana, existe una toponimia que alterna y confunde lo imaginario con lo real. ${ }^{10} \mathrm{En}$ efecto, notamos que "tras la emergencia ficcional de Santa María" las ciudades capitales de Buenos Aires, donde residía Onetti al escribir La vida breve, y Montevideo cuna de El pozo (1939), "pasan a constituirse en lugares alternativos de una topología que tiene a esa ciudad imaginaria como núcleo dominante" (Ferro 2011: 20). Es decir, con la aparición de Santa en el espectro espacial de la escritura, se opera una suerte de "descentralización imaginaria" de los núcleos de focalización literaria y de acción de la narración que se centraban sobre todo en Buenos Aires, haciendo pasar a estas capitales al grado de "ciudades satélite".

La transfiguración que sufren Buenos Aires y Montevideo es producida también a nivel nominal: Buenos Aires es llamada a veces "la capital"; Montevideo, ciudad natal del escritor, nunca será denominada como tal, sino a partir de fragmentos escritos y sonoros de la capital uruguaya bajo el nombre de "Lavanda". Como sugiere Luz Aurora Pimentel, "los cimientos de estas construcciones imaginarias habremos de encontrarlos en el nombre, el armazón en el deseo" (Pimentel 1999: 3). Vemos que escribir un lugar para Onetti no será hacerse del espacio real sino modelar de acuerdo a sus inclinaciones estéticas el espacio de la experiencia, en parte, a partir de lo que Elisabeth NardoutLafargue llama una "transnominación". ${ }^{11}$ Es así que por su materialidad y contigüidad sonora Lavanda remite, por los espacios que se habitan, se recorren y se observan, a la capital uruguaya, en alusión a "La Banda Oriental" antiguo nombre del territorio que hoy ocupa Uruguay. ${ }^{12}$

A su vez, en Cuando ya no importe (1993), última novela de Onetti, notamos que por un lado, el relato hará mención de "Monte" en referencia a Montevideo y por su relación con Buenos Aires, "la gran capital"13, y por otro lado, se hablará también de "Santamaría"14 que muestra en su paisaje los vestigios y reacomodamiento de la Santa María destruida en el relato que aquí comentaremos. Es así como el cambio en el onomástico de la ciudad es cifra de una alteración del espacio ficcional: el nombre condice de manera tangencial con rasgos referenciales que, en el caso de Onetti, tienen 
que ver menos con una identidad geográfica que con una reconfiguración de la experiencia en las idas y venidas del autor de Montevideo a Buenos Aires ${ }^{15}$ - y una estética literaria. Como lo observa Pimentel,

[...] el nombre de una ciudad, como el de una persona-o el de un personaje, en el caso de la ficción-es un centro de imantación semántica al que convergen toda clase de significaciones arbitrariamente atribuidas al objeto nombrado, de sus partes y semas constitutivos, y de otros objetos e imágenes visuales metonímicamente asociados al nombre. (Pimentel 1999: 4)

\section{La novela}

Dejemos hablar al viento es la primera novela que el escritor uruguayo edita en el exilio (1975), en 1979. En efecto, esta novela ha sido escrita en los dos lados de las orillas mayores de la cultura hispánica, y su trama, el exilio de uno de los personajes onettianos, ya se venía delineando desde Montevideo. ${ }^{16}$ En rasgos generales, esta novela cuenta en doble partida las peripecias de Medina, personaje hasta ahora secundario de la saga de Santa María, en un exilio voluntario y luego arrepentido en Lavanda, ciudad imaginaria. En Lavanda Medina se dedica a ejercer "vidas breves" (ref), profesiones falsas para diversión y venganza de su protectora y amante Frieda, también ella sanmariana, lo que posibilita toda una serie de encuentros con personajes del pasado y "aparentes" nuevas caras que no cesan de transportarlo en el recuerdo a Santa María en un juego de imaginación y ensoñación. Durante la aventura Lavanda, se hace cada vez más presente el deseo del regreso a Santa María, que se realiza por un golpe de gracia literario: el de la constatación de ser una creación literaria, imaginada, y la consecuente posibilidad de volver soñando e imaginando. Ya de regreso a Santa María, tras distintas peripecias que tienen como hilo conductor el de la "salvación" de un posible hijo (ref) y que serán presenciadas por los personajes que también formaron parte de la estancia en Lavanda, Medina se resuelve a llevar a cabo una "operación de limpieza": destruir la ciudad imaginaria con un incendio por encargo.

Es importante destacar que la estructura textual de esta novela se divide en dos partes -sencillamente intituladas "Primera parte" y "Segunda parte"-, donde el espacio y el punto de vista narrativos son la marca que distingue una de otra. La primera parte es "escrita" por Medina, en primera persona, que se posiciona como narrador de sus 
experiencias en Lavanda. La segunda, nos es ofrecida por un narrador omnisciente que narra las peripecias del personaje una vez regresado a Santa María. Así como en la geografía onettiana Lavanda está separada de Santa María por un río y la voluntad del "Dios-Brausen", los relatos que componen la novela se encuentran separados sin transición alguna: un silencio textual, podemos pensar, traduce el traspaso imaginario de un lugar a otro.

\section{Lavanda}

La estancia de Medina en Lavanda se nutre del ejercicio de sus profesionesidentidades inventadas por Frieda y Quinteros, y la marejada de "recuerdos inventados" y recuerdos de su pasado en Santa María. Con respecto a las profesiones, Medina ejerce como "enfermero, casi, falso, ex médico" (Onetti 1979: 13), pintor de retratos y desnudos, dibujante en una agencia de publicidad. Dejemos hablar al viento es una obra que ya desde su narratividad delinea movimientos de ida y vuelta dentro del corpus onettiano: se lee toda una serie intertextualidades, citas, injertos de injertos, de imágenes reverberadas de otras imágenes, etc. Estos procedimientos son observables sobre todo en la primera parte, pues el personaje busca el medio para volver a Santa María por medio de visitas extrañas, de encuentros tangenciales sin éxito, ${ }^{17}$ que en su conjunto componen un collage narrativo fragmentado y discontinuo. Escribe Medina: "Yo buscaba un hermano, un desacatado, un apátrida como yo, alguien que hubiera escapado de Santa María sin permiso de Brausen, por asco a Brausen y a todo lo que de él fluía" (Onetti 1979: 48).

A lo largo de la narración de la estadía en Lavanda, se alude a lugares cuya referencia directa es la capital uruguaya y que espacializan encuentros (direcciones exactas (13); puntos de vista (la avenida Agraciada, La embajada argentina); que mencionan lugares con connotación socio-económica y de residencia (la Gran Punta de las Carretas, el mercado viejo próximo a demolición); espacios paisajísticos (la playa); lugares que inspiran asociaciones a Santa María (el cementerio);18 lugares que "están impregnados de la nostalgia de la patria perdida" (Verani 1989: 732). ${ }^{19}$

Dentro del universo imaginario onettiano Lavanda, una "Montevideo disfrazada" adquiere una dimensión ficcional, presentándose como espacio alternativo, en función 
de la ciudad que le da sino nacimiento, posibilidad de aparecer. Esto responde a lo señalado por Westphal quien señala la potencialidad ficcional que tienen los lugares escritos, "les espaces humains ne deviennent pas imaginaires en intégrant la littérature; c'est la littérature qui leur octroie une dimension imaginaire, ou mieux: qui traduit leur dimension imaginaire intrinsèque en les introduisant dans un réseau intertextuel." (Westphal 2000: 21) Habitados, sufridos, en nuestro caso, por el escritor los espacios ficcionales entran en una dimensión paralela a su realidad para devenir, desde lo privado de la experiencia, patrimonio literario colectivo.

\section{Transgresiones del espacio imaginario}

La evasión de Santa María “- Porque estaba harto - dice el personaje -, porque me asfixiaba, porque odiaba a Brausen" (Onetti 1979: 136), se logra a partir de la transgresión del orden narrativo-espacial, traducida en el paso de la legalidad a la ilegalidad: el comisario de Santa María se escapa con el traficante que debía apresar. ${ }^{20}$ La ocasión de la transgresión moral, legal, es acompañada por lo climático, marca irrefutable de la narrativa onettiana. En el desorden de la tormenta, la tormenta de Santa Rosa precisamente, se abren las puertas hacia el otro lado "Era en Santa María, en un marzo húmedo y caluroso con apenas amagos, alharacas de tormenta, como si el tiempo hubiera aceptado la modalidad de los pobladores del otro lado, de Lavanda, río por medio" (idem: 24). La vulneración del espacio por la tentación de tratar de ser Dios ${ }^{21}$ manifiesta en la novela la imagen de un ángel caído, esta vez auto-desterrado del irónico paraíso de Santa María y destinado a "los trabajos y los castigos" (idem: 13) en Lavanda. En un principio, el espacio lavandiano es vivido bajo un sentimiento de reciprocidad: el personaje se distrae y se motiva con el ejercicio de la pintura y de encuentros femeninos. Poco a poco, la caducidad del espejismo espacial que constituyen Lavanda y Santa María llevará al deseo imperioso del regreso, y aquí el río-barrera juega un rol importante en la reverberación tanto imaginaria - a manera de las dos Valdrade de Calvino ${ }^{22}$ - como referencial $^{23}$ en lo que concierne a Montevideo y Buenos Aires, ciudades unidas y separadas por el Río de la Plata:

Separado de Santa María por una crisis de orgullo, andaba, más o menos era, entre los habitantes de Lavanda con un poder de separación, de crítica, paciencia y entrega que me hizo feliz o no 
sufriente durante muchos meses. Los miraba sin dejar de verme, hablaba diciendo casi siempre las frases correctas y ellos se equivocaban pocas veces" [...] Andaba sin propósito, jugando con un haz de coincidencias que - ya estaba sospechando - sólo podía darse en Santa María, la perdida. [...] Nada tenía que ver yo con los lavandianos (idem: 34-35)

La "obsesión del regreso" va creciendo a medida que diversos textos que cifran el pasado en Santa María van "invadiendo" en un juego intertextual el espacio del imaginario lavandino. ${ }^{24}$ Es que sin ser el espacio de la infancia, Santa maría es el lugar que por obra creadora de Brausen ha modelado su "Ser" en función del "Estar" en un lugar. El estar en Lavanda se descubre a la conciencia de Medina como el no-estar en Santa María, un espacio que se vive como un no-paraíso fuera de Santa María, "la perdida". Al respecto declara Ferro:

La escritura de Medina tiene la forma de un viaje hacia el pasado, cada encuentro es como una detención que diversifica el orden de la memoria [...] el tiempo [...] un archipiélago disperso [...]. Su presente de la escritura es el desarraigo del exilio [...] Medina es un "extranjero" -en la 2da parte se cita a Mersault- su modo de concebir la temporalidad parece anular el futuro y radicarse en un tiempo ya pasado. (Ferro, 2011: 449-50)

En el siguiente párrafo, intrusión de un injerto textual que se lee en la novela Juntacadáveres, se expresa el proceso de creación de una ciudad imaginaria, un proceso que se va degradando poco a poco en un movimiento de arriba abajo, en el que la obligación de una luz benefactora termina dando nacimiento a la inevitable, "odiable" según el texto, vida en sociedad:

Es fácil dibujar un mapa del lugar y un plano de Santa María, además de darle nombre; pero hay que poner una luz especial en cada casa de negocio, en cada zaguán y en cada esquina. Hay que dar una forma a las nubes bajas que derivan sobre el campanario de la iglesia y de las azoteas con balaustradas cremas y rosas; hay que repartir mobiliarios disgustantes; hay que aceptar lo que se odia, hay que acarrear gente de no se sabe dónde para que habiten ensucien, conmuevan, sean felices y malgasten. (Onetti 1979: 53)

Este fragmento pertenece al capítulo "Un viaje" de la primera parte donde, sin éxito, cree sentir en la imagen de una prostituta la evidencia de una pista que lo 
devuelva a Santa María. El viaje se trata aquí de un transporte imaginario hacia su ciudad en donde se armoniza lo bucólico con lo abyecto, donde la ensoñación recorre un paisaje compuesto de la crudeza de vivir en Santa María donde lo decadente es parasitario de la existencia de sus habitantes:

Santa María y las fogatas que hacen burbujear la resina y retuercen hojas muertas en los anocheceres de abril. La bosta y ese olor detenido de improvisto, apenas amenazante, de los orines en el muladar. [...] El tabaco y el café humeando en mi oficina del Destacamento, los ácidos en el pequeño laboratorio, el formol y la muerte en la Morgue, también pequeña pero suficiente. [...] Un poco más lejos, como quien va hacia la Colonia -aquello, si viera, está tan cambiado me han dicho- madreselva, pasto en el alba, azahares, la tierra siempre propicia, un costillar asándose entre árboles invisibles. Los largos almacenes frutales a lo largo del río, el hierro oxidado del astillero, los endurecidos pantalones supersticiosos de los pescadores en el espigón. Los crédulos y perseverantes repintando, [...] casitas, botes y lanchas en la playa de Villa Petrus, [...]. Y por encima del paisaje apenas quebrado y por nuestras horas de dicha, desgracia o lucidez, el conflicto, exactamente en mitad del celo, de los verdes que llegaban de las charcas y los plomos violentos del río, parvas y pescado muerto. (idem: 54 )

\section{La vuelta y la implosión de la ciudad}

La segunda parte de la novela es fruto de una segunda transgresión de los límites de las ciudades imaginarias que imposibilitaban el retorno. Este desplazamiento es posibilitado por una ruptura de tipo "maravillosa" que rompe con todo realismo de lo escrito: Larsen, uno de los personajes más destacados de la obra onettiana, ${ }^{25}$ entra en escena resucitado, y no transfigurado sino agusanado luego de dos desapariciones posibles del espacio de Santa María. ${ }^{26}$ Es Larsen o "Junta" quien le ofrece a Medina las llaves del subterfugio que habría de conducirlo a su ciudad "Usted puede ir a Santa María cuando quiera. Y sin que nada le cueste, sin viaje siquiera" (idem: 137). Se trata de un fragmento perteneciente a La vida breve, que según el personaje resucitado es un extracto de "los libros sagrados", que atestan la fundación de la ciudad imaginaria, y que se diferencia en el texto por el uso de itálicas:

Además del médico, Díaz Grey y de la mujer, tenía ya la ciudad de provincia sobre cuya plaza principal daban las dos ventanas del consultorio de Díaz Grey. Estuve sonriendo, asombrado y agradecido porque fuera tan fácil distinguir una nueva SM en la noche de primavera. La ciudad con 
su declive y su río, el hotel flamante y, en las calles, los hombres de cara tostada que cambian, sin espontaneidad, bromas y sonrisas. (ibidem)

Para Larsen este extracto constituye la prueba de qué el espacio de Santa María se encuentra al alcance de la mano, "para los hombres de lecturas" dice, a partir de la imaginación y el sueño. Larsen, ya en el espacio intemporal de los muertos, pareciera comprenderlo y saberlo todo, le explica:

-Brausen. Se estiró para dormir la siesta y estuvo inventando Santa María y todas las historias. Está claro. / - Pero yo estuve allí. También usted. / - Está escrito, nada más. Pruebas no hay. Así que le repito: haga lo mismo. Tírese en la cama, invente usted también. Fabríquese la Santa María que más le guste, mienta, sueñe personas y cosas, sucedidos. (idem: 138)

A partir de esta "tentación"27 Medina entra en el juego de la imaginación y se desliza secretamente en Santa María cuyo letrero de entrada "rezaba: ESCRITO POR BRAUSEN" (idem: 141). Pensamos que es este personaje que toma el poder de la narración omnisciente, accede a su deseo primario de ser Dios y perfila en la segunda parte un Comisario Medina "semipoderoso" - pues, como en La vida breve, aparece el mismo Onetti en la escena para poner orden en medio del caos), ${ }^{28}$ lúcido - por narrar de manera omnisciente - y despiadado: "se cree que es Dios": por los dichos de los vecinos; por el derecho de tener sexo con la mujer de su subalterno, por el poder de disponer de la vida de ciertos personajes, por la capacidad de llamar del más allá de Santa María personajes anteriores a la saga; ${ }^{29}$ por la esperada posibilidad de pintar lo que en Lavanda le era imposible; por, en fin, decidir sobre la suerte de Santa María e inmolarla con un incendio: "esto lo quise durante años, para esto volvi" (Onetti 1979: 246) confiesa Medina vislumbrando el apocalipsis.

El retorno a Santa María signa el punto final de la ciudad maldita que Medina constata más decadente que nunca. El tiempo, que pasa sin marcas explícitas en la narración, muestra sus efectos de decadencia tanto en la ciudad como en los habitantes que la sufren: "Todo en esta ciudad [...] sufrimos de dermatitis, cada día se nos cae un pedazo de piel, o un recuerdo. 0 también una cornisa. Cada día nos sentimos más solos, como en exilio" (Onetti 1979: 189). Medina ha vuelto a lo irrecuperable, y lo han seguido sus fantasmas de Lavanda - Frieda, sus amantes, un posible hijo a quien obstinadamente 
quiere salvar de la perdición sanmariana. Díaz Grey, personaje-alma de la ciudad, le reprocha:

Yo ya estoy resuelto a morir aquí [...]. Pero usted. Usted que logró zafarse de Dios o del diablo. Con toda franqueza no entiendo por qué volvió. Salvo que lo atrajera el famoso amor por la mugre [...] -Si - dijo [Medina] con voz de cautela - me escapé en una lancha y volví en otra. Vine de visita, para pasar revista. Por lo menos eso creía. Después descubrí que tenía algunas cosas que hacer (Onetti 1979: 190)

Estas diligencias se refieren al acto de incendiar la ciudad por encargo a un personaje pirómano, El Colorado, un día de tormenta donde nuevamente y como debía ser el viento tiene la última palabra:

[...] estuve deseando esto tanto tiempo que ahora que puede ser, que es seguro, me siento enfermo y débil; eso que llaman depresión [] además, pienso en el viento. Mientras reventamos de calor se acerca Santa Rosa con su tormenta. No puede demorar. Pero ¿quién adivina de qué lado soplará el viento? (Onetti 1979: 244).

\section{Conclusiones}

Luego de un acercamiento a la espacialidad en Dejemos hablar al viento, novela que concentra todo el potencial del imaginario onettiano (imagen del deterioro moral y físico, espacial, imágenes metafóricas y paródicas del acto de creación), hemos observado de qué manera se perfilan nuevos lugares en el mapa literario rioplatense, en este caso con la aparición casi mágica de Lavanda. Esta nueva presencia geográfica viene a asentar con más fuerza la centralidad de Santa María, capital del territorio onettiano, al proponerse como lugar del destierro, del recuerdo, de la recurrencia incesante del imaginario que se ha forjado en Santa María. Sin embargo esta condensación narrativa, muchas veces inconexa en la novela, actúa como una especie de carga que lleva a la eclosión del espacio una vez el personaje retornado por fin a su ciudad. Sin ser el final definitivo de la obra de Onetti, este apocalipsis es la marca de un proceso de "desacomodamiento" del espacio de la narración, en Dejemos hablar al viento a causa del cambio de autoridad narrativa, la de un personaje-dios vengativo, proceso que seguirá su curso de recursividad en la escritura posterior del escritor uruguayo. 


\section{Bibliografía}

Balderston, Daniel (2009), "Introducción del coordinador", in Juan Carlos Onetti. Novelas cortas, Collección archivos "Nueva serie”, Vol. 59, Ed. Alción, Córdoba (Arg.), versión electrónica: http://www.mshs.univpoitiers.fr/crla/contenidos/Archivos/introduc/ intro_60.pdf [Abril 2015]

Calvino, Italo (2012), Le cità invisibili, Milan, Ed. Mondadori.

Corbatta, Jorgelina (2005), Juan José Saer: Arte poética y práctica literaria, Buenos Aires, Corregidor.

Ferro, Roberto (2010), "Dejemos hablar al viento la catástrofe de la incesancia", in Reales Liliana y Ferro Roberto (coord.), Os anhos de Onetti na Espanha, Florianopolis, Letras comtemporâneas, pp. 45- 58.

-- (2013), La fundación imaginada, Buenos Aires, Corregidor.

Grassin, Jean Marie (2000), "Pour une science des espaces littéraires”, introduction a La Géocritique. Mode d'emploi, Limoges, Presses universitaires de Limoges, pp. I-XIII.

Martínez Moreno, Carlos (1971), "Montevideo en la literatura y en el arte”, suplemento Serie Montevideo. Revista. Nuestra Tierra, no6, agosto, 1971.

Martínez, Carlos (1980), “Onetti: decadencia y destrucción de Santa María”, in Punto de vista, $\mathrm{n}^{\circ}$ 8, pp. 29-33.

Muñoz Molina, Antonio (1994), "Sueños realizados: invitación a los relatos de Juan Carlos Onetti”, Prólogo a Juan Carlos Onetti. Cuentos completos, Madrid, Alfaguara, pp. 925.

Nardout-Lafarge, Élisabeth (2013), “Instabilité du lieu dans la fiction narrative contemporaine. Avant-propos et notes pour un état présent", in Temps zéro, no 6, versión electrónica: http://tempszero.contemporain.info/document974 [Abril 2015] Onetti, Juan Carlos, 2007 [1939], El pozo, Madrid, Punto de Lectura.

-- (2009) [1949], "La casa en la arena”, in Onetti. Cuentos Completos, Madrid, Alfaguara, pp.136-148. 
-- (1979) [1950], La vida breve. Barcelona, Argos Vergara.

-- (2007) [1953], Los adioses, Madrid, Punto de Lectura.

-- (2008) [1959], Para una tumba sin nombre, Madrid, Punto de Lectura.

-- (2008) [1961], El astillero, Madrid, Punto de Lectura.

-- (2008ª $)$ [1964], Juntacadáveres, Madrid, Punto de Lectura.

-- (2009b) [1964], "Justo en treintaiuno", in Onetti. Cuentos Completos, Madrid, Alfaguara, pp. 305-311.

--- (1999) [1979], Dejemos hablar al viento, Madrid, Espasa Calpe, Narrativa del siglo xx.

--- (2008) [1993], Cuando ya no importe, Madrid, Punto de Lectura.

Pimentel, Luz Aurora (1999), "Florencia, Parma, Combray, Balbec...Ciudades de la imaginación en el mundo de En busca del tiempo perdido", en Lapoujade María Noel (Coord.), Espacios Imaginarios, Coll. Jornadas, México, Facultad de Filosofía y Letras, UNAM, pp. 229-44.

Quesada Castro, Fernando (1985), "Ética narrativa", in Revista de estudios políticos, no 43, pp. 181-196. Versión electrónica: http://dialnet.unirioja.es/servlet/ articulo?codigo $=26814$ [Abril 2015]

Rodríguez Monegal, Emir (1970a), “Conversación con Juan Carlos Onetti” [Revista Eco, n. 119, Bogotá, marzo, p. 442-475], versión electrónica: http://www.archivodeprensa.edu.uy/biblioteca/emir_rodriguez_monegal/bibliografia/ prensa/artpren/eco/eco_19.htm [Abril 2015]

-- (1970b), Prólogo a las Obras Completas de Juan Carlos Onetti, México, Aguilar, p. 1941. Versión electrónica: http://www.literatura.us/onetti/monegal.html. [Abril 2015]

San Román, Gustavo (2000), "La geografía de Santa María en El astillero", in Bulletin of Hispanic Studies, Liverpool, 77 pp. 107-121, versión electrónica: http://www.onetti.net/es/descripciones/san-roman_5. [Abril 2015]

Verani, Hugo (1989), “Onetti y el palimpsesto de la memoria”, in Neumeister Sebastián (Coord.), Actas del IX Congreso de la Asociación Internacional de Hispanistas: 18-23 agosto 1986, Berlín, Vervuert Verlagsgesellschaft, pp. 725-732. 
Westphal, Bertrand (2000), "Pour une approche géocritique des textes", in Westphal (Dir.), et Grassin (Préf.), La géocritique. Mode d'emploi, Limoges, Presses universitaires de Limoges, pp. 9-39.

Cecilia Ramirez est Doctorante en études hispanoaméricains de l'université Blaise Pascal au sein du CERHAC sous la direction de M. Axel Gasquet, en préparation d'une thèse traitant les convergences, divergences et décalages de l'imaginaire littéraire de Juan Carlos Onetti et Juan José Saer. Elle s'intéresse au traitement de l'imaginaire de l'espace des auteurs à travers les déplacements et l'intériorité des personnages délignés dans leur œuvre fictionnelle.

Actuellement elle occupe un poste de lectrice de langues au département d'espagnol de l'université Blaise Pascal où elle assure des cours de langue, de traduction et de littérature. 


\section{Notas}

1 "El lenguaje ciertamente alude a un mundo de realidades, pero también aduce — a su vez- la densidad ontológica otorgada a tales entidades, y con ello genera una actitud ética como marco referencial" (Quesada, 1985: 184).

${ }^{2}$ Con la excepción de Los adioses (1953), en donde la acción se desarrolla en un espacio distinto al de Santa María.

3 Término tomado del estudio de Jorgelina Corbatta que equipara el espacio onettiano con el del escritor argentino Juan José Saer, los cuales “constituyen creaciones literarias sintéticas, construida sobre una base de elementos reales que adquieren, a través de la escritura una dimensión mítica” (2005: 149).

${ }^{4}$ El autor continúa: "Espacio mítico que se ha comparado con el Yoknapatawpha County de Faulkner y que, más allá de las diferencias, precede al Macondo de García Márquez" (Martínez 1980: 29)

${ }^{5}$ Cabe señalar que los personajes de Santa María van y vienen, llegan y se retiran de este lugar imaginario, conectado por el transporte en común (tren, ómnibus, lancha) con otros espacios de referente real o ficticios: por dar algunos ejemplos, desde Colón y Enduro, espacios ficticios, en El astillero (1961) y Juntacadáveres (1964) respectivamente; desde y hacia Buenos Aires en Para una tumba sin nombre (1959).

${ }^{6}$ A pesar de la insistencia de la crítica en general, el escritor no ha aseverado la relación toponímica: "ERM: Buenos Aires fue bautizada como Santa María del Buen Aire. ¿Será por eso?

/ JCO: El origen puede ser ese." (Rodríguez Monegal 1970a: sn)

7 Tomamos estos términos en función a lo señalado por Claude Grève, citado por Grassin: “L'espace littéraire, transposition du sensible ou d'un "ailleurs" imaginaire, à partir d'un réel déconstruit et reconstruit, apparait comme un moyen privilégié de s'adresser à l'imagination du lecteur ou du spectateur" (Grassin 2000: X).

${ }^{8}$ El subrayado es nuestro.

${ }^{9}$ Existe un esbozo del mapa de Santa María encontrado en los borradores de la escritura de la novela Juntacadáveres (1964). Ver a este respecto Daniel Balderston, “Introducción del coordinador”, en Juan Carlos Onetti. Novelas cortas, Colección archivos “Nueva serie”, Vol. 59, Ed. Alción, Córdoba (Arg.), 2009. http://www.mshs.univ-poitiers.fr/crla/contenidos/Archivos/introduc/intro 60.pdf

10 “Santa María y Puerto Astillero comparten un espacio mayor, que incluye otras poblaciones: Colón, El Rosario, Enduro, Mercedes, Míguez, Buenos Aires” (San Román 2000: sn) .

11 “[...] bien de noms fictifs sont à la fois des interpolation et le résultat de multiples surimpressions. On se demandera également si toute nomination fictive n'est pas, de fait, une transnomination" (NardoutLafargue 2013 : sn).

12 El nombre Lavanda actúa como una sinécdoque de Montevideo, que como capital del territorio nacional, remite, también como sinécdoque al país, y por ende a su territorio. "ERM: ¿En la novela se identifica como Montevideo? /JCO: Se reconoce que es Montevideo, se puede declarar que es Montevideo. Lo que me pasa es que no quiero seguir hablando de esto..." (Rodríguez Monegal, 1970a: sn). 
13 “También recuerdo que por aquellos tiempos la gente de Monte huía de su ciudad, cruzaba el río para llegar a la gran capital, transformada entonces en cabecera del tercer mundo, erizada con los cartones y latas herrumbradas que construían lo que llamaban casas en cientos de Villas Miseria que iban aumentando cada día más cercanas y rodeaban el gran orgullo fálico del obelisco" (Onetti 1993: 13, el subrayado es nuestro).

14 "El profesor me preguntó si el nombre de Santamaría me era conocido" / "ERM: ¿En la novela se identifica como Montevideo? /JCO: Se reconoce que es Montevideo, se puede declarar que es Montevideo. Lo que me pasa es que no quiero seguir hablando de esto..." (Rodríguez Monegal 1979 a: sn ).

15 "JCO: Mirá, el hombre, el hombre que había huido de la ciudad maldita. / ERM: ¿De Santa María? / JCO: Sí, pero no pienso entrar por ahora en lo de Santa María, porque detrás de Santa María están exactamente cosas harto conocidas. No, mirá: ese hombre se va de Santa María y se viene a Montevideo. Es un poco como lo que me pasó a mí, cuando volví de Buenos Aires a Montevideo, después de tantos años.", idem.

${ }^{16}$ Ver entrevista de Rodríguez Monegal a Juan Carlos Onetti, idem.

17 Habla el personaje con respecto a sus encuentros que no lograban darle una pista hacia la ciudad perdida: "ella nunca había estado en la ciudad perdida; no ella [...] aunque es cierto [...] una amiga [...] estuvo hará años en Santa María [...], desde allí me mandó unas postales que todavía tengo, pero ella tampoco vivió nunca en Santa María" (Onetti 1979: 55); "la yunta de monstruos perversos y elusivos, inmundos de vejez y terquedad vital, resueltos a no servirme ni siquiera con un indicio falso que yo pudiera torcer para que encajara en mi esperanza. Hijos de puta, tan ajenos a mi angustia, desviando hacia una noche y una selva interminable el camino estrecho que podría llevarme a Santa María", (Onetti 1979: 57).

18 Páginas de la novela que hacen referencia a los lugares citados: 13, 22, 14, 34,38, 66,121, respectivamente.

${ }^{19}$ He aquí más referencias reunidas por el crítico: "Lavanda está descrita para que se reconozca a Montevideo. Nombres de lugares (El Cementerio Central, la playa Ramírez, el Parque Hotel) y el de calles (Isla de Flores, Carlos Gardel) de los alrededores del Barrio Sur donde vivía Onetti, u otros lugares típicos de la ciudad (El Buceo, el restorán Morini, la Plazoleta del Gaucho, la óptica Ferrando, la Avenida Agraciada, el Teatro Solís)", (Verani, 1989: 732).

20 "fue justo entonces y cuando, queridos animales, sin posibilidad de conocer nunca la causa, que guardé la idiotez de la pistola [...]. Sentí de pronto, sin alivio ni tristeza, que yo había dejado de tener motivo. Me serví otro caso y le pregunté al Pibe Manfredo: / - ¿A qué hora cruzamos?", (Onetti 1979: 125).

${ }^{21}$ El comportamiento del personaje se basa en la ambición de ejercer el poder del dios-fundador del espacio imaginario que se traducirá en la novela en el tema de la paternidad y de la creación artística (la pintura). Este tema será uno de los que más pondrán de realce en la obra de Onetti la puesta en escritura de la parodia del autor. Ver a este respecto FERRo Roberto, La fundación imaginada, pp. 449-455. 
22 "Lo specchio ora accresce il valore alle cose, ora lo nega. Non tutto quel che sembra valere sopra lo specchio resiste se specchiato [...] Le due Valdrada vivono l'una per l'altra, guardandosi negli occhi di continuo, ma non si amano", (Calvino 2012: 52).

${ }^{23}$ Carlos Martínez Moreno expresa, citando a su vez a Ángel Rama, con respecto a la narrativa urbana que en Uruguay se inaugura con la escritura de Onetti: "Lo que comienza con Onetti es un tiempo presente de la ciudad como escenario, como suscitación y como tema. "Es más probable que Onetti -aventura Ángel Rama - quisiera afirmar que la literatura -pensando siempre en la narrativa- debía expresar la nueva ciudad que era Montevideo, en esto eco atenuado de la monstruosa capital porteña [Buenos Aires]: una ciudad tensa, dramática, moderna, más que nunca parecida a las europeas y norteamericanas o más decidida a parecérseles."”, (Martínez Moreno 1971: 37).

${ }^{24}$ El ejercicio de enfermero o ex médico como remedo de la figura de Díaz Grey, personaje narrador de la saga; el espacio de la farmacia que rememora la botica de Santa María; la profesión de pintor que evocan las clases de pintura durante su infancia; transcripciones casi idénticas de El pozo, "Justo el treintaiuno" (1964), La vida breve, intrusión de personajes ajenos a la saga, entre otros son marcas de esta invasión imaginaria.

${ }^{25}$ Ver en las novelas El astillero o Juntacadáveres.

${ }^{26}$ Dos desapariciones son imaginadas en la lectura del final de El astillero.

${ }^{27}$ Nombre del capítulo correspondiente a las líneas citadas.

${ }^{28}$ Onetti aparece como juez, haciéndose llamar "Usía". Es descrito con las mismas palabras que Brausen ha utilizado para Onetti en La vida breve.

${ }^{29}$ Se trata del "Colorado", que aparece en el cuento "La casa en la arena" (1949). 


\title{
Quelle place pour l'écrivain dans les portraits de pays photo-illustrés?
}

\author{
Anne Reverseau \\ FWO / KU Leuven
}

Résumé: Cette communication s'intéresse aux contributions des écrivains dans les livres de voyage illustrés par la photographie que l'on peut appeler « portraits de pays ». Dans les années 1950 et 1960, ce genre éditorial est à son apogée et de nombreux écrivains sont sollicités pour rédiger légendes, préfaces, notices, avant-propos, autant de textes fictionnels ou documentaires visant à compléter le portrait d'une entité géographique. Ces objets hybrides seront ici abordés dans une perspective interdisciplinaire de façon à mettre en avant les différents équilibres possibles entre les représentations linguistico-littéraires d'un lieu, en l'occurrence d'un pays, et ses représentations photographiques. Il s'agira de montrer, au-delà d'une approche purement textuelle, les rapports de force et le difficile partage des territoires, pour poser les bases d'une poétique de la collaboration. Cette étude s'appuiera sur un choix représentatif de ce genre photo-textuel : La France de profil de Claude Roy et Paul Strand (La Guilde du Livre, 1952), Belgique, pays de plusieurs mondes de Franz Hellens et Maurice Blanc (La Guilde du Livre, 1956), Le Brésil, Des Hommes Sont Venus de Blaise Cendrars et Jean Manzon (Les documents d'art, 1952) et Les Pays-Bas de Pierre Mac Orlan, Arielli et A. Ginsbourg (Albin Michel, 1965).

Mots-clés: géographie, portrait, illustration photographique

Resumo: Este artigo intereessa-se pelos contributos dos escritores nos livros de viagem ilustrados pela fotografia que pode ser chamado de “ retratos de paises” Nos anos 1950 e 1960, esse género editorial está no apogeu e inúmeros escritores são soliciatdos para escrever legendas, prefácios, notas, preâmbulos; muitos textos ficcionais ou documentais que visavam completar o retrato de uma entidade geográfica. Esses objetos híbridos serão aqui abordados numa perspectiva interdisciplinar afim de destacar os diferentes equilíbrios possíveis entre as representações linguístico-literárias de um lugar, neste caso um país, e suas representações fotográficas. Tratar-se-á de mostrar, para além de uma abordagem meramente 
textual, as relações de força e a difícil partilha dos territórios, para lançar as bases de uma poética da colaboração. Este estudo basear-se-á numa seleção representativa desse género foto-textual: La France de profil de Claude Roy e Paul Strand (La Guilde du Livre, 1952), Belgique, pays de plusieurs mondes de Franz Hellens e Maurice Blanc (La Guilde du Livre, 1956), Le Brésil, Des Hommes Sont Venus de Blaise Cendrars e Jean Manzon (Les documents d'art, 1952) e Les Pays-Bas de Pierre Mac Orlan, Arielli et A. Ginsbourg (Albin Michel, 1965).

Palavras-chave: geografia, retrato, ilustração fotográfica.

Le Brésil de Blaise Cendrars, Le Portugal que j'aime de Jacques Chardonne ou encore Le Japon de Nicolas Bouvier : rares sont les ouvrages appartenant à la catégorie des portraits de pays photo-illustrés à être restés dans la mémoire collective, même si les amateurs de photographie et les collectionneurs connaîtront peut-être la production de La Guilde du Livre, notamment celle d'Henriette Grindat ou la collection «Petite planète » au Seuil. Les portraits de pays photo-illustrés constituent pourtant dans les années 1950 et 1960 un phénomène éditorial majeur. Le genre - des livres de voyage illustrés par la photographie qui visent à faire le portrait d'un pays - est alors à son apogée et de nombreuses collections se partagent le marché de langue française : « Les Beaux Pays » (Arthaud, Grenoble), « Escales du Monde » (Les Documents d'Art, Monaco), «L'Atlas des Voyages » (Rencontre, Lausanne), «Itinéraire historique et contemporain » (Albin Michel, Paris), «Le Monde en couleurs » (Odé, Paris) ou encore la maison d'édition Sun à Mulhouse et, bien sûr, le club de livres de Lausanne, La Guilde du Livre.

Il n'est pas anodin que l'on se souvienne justement du Brésil de Cendrars ou du Portugal de Chardonne : on a oublié le photographe Jean Manzon, dont seule une petite part des clichés ont été repris dans la réédition du Brésil, tout comme les nombreux photographes qui ont illustré le Portugal des éditions Sun (le cas de Bouvier, à la fois écrivain et photographe, est à part). C'est que ces livres font désormais partie de leur bibliographie, ce qui n'est pas forcément le cas des nombreuses préfaces qu'ont rédigées Paul Morand, Pierre Mac Orlan, et même Tzara ou encore Robbe-Grillet !

On le voit, nombreux sont les écrivains à avoir été sollicités pour rédiger légendes, préfaces, notices, avant-propos et autres textes fictionnels ou documentaires visant à compléter le portrait d'une entité géographique. Alors que dans les années 1930, qui semblent correspondre à la formalisation du genre, on faisait surtout appel à 
des écrivains-reporters ou écrivains-voyageurs - les « littérateurs du verbe partir » dont se moque Aragon dans le Traité du style (Aragon 1991: 80) - ceux à qui l'on passe commande dans les années 1950 et 1960 sont beaucoup divers. Dès lors, il est légitime de se demander pourquoi dans l'espace francophone, on fait alors appel aussi massivement aux écrivains. Quelle est leur place dans ces objets hybrides dont l'auctorialité aussi bien que le statut littéraire sont problématiques? Comment s'équilibrent, dans ces portraits de pays, les représentations linguistico-littéraires et les représentations photographiques d'un lieu?

L'analyse de la place concrète et symbolique de l'écrivain dans les portraits de pays photo-illustrés des années 1950 et 1960 met à jour, au-delà d'une approche purement textuelle, les rapports de force et un difficile partage des territoires. De la place de l'écrivain à la place de la littérature, il y a peu à franchir. En cherchant à poser les bases d'une poétique de la collaboration, cette étude montre, à travers le goût pour les citations et les anthologies littéraires en particulier, que l'écrivain est autant une caution culturelle qu'un compilateur d'images.

\section{De la place concrète à la place symbolique: l'écrivain comme caution culturelle}

La place de l'écrivain est d'abord une question de paratexte : où et comment l'écrivain est-il mentionné sur la première de couverture, sur la jaquette, sur la page de titre ou en quatrième de couverture? L'écrivain n'est pas le seul auteur dans les portraits de pays photo-illustrés, qu'il signe avec des graphistes et des photographes, mais aussi, parfois des publicistes. Ainsi, dans Les Pays-Bas, trois noms figurent sur la page de titre: «Introduction / Pierre Mac Orlan // Photographies de Arielli // Commentaires / A. Ginsbourg» (FIG 1). La page suivante précise: "recherches iconographiques, maquette et mise en pages d'Arielli ». La couverture de Liban Lumière des siècles indique quant à elle «Texte liminaire de Max-Pol Fouchet // Photos Fulvio Roiter ». Les pratiques dépendent des maisons d'édition et sont révélatrices d'une politique éditoriale dans le cadre de laquelle la fonction dévolue au littéraire constitue l'un des facteurs déterminants.

Chez Marguerat, à Lausanne, par exemple, les écrivains apparaissent en premier, mais les photographes sont mis en valeur par des expressions comme « photographies 
originales » ou « inédites », ce qui «met l’accent, écrit Alessandra Panigada, sur le travail du photographe, auquel on doit également l'organisation de la partie illustrée » (Panigada 2012). Les pratiques peuvent également varier avec le temps dans les livres photo-illustrés, comme en témoigne le cas du fameux portrait de ville Paris de nuit: présenté en 1933 comme un livre de Paul Morand, avec « 60 photos inédites de Brassaï » - le nom du photographe n'étant sur la couverture originale pas plus gros que celui du directeur de la collection Jean Bernier - l'ouvrage phare de Brassaï voit ensuite le photographe tenir le haut de l'affiche tandis qu'est mentionné, sous la photographie de couverture, « Texte de Paul Morand ». Ce renversement dans les hiérarchies montre que la place de l'écrivain dans le paratexte dépend de son degré de notoriété mais aussi des pratiques d'époque.

Dans les portraits de pays photo-illustrés, les écrivains signent souvent la préface, qui, quel que soit son prestige, est un texte de statut secondaire. Dans Belgique, pays de plusieurs mondes, l'écrivain et le photographe apparaissent côte à côte, mis sur un pied d'égalité, séparés par une barre verticale sur la couverture (FIG 2). Mais l'ouvrage ne peut être considéré comme un livre de Franz Hellens : son texte, numéroté en chiffres romains est mentionné dans la table des illustrations à la fin, comme «Ouverture de Franz Hellens », tandis que l'auteur des photos n'est pas précisé. C'est donc qu'éditorialement parlant Belgique, pays de plusieurs mondes est donné à lire comme un livre de Maurice Blanc. Franz Hellens, écrivain belge reconnu, y a alors un statut d'invité, convoqué pour sa nationalité, sa célébrité et ce qu'il symbolise. Le fait que le nom du préfacier figure comme auteur en couverture montre que l'auctorialité pose problème dans ces objets hybrides.

Dans les livres de photographie portant sur les pays, les «introductions», «textes liminaires», avant-propos et autres préfaces ont un rôle plus évocatif qu'informatif. On demande aux écrivains de mettre l'eau à la bouche, en utilisant leur subjectivité et leurs souvenirs personnels. C'est là une mission dont Mac Orlan s'acquitte parfaitement dans Les Pays-Bas qui commence en Flandre belge (!), avec des souvenirs de Sluis et de Knokke, à la frontière, et enchaîne sur des souvenirs personnels de lectures et de peintures. Cette introduction, qui contient peu de choses sur les Pays-Bas, est davantage un texte sur l'imaginaire des Flandres et du Nord, ce qui justifie l'ajout des 
textes informatifs du publiciste Ginsbourg, qui sont quantitativement plus importants que le texte de Mac Orlan ${ }^{1}$. Dans cet ouvrage, les rôles évocateurs et informatifs sont clairement séparés, mais c'est loin d'être le cas partout.

Parfois, les éditeurs demandent d'autres textes que la préface aux écrivains. En général, il s'agit de rédiger les légendes des photographies, de manière plus ou moins développée. Ce phénomène semble constituer une véritable recette dans les livres de photographie sur Paris depuis le livre de photographie Paris vu par Kertész, dont préface et légendes sont rédigées par Mac Orlan, qui imagine, dans de vrais microrécits, la vie des lieux et des personnes apparaissant dans les photographies ${ }^{2}$. Ce sont aussi les légendes qu'on demande à Paul Morand pour Le Portugal que j'aime. Dans L'Espagne d'«Escales du monde», les photographies sont légendées par de courts textes, en italiques, qui semblent des citations de la préface, selon une vieille tradition du livre illustré. Cette pratique est une façon de réutiliser le texte littéraire, de resserrer le dialogue avec les photographies et peut-être de démultiplier l'écrivain. T’Serstevens se prête tout à fait à cette surprésence. «Tolède n'est qu'un dédale de ruelles à tous les plans de l'altitude » ou « Près de San Juan de Los Reyes qui se découpe ici sur le ciel bleu noir » (FIG 3) (T’Serstevens, 1952 : 19-20). Les légendes sont au-delà de l'informatif car si elles indiquent le lieu de la photo, elles insistent sur un détail pittoresque, utilisent la métaphore et l'emphase et expriment des opinions et sentiments personnels, bref, jouent la carte du « littéraire ».

Ce qui nous amène à l'une de nos questions principales : quelle est la valeur ajoutée de l'écrivain par rapport au journaliste, par exemple, dans ce genre éditorial ? Pourquoi leur confie-t-on préfaces et légendes plutôt qu'à un historien, un représentant politique, voire un diplomate? C'est que l'écrivain fait figure d'autorité culturelle d'un pays, mais que cette représentativité n'est ni celle de la diplomatie ni celle du monde politique: l'écrivain est un ambassadeur spirituel. Aussi l'écrivain est-il une caution culturelle. Dans Seuils, Genette estime que les jeux d'échos ou d'emprunts « apportent au texte la caution indirecte d'un autre texte, et le prestige d'une filiation culturelle » (Genette, 1987 : 87) : le nom d'un écrivain a lui aussi des effets connotatifs et implique tel ou tel type de discours (narratif, poétique, politique, historique, etc.). 
Une des valeurs ajoutées des écrivains dans ce genre éditorial est, il ne faudrait pas l'oublier, une caution institutionnelle. De nombreux textes de portraits de pays sont signés de membres "de l'Académie française», ce qui relève d'une tentative de séduction du grand public, mais aussi d'une quête de légitimité pour ces livres illustrés qui ne sont pas considérés comme littéraires et figurent, dans les librairies et les bibliothèques dans les rayonnages «Voyage », "Géographie», ou, pire, « Tourisme». Tout comme l'obsession du touriste est de se distinguer à tout prix des autres touristes (ainsi que l'a montré Jean-Didier Urbain), l'obsession des livres de tourisme est de se distinguer des autres livres de tourisme, notamment des guides, comme nous le rappelle un texte de présentation de la collection «Petite planète», en 1957 : «Le monde pour tout le monde : l'essentiel des connaissances actuelles sur un pays et tout ce qu'on ne trouve pas dans les guides » (Geneix, n.d.) ${ }^{3}$.

La place concrète de l'écrivain dans les portraits de pays photo-illustrés traduit sa place symbolique: c'est lui qui apporte une caution commerciale, culturelle et institutionnelle. En examinant maintenant plus en détail le partage des territoires dans ces collaborations éditoriales, on fera apparaître de nouvelles formes d'auctorialité.

\section{De la place au territoire : collaboration et partage de l'auctorialité}

Le territoire est un lieu en rapport avec une collectivité humaine, un lieu de rencontre, amené à évoluer, entre une population, une histoire, une géographie. Comme les territoires dont ils traitent, les portraits de pays sont des lieux de rencontre entre différents intervenants, même si les différents auteurs se sont contentés d'apporter leur pierre à l'édifice sans concertation. La collaboration est néanmoins plus riche lorsque les ouvrages ont fait l'objet de véritables rencontres, souvent souhaitées par les directeurs de collection et éditeurs. C'est le cas de la collection «Merveilles de la Suisse » où l'initiative revient à l'éditeur Jean Marguerat, qui met en contact le photographe et l'écrivain, «leur proposant de participer de façon collaborative à sa réalisation ${ }^{4}$ » (Panigada 2012). Parfois, la collaboration commence en dehors de tout support éditorial, comme c'est le cas entre Cendrars et Doisneau pour La Banlieue de Paris, publié en 1949, mais dans d'autres cas, souvent par pur opportunisme éditorial, l'écrivain ne rencontre même pas le photographe. 
De nombreux portraits de pays n'offrent pas de possibilité de rencontre interpersonnelle dans la mesure où les photographies proviennent de sources multiples, comme dans les collections «Petite planète » ou «Escales du monde ». En présentant cette dernière en préambule au volume sur la Hollande, André Siegfried utilise néanmoins le terme de «collaboration » : «Les éditeurs des Documents d'Art ont estimé qu'une collaboration de l'image, des écrivains et des poètes serait encore la meilleure formule » (Leprohon 1951 : XIII). La question de l'appropriation du livre et de l'espace de la photographie par l'écrivain se pose tout de même, comme on le voit dans L'Espagne où T’Serstevens intervient à trois endroits dans le dispositif du livre : dans le grand texte introductif "Âme et visages de l’Espagne», dans les légendes et dans les notices des photographies, réunies à la fin. C'est dans ces notices que l'écrivain semble trouver un espace qui lui convienne : il y développe de petits textes descriptifs qui peuvent inclure pensées et souvenirs de façon très libre, malgré leur caractère contraint - numérotés, mis en séries, avec la mention systématique de la source de l'image. Ces notices donnent à l'ouvrage un statut d'album personnel: «ce sont peut-être là-haut les ruines de l'Alcazar; je ne les reconnais pas de ce côté... » (T’Serstevens 1952 : t. 1, 101) est un commentaire subjectif, comme on le ferait avec un ami. La position de l'écrivain est parfois surprenante, refusant par exemple d'être un expert: «Je n'ai jamais vu ce précieux retable et m'en excuse (on ne peut pas tout voir) » (idem: 103). L'auteur profite de cet espace pour interagir concrètement avec les images, en commentant le travail du photographe, que ce soit pour le féliciter («Rien de plus typique que cette photo 31 . On y est ! Ça sent la gomina et la pâte dentifrice» (idem: 103)) ou le critiquer (« La photo donne l'illusion d'une oasis africaine. Ce n'est pas du tout ça » (T’Serstevens 1952 : t. 2, 109)). Dans les notices, beaucoup plus que dans le texte d'introduction, emphatique et définitif, l'écrivain se soucie des images qui sont présentées au lecteur. Elles deviennent prétextes à une réflexion générale sur le tourisme («Ceci me fait penser qu'on devrait faire un "Guide négatif du Tourisme" qui vous renseignerait sur tous les endroits à ne pas voir » (T'Serstevens 1952 : t. 1, 107)) et l'occasion de redresser les images faussées que peuvent donner la photographie, en les remettant en contexte et en élargissant la perspective : «Le touriste aurait tort de s'imaginer qu'on s'habille et danse ainsi tous les 
jours » (T'Serstevens 1952 : t. 2, 111) lit-on au sujet d'une planche couleur représentant des andalouses en costume de corrida.

Le portrait de pays photo-illustré met donc en cause l'auctorialité traditionnelle du littéraire en la situant en plusieurs lieux et en en chargeant plusieurs instances. Face à ce territoire à partager, certains écrivains laissent faire et se contentent de livrer leur texte, et d'autres, comme T’Serstevens, véritable spécialiste du genre, cherchent à reprendre la main, à saturer de mots les images, à les encadrer, par la préface, les notices et les légendes. D'autres encore prennent en main en photographiant euxmêmes les lieux qu'ils décrivent ${ }^{5}$.

Une des attitudes récurrentes face à cette auctorialité partagée est l'affirmation d'une supériorité du texte sur l'image. «Aucune photo ne peut donner une idée de cette craquelure de ruelles qu'est Séville » (idem: 102), lit-on dans L'Espagne et ils sont ainsi nombreux à affirmer le rôle de l'écrivain, comme s'il s'agissait de jouer des coudes face à une photographie efficace et envahissante. On retrouve dans bien des portraits de pays le besoin, pour l'écrivain, de définir l'objet auquel il collabore, et, par la bande, sa place dans ces ouvrages. Dans Les Pays-Bas, Mac Orlan écrit que le livre qu'il préface est « un témoignage plus efficace qu'un guide officiel: un témoignage de compréhension » (MacOrlan et Arielli 1965 : 5-6). C’est cette capacité de compréhension qui sert de caution à l'authenticité, valeur phare des portraits de pays. Celle-ci est garantie par la subjectivité de l'écrivain, à qui l'on demande de faire en profondeur le portrait de pays qu'il connaît.

Du point de vue de l'éditeur cette fois, l'authenticité est une des valeurs ajoutées de l'écrivain. Dans la présentation de sa collection, « Escales du monde », André Siegfried justifie le recours au texte ainsi :

les éditeurs [...] n'ont pas cru pouvoir se fier uniquement à l'image : ils ont estimé indispensable de recourir au texte écrit, c'est-à-dire au commentaire, à l'appoint de l'intelligence. [...] La photographie est toujours ce qu'il y a de plus exact, mais non pas nécessairement ce qu'il y a de plus vrai. (Leprohon 1951 : XI-XIII)

Il justifie l'apport du texte en reprenant l'opposition canonique entre réalité et vérité et en l'appliquant au rapport entre texte littéraire et images photographiques. Ici, 
ce n'est pas la subjectivité de l'écrivain qui sert de plus-value, mais ses capacités discursives. Le «vrai » est en quelque sorte le pouvoir du logos face aux images. Mais alors, quelle différence entre le discours de l'écrivain et un discours informé, journalistique ou scientifique?

C'est peut-être pour son sens de la complexité que l'écrivain est convoqué dans les portraits de pays. La tâche est en effet difficile : comment dépasser les contradictions d'un pays ? Comment rendre compte de la multiplicité et de la complexité ? C'est là un véritable topos du portrait de pays, exprimé avec beaucoup de justesse par Andrée Chedid dans le volume de «Petite planète » sur le Liban :

Petite terre. Quelques heures suffisent pour la sillonner, pour toucher ses frontières, les mots pour la décrire devraient tenir dans une coupe. Mais la phrase qui allait naître, s'inscrit dans le vent, balayée, gommée aussitôt. [...] // «N’y touchez pas », s'entend-on dire aussi. Trop d'imbrications, de complexités. Même à vol d'oiseau on ne s'en tire pas! Décrivez plutôt un pays lisse, d'une seule coulée ». «Un pays lisse ? ... Vous en connaissez ?... Ou bien un homme sans souterrains, des visages sans labyrinthes, des mots sans couloirs ? // Peu à peu l'obstacle aiguise l'appétit. L'insaisissable n'a aucune raison de décourager, il tient de la vie même. Abordons ce pays sans écarter la fascinante déraison, ni l'entendement du cœur ; [...]. (Chedid $1969: 6)$

Cette ouverture d'un portrait de pays très « littéraire » a l'allure d'une captatio benevolentiae, mais affirme clairement la force des «mots » qui « se pressent » au seuil du livre (idem: 7). Ce texte dit aussi combien le portrait de pays est un genre qui doit jouer avec les clichés et déjouer les attentes. Il n'est pas anodin que le texte de Cendrars sur le Brésil s'ouvre sur une satire des touristes des paquebots qui braquent leurs appareils photographiques sur le «Paradis terrestre» et font «tirer des photos au format des cartes postales illustrées que l'on mettrait par centaines dans la boîte aux lettres à la prochaine escale » (Cendrars 1952 : XI) : c'est là une façon d'opposer portrait photographique et portrait textuel, plus à même d'aborder un pays en profondeur.

Face aux belles planches du noir et blanc contrasté de l'héliographie ou aux spectaculaires reproductions couleur des portraits de pays dans lesquels ils publient, les écrivains font en effet souvent le choix de se concentrer sur leurs privilèges et de ne faire ce que ne peuvent faire que les mots. Le texte qui ouvre La Chine dans un miroir de 
Claude Roy est à cet égard symptomatique : «La Chine, bien entendu, ne ressemble pas : ce ne serait pas la peine d'être la Chine. Elle ne ressemble pas aux coteaux et aux expressions modérés, aux horizons et aux raisons mesurés au quart de millimètre, à ce clair génie français, à ce clair génie italien, à ce clair génie suisse [...] » (Roy 1953 : 7). Claude Roy choisit de dire tout ce que la Chine n'est pas avant de dire ce qu'elle est: «Pour ce qui est de la sagesse gréco-latine, des grandes traditions helléno-romaines, des jardins de curés, des vergers d'amour et des cieux gris couleur gorge de pigeon, il vaut mieux ne pas chercher cela en Chine » (ibidem). Cet incipit fait ce que ne peut faire qu'un texte, décrire par la négative. Il crée un effet d'attente qui appartient aux procédés de dramatisation.

Malgré ces tentatives de contrôle, la responsabilité éditoriale échappe nécessairement aux écrivains puisque les portraits de pays photo-illustrés sont des objets hybrides dont le sens se construit sur le texte, les images et les interactions qu'ils suscitent chez le lecteur. Avec ces bouleversements de l'auctorialité, le lecteur devient en effet une pièce maîtresse du dispositif. Philippe Ortel écrit ainsi qu'en « dotant d'un contexte iconique le texte et d'un contexte discursif l'image, [le livre illustré photolittéraire] fait émerger un ensemble d'indications réciproques dont la particularité est de n'exister que dans le regard du lecteur», ce qui l'amène à conclure : "l'écrivain ne peut donc pas contrôler complètement les effets de l'illustration. » (Ortel 2008 : 19) ${ }^{6}$

La place de l'écrivain est donc celle que lui donne le dispositif photo-textuel luimême, mais, aussi, sur un plan plus symbolique, le rôle qu'il accepte ou rêve de prendre dans une auctorialité partagée. Cette place symbolique est souvent renforcée par une large présence du littéraire dans les portraits de pays photo-illustrés.

\section{De la place de l'écrivain à la place de la littérature : anthologies et citations dans les portraits de pays photo-illustrés}

La place de l'écrivain dans les portraits de pays, au-delà de sa position et de son statut symbolique, engage la place de la littérature. On ne peut qu'être frappé, dans ces livres d'images, par la place donnée à la chose littéraire au sens large, notamment aux citations et à l'anthologie, que l'on peut considérer comme une forme développée de la citation. 
La citation a une fonction ornementale ou didactique, dans le cadre d'un discours informatif, comme, lorsque, dans un portrait du Brésil, Charles Vanhecke décrit Brasilia en construction en s'appuyant sur les déclarations de Lucio Costa et Oscar Niemeyer (Vanhecke, 1976 : 37), mais elle a un rôle spécifique dans les portraits de pays. Elle sert à insister sur une filiation et sur la pérennité des identités nationales, reprenant à son compte l'idée romantique selon laquelle la littérature exprime l'âme d'une nation.

Dans L'Espagne, de la collection «Les Beaux-pays», Yves Bottineau s'interroge : « qui ne se laisse séduire par l'invitation au voyage que l'Espagne nous adresse ? » et y répond par des «vers de Joan Salvat-Papasseit [qui lui] reviennent à la mémoire » (Bottineau 1959 : 11-12). La citation peut aussi être convoquée hors du texte introductif, isolée sur une page, comme dans le volume de «Petite planète » sur l'Italie où l'on trouve, en guise de légende d'une photographie d'une fontaine anthropomorphe de l'agence "Anderson-Giraudon» cette citation de Pétrarque : «Volgi a me gli occhi, e $i$ miei sospiri ascolta » (traduite par « Tourne vers moi tes yeux, et entends mes soupirs » (Lechat 1954 : 166-167) (FIG 4). Il s'agit ici de créer des échos en jouant sur la reprise du motif de l'œil et la circulation du regard sur la double page, mais aussi d'évoquer Pétrarque, figure centrale de l'identité italienne. D’une certaine façon, dans le texte ou isolée par la maquette, la citation convoque d'autres cautions culturelles. Certains portraits de pays, comme Liban d'Andrée Chedid, donnent une place privilégiée à la littérature, en particulier à la poésie qui se prête à merveille à la légende, au raccourci et aux effets d'écho ${ }^{7}$ : les poètes libanais Fouad Gabriel Naffah (14) et Djalal-Eddine Roumi (55) voisinent avec les poètes français comme Nerval (73) et le chapitre consacré à la langue et la culture s'ouvre sur une photographie de l'écrivain Leila Baalbaki (150).

Certains portraits de pays fournissent de véritables anthologies littéraires où les textes cités fournissent un portrait fragmenté et indirect, un portrait subjectif à plusieurs voix. Belgique, pays de plusieurs mondes fournit ainsi une large anthologie de textes littéraires concernant la Belgique : après les 11 pages de la préface d'Hellens et une inattendue recette de « choesels au Madère » (6), ce sont 35 extraits de prose ou poèmes qui accompagnent les photographies. On remarque que contrairement aux citations de Pétrarque ou de Joan Salvat-Papasseit, celles des autorités culturelles belges sont complétées par des écrivains français, puisque Verlaine y est aussi présent que 
Verhaeren. Les citations sont données comme texte autonome, et placées, dans une belle maquette, en écho aux photographies. Parfois, seul un vers est cité et sert de légende, en corrélation étroite avec les photographies, comme «La plaine immense et nue où les nuages passent... » et « les blanches maisons » de Verhaeren au-dessus de deux belles héliogravures au format carré (Hellens et Blanc 1956: 74-75) (FIG 5). L'effet anthologique permet ici de multiplier la présence d'écrivains de prestige contrairement aux livres photo-illustrés de Claude Roy qui s'attachent à une forme populaire de littérature.

Dans ses ouvrages, l'anthologie devient une véritable forme poétique. La France de profil de Claude Roy et Paul Strand présente une anthologie moins traditionnelle, composée de chansons médiévales comme «Le Roi Renaud» ou «Réveillez-vous Picards» (96), mais aussi d'une chanson antimilitariste de 1917 «La Chanson de Craonne » (97). Elles ne sont ni intégrées à un texte ni commentées, et leur mise en série crée un effet de collage. Claude Roy semble vouloir qu'un sens surgisse de ces textes comme lorsqu'il juxtapose sur une double page des petites annonces, faits divers et carnets roses (74-75). Dans le même ouvrage, on découvre, au-dessous d'une photographie de voiliers au port, la chanson «Les filles de la Rochelle». Les chansons, poèmes et textes littéraires sont des documents qui se joignent aux photographies de Paul Strand pour offrir un portrait « de profil », nécessairement partial et partiel, d'une France populaire, humble et rurale.

Dans La Chine dans un miroir, que Claude Roy publie l'année suivante, ce goût pour l'anthologie prend encore une autre ampleur. L'écrivain apparaît ici comme un compilateur de génie qui réunit, avec un beau texte introductif et une superbe maquette, photographies, dessins, chansons, poèmes, contes, avec une prédilection pour les « chansons enfantines », comme dans la double page sur le chameau (Roy 1953 : 44-45) (FIG 6). En effet, textes et photographies sont présentés comme des documents permettant de dresser le portrait de la Chine puisqu'en dessous des «illustrations photographiques», on trouve mentionnées des «illustrations littéraires » en page de titre. Le titre prend alors tout son sens: la Chine se présente au lecteur francophone «dans un miroir », c'est-à-dire à travers ses propres textes, même si le 
miroir de la traduction est nécessairement déformant. La Chine est vue par elle-même grâce à sa littérature populaire.

Même s'il ne s'agit ni de photographie, ni à proprement parler d'un portrait de pays, on évoquera ici Lisbonne voyage imaginaire de Nicolas de Crécy et Raphaël Meltz, exemple encore plus radical d'anthologie littéraire, puisque le texte utilise largement extraits de romans, récits de voyage, correspondance, etc. Ce récit de (non-)voyage illustré par le dessin obéit à la même logique anthologique de Belgique, pays de plusieurs mondes, La Chine dans un miroir ou La France de profil : il s'agit de proposer une vision d'un pays par ceux qui l'ont vu et décrit. Il s'agit également de se confronter à la difficulté que pose la question du stéréotype dans les portraits de pays. «Or, que sont les stéréotypes et les clichés sinon justement des citations? » (Compagnon 1979 : 29). En voulant décrire un pays, une ville, une région, on répète nécessairement ce qui a déjà été dit, contribuant à la constitution et au renforcement des clichés. Puisque tout a déjà été dit, ne faudrait-il pas maintenant recopier ? Puisque tout a déjà été dit, ne faudrait-il pas que l'écrivain se transforme en compilateur? Sans poser explicitement cette question ce qui conduirait à dévoiler le dispositif du livre -, l'ouverture de Lisbonne voyage imaginaire interroge les fondements du récit de voyage :

Dire du mal, d'accord. Mais, sinon, comment décrire, comment peut-on décrire une ville? Comment croire qu'on peut? Décrire quoi ? Par le menu, rue après rue, lieux après lieux, ou, au contraire, les sensations - petites notations poétiques qui, par fragments, composeraient le portrait de Lisbonne? Doit-on la diviser par quartiers? Chercher une cohérence : d'abord Baixa, ensuite Alfama, et puis après Bairro Alto ? Et le temps qui passe sur la ville, on le raconte, comment dans un récit de voyage? (De Crécy et Meltz 2002 : 8)

\section{Vers une poétique de la collaboration?}

Observer la place des écrivains dans les portraits de pays photo-illustrés permet de poser les bases d'une étude de la collaboration entre écrivains et photographes. Malgré les difficultés soulevées par le caractère hybride et hétérogène des portraits de pays et leurs impératifs techniques et commerciaux, c'est précisément leur caractère partagé et impur, à la frontière du littéraire et du non-littéraire, qui intéresse aujourd'hui. ${ }^{8}$ 
Certes, la Guilde du Livre accorde, plus que d'autres, une grande place à la littérature. Certes, la poésie de Claude Roy procède, plus que d'autres, par citations. Il n'empêche que la place de l'écrivain et de la littérature dans les portraits de pays photoillustrés de la sphère francophone est tout à fait privilégiée, reflétant ainsi le rôle dévolu à la littérature dans la sphère culturelle. Citations et effets d'anthologie montrent que la littérature occupe la place d'une voix collective, celle de la culture. Ce premier balisage permet également de faire apparaître quelques constantes à travers un corpus limité mais relativement représentatif : l'édition illustrée a besoin de l'écrivain comme caution culturelle et institutionnelle, c'est son regard à la fois informé et subjectif qui est recherché. L'écrivain est, pour l'éditeur, gage d'authenticité et de profondeur dans le portrait de pays : garant du respect de la complexité, il est aussi celui qui permet la synthèse. Aussi le texte ne s'oppose-t-il pas aux photographies : il les complète, les rend lisibles, et transforme, précisément, une série d'images en portrait.

\section{Bibliographie}

Aragon, Louis [1928] (1991), Traité du style, Paris, Gallimard, «L'imaginaire ».

Arielli et Mac Orlan, Pierre (avec des commentaires d'A. Ginsbourg) (1965), Les PaysBas, Paris, Albin Michel, « Itinéraire historique et contemporain ».

Bottineau, Yves (1959), L'Espagne, Paris, Artaud, « Les Beaux Pays ».

Bouillon, Marie-Ève (2014), « Le Panorama. Merveilles de France, Algérie, Belgique, Suisse », in Études photographiques, $\mathrm{n}^{\circ}$ 31, Printemps 2014, < http://etudesphotographiques.revues.org/3401> [20 avril 2015].

Bouvier, Nicolas (1967), Le Japon, Lausanne, éditions Rencontre, « L’Atlas des Voyages ». Cartier-Bresson, Henri et Robbe-Grillet, Alain (1968), Impressions de Turquie, Paris, Bureau de tourisme et d'information de Turquie. 
Cendrars, Blaise et Manzon Jean (1952), Le Brésil, Des Hommes Sont Venus, Monaco, Les documents d'art, « Escales du monde ». (réédité en 2010, Paris, Gallimard « Folio »). Chardonne, Jacques (avec des textes de Michel Déon \& Paul Morand) (1963), Le Portugal que j'aime, Mulhouse, Éditions Sun.

Chedid, Andrée (1969), Liban, Paris, Éditions du Seuil, coll. « Petite planète ». Compagnon, Antoine (1979), La Seconde main ou le Travail de la citation, Paris, Seuil.

Fouchet, Max-Pol et Roiter Fulvio (1967), Liban, Lumière des siècles, Lausanne, Éditions Clairefontaine.

Geneix, Nicolas. (en cours). "La collection "Petite Planète" (Seuil) - "Sous la direction de Chris Marker, 1954-1964"», Fabula, Atelier de création littéraire. $<$ http://www.fabula.org/atelier.php?La collection Petite Planete $>$ [20 avril 2015].

Genette, Gérard (1987), Seuils, Paris, Seuil.

Hellens, Franz et Blanc, Maurice (1956), Belgique, pays de plusieurs mondes, Paris, La Guilde du Livre.

Lechat, Paul (1954), Italie. Paris, Éditions du Seuil, coll. « Petite planète ».

Leprohon, Pierre (introduction par André Siegfried) (1951), La Hollande, Monaco, Les documents d'art, « Escales du monde».

Mac Orlan, Pierre (1934), Paris, vu par André Kertész, Paris, Éditions d'histoire et d'art, librairie Plon.

Meltz Raphaël et de Crécy, Nicolas (2002), Lisbonne : Voyage imaginaire, Paris, Casterman, « Carnets de voyages ».

Nourissier, François (avec une préface de Paul Morand) (1968), La Suisse que j'aime, Mulhouse, Éditions Sun.

Ortel, Philippe (2008), « Trois dispositifs photo-littéraires. L'exemple symboliste », in Montier, Jean-Pierre et al. (dir.), Littérature et photographie, Rennes, Presses Universitaires de Rennes, «Interférences », pp. 17-35.

Panigada, Alessandra (2012), «Les Éditions Jean Marguerat : Merveilles de la Suisse», Photo d'encre. Le livre de photographie à Lausanne, 1945-1975, exposition virtuelle sous la dir. d'Olivier Lugon. <http://wp.unil.ch/livre-photo/la-librairiemarguerat/merveilles-de-la-suisse/\#sthash.DWW07vXV.dpuf> [20 avril 2015]. 
Photo d'encre. Le livre de photographie à Lausanne, 1945-1975 (2012), Exposition virtuelle sous la dir. d'Olivier Lugon, UNIL, <http://wp.unil.ch/livre-photo/> [20 avril 2015].

Roy, Claude et Strand Paul (1952), La France de profil, Lausanne, La Guilde du Livre.

Roy, Claude et Collomb Denise (1953), La Chine dans un miroir, Lausanne, La Guilde du Livre.

Urbain Jean-Didier (2002), L'Idiot du voyage. Histoires de touristes, Paris, Petite Bibliothèque Payot.

Sved Étienne et Tzara Tristan (1954), L'Egypte face à face, Lausanne, La Guilde du Livre. T’Serstevens, Albert (1952), L'Espagne, Monaco, Les documents d'art, «Escales du monde ».

Vanhecke, Charles (1976), Brésil, Paris, Éditions du Seuil, coll. « Petite planète ».

Anne Reverseau est Post-doctorante à l'université de Leuven en Belgique, je travaille sur le document et l'esthétique documentaire dans la littérature française de 1900 à 1950. L'ouvrage tiré de ma thèse de doctorat sur l'imaginaire photographique dans la poésie moderne est sur le point de paraître en janvier 2015 aux PUPS (Le Sens de la vue. Le Regard photographique dans la poésie moderne française). J'ai récemment co-édité Poésie et médias, XXe-XXIe siècle (Paris, Nouveau Monde, 2012), The Aesthetics of Matter: Modernism, The Avant-Garde and Material Exchange (Berlin, De Gruyter, 2013) et le numéro 109 de La Licorne sur « Littérature et document autour de 1930 » (Rennes, PUR, 2014). Au sujet du documentaire géographique, je travaille actuellement à un volume sur les portraits de pays photo-illustrés pour la collection « Lire et voir » chez Minard et, en anglais, à un volume sur les portraits de villes photo-illustrés, aux presses universitaires de Leuven. 


\section{Liste des illustrations}

FIG 1 : Arielli et Pierre Mac Orlan. 1965. Les Pays-Bas, Paris, Albin Michel, «Itinéraire historique et contemporain ». Page de titre (DR).

FIG 2 : Franz Hellens et Maurice Blanc. 1956. Belgique, pays de plusieurs mondes, Paris, La Guilde du Livre. Page de couverture (DR).

FIG 3 : Albert T’Serstevens. 1952. L'Espagne, Monaco, Les documents d'art, « Escales du monde », pp. 19-20 (DR).

FIG 4 : Paul Lechat. 1954. Italie. Paris, Éditions du Seuil, coll. « Petite planète », pp. 166167 (DR).

FIG 5 : Franz Hellens et Maurice Blanc. 1956. Belgique, pays de plusieurs mondes, Paris, La Guilde du Livre, pp. 74-75 (DR).

FIG 6 : Claude Roy et Denise Collomb. 1953. La Chine dans un miroir, Lausanne, La Guilde du Livre, pp. 44-45 (DR).

\section{Notes}

${ }^{1}$ Les textes informatifs fonctionnent comme des légendes mais sont très développés. Ils occupent 40 pages.

2 Voir plus tard, les légendes de Claude Roy, pour Paris de René Burri (1950) ou celles de François Cali pour Sortilèges de Paris (1952), ainsi que les légendes d'Antoine Blondin pour Paris que j'aime (1956) et La France que j'aime (1964).

${ }^{3}$ Cette collection, lancée en 1952 au Seuil, était ainsi présentée en 1957 dans les encarts publicitaires des collections Microcosme (sans faire mention de l'illustration fort abondante pour l'époque). Une des particularités de la collection est qu'elle fait appel à des écrivains peu connus qui explorent le pays en profondeur et ne se contentent pas d'une préface.

${ }^{4}$ Elle ajoute « Dans la phase d'élaboration, l'ingérence de l'éditeur est apparemment minime. L'écrivain et le photographe ont une liberté presque totale, dans la mesure où ils respectent les accords pris préalablement. Lorsqu'il est nécessaire, l'éditeur intervient pour solliciter la remise du texte ou proposer des modifications, afin de respecter les délais fixés avec l'imprimeur et honorer ainsi l'engagement envers sa clientèle ». 
${ }^{5}$ Outre le cas de Nicolas Bouvier, bien connu, se glissent aussi des photos des auteurs dans L'Espagne de T’Serstevens ou des photos de Chris Marker dans la collection «Petite planète ».

${ }^{6}$ Le dispositif photo-textuel est analysé plus précisément dans la suite du texte : il s'agit, explique Philippe Ortel d'une relation par contiguïté mais aussi par modèles intériorisés : « chaque système sémiotique se transforme en outil interprétatif, capable d'agir sur son partenaire » (Ortel, $2008: 20$ ).

${ }^{7}$ Il faudrait développer la spécificité de la citation poétique et le rôle privilégié des poètes dans les portraits de pays et de villes. Dans le Paris des rêves d'Izis (Guilde du Livre, 1950) best-seller de l'édition photo-littéraire, chaque image est accompagnée d'un court texte manuscrit de nature en général poétique (Roy, Ponge, Eluard, Breton, Carco, Tardieu, etc.). Dans Lisboa, Cidade Triste e Alegre de Victor Palla et Costa Martins (1959), ce sont des textes de six poètes qui accompagnent les images.

${ }^{8}$ Cet article consiste en un balisage de problématique, premier jalon d'un projet de recherche plus large sur les portraits de pays, qui en est à ses débuts. Le premier ouvrage collectif que j'ai dirigé sur le sujet, intitulé Portraits de pays photo-illustrés, un genre photo-textuel, paraîtra en septembre 2015 dans la collection «Lire et voir» chez Minard, et constituera un panorama des objets d'études de ce projet de recherche collectif. 


\title{
Du relevé du réel au récit du lieu : voyage dans les Albums de Croquis d'Albert Laprade, architecte
}

\author{
Claire Rosset \\ Laboratoire Les Métiers de l'Histoire de l'architecte, édifices-villes-territoires \\ Ecole Nationale Supérieure d'Architecture de Grenoble \\ Université Grenoble-Alpes [France]
}

Résumé: L'architecte Albert Laprade (1883-1978) pratique le relevé d'architectures traditionnelles. Après un travail de re-dessin, il publie, de 1942 à 1968, ses croquis dans huit albums. Ils proposent un parcours à travers la France, l'Europe méridionale, l'Espagne, le Maroc et le Portugal. Nous nous intéresserons à la pratique du relevé d'architecture comme prise de mesure du réel. A partir des croquis issus des archives de l'architecte, nous analyserons la description architecturale des lieux. Nous examinerons ensuite le processus de re-dessin qui permit à l'architecte de transformer le croquis d'observation pour la publication, formulant l'hypothèse qu'au cours de ce travail, l'architecte construit une image pittoresque de l'architecture. Enfin, par la lecture de la composition des planches, nous interrogerons la mise en récit du lieu. Nous supposons que dans la publication de ces albums, l'architecte cherche à construire une image mythifiée des lieux représentés. Ainsi dans le processus qui conduit Laprade du relevé du réel à la publication de ces albums, nous chercherons à comprendre en quoi les outils de l'architecte lui permettent de participer à la mise en fiction du lieu.

Mots-clés: Laprade, architecte, lieu, mise en récit

Resumo: 0 arquiteto Albert Laprade (1883-1978) pratica o registo de arquiteturas tradicionais. Depois de um trabalho de redesenho, publica de 1942 a 1968, seus esboços em oito álbuns. Estes proporcionam uma viagem através da França, Europa do Sul, Espanha, Marrocos e Portugal. Interessar-nos-emos pela prática do registo da arquitetura enquanto medição do real. A partir de esboços de arquivos do arquiteto, 
analisaremos a descrição arquitetónica dos lugares. Examinaremos de seguida o processo de redesenho que permitiu que o arquiteto transformasse o esboço de observação no intuito da publicação, formulando a hipótese que, no decurso desse trabalho, o arquiteto vai construindo uma imagem pitoresca da arquitetura. Por fim, através da leitura da composição dos desenhos, questionaremos a narrativização do lugar. Supor-se-á que, nesta obra, o arquiteto procura construir uma imagem mitificada dos lugares representados. Assim, no processo que ao ler a composição dos conselhos, vamos questionar o lugar de contar histórias. Assim, no processo que leva Laprade do registo do real à publicação desses álbuns, procuraremos entender em que medida as ferramentas do arquiteto lhe permitem participar na ficcionalização do lugar.

Palavras-chave: Laprade, arquitetura, lugar, ficcionalização

«VEDERE E OVARE » «Observer et travailler»

DANTE

Ainsi s'ouvre l'album de croquis Europe méridionale et Asie mineure (Laprade 1952a) publié par l'architecte Albert Laprade (1883-1978), quatrième album de la série qui en comptera huit entre 1942 et 1967. Ces ouvrages se présentent tous sous le même format : des planches entièrement remplies de dessins à main levée d'architecture « au programme modeste » (Laprade 1952b: s.p.), à la «sensibilité populaire » (Laprade 1958: s.p.). Au fil des albums, ces croquis tracent un parcours à travers la France provinciale (en cinq volumes), Paris, l’Europe méridionale, l'Asie mineure, l’Espagne, le Portugal et le Maroc. La publication de ces carnets a connu un important succès de librairie dépassant le lectorat professionnel. Elle a participé d'une part à la reconnaissance de l'architecte au-delà de sa production bâtie ${ }^{1}$ et, d'autre part à la valorisation de l'architecture vernaculaire.

L'injonction « observer et travailler» révèle l'ambivalence de ces carnets, qui oscillent entre récit de voyage et recueil ou inventaire d'architecture vernaculaire. La publication de ces carnets est d'autant plus surprenante qu'elle ne renvoie à aucun type d'ouvrages d'architectes ou d'architecture ${ }^{2}$ et qu'elle semble dépasser une pratique 
traditionnelle d'architecte, le relevé, pour proposer un regard particulier sur les éléments représentés. Ainsi, à partir de l'expérience d'Albert Laprade et de la publication de ses carnets de croquis, nous chercherons à comprendre dans quelle mesure l'architecte, par la mobilisation de ses outils, participe à la mise en fiction des lieux.

Nous supposerons alors qu'Albert Laprade met en place un processus de narration dans la fabrication de ses carnets, transformant un savoir-faire architectural en récit par l'image.

Le corpus premier, élément déclencheur de la réflexion, est constitué des huit Albums de croquis publiés chez Vincent, Fréal \& Cie de 1942 à 19673. Ces albums constituent en soi une série éditoriale (Marpeau 2010), se répondant les uns aux autres par la structure même des ouvrages, comme par le voyage qu'ils proposent.4 L'objectif annoncé par l'architecte est celui de « conserver la trace de chefs-d'œuvre anonymes » (Laprade 1942a: s.p.).

Par ailleurs, nous ferons appel à un second corpus constitué des croquis in situ, des relevés à partir desquels Laprade a initié son travail de publication, et qui sont conservés aux archives de l'Institut Français d'Architecture ${ }^{5}$ (IFA). Le fonds est, entre autre, constitué de carnets de croquis et de dessins isolés (classés et triés par ordre alphabétique), ainsi que de quelques planches préparatoires aux ouvrages.

Croiser les deux corpus nous permet de mettre en évidence le processus de narration par la représentation. Nous l'analyserons en trois étapes :

- la pratique du relevé d'architecture,

- le procédé de re-dessin,

- la composition des planches des Albums de croquis.

\section{Relever le réel pour « apprendre à voir »}

Le dessin d'architecture est le dessin géométral : le dessin géométral est le dessin exact, on peut dire le dessin par excellence. Tandis que le dessin pittoresque représente seulement l'aspect des objets, tels qu'ils paraissent, le dessin géométral les représente tels qu'ils sont. (Guadet, 1901 : 35) 
La formation architecturale aux Beaux-Arts dote les architectes d'outils qui leur sont propres: un système de représentation de l'espace architectural, système géométral (plan, coupe, élévation). Comme le rappelle Philippe Boudon, le dessin d'architecte a la particularité de représenter un objet qui n'existe pas encore (Boudon 1992) ; la représentation géométrale est en cela outil de conception qui, au-delà de ce que dit Julien Guadet ( $c f$. supra), permet de représenter les objets tels qu'ils seront. Cependant, l'apprentissage passe, dans le même temps, par une pratique du relevé d'architecture qui, elle, vise à «dresser par l'intermédiaire de la représentation, le constat daté de la forme effective du bâti, avec comme référence, constante l'objet » (Saint-Aubin 1992 : p.16). Le relevé d'architecture est ainsi un outil de perception qui permet connaissance et analyse du bâti existant, notamment issu de la culture classique gréco-romaine. La pratique du dessin est alors, comme le rappelle Viollet-le-Duc dans l'ouvrage Histoire d'un dessinateur, une réelle méthode pédagogique permettant « le travail matériel, l'exercice de l'œil et de la main » (Viollet-le-Duc 1879).

Albert Laprade, entré aux Beaux-arts de Paris en 1903, pratique le relevé d'architecture. La consultation d'un carnet de croquis antérieur à sa formation (titré « $A$. Laprade $1^{\text {er }}$ carnet d'étude 1901-1902 $»^{6}$ ) montre une préparation au langage des formes classiques au cours d'un voyage privé à Rome. Le jeune homme relève les édifices de la grande culture (comme le Panthéon), et les éléments de composition architecturale (escaliers, portiques, colonnes ...), suivant les préconisations de Guadet : « ne faites pas de croquis en vue d'une collection de documents ; faites-les pour le profit d'étude que vous en titrez, pour apprendre à voir » (Guadet 1901 : 51). Lors de son séjour au Maroc dans les équipes de Prost, Laprade décentre sa pratique du relevé d'architecture vers un nouvel objet d'étude: l'architecture traditionnelle et vernaculaire. Par le dessin, il investit des cultures nouvelles et les introduit dans le champ scientifique, afin d'interroger les savoir-faire et les modes d'habiter locaux. Il prolongera cette pratique « de façon désintéressée pendant une vie entière, rapidement, pour [son] seul plaisir, parfois d'un train, d'un bateau, d'une auto ou d'un car, au cours d'un congrès, de visites de chantiers éloignés, et surtout à l'époque d'une jeunesse studieuse » (Laprade 1952b : s.p.). 
Nous analyserons donc les croquis conservés dans le fonds d'archive de l'IFA afin de comprendre en quoi le relevé est un outil de perception chez Laprade.

Les croquis présents dans les fonds sont tous réalisés in situ, à la mine de plomb dans la grande majorité des cas et collectés sur des carnets au format poche (de 6x8 cm à $12 \times 20 \mathrm{~cm})^{7}$. Le relevé, comme catégorie de représentation architecturale, passe «par deux décisions : le choix primordial de la taille de représentation, (...) et le choix du mode de visualisation » (Saint-Aubin 1992 : 18). L'échelle des représentations est, dans le cas présent, fortement déterminée par les dimensions du support. Dans ces conditions, il est intéressant de constater que celles-ci ne semblent pas influencer l'architecte dans le choix des éléments représentés. En revanche, dans la mesure du possible, les édifices sont cotés, voir doublés de détails à une autre échelle de représentation. L'échelle, en interrogeant la dimension des choses par rapport à l'observateur, est le premier marqueur de l'utilisation du dessin comme méthode de perception. L'utilisation des cotes ou des jeux d'échelles inscrit un niveau d'information supplémentaire et reflète une tentative de représentation objective de l'objet.

Du détail technique à la vue paysagère, des motifs de pavements au profil des rues, de la typologie d'habitat à la vue d'ambiance, Albert Laprade s'empare de tout type d'édifices, au moyen de la représentation géométrique et de la perspective. Hormis dans les pages de son $1{ }^{\text {er }}$ carnet d'étude, nous constatons que les éléments relevés sont, avant tout, de la « petite architecture $»^{8}$ (tente berbère, habitat modeste, ferronnerie, ...) et non pas les édifices reconnus par la culture architecturale classique. Par ailleurs, un certain nombre de croquis atteste des transformations, de la modernisation de l'espace habité au début du XXe siècle : relevé détaillé de mobilier sanitaire ou électroménager, groupes de distribution électrique, usines... L'hétérogénéité des éléments représentés, dans leur nature comme dans leur échelle, éloigne la démarche d'Albert Laprade de celle de l'inventaire, la rapproche d'une « façon d'éducation par l'habitude d'observer » (Violletle-Duc 1879 : 67).

Au-delà des dessins qui servirent de base aux Albums de croquis, certaines pages des carnets in situ nous ont paru particulièrement intéressantes. Sur quelques doublepages au format paysage, l'architecte consigne des croquis regroupés par thématique: les jardins, le calepinage des briques, les chapiteaux... Ainsi, à partir du coin en haut à 
gauche de l'espace de la feuille s'accumulent des séries de représentations détaillées ou schématiques. L'échelle de représentation est du même ordre de grandeur permettant de comparer les objets les uns aux autres. Au cours de cet exercice, il semblerait que l'architecte utilise la pratique du relevé pour constituer une boîte à outils personnelle autour d'éléments de composition. Le dessin apparaît ici, conformément aux préconisations de Viollet-le-Duc, comme «un moyen de consigner les observations à l'aide d'un langage qui les grave dans l'esprit » (Viollet-le-Duc 1879 : 61).

Le parcours dans les carnets de croquis in situ d'Albert Laprade révèle son aptitude à appréhender, à mesurer le monde par le dessin. L'architecte construit ainsi une connaissance spécifique du réel, basée sur un souci du dimensionnement, des matériaux et de l'ordonnance des éléments. Le dessin semble alors bien plus servir à apprendre à voir qu'à illustrer les mémoires qui relatent, par exemple, les voyages pittoresques du xix ${ }^{\mathrm{e}}$ siècle (Jeanjean-Becker, 2002).

Le relevé, le croquis d'observation est alors pour l'architecte un médium de description, un « outil d'investigation » (Recht 1998 : 11) des lieux. Par l'utilisation d'un langage non verbal (Arasse, 2004), il donne à voir un certaine lecture architecturale de l'espace.

\section{Re-dessiner pour figurer}

Chômeur dès le début de 1939, j'avais entrepris, pour occuper mon esprit, de réunir et de classer les notes sans nombre prises au cours de voyage à travers la France et le bassin méditerranéen, depuis l'Asie mineure jusqu'au Maroc. C'était innocemment me condamner à vingt-cinq ans de travaux forcés. (Laprade 1967 : s.p.)

Les «vingt-cinq ans de travaux forcés » auxquels Laprade a consentis furent davantage dus à l'important travail de re-dessin qu'a nécessité le passage du croquis in situ au croquis publié qu'au au fait de devoir réunir et classer ses nombreux croquis.

Cependant, avant même le travail propre à la publication, le procédé du re-dessin est présent dans la pratique d'Albert Laprade. En effet, sur le $1^{\text {er }}$ carnet d'étude notamment, les relevés sont dans l'ensemble tracés à l'encre. A la fin du carnet, la rigueur de l'exercice semble s'être estompée et le crayonné à la mine de plomb apparaît 
sous l'encrage. Dans l'élaboration de son premier carnet d'étude, Albert Laprade passe du croquis in situ au rend $u^{9}$. Ainsi, l'apprenti architecte travaille à la stabilisation de son trait, à la codification de la représentation et à la précision de son dessin que ne lui permettent probablement pas les conditions de relevé in situ. Le re-dessin est une manière de travailler sur le dessin lui-même pour en donner un nouveau niveau de lecture, qui s'éloigne de l'observation.

Dans le cas présent, nous constituerons plus précisément comme objet d'étude le processus de re-dessin propre à la publication. Annoncé pour pallier le chômage intellectuel lié à la Seconde Guerre mondiale, le re-dessin a fait l'objet d'un important travail d'agence, pour lequel Laprade sollicite de nombreux architectes. Vincent Barré rappelle la participation «d'excellents dessinateurs comme les architectes Brabant, Righi et Bouchain, son petit-fils Luc Barré ou le peindre Marie-Josèphe Tournon » (Barré 2006 : 6) : un «"esprit d'atelier" que l'architecte se plaisait à valoriser» (idem: 7). Le résultat de ce travail nous est accessible aujourd'hui en confrontant et en comparant le croquis in situ et le croquis publié.

Les dessins tels qu'ils sont conservés aux archives nous permettent de mettre en évidence plusieurs stades dans le travail de re-dessin. Nous constatons d'abord un premier système de classification des croquis découpés des carnets d'origine, qui procède par unité géographique ${ }^{10}$ et non par thématique comme avaient pu l'être certaines pages des carnets de croquis. Dans un deuxième temps, l'architecte opère un travail de sélection. Nous avons en effet identifié un système de codification, effectué au crayon rouge sur les dessins. Par ce deuxième temps de manipulation, Laprade inscrit un paratexte sur le croquis in situ grâce auquel il sélectionne ou rejette les croquis isolés, indique des manques sur les relevés (comme la hauteur d'une colonne) ou encore marque les traits de coupe ou les éléments à reprendre en détail. L'apposition de cette couleur rouge sur le croquis in situ démontre que ce dernier devient bien la matière première du croquis publié.

Enfin, le plus important du travail est dans le re-dessin lui-même qui transforme le crayonné in situ en dessin à l'encre. Le fait le plus flagrant, à la consultation des Albums de croquis, est la grande homogénéité graphique des croquis publiés. Cette unité interroge d'autant plus que de nombreuses personnes ont travaillé sur ce projet. 
Lorsque nous isolons les croquis publiés et les croquis de référence, nous pouvons identifier plusieurs éléments constitutifs de ce processus. Nous constatons que souvent, l'échelle de représentation est la même, ou du même ordre de grandeur. Laprade reste en ce sens assez proche du croquis d'observation. En revanche, nous remarquons un grand nombre de modifications du contenu des représentations. Si les croquis in situ étaient souvent synthétiques, voire non finis, l'ensemble des éléments publiés est abouti. Nous voyons alors les symétries des éléments inachevées dans le premier temps de dessin consciencieusement complétées. Le trait se précise, les rapports de dimensionnement se clarifient grâce aux annotations in situ des grandeurs, les remplissages ou les ombrages sont appliqués. Les transformations les plus impressionnantes sont celles qui semblent corriger en tout point le croquis initial. Dans le cas de la Maison du lieutenant, publié dans le deuxième album (Laprade 1942b), alors que le croquis initial notait par un dessin perspectif exécuté rapidement les ordres de grandeur de l'édifice, le positionnement des ouvertures et le rythme donné par les coursives extérieures, le dessin publié est d'une précision extrême : la diversité des matériaux apparaît, l'ensemble des percements de façade et l'accroche de l'édifice au sol (par le dessin des escaliers ou des pierres d'angle) également. Alors que le croquis d'observation était synthétique, donnant à voir ce sur quoi l'architecte avait porté attention: les éléments de composition et de rythme, le croquis publié fabrique une image de l'édifice qui se veut proche du réel.

Ainsi, dans le travail de re-dessin, Albert Laprade utilise le relevé comme médium de son dessin publié. Dès lors, il passe d'une représentation descriptive issue d'un processus d'investigation in situ à une représentation figurative de l'architecture. Il construit une image pittoresque de l'architecture en ce sens que l'homogénéité des dessins et le choix des éléments représentés cherchent essentiellement à redonner « l'aspect des objets » (Guadet 1901 : 35) et non à produire par le dessin une analyse de l'existant. Dans l'exercice du re-dessin, Laprade travaille à la fabrication d'une image subjective du réel rapprochant le travail de l'architecte de celui du peintre. Il passe ainsi du relevé comme outil de connaissance du réel au dessin comme outil de figuration de l'architecture. 


\section{Composer pour « donner à penser »}

Et ces notes éparses, prises sur des carnets, des bouts de papier, des dos d'enveloppes, ont été groupées, recalquées, pour former cette collection d'œuvres charmantes, rayonnantes d'esprit et de liberté, résultat tantôt d'une science extrême, tantôt de la plus divine innocence. (Laprade 1952a)

Du relevé au re-dessin, nous nous sommes intéressés à un travail sur l'architecture, sur la manipulation graphique de l'objet architectural. L'analyse des Albums de croquis dans leur forme complète nous met face à un autre enjeu : la question du lieu et de sa fabrication par l'architecte. En effet, comme le rappelle Laprade, l'objet même de ces albums était de montrer «l'ambiance des villes anciennes, ou des campagnes, et [de] rendre leur caractère » (Laprade 1967: s.p.).

La structure de tous les livres est similaire et sépare planches de croquis et préface rédigée par Laprade. L'ouvrage s'ouvre sur une carte de la région concernée par le volume, suivie du texte introductif et de l'ensemble des planches remplies de croquis. Les cartes simplifiées, probablement re-dessinées par l'architecte, ne présentent que les lignes de cote, les cours d'eau et certaines des communes présentes dans les planches. L'ensemble de ces éléments a la même valeur graphique. Par ailleurs, ces cartes ne sont pas délimitées par un cadre, et les traits se perdent dans le blanc de la planche. Ainsi, non seulement elles construisent une homogénéité à l'intérieur la région représentée, mais leurs contours flous invitent à la poursuite du voyage, appellent les autres régions, les autres Albums. Les préfaces des ouvrages, quant à elles, reviennent sur la démarche et l'objectif de ces publications, en revendiquant une lecture des territoires par leurs acteurs, ces «gens de métiers: architectes, maçons, appareilleurs, menuisiers, serruriers » (Laprade 1952: s.p.) et par le savoir-faire populaire, local, traditionnel. Ainsi, avant même le parcours des régions par le croquis, Albert Laprade précise son objet d'étude : un lieu édifié, habité.

Nous cherchons ensuite à comprendre comment l'architecte Albert Laprade construit le lieu en utilisant l'Album, la publication comme médium. Nous analyserons ainsi la composition des planches de croquis, considérant avec Hélène Jannière la « page comme espace de production » (Jannière 2002: 49) dans les publications d'architecte au 
début du $\mathrm{xx}^{\mathrm{e}}$ siècle. Nous verrons donc dans quelles mesures ce travail participe à la mise en fiction du lieu.

La composition des planches est difficile à appréhender du fait de la masse d'informations qu'elle organise (ou désorganise). Les pages rassemblent un grand nombre de croquis (en moyenne entre quinze et vingt pour les planches étudiées) sous une entité géographique inscrite de manière systématique en bas à droite de la page. Face à ces planches dont l'espace est totalement occupé, l'observateur éprouve la sensation première d'un capharnaüm. Elle est renforcée par la juxtaposition d'éléments de nature et de dimensions différentes comme par exemple le profil d'une rue et le détail d'une vasque de fontaine. Ainsi, Laprade privilégie une lecture d'ensemble en saturant l'espace de la planche en la privant d'un sens de lecture. L'homogénéité graphique de l'ensemble des planches et le glissement d'une localité à une autre différencie son travail d'une classification d'ordre typologique même si les éléments sont regroupés sous une entité géographique. Ainsi, au regard pressé ou oisif, il propose une image globale du lieu.

Les quelques espaces qui ne sont pas occupés par les croquis le sont par des légendes manuscrites. Le système des légendes construit un second temps d'appréhension des planches. En effet, sans gêner la lecture globale de la planche ni celle des édifices représentés, il oblige à entrer dans le détail de la page, à chercher l'information. Les légendes sont de deux natures: des informations descriptives, factuelles (nom de rue, matériau, date, fonction, etc.) et des annotations appréciatives qui souvent portent un jugement de valeur sur l'objet présenté («on en trouve beaucoup », «cette charmante vieille masure», ....). ${ }^{11}$ Ce paratexte rapproche les planches de l'album du récit ou du guide de voyage, doublant la description architecturale du lieu par de petites histoires ponctuelles qui achèvent d'inscrire la représentation des édifices dans un style narratif.

La fabrication d'une image des lieux passe également par la confrontation des croquis re-dessinés à l'espace de la page. Dans un premier temps, nous constatons que si tous les types de représentation géométrale sont encore présents dans les Albums et systématiquement cotés, la majorité des dessins sont des élévations voire des vues perspectives. En privilégiant ces modes de représentation plus proches de la perception, 
l'architecte semble s'attacher à construire l'image d'un lieu plus qu'à analyser l'architecture. ${ }^{12}$

Par ailleurs, la juxtaposition d'éléments de nature différente et d'échelles variées rapproche les Albums des carnets de croquis. En effet, en disposant sur l'espace de la même planche des éléments sans rapports de proportions, l'architecte se rapproche de la prise de note in situ, où l'espace disponible détermine l'échelle de représentation. De plus, il s'agit ici d'un contre-pied total avec la composition architecturale classique qui suppose de faire correspondre plan, coupe et élévation à la même échelle pour une compréhension la plus objective possible de l'édifice. Cette composition pittoresque (au sens du regard du peintre) encourage au contraire le mouvement personnel et aléatoire de l'œil sur la planche et favorise l'effet de surprise.

Chez Laprade, le croquis in situ isole l'élément architectural de son contexte pour s'attacher à une lecture architectonique du bâti. A l'inverse, la composition des planches met en regard les différents édifices construisant ainsi un nouveau contexte : l'élément architectural s'insère dans un nouveau lieu. La force de ce processus est qu'il ne restreint pas le lieu à une image figée mais permet d'en faire naître une multitude toujours renouvelée par le lecteur.

Le dernier élément surprenant et qui nous conforte dans l'hypothèse d'une mise en récit des lieux par l'architecte est l'adjonction de personnages sur un grand nombre de représentations. L'utilisation du corps dans les représentations architecturales est fréquente : elle permet en un coup d'œil de donner une échelle à l'édifice représenté. Cependant, dans le cas présent, ces personnages sont annoncés à la fin de chaque préface, à la manière d'un avertissement: «à travers ces croquis, diverses figures dessinées par Arlette Barré-Laprade ${ }^{13}$ ». Au-delà de cette précision, une attention particulière à ces figures révèle qu'elles sont, dans leur majorité, anachroniques, vêtues ici d'habits vernaculaires, là de costumes datables de l'époque romantique ou de la Renaissance par exemple. Leurs attitudes participent à rendre vivantes les représentations, à les transformés en scènes. L'espace architectural se transforme alors en un lieu habité. Le décalage temporel entre l'époque de l'observation, le $\mathrm{xx}^{\mathrm{e}}$ siècle, et l'époque représentée fait écho à la volonté d'Albert Laprade de «conserver la trace » (Laprade 1942a: s.p.) en « voyant le Passé en homme de [son] temps » (Laprade 1952a: 
s.p.). En faisant appel à ces figures, l'architecte crée une histoire fictive des lieux qui une fois de plus favorise l'imagination plus que l'approche scientifique.

Paul Ricœur considère que «la mise en récit projette dans l'avenir le passé remémoré » (Ricœur 1998: 45). En nous proposant une lecture non verbale, graphique, cumulative et non-linéaire de l'architecture traditionnelle des différentes régions de France ou du bassin méditerranée, Albert Laprade travaille, dans les Albums de croquis, à une mise en récit des lieux. Concluant la préface du Premier Album par l'injonction «Puissent les planche de ces albums être comme des idées et donner à penser», il démontre qu'il est conscient du pouvoir de fictionnalisation du lieu que recèle le croquis d'architecture.

\section{Relever l'architecture, raconter le lieu}

«Voir, c'est savoir» affirmait Viollet-le-Duc dans Histoire d'un dessinateur. Comment on apprend à dessiner (Viollet-le-Duc 1879). En effet, en mobilisant le relevé comme outil de mesure de l'existant, du bâti, l'architecte mobilise simultanément ses facultés visuelles et sa capacité à les transcrire graphiquement. Il conduit ainsi un « effort de description » qui aide à « bien voir » (Recht 1998: 11) en dimensionnant, nommant, classant, hiérarchisant les éléments architecturaux. Le travail de re-dessin permet, dans un deuxième temps, de dépasser la description architecturale du réel pour en donner une représentation figurative. L'architecte transgresse les informations contenues dans le relevé et en propose une interprétation. Il construit ainsi une image subjective, ici pittoresque, du réel. Enfin, la présentation des planches des Albums, en confrontant les figures architecturales les unes aux autres, établit une séquence narrative qui propose un voyage à travers des lieux re-composés, fictifs.

Ainsi, à travers Albums de croquis, Albert Laprade met en place un processus qui transforme le relevé d'architecture en récit du lieu. La mobilisation de ses outils d'architecte (la représentation architecturale, le re-dessin, la composition) et des possibilités offertes par la publication lui permet le passage de la description à la narration. Alors, en prenant en compte un acteur supplémentaire : le lecteur, la mise en fiction permet de dépasser le «voir, c'est savoir » et laisse imaginer un voir, c'est savoir et c'est donner à voir, c'est « donner à penser »! 
La lecture du processus développé par Laprade dans les Albums de croquis, met en évidence la capacité des outils et savoir-faire de l'architecte à raconter le lieu. Au-delà de ce constat, plusieurs interrogations émergent. Quel statut ont les préfaces dans les Albums, et quel rôle joue l'écrit littéraire pour l'architecte? Dans quelle mesure la mise en scène du métier d'architecte par Laprade participe-t-elle à brouiller les limites entre espace réel et espace représenté ? Et enfin, comment interroger la réception de ces Albums par le lectorat et leur participation aux débats contemporains de leur publication?

\section{Bibliographie}

Arasse, Daniel (2004), Histoires de peintures, Paris, France culture/Denoël.

Barré, Vincent (préface) (2006), Les carnets d'architecture d'Albert Laprade, Paris, Kubik éditions.

Boudon, Philippe (1992), "“Ceci sera une pipe”, ou de l'espace de représentation à l'espace réel », in Le dessin et l'architecte. Excursion dans les collections de l'Académie d'architecture, Paris, Éd. du Demi-cercle, éd. du Pavillon de l'Arsenal, pp. 21-23.

Carpo, Mario (2008), L'architecture à l'âge de l'imprimerie : culture orale, culture écrite, livre et reproduction mécanique de l'image dans l'histoire des théories architecturales. Paris, Éd. de la Villette.

Chabard, Pierre, Kourniati, Marilena (dir.) (2013), Raisons d'écrire : livres d'architectes, 1945-1999, Paris, Éd. de la Villette. 
Garric, Jean-Philippe, Nègre, Valérie, and Thomine, Alice (dir.) (2008), La construction savante : les avatars de la littérature technique, Paris, Éd. Picard/ INHA.

Guadet, Julien (1901), Eléments et théorie de l'architecture, Paris, Aulanier et Cie.

Jannière, Hélène (2002), Politiques éditoriales et architecture moderne : l'émergence de nouvelles revues en France et Italie (1923-1939), Paris, Éd. Arguments.

Jeanjean-Becker, Carol (2002), «Les récits illustrés de voyages pittoresques : une mode éditoriale », in Leniaud, Jean-Michel, Bouvier, Béatrice (dir.), Le livre d'architecture : $x v^{e_{-}}$ $x x^{e}$ siècle, Paris, École des chartes, pp. 23-51.

Laprade, Albert (1942a), Croquis. $1^{\text {er }}$ Album, Du Nord à la Loire, Paris, Vincent, Fréal et Cie.

Laprade, Albert (1942b), Croquis. $2^{e}$ Album, Région de l'est, Paris, Vincent, Fréal et Cie.

Laprade, Albert (1952a), Croquis. Europe méridionale et Asie mineure, Paris, Vincent, Fréal et Cie.

Laprade, Albert (1952b), Croquis. $3^{e}$ Album, Région du Midi, Paris, Vincent, Fréal et Cie. Laprade, Albert (1957), Croquis. $4^{e}$ Album, Région du Centre, Paris, Vincent, Fréal et Cie. Laprade, Albert (1958), Croquis. Portugal, Espagne, Maroc, Paris, Vincent, Fréal et Cie. Laprade, Albert (1967), Croquis. 5e Album, Région de l'ouest, Paris, Vincent, Fréal et Cie. Laprade, Albert (1967), Croquis. Paris, Quartier du Centre, les Halles, le Marais, Paris, Vincent, Fréal et Cie.

Leniaud, Jean-Michel, Bouvier, Béatrice (dir.) (2002), Le livre d'architecture : $x v^{e}-x x^{e}$ siècle, Paris, École des chartes.

Lucan, Jacques (2009), Composition, non-composition: architecture et théories, $x^{2} x^{e}-x^{e}$ siècles, Lausanne, Presses polytechniques et universitaires romandes.

Marpeau, Benoit (2010), « La collection, objet éditorial paradoxal ». Cahiers du CRHQ [en ligne], $\mathrm{n}^{\circ} 2$, pp. 4-18, <http://www.crhq.cnrs.fr/cahiers/2/c2.pdf> [07-08-2014]. 
Recht, Roland (1998), «Introduction », in Recht, Roland (dir.), Le texte de l'œuvre d'art : la description, Strasbourg, Presses universitaires de Strasbourg/Musée d’Unterlinden, pp. 11-17.

Ricoeur, Paul (1998), « Architecture et narrativité ». Urbanisme, n³03, pp. 44-51.

Saint-Aubin, Jean-Paul (1992), Le relevé et la représentation de l'architecture, Paris, Association Études, loisirs et patrimoine.

Viollet-le-Duc, Eugène-Emmanuel (1879), Histoire d'un dessinateur, comment on apprend à dessiner, Paris, J. Hetzel.

Claire Rosset est architecte diplômée d'état. Elle est doctorante en architecture depuis décembre 2012 au sein du laboratoire Les Métiers de l'Histoire de l'Architecture, édifices-villes-territories, à l'Ecole Nationale Supérieure d'Architecture de Grenoble, sous la direction de Catherine Maumi, et en contrat CIFRE avec le CAUE de Haute-Savoie. Son travail de thèse, intitulé « De l'architecture comme médium au média-architecture: construction d'un imaginaire et pensée du monde moderne. Albert Laprade et la culture locale au XXe siècle », interroge la construction d'un regard instruit et d'un discours architectural par les architectes au début du XXe siècle, dans la mise en place d'une pensée du projet à la fois locale et moderne. 


\section{Notes}

${ }^{1}$ Albert Laprade, diplômé des Beaux-Arts de Paris en 1907, commence sa carrière en 1915 au Service des Plans de Villes au Maroc, dans l'équipe de l'architecte-urbaniste Henri Prost et du maréchal Lyautey. De retour à Paris, il s'inscrit sur la scène architecturale française lors de l'Exposition internationale des arts décoratifs (1925) ou avec le garage Citroën de la rue Marbeuf à Paris (1928-1929). D’autres édifices, comme le Musée permanent des colonies pour l'Exposition coloniale de Paris (1931) ou le barrage de Génissiat (1939-1950), acquièrent une renommée importante. Laprade participe également à de nombreuses rédactions de revue d'architecture.

${ }^{2}$ Aujourd'hui, un certain nombre d'études s'intéresse à la publication architecturale. Nous pouvons citer, en plus du travail pionnier de Mario Carpo (Carpo, 2008), les travaux sur le livre et l'architecte (Leniaud et Bouvier, 2002), sur la littérature technique en architecture (Garric et al., 2008), ou encore sur les « raisons d'écrire » de l'architecte (Chabard and Kourniati, 2013).

${ }^{3}$ Nous en trouverons la bibliographie complète en fin d'article. Si le titre de ces ouvrages suit le type Croquis. Premier. Du Nord à la Loire, pour alléger le texte et la lecture nous ferons appel à eux en mentionnant simplement Album(s) de croquis ou Album(s).

${ }^{4}$ Le fait de fractionner la France en plusieurs régions situe dès l'origine les publications dans une logique sérielle. De plus les introductions comportent de nouveaux renvois vers des Albums passés ou à venir.

${ }^{5}$ Les archives de l'IFA, fonds Albert Laprade 317AA, comptent près de 35000 croquis et de nombreux carnets.

${ }^{6}$ Archives IFA, fonds Albert Laprade 317AA5-7

7 Si la majorité des croquis sont isolés de leur support d'origine et, après un travail archivistique, regroupés dans des classeurs par ordre alphabétique des lieux représentés, le format et le type de papier renvoient aux carnets encore présents que nous avons pu feuilleter.

8 « Petite architecture », expression utilisée par Albert Laprade dans une de ses notices biographiques Archives nationales 403AP180

${ }^{9}$ Le rendu, dans la tradition architecturale classique, s'oppose à l'esquisse qui est une représentation spécifique à la phase d'étude du projet. Le rendu peut alors être considéré comme «l'habilité et la recherche d'effets graphiques développées par les élèves [des Beaux-arts] au détriment souvent de la représentation exacte ou vraisemblable des données constructives » (Lucan, 2009 : 123).

${ }^{10}$ La mise en place de ce système de classification est accentuée par la présentation actuelle des archives, triant les croquis par ordre alphabétique des villes. Cependant, compte tenu de la présentation des Albums de croquis, il semble incontournable que l'agence ait procédé de la sorte. 
${ }^{11}$ L'utilisation de la légende dans la construction d'un discours secondaire par Albert Laprade a été en partie étudiée lors de notre intervention «Article vs. album. Mise en jeu des dispositifs éditoriaux par Albert Laprade » à la Journée d'étude doctorale Critique et historiographie à Rennes le 7 février 2014.

${ }^{12}$ L'analyse des détails constructifs publiés renforce cette hypothèse : ils sont en définitive assez peu opératoires et semblent plutôt participer à la mise en scène d'un savoir-faire professionnel.

${ }^{13}$ Arlette Barré-Laprade, une des filles de l'architecte, est sculpteur de profession. 



\title{
Territoire et imaginaire néolibéral. Buenos Aires
}

\author{
Fernando Stefanich \\ Université de Lorraine (Metz)- Laboratoire Ecritures
}

Résumé: A partir des années 90, la ville de Buenos Aires modifie radicalement son profil. Les groupes sociaux - qui luttent pour les ressources, les espaces et les symboles - sont soumis à des forces centrifuges et centripètes. Le centre-ville s'atomise, les quartiers privés prolifèrent à la périphérie tandis que les déclassés remplissent les bidonvilles. Cet éclatement du territoire est dû à la politique néolibérale qui ne fait qu'accroître les inégalités et qui forge un nouvel imaginaire dominé par l'état de nature (Hobbes), le néo-tribalisme (Maffesoli), les peurs sociales et les obsessions sécuritaires (Bauman). Pour mener à bien ce projet, qui confrontera au moins deux romans - Las viudas de los jueves de Claudia Piñeiro, Puerto Apache de Juan Martini et El muchacho de los senos de goma de Sylvia Iparraguirre - nous ferons appel, entre autres disciplines, à la sociologie urbaine, la sociocritique et la narratologie.

Mots-clés: Buenos Aires, territoire, imaginaire

Resumo: A partir dos anos 90, a cidade de Buenos Aires modifica radicalmente o seu perfil. Os grupos sociais - que lutam por recursos, espaços e símbolos - estão submetidos a forças centrífugas e centrípetas. O centro da cidade atomiza-se, os condomínios fechados proliferam na periferia enquanto os desfavorecidos enchem os bairros de lata. Esta divisão do território é devida à política neoliberal que não faz senão aumentar as desigualdades e forja um novo imaginário dominado pelo estado de natureza (Hobbes), o neotribalismo (Maffesol), os medos sociais e as obsessões securitárias (Bauman). Para levar a cabo este projeto que confrontará pelo menos dois romances - Las viudas de los jueves de Claudia Piñeiro, Puerto Apache de Juan Martini e El muchacho de los senos de goma de Sylvia Iparraguirre - socorrer-nosemos, entre outras disciplinas, da sociologia urbana, da sociocrítica e da narratologia.

Palavras-chave: Buenos Aires, território, imaginário 
Ce travail a pour but d'analyser la transformation de la ville de Buenos Aires au cours des années 90, années marquées par la primauté du néolibéralisme. La situation économique attire des habitants des autres villes et des pays limitrophes. La capitale argentine modifie radicalement son profil. Les groupes sociaux - qui luttent pour les ressources, les espaces et les symboles - sont soumis à des forces centrifuges et centripètes, ascendantes et descendantes. Ils se livrent à un travail de sacralisation et désacralisation du territoire, de construction et déconstruction.

Notre corpus comporte trois romans : Las viudas de los jueves (Claudia Piñeiro), Puerto Apache (Juan Martini) et El muchacho de los senos de goma (Sylvia Iparraguirre). Publié en 2005, le premier décrit les conditions de vie dans un quartier privé tandis que le second, qui date de 2002, rend compte de la réalité du pays à travers le regard des habitants d'un bidonville. Le troisième texte, celui de Sylvia Iparraguirre, nous fait découvrir la ville en brossant le portrait d'un vendeur à la sauvette, Cristóbal, jeune homme débrouillard qui commercialise des produits d'importation.

\section{Le contexte}

Le cas qui nous occupe est l'Argentine des années 90. Pour cela, il faut faire un peu d'Histoire. Pour Naomi Klein, le libéralisme est introduit en Amérique latine le 11 septembre 1973, date du coup d'État de Pinochet au Chili. Klein décrit en détail le débarquement des théories de Milton Friedman et de l'École de Chicago, leur lutte contre les développementalistes, le rôle de la Fondation Ford. Klein définit le coup d'État de Pinochet contre Salvador Allende comme «partenariat entre l'armée et les économistes » (2008: 92).

En 1983, le pays se libère de la dictature. Cette année-là, les deux partis historiques s'affrontent. Lúder pour le péronisme et Alfonsín pour le radicalisme. C'est ce dernier qui remporte les élections. La gestion d'Alfonsín peut être qualifiée de gouvernement de transition; il essaie de pacifier le pays (théorie des deux démons) et réussit à consolider la démocratie en faisant face à deux tentatives de coup d'état. Vers la fin de son quinquennat, l'hyperinflation éclate et Alfonsin doit avancer les élections.

En 1989, Carlos Menem est élu président. Il était, jusqu'alors, gouverneur de la province de La Rioja. Il faut signaler que certaines régions du pays sont le fief d'un 
homme ou d'une famille, elles gardent encore des traces du féodalisme espagnol. Ainsi, nous trouvons Menem à La Rioja, Saadi à Catamarca ou encore Rodríguez Saá à San Luis.

Menem réussit à désamorcer le péril militaire et qu'il tente de pacifier le pays par le biais d'une série d'indults. En outre, il flexibilise le travail et réduit l'État en privatisant (bradant?) ses entreprises (trains, YPF, Aerolíneas Argentinas). C'est l'époque de la performance. Un minimum d'État pour un maximum de marché. Ces privatisations ont été possibles grâce à la «stratégie du choc » décrite par Naomi Klein (les crises sont des chocs qui permettent aux gouvernements d'introduire des réformes violentes et impopulaires). Dans le cas qui nous concerne, le choc fut produit par l'hyperinflation alfonsiniste.

\section{De la crise comme un marathon de danse}

Georg Simmel, dans Les pauvres, nous éclaire sur la relativité du concept de pauvreté : «La relativité de la pauvreté ne correspond pas à la relation entre les moyens individuels et les fins individuelles réelles mais aux fins liées au statut de l'individu, à l'apriori social qui varie selon le statut. » (apud Etienne et Mendras 1996:149) Autrement dit, la pauvreté existe dans toutes les classes sociales. Le métier de bourgeois exige une mise en scène, un style de vie difficile à maintenir du fait des fortes turbulences que provoque la crise. Il nous paraît pertinent de citer ici l'anecdote qu'Ernst Bloch ramène à la mémoire dans Héritage de ce temps : «La salle des fêtes de Francfort a organisé [...] un Championnat International de Marathon de Danse. [...] les couples doivent conserver un aspect socialement digne. La dignité du soulier verni étroit, des faux cols, [...] Le vainqueur du championnat est le couple qui est le dernier à s'effondrer sur le parquet de danse » (Bloch 1977 : 40). L'anecdote reflète avec précision l'esprit de l'époque. Cette vision de la vie contemporaine comme un marathon de danse se manifeste aussi, comme il est logique, dans les phénomènes de surface. Les émissions télévisées (Loft Story, Survivor, Le Maillon faible) se fondent sur la «jetabilité » des humains et sur leur élimination; ainsi, dans Les veuves du jeudi, nous lisons : «Son but [celui du Tano], ce n'était pas de cacher sa déchéance aux autres, c'était de ne pas se laisser déchoir. (Piñeiro 2014 : 278) » Le monde Big Brother est un monde « d'individus 
qui ne peuvent compter que sur leurs propres ruses et tentent de se montrer plus malins les uns que les autres et de s'entre éliminer (Bauman $2008: 110$ )».

\section{Ville et imaginaire}

La cartographie aussi bien que le cadastre révèlent la réalité physique de la ville, le simple inventaire de ses accidents géographiques, de ses rues, avenues, ponts et constructions, mais il est impossible de définir une ville rien qu'à partir de sa stricte réalité matérielle (Cambier 2005 : 84).

On sait que les utopies sont en rapport avec la situation de certaines classes sociales à un moment historique donné. Autrement dit, les utopies constituent dans un premier moment des créations de l'imagination (phantasie) d'un groupe social - ce sont le produit de l'imaginaire social - et ont pour but la transformation de l'ordre existant. La Génération de 80 prend le pouvoir dans l'Argentine de la fin du dix-neuvième siècle et c'est précisément l'utopie européanisante de ce groupe - avec des personnalités telles que Lucio Mansilla, Eduardo Wilde, Miguel Cané - qui façonnera la capitale. C'est la période où l'on entreprend la rénovation du port, la construction du Théâtre Colón, du Palais Barolo, du Palais du Congrès et du Palais de Justice, l'inauguration de l'Avenue de Mayo et la réalisation de travaux de construction sous la direction d'architectes français tels que René Sargent (responsable des Palais Alvear, Errázuriz, Bosch) ou Jules Charles Thays qui serait nommé Directeur de Parques y Paseos en 1891 et qui concevrait de nombreux travaux publiques: le Jardin Botanique et les Bois de Palermo, les parcs Lezama, Centenario ou Rivadavia, les places Constitución, Congreso et la Place de Mayo. La source d'inspiration est le Paris de Haussmann. La célébration fastueuse et pompeuse du Centenaire illustre clairement la mentalité de l'époque.

Ainsi, la ville de Buenos Aires est historiquement divisée en deux : un centre construit autour de la Place de Mayo, l'ancienne Place Mayor du temps de la colonisation espagnole, et les quartiers périphériques. L'épidémie de fièvre jaune de 1871 provoquera le déplacement des familles aisées vers le nord de la Place de Mayo (plus tard, à partir de 1914 font leur apparition les commerces et les services publics donnant naissance à ce qu'on appelle la City), alors que l'ancien centre historique - Montserrat, San Telmo - situé au Sud, s'appauvrit. 
En dehors de la ville, il y a la pampa, mythique elle aussi, mythique dans son immensité, dans sa solitude. La pampa est un vide, un océan de terre, un territoire sauvage, le territoire du gaucho. Et aux frontières, la lutte. La lutte sourde entre deux configurations antagoniques : la ville et la pampa.

Nous avons vu de quelle manière Buenos Aires avait été modelée par l'utopie européanisante de la Génération de 80. On pourrait dire autant de l'utopie premiermondiste des années quatre-vingts symbolisée par Puerto Madero. Ce n'est pas un hasard si la construction de Puerto Madero est commencée dans les années quatrevingts (1880). En effet, en 1882 Eduardo Madero fut chargé par le gouvernement de construire un nouveau port car la faible profondeur du Río de la Plata rendait difficile les manœuvres de décharge; les travaux démarrèrent en 1887. Un siècle plus tard, en novembre 1989, le gouvernement de la Nation et celui de la ville signent l'acte d'association en vue de l'urbanisation de la zone de Puerto Madero. En peu de temps, Puerto Madero est devenu un centre commercial puissant avec restaurants, bureaux et logements privés, le tout selon un design moderniste à l'image du Puente de la Mujer, inauguré en 2001 et conçu par le prestigieux architecte et ingénieur espagnol Santiago Calatrava. Cette répétition historique ne devrait pas nous étonner ; dans Le 18 Brumaire de Louis Bonaparte, Karl Marx signale : « Hegel note quelque part que tous les grands événements et personnages historiques surviennent pour ainsi dire deux fois. Il a oublié d'ajouter : une fois comme [grande] tragédie et la fois d'après comme [misérable] farce » (1994 : 437).

Parallèlement, les bidonvilles verront leur population augmenter d'une manière considérable.

\section{La médiévalisation de la ville}

Pour Eugenio d'Ors, « une réflexion attentive révèle la présence de systèmes, de synthèses effectives, qui rassemblent les éléments lointains, et dissocient les éléments proches ou contigus » (2000: 67). Chaque époque, chaque parcelle d'Histoire possède sa propre centralité sous-jacente qui l'organise. Il n'est pas anecdotique de rappeler ici qu'Ernst Bloch, dans L'héritage de ce temps, développe le concept de multiplicité temporelle en soulignant que «de véritables paysages urbains du Moyen Âge dorment 
dans la vie d'aujourd'hui » (1977 : 100). Il en est de même pour Umberto Eco. En partant d'un texte de Roberto Vacca (Il Medioevo prossimo venturo), Eco s'adonne à un jeu interprétatif et prédictif, avec des réflexions qu'on peut lire dans « Le nouveau Moyen Âge », article qu'il intègre dans La guerre du faux (2008). Dès qu'on pense au Moyen Âge, on pense aux épidémies, aux massacres, à l'intolérance, à l'obscurité. Il s'agit pourtant d'une époque beaucoup plus complexe. Pour Eco, la période médiévale se caractérise par la dégradation de la paix, la menace barbare, l'effondrement du pouvoir international (crise du contrôle central). Dans son article rédigé en 1979, l'intellectuel italien constate la crise de la Pax americana et la disparition non pas du monde romain mais de l'Homme libéral, «l'entrepreneur de langue anglo-saxonne qui a eu avec Robinson Crusoé son poème primitif et avec Max Weber son Virgile » (2008: 67). Eco ne se doutait pas qu'un peu plus tard, dans les années quatre-vingt, sous les gouvernements de Ronald Reagan et de Margaret Thatcher, les théories de Milton Friedman allaient s'imposer dans le monde et que nous allions glisser vers une ère néo-libérale et postpanoptique. Dans la même lignée, un autre intellectuel italien, Giuseppe Sacco, développe le thème de la médiévalisation de la ville contemporaine, « une série de minorités qui refusent d'être intégrées constituent des clans; chaque clan repère un quartier qui devient son centre, souvent inaccessible: on en arrive à la notion de contrada médiévale » (Eco $2008: 70)$.

Nous pouvons aussi citer Italo Calvino, pour qui « les villes comme les rêves sont faites de désirs et de peur» (1996: 56). En d'autres mots, le territoire est modelé par l'imaginaire. C'est dans ce sens que J.-F. Mattéi définit la pensée comme étant l'oasis de l'idée, car «la civilisation s'est [...] donné la représentation d'une enceinte close, pénétrée de jardins, et cernée de tous côtés par le désert des Barbares » (2004 : 277). Le parallélisme entre les deux époques - postmodernisme et Moyen Âge - peut également être appliqué à d'autres aspects de la vie sociale. Au Moyen Âge par exemple, on voyageait dans l'insécurité, situation qui n'a pas beaucoup changé de nos jours. Un autre point commun, c'est la détérioration écologique : on a eu beau prendre conscience de l'importance de la préservation de la planète, on n'arrête pas pour autant de produire des gadgets rapidement périssables et d'entasser des déchets. Mentionnons encore, pour finir, le besoin permanent de réadaptation et de réinsertion : le Moyen Âge étant 
une époque de transition permanente, la mobilité et la flexibilité étaient devenues deux composantes essentielles à la survie, comme il en est encore de nous jours.

\section{La citadelle}

Dans Fortress America: Gated communities in the United States (1997), Edward James Blakely et Mary Gail Snyder les définissent comme « des ensembles résidentiels délimités par une clôture, le plus souvent composés d'habitations unifamiliales, dont l'accès est limité et surveillé (caméras de surveillance, barrières, personnel de sécurité) et où les espaces d'usage communautaire (rues, trottoirs, parcs, etc.) sont privés plutôt que de propriété publique ». Né aux Etats-Unis, le phénomène des gated communities va rapidement se répandre dans le monde entier. On les connaît sous la dénomination de : condominios fechados au Brésil, fraccionamientos au Mexique, countries ou barrios cerrados en Argentine, communauté emmurée au Québec, compounds en Afrique du Sud. Dans leur ouvrage, Blakely et Snyder identifient trois typologies de gated communities : les lifestyle communities, les prestiges communities et les security communities. En réalité, il s'agit d'un cocktail qui comporte - à des proportions variables - les trois éléments. Quoi qu'il en soit, les classes hautes et moyennes désertent la ville et le territoire se trouve parsemé de citadelles.

\section{L'étranger ante portas}

La ville est un « territoire ambivalent, lieu de liberté comme de danger (Bauman 2010 : 94) ». L'étranger, l'Autre est - tant au Moyen Age qu'à notre époque - porteur de maladie, contagieux, et l'hygiène est fournie par les outils de séparation. Dans cette dynamique, le quadrillage des villes est une façon (non réussie) de réduire l'étrangeté de la ville. Le thème de l'étranger est central dans l'œuvre de Zygmunt Bauman, mais il s'agit moins de l'étranger en-soi que de sa proximité, de la menace qu'il représenterait : «Aux yeux des Anciens, qui inventèrent ce mot pour désigner les non-Grecs (et plus tard ceux qui vivaient en dehors du droit romain), les barbares n'étaient source de peur que lorsqu'ils approchaient de trop près et qu'ils se tenaient eux-mêmes ante portas [...]» (idem : 116). 
De nos jours, tout est mis en place pour réduire le contact, pour que l'élément étranger soit neutralisé. Menacé par l'étranger ante portas, l'homme cherche à construire un « chez soi » sécurisant. Ainsi, la ville qui émerge à la fin du développement moderne est un espace hétérogène. Il s'agit d'un agrégat de secteurs dont les lignes de démarcation sont parfois tracées avec netteté et surveillées. C'est le cas des countries. L'habitant du country prend sa voiture (en préférence un $4 \times 4$ équipé de vitres teintées) et l'autoroute le conduit à son lieu de travail. Sur le chemin il y a un bidonville mais il ne le voit pas, il va trop vite. Pourtant, voyager peut s'avérer dangereux car, comme au Moyen Age, les véhicules sont parfois interceptés par des brigands, des bandits de grand chemin. L'étude de noms donnés à ces countries s'avère révélatrice. Parmi les countries répertoriés, on en trouve un appelé «El Fortín » et un autre «Fortín del Pozo ». Et ce n'est pas un hasard. Le fortín était une petite forteresse que l'on construisait pour se protéger des malones, des attaques des indigènes. C'est ici que le concept d'étranger ante portas de Bauman prend toute sa dimension. Les résidents du country vivent leur réalité comme un exil intérieur, un exil qui les oblige à quitter amitiés, familles, endroits. Celui qui lirait le roman en faisant abstraction du contexte pourrait penser qu'au dehors, à l'extérieur du country, il se passe quelque chose de terrible et que le texte s'inscrit dans la lignée des ouvrages apocalyptiques produits par exemple à la suite des attentats du 11 septembre.

Le texte de Piñeiro décrit donc une société sectaire, une société qui dresse des murailles et qui sépare. Pourtant, l'apparition des countries en Argentine obéit à de multiples facteurs. Bien que les habitants des countries mettent d'habitude l'accent sur le retour à la nature, il faut signaler que doucement et progressivement le quartier se dévalorise au point de perdre sa fonction de générateur et de garant de statut social. Il y a donc quelque chose qui dépasse la simple quête d'une vie saine et l'élément sécuritaire. C'est la construction de prestige, la construction d'un espace hominien et hermétique, d'une communauté affective qui élimine l'altérité, l'étrangeté, ce qui est différent, une communauté affective fondée sur l'affinité. 


\section{Néotribalisme ou ersatz communitaire?}

Jean Baudrillard voit dans le postmodernisme un retour au communautarisme : «Partout on recycle les facultés perdues, ou le corps perdu, ou la socialité perdue [...] » (1981 : 27). Étant donné le besoin de communautarisme, «le problème central de la postmodernité sera de créer des ersatz de communauté pour fabriquer ou même vendre un sentiment de communauté [...] (2010:109)». Le marketing l'a bien compris et les entreprises construisent leurs ersatz à travers les marques et le luxe. Les countries, eux aussi, vendent cette illusion d'appartenance. Ersatz de communauté, le country est moins une façon de «vivre-ensemble » qu'une façon de vivre « entre-nous », entre des personnes qui se reconnaissent.

L'idée de ville assiégée conduit à la construction des countries qui opèrent comme des endroits aseptiques, véritables oasis loin du chaos et du désordre de la ville. La réalité a été remplacée par une série de simulacres. Baudrillard affirme que « lorsque le réel n'est plus ce qu'il était, la nostalgie prend tout son sens. Surenchère des mythes d'origine et des signes de réalité [...] (1981 : 17) ». Aussi le country se fonde-t-il sur deux concepts. D’un côté la nostalgie communautaire. D’un autre côté, en plus de la nostalgie communautaire, le country nous renvoie au retour de l'homme dans la nature. Car l'échec du concept de progrès - mythe sur lequel se fonde la modernité - dénoncé déjà par l'École de Francfort, conduit au repli de l'homme. L'opposition entre l'homme et la nature (Descartes proclamant un homme «maître et possesseur de la nature ») entre dans une nouvelle étape. Ce sont les temps de l'écologie où l'homme s'interroge sur son lieu dans le monde.

\section{Le ghetto}

Le néolibéralisme ne fera qu'accroître les inégalités et le Buenos Aires des countries coexiste avec celui des bidonvilles. La société de la minceur est celle de l'obésité, soutient Lipovetsky à l'heure de définir l'hyper modernisme. Même constat pour Zygmunt Bauman : «Dès le départ, nous dit-il, la modernité a produit, et continue de produire, d'énormes quantités de déchets humains (2010 : 149). » Italo Calvino le disait à sa façon en décrivant la ville imaginaire de Léonie : "l’opulence de Léonie se mesure à celles que chaque jour sont mises au rebut pour faire place à de nouvelles. Au 
point qu'on se demande si la vraie passion de Léonie est vraiment, comme ils disent, le plaisir des choses neuves et différentes, ou si ce n'est pas plutôt l'expulsion, l'éloignement, la séparation [...]» (1996: 133-135).

Les travaux développés par l'École de Chicago sont particulièrement utiles pour ce type d'analyse. Aux commencements du vingtième siècle, la ville nord-américaine de Chicago connaît - à l'égal que Buenos Aires - une explosion démographique suivie d'un accroissement significatif de la délinquance. Pour cette École qui s'attache à étudier le délit en fonction de l'espace physique, la ville apparaît comme un laboratoire social. La recherche sociologique organise la ville en zones, prend le ghetto comme objet d'investigation et montre la manière dont chaque aire naturelle (territoire où un groupe donné partage une manière d'être, un mode de vie, des perspectives spécifiques, qui trie sa population conformément aux appartenances sociales, ou culturelles et au statut social) recompose à sa manière un lien social partiel de type communautaire.

Toute une tradition théorique à orientation marxiste représentée par des auteurs comme Walter Benjamin, Siegfried Kracauer et Theodor Adorno, se fonde sur l'exclusion, fixant le regard sur ceux qui sont restés au bord du chemin :

\footnotetext{
Pour ne plus écrire l'histoire des vainqueurs, la théorie doit aussi se tourner vers ce qui [...] est resté au bord du chemin - ce qu'on pourrait appeler les déchets - et les coins sombres qui avaient échappé à la dialectique. C'est le propre du vaincu de paraître insignifiant, excentrique, dérisoire du fait même de son impuissance. La théorie se trouve renvoyée à un matériel imparfait, opaque, non encore élucidé, qui possède de ce fait des traits anachroniques mais n'est pas totalement désuet parce qu'il a déjoué la dynamique de l'histoire. (Adorno 1980 : 143)
}

Nous pourrions également inscrire dans cette voie certaines pièces de théâtre de Samuel Beckett dont Residua et Detritus, de Samuel Beckett. On perçoit donc une volonté de reconstituer l'histoire à partir des déchets qui s'entassent aux portes des villes et de doter cette reconstitution d'un cadre théorique et d'une poétique.

À l'heure d'envisager une poétique du résiduel, nous pensons inévitablement aux peintures qui conforment la série «Juanito Laguna» de l'artiste peintre argentin Antonio Berni. Empiffrée, la ville industrielle riche vomit ses déchets et c'est dans ces dépotoirs que Juanito Laguna vient clocharder. C'est avec les déchets de la société de 
consommation que Berni «peint» ses tableaux et que Martini écrit Puerto Apache, roman qui montre un corps social corrodé par le chômage et la précarité du monde du travail ; les récits de vie rendent compte de la dégradation progressive non seulement du prolétariat mais également d'un secteur de la classe moyenne.

\section{Nomadisme}

Vendeur à la sauvette, le personnage principal du roman El muchacho de los senos de goma, Cristóbal, est particulièrement mobile. Au fil des pages, nous le suivons de l'Avenue Warnes (La Paternal) au quartier Centenario en passant par la City ou encore La Costanera.

«L'idée selon laquelle, nous dit Adorno, le citadin moderne serait un nouveau genre de nomade mérite particulièrement d'être soulignée. Elle n'exprime pas seulement l'angoisse et l'aliénation, mais aussi l'anhistoricité montante d'une condition dans laquelle les hommes ne s'éprouvent plus que comme les objets de processus opaques et, ballottés entre le choc soudain et l'oubli soudain, en sont plus capables d'une expérience continue du temps. Spengler voit le lien entre l'atomisation et le type humain régressif, tel qu'il ne s'est totalement révélé que sous le signe des déchaînements totalitaires: "Chacune de ces somptueuses métropolis abrite une misère horrible, un retour de toutes les habitudes de vie à l'état sauvage, cultivant dès aujourd'hui un nouvel homme primitif, entre pignon et mansarde, cave et arrière-cour" (cf. II, 95) » (Adorno $2003: 46)$.

\section{Le buscavidas}

Cristóbal est dépeint comme entrepreneur et débrouillard. Il évolue dans un socio-historique (Castoriadis) marqué par l'incertitude et l'instabilité. Le néolibéralisme a plongé l'homme dans un état de nature (Hobbes), un contexte de darwinisme social hyper-compétitif où le mot-clé est la performance.

Au cours des années quatre-vingt-dix, les turbulences économiques se succèdent. Dans l'un des chapitres, le personnage principal des Veuves du jeudi les énumère : «En feuilletant les pages antérieures de mon carnet, je retrouvais un à un les noms des différents effets économiques qui nous avaient frappés au cours de ces dernières années 
[...]. 1994 effet Tequila [...] ; 1997, crise asiatique [...] ; 1998, effet Vodka [...] ; 1999, effet Caïpirinha [...] ; 2001, effet Mate cocido [...] » (Piñeiro 2014 : 262-266). Le système capitaliste se nourrit des crises qui, bien que différentes, finissent toutes par se ressembler du fait qu'elles produisent des effets identiques. Le sociologue français Edgar Morin s'attaque aux crises provoquées par la croissance des villes au dix-neuvième siècle, des crises qui sont à l'origine « des répressions profondes, des incertitudes de vie et de survie (chômage), des agglomérats anomiques, des dérèglements multiples (délinquance, alcoolisme) [...]» (Morin 1994 : 379).

Même constat pour Galeano : «Les centres urbains se gonflent au point d'éclater. En 1950, l'Amérique Latine avait six villes de plus d'un million d'habitants. En 1980, elle aura vingt-cinq. Les légions de travailleurs que la campagne rejette partagent, aux abords des grandes villes, le sort que le système réserve aux jeunes citadins “excédentaires" (385).

Or, comment survivre dans un tel contexte lorsqu'on n'a rien à offrir? Les analyses de François Dubet vont se centrer sur la figure du «galérien ». Le "galérien » est condamné à " ramer», sans espoir d'intégration. Cette situation peut générer haine et violence, les seuls moyens d'expression des exclus (Guibert et Jumel 2002 : 92). Pour Galeano, «On y perfectionne les pratiques des buscavidas (débrouillards) permettant de survivre. "Le système de production a montré une nette insuffisance dans la création d'un recrutement rentable capable d'absorber la force de travail grandissante de ces régions, et spécialement la main d'œuvre urbaine [...]” » (1981 : 385-386).

L'art latino-américain s'est fait l'écho de ce personnage avec par exemple le comédien mexicain Cantinflas, la bande dessinée « Condorito » (Chili) ou encore la série argentine « Buscavidas » (1984-1988).

Nous pouvons associer le buscavidas au pícaro. Ce personnage se consolide certes à la Renaissance (Lazarillo de Tormes, 1553) mais est né au Moyen Age à cause de l'émergence d'une économie régie par l'argent. Il s'agit d'un antihéros, un personnage sans scrupules, un marginal qui cherche à se faire une place dans la société et emploie tous les moyens pour subsister. Il est par conséquent un personnage déviant. Celle-ci est la principale différence avec le buscavidas car ce dernier ne franchira jamais cette frontière. Leur différence est donc d'ordre moral. Ses caractéristiques principales sont, 
au-delà de la mobilité, la mètis (intelligence de la ruse) et le kairos (capacité à saisir les opportunités). Nous pouvons le décrire comme un personnage rusé mais intègre voire noble, synthèse en quelque sorte de deux personnage médiévaux: le pícaro et le chevalier.

\section{Conclusion}

Les trois romans de notre corpus décrivent fidèlement la métamorphose subie par la ville de Buenos Aires au cours des années quatre-vingt-dix. Le centre-ville s'atomise, les quartiers privés prolifèrent à la périphérie tandis que les déclassés remplissent les bidonvilles. Cet éclatement du territoire, dû à la politique néolibérale, ne fait qu'accroître les inégalités et forge un nouvel imaginaire dominé par l'état de nature (T. Hobbes), les peurs sociales et les obsessions sécuritaires (Z. Bauman).

Les éléments relevés par notre travail comparatiste nous font adhérer à la thèse de la médiévalisation de la ville. La réapparition des citadelles et des ghettos, l'insécurité, le nomadisme et la ruse comme réponse à l'instabilité ambiante sont autant de traits communs au Moyen Âge et à notre époque. 


\section{Bibliographie}

Adorno, Theodor W. (2003), Prismes. Critique de la culture et société, Paris, Payot, coll. «Critique de la politique ».

Adorno, Theodor W. (1980), Minima moralia, Paris, Payot, coll. "Critique de la politique ».

Baudrillard, Jean (1981), Simulacres et simulation, Paris, Galilée, coll. « Débats ».

Bauman, Zygmunt (2008), L'amour liquide, de la fragilité des liens entre les hommes, Paris, Hachette, coll. « Pluriel ».

Bauman, Zygmunt (2010), La vie en miettes, Paris, Hachette, coll. « Pluriel ».

Benjamin, Walter (2000), OEuvres I et III, Paris, Gallimard, coll. « Essais ».

Blakely Edward J. et Mary G. Snyder (1997), Fortress America : Gated communities in the United States, Washington DC, Lincoln Institute of Land Policy, Brookings Institution Press et Cambridge.

Bloch, Ernst (1977), Héritage de ce temps, Paris, Payot, coll. « Critique de la politique ».

Calvino, Italo (1996), Les ville invisibles, Paris, Seuil, coll. « Points ».

Cambier, Alain (2005), Qu'est-ce qu'une ville, J. Vrin, coll. « Chemins philosophiques ».

D’Ors, Eugenio (2000), Du baroque, Paris, Gallimard, coll. « Essais ».

Eco, Umberto (2008), « Le nouveau Moyen Âge », dans La guerre du faux, Paris, Grasset, coll. « Les cahiers rouges ».

Etienne, Jean et Mendras, Henri (1996), Les grands auteurs de la sociologie, Paris, Hatier, coll. « Initial».

Galeano, Eduardo (1981), Les veines ouvertes de l'Amérique latine. Une contre-histoire, Paris, Plon, coll. « Terre Humaine. Civilisations et sociétés ».

Guibert, Joel et Jumel, Guy (2002), La socio-histoire, Paris, Armand Colin, Paris, « Cursus ».

Iparraguirre, Sylvia (2007), El muchacho se los senos de goma, Buenos Aires, Alfaguara. Ebook

Klein, Naomi (2008), La stratégie du choc ou la montée d'un capitalisme du désastre, Leméac/Actes Sud. 
Lipovetsky, Gilles et Charles, Sebastien (2004), Les Temps Hypermodernes, Paris, Grasset, coll. « Nouveau Collège de Philosophie ».

Mattéi, Jean François (2004), La barbarie intérieure, Paris, PUF, coll. «Intervention philosophique ».

Martini, Juan (2002), Puerto Apache, Buenos Aires, Sudamericana.

Marx, Karl (1994), CEuvres IV (Politique), Paris, Gallimard, coll. « Pléiade ».

Morin, Edgar (1994), Sociologie, Paris, Seuil, coll. « Points ».

Piñeiro, Claudia (2014), Les veuves du jeudi, Paris, Actes Sud.

Fernando Stefanich est docteur en Études romanes (Paris IV-Sorbonne). Il a publié l'essai Meurtropolis: vie sociale et intrigue policière et trois romans (Cuesta abajo, Una muerte para Roberto Duran, Roña). Actuellement, il est enseignant (ATER) à l'Université de Lorraine (Metz, laboratoire Écritures). 



\title{
«Trois écritures pour une même lecture?
}

La ville de Marseille dans Les Marins perdus de J.-C. Izzo, en roman, en bande dessinée et en cartographie géo-littéraire »

\author{
Florence Troin \\ UMR 7324 CITERES, CNRS \& Université de Tours, France
}

Résumé: L'auteur de romans policiers J.-C. Izzo a pour habitude de placer la ville de Marseille au cœur de ses intrigues, permettant au lecteur-géographe d'être en immersion totale dans la cité phocéenne, à la (pour)suite du héros. Il sera question d'étudier cette description du territoire marseillais en nous appuyant sur Les Marins perdus, roman d'Izzo qui a la particularité d'avoir été adapté en bande dessinée (C. Belin). À ces deux types d'écriture s'ajoute celle que nous proposons de mettre en œuvre, sous la forme d'une mise en carte(s) du récit. C'est en effet par le prisme de la carte que l'on réfléchira aux représentations que ces deux médias produisent, en se posant la question de savoir si les Marseille(s) décrits, dessinés et cartographiés sont strictement identiques, opposés ou complémentaires ? Autrement dit, réfléchir aux apports respectifs de ces différentes écritures/lectures d'un territoire fictionnel.

Mots-clés: ville de Marseille, , J.-C. Izzo, mise en carte, territoire fictionnel

Resumo: $\mathrm{O}$ autor de romances policiais J.-C. Izzo tem por hábito colocar a cidade de Marselha no centro das suas intrigas, permitindo ao leitor-geógrafo estar em imersão total na cidade marselhesa, em busca /seguindo o herói. Tratar-se-á de estudar esta descrição do território marselhês, apoiando-nos em Les Marins perdus, romance de Izzo que tem a particularidade de ter sido adaptado para banda desenhada (C. Belin). A estes dois tipos de escrita vem juntar-se aquela que nos propomos implementar sob a forma de mapa(s) da narrativa. É com efeito pelo prisma do mapa que iremos reflectir sobre as representações que os dois media produzem, colocando-se a questão de saber se as Marselha(s) descritas, desenhadas e 
cartografadas são estritamente idênticas, opostas ou complementares. Dito de outro modo, trata-se de reflectir sobre os contributos respectivos destes diferentes escritas/leituras de um território ficcional.

Palavras-chave: cidade de Marselha, J.-C. Izzo, mapear, território ficcional

Sur les pas des Marins perdus de Jean-Claude Izzo - auteur de romans policiers qui a pour habitude de placer la ville de Marseille («sa » ville avait-il coutume de dire ${ }^{1}$ ) au cœur de ses intrigues -, cet article propose au lecteur-géographe une immersion totale dans la cité phocéenne.

Le choix des Marins perdus tient à deux raisons :

- Après avoir beaucoup travaillé sur deux des trois volumes de la Trilogie Fabio Montale $^{2}$ qui a fait d'Izzo un auteur à succès et après avoir constaté la place de l'espace dans cette œuvre, l'idée d'étudier un autre roman du même auteur a émergé, afin de confirmer la thèse selon laquelle Izzo est véritablement un écrivain-géographe.

Le choix des Marins perdus s'est imposé - plutôt qu'un travail sur le $3^{\mathrm{e}}$ volume de la Trilogie ${ }^{3}$ - dans l'espoir, également, de sortir de l'univers pas toujours très « rose » du héros Fabio Montale qui tente de combattre tous les maux de la planète, ceux engendrés par la mafia, le racisme ou la montée du Front national...

- Deuxième raison : Les Marins perdus d'Izzo ont été adaptés en bande dessinée par Clément Belin - un dessinateur autodidacte qui a été marin dans une autre vie - et la tentation était grande de comparer les deux écritures d'un même scénario, tout en se focalisant sur leurs descriptions respectives de l'espace.

Alors, si l'objectif de travailler sur un sujet un peu plus enjoué n'a pas été atteint (dans Les Marins perdus, nous sommes cette fois dans la thématique des cargos abandonnés par leurs armateurs pour cause de faillite... le tout doublé d'une histoire de prostitution...), le deuxième objectif - celui de la comparaison - a, selon nous, porté ses fruits.

Dans un premier temps, nous reviendrons sur la mise en scène de Marseille par Izzo dans le roman, qui nous livre un lot important de toponymes, lesquels nous transportent d'un quartier à l'autre de la ville, mais pas seulement puisqu'Izzo « sort du cadre » cette fois pour une véritable croisière en Méditerranée - sur la Figure 1, tous les 
noms de mers ont été cités au moins une fois dans le roman - et sur les autres mers du globe, nous faisant traverser des détroits, emprunter des canaux et accoster dans de multiples autres ports que Marseille, nous y reviendrons.

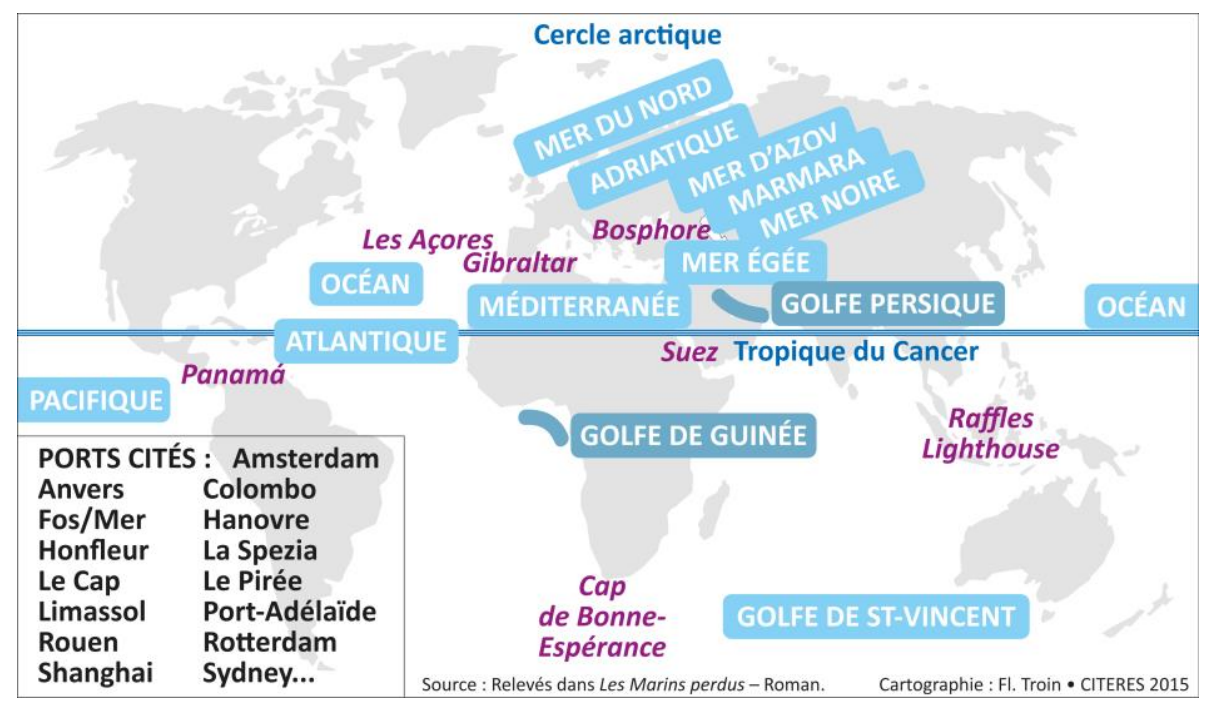

Figure 1. Les toponymes à consonnance « marine » cités dans Les Marins perdus - roman.

Cartographie : Fl. Troin • CITERES 2015

Cette profusion de lieux énoncés nous conduira - dans un deuxième temps - vers une lecture géographique du roman et aboutira, très naturellement, à une mise en cartes: il ne s'agit pas d'étudier une carte dans une œuvre littéraire (il n'y en a pas dans le roman), ni d'établir une géographie de la littérature à la Franco Moretti ${ }^{4}$, mais bien de concevoir des cartes à partir du roman.

Cette mise en carte(s), déjà travaillée en profondeur pour Total Khéops avec Muriel Rosemberg pour exposer « la relation vitale et littéraire que Jean-Claude Izzo a établie avec Marseille $»^{5}-$, nous semble être une nouvelle façon de lire le roman. En effet, elle nous révèle des éléments pas nécessairement apparus à la « simple » lecture du roman et nous livre un certain nombre d'enseignements que nous nous proposons de détailler, en faisant systématiquement la comparaison roman/bande dessinée.

Avec une constante : c'est toujours par le prisme de la carte que l'on réfléchira aux représentations que ces deux médias produisent, en se posant la question de savoir si les univers géographiques décrits, dessinés et cartographiés sont strictement 
identiques, opposés ou complémentaires ? Autrement dit, nous réfléchirons aux apports respectifs de ces différentes écritures/lectures d'un territoire fictionnel.

\section{LA « MARQUE DE FABRIQUE » D'IZZO : UNE PROFUSION DE TOPONYMES POUR UNE MISE EN SCENE/CARTES DE MARSEILLE}

La profusion des toponymes dans ses romans est donc une marque de fabrique de Jean-Claude Izzo comme en témoigne ce parallèle entre les Marins perdus et la Trilogie (cf. Tab. 1) : si l'on ne considère que les toponymes « marseillais », c'est-à-dire ceux concernant l'agglomération, on aboutit - pour la Trilogie - à un total faramineux de $596^{6}$ pour 1010 pages de texte, soit un toponyme toutes les deux pages en moyenne.

Tableau 1. La profusion de toponymes cités dans Les Marins perdus - roman et la Trilogie.

\begin{tabular}{|c|c|c|c|}
\hline & $\begin{array}{c}\text { Nb. de } \\
\text { toponymes }\end{array}$ & Nb. de pages & Ratio \\
\hline Total Khéops & 276 & 348 & 1,26 \\
\hline Chourmo & 223 & 363 & 1,62 \\
\hline Soléa & 97 & 299 & 3,08 \\
\hline Total/Moyenne Trilogie & total =596 & total = 1010 & 1,98 \\
\hline Les Marins perdus & 120 & 312 & 2,60 \\
\hline
\end{tabular}

Source : Relevés dans Total Khéops, Chourmo, Soléa et Les Marins perdus - roman.

Dans Les Marins perdus, le ratio passe à un toponyme toutes les deux pages et demi (120 toponymes «marseillais » pour 312 pages) mais cette relative «faiblesse » s'explique aisément par le fait que Les Marins perdus, nous l'avons déjà exprimé, est un roman qui nous propulse hors de Marseille, et ce bien que le bateau soit amarré à quai. Ainsi, ce ne sont pas moins de 165 nouveaux toponymes qu'Izzo nous livre, pour un nombre d'occurrences supérieur à 300 (314), les occurrences étant le nombre de fois où ces termes sont énoncés : ex. du toponyme Marseille, 55 fois cités !

Si nous additionnons ces lieux que nous avons appelés « extérieurs », avec ceux qualifiés « d'intérieurs » (Marseille, les Bouches-du-Rhône et le reste de la France), nous parvenons à un total très précis de 310 toponymes pour un roman de... 312 pages... et 
633 occurrences (cf. Tab. 2). Autrement dit un roman que l'on peut qualifier aisément de « géographique».

Tableau 2. Lieux « intérieurs » et « extérieurs » dans Les Marins perdus - roman.

\begin{tabular}{|l|c|c|}
\hline & Nb. de toponymes & Nb. d'occurrences \\
\hline Lieux « intérieurs »* $^{*}$ & 144 & 264 \\
\hline Lieux « extérieurs »** & 165 & 314 \\
\hline Toponyme « Marseille» & 1 & 55 \\
\hline Total & 310 & 633 \\
\hline
\end{tabular}

*: lieux contenus dans l'agglomération marseillaise, dans les Bouches-du-Rhône et dans le reste de la France.

** : lieux extérieurs à la France et toponymes à consonnance marine.

Source : Relevés dans Les Marins perdus - roman.

Avant de voir s'il en sera de même pour la bande dessinée, étudions la mise en cartes de ce récit et voyons ce qu'elle nous permet de lire, non pas entre les lignes, mais en quelque sorte entre les lieux...

\section{Une composition urbaine tripolaire}

Sur cette première carte à l'échelle du périmètre municipal de Marseille - pour une vision d'ensemble - ont été positionnés tous les toponymes présents dans le récit, à savoir :

- des points pour figurer des lieux précis comme les bâtiments historiques, une plage, une prison, mais surtout des bars! [pas moins de 14 pour 32 points]

«Les villes n'existaient pas. Ici ou ailleurs, il ne faisait que les traverser, indifférent. Une ville n'était qu'une somme de bars, de boîtes de nuit et de putes. » (Izzo, 1997 : 194)

- des lignes pour représenter les axes cités parmi lesquels la Canebière, l'autoroute du Soleil et la corniche, éléments clés de la trame viaire marseillaise ;

- et des ellipses pour signifier les quartiers comme ceux de Beaumont ou d'Endoume, mais aussi les ensembles géographiques comme les îles du Frioul ou la chaîne de l’Estaque. 
Elle avait grandi un peu à l'écart de la ville. À Beaumont, un quartier italien, à l'est. (Izzo 1997 : 194)

On se rend alors compte que le récit s'organise selon trois pôles : le port, point de départ et d'arrivée des protagonistes lorsqu'ils quittent temporairement leur bateau ; le centre-ville et le quartier d'Endoume-Le Roucas-Blanc.

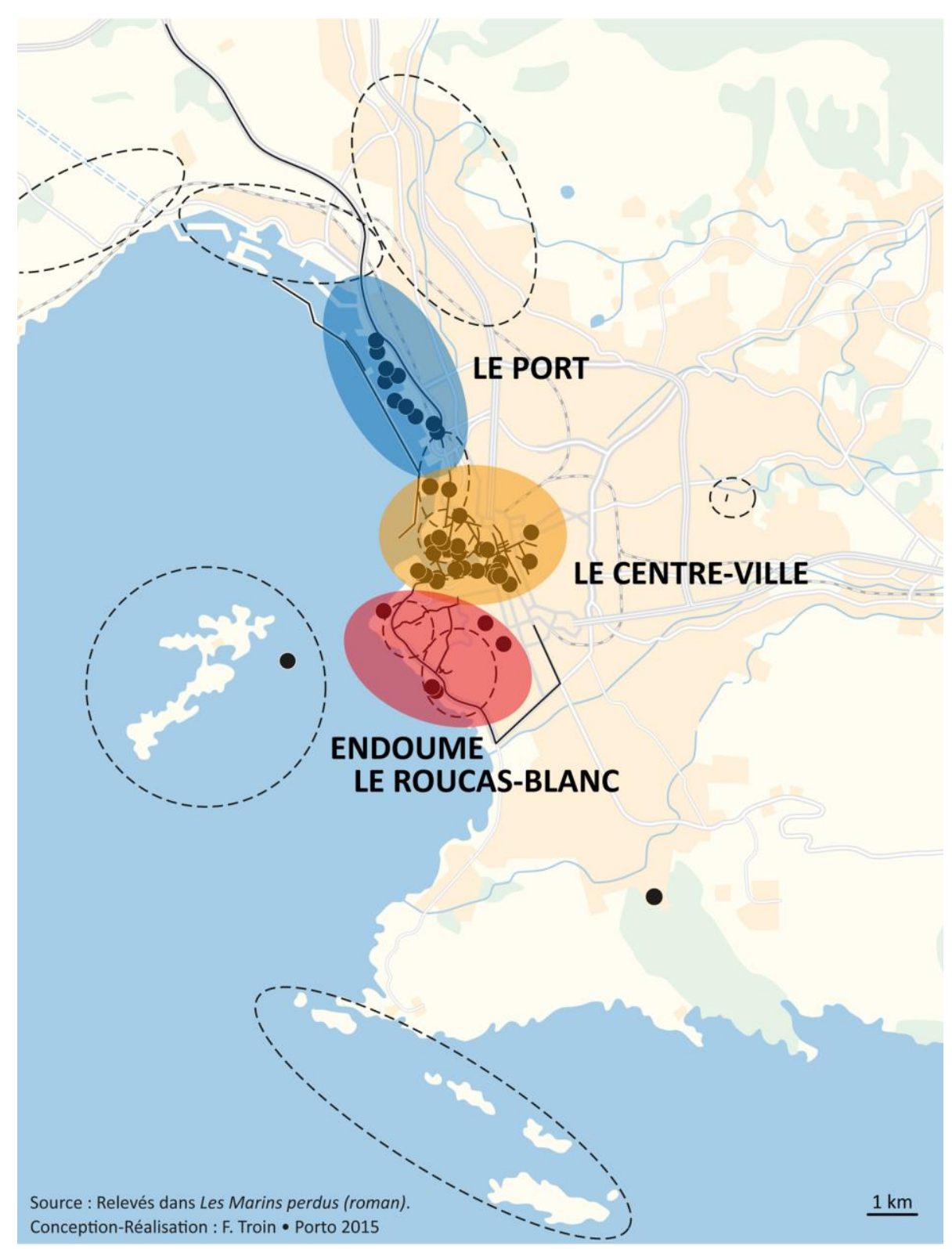

Figure 2. Les toponymes des Marins perdus - roman : une composition urbaine tripolaire.

Cartographie : Fl. Troin • CITERES 2015 


\section{Un centre-ville arpenté à pied}

À l'échelle du centre-ville arpenté à pied (Fig. 3a), en poussant l'analyse à l'aide de formes proportionnelles aux occurrences (Fig. 3b), et en ne conservant dans un deuxième temps que les lieux dont l'occurrence est supérieure à une (Fig. 3c), on retrouve les trois pôles énoncés précédemment : au nord, la partie du port qui jouxte La Joliette; pour le centre, principalement le bas du Panier, quartier historique de Marseille, le Vieux-Port et l’Opéra ; et, à nouveau, le Roucas-Blanc.

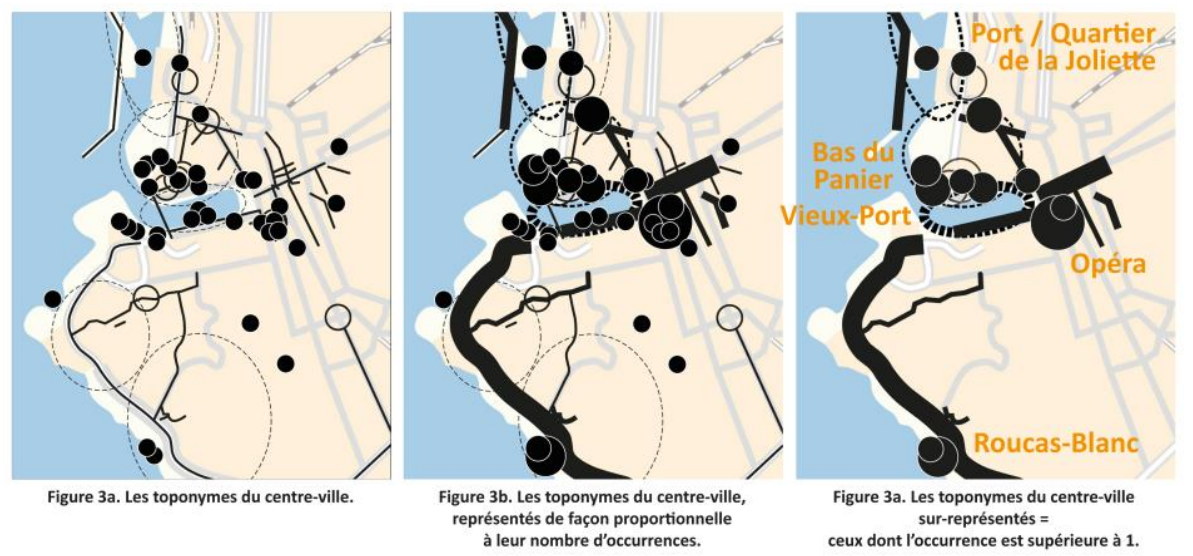

Figure 3. Les toponymes des Marins perdus - roman :

une composition urbaine tripolaire que l'on retrouve à l'échelle du centre-ville.

Cartographie : Fl. Troin • CITERES 2015

Ainsi, fidèle à sa réputation, Jean-Claude Izzo nous transporte dans les lieux les plus emblématiques de Marseille, n'omettant pas de mentionner Notre-Dame-de-laGarde, la Cathédrale de la Major et encore moins le Vieux-Port, trois lieux qui - si l'on rajoute le fameux stade Vélodrome des amateurs de foot - ont fait la réputation de Marseille.

Izzo fait donc dans le classique et le guide touristique, mais l'auteur engagé - qui a également exercé le métier de journaliste -, n'hésite jamais à saupoudrer ses romans des pincées nécessaires aux rappels qui ont fait l'histoire sociale de Marseille et ont créé les disparités sociogéographiques actuelles de « sa » ville.

La question est de savoir maintenant ce qu'il en est de la bande dessinée que l'on dit, dans une publicité des éditions Futuropolis, «l’adaptation parfaite du roman »? 


\section{COMPARAISON ROMAN / BANDE DESSINÉE}

Inutile d'être devin pour pressentir que l'adaptation d'un roman de 312 pages en une bande dessinée de 84 pages - même si celle-ci est classée dans la catégorie des « romans graphiques $»^{7}$ - va engendrer une réduction de la quantité de textes, ce qui aura nécessairement une répercussion sur le nombre de toponymes.

Ainsi, les chiffres parlent d'eux-mêmes (cf. Tab. 3): nous sommes tout simplement dans un rapport de 1 à 5 pour le nombre de toponymes [5 fois plus dans le roman] et même de 1 à 6 pour le nombre d'occurrences. Méthodologiquement parlant, précisons que, pour la bande dessinée, le comptage a tenu compte des toponymes mentionnés à la fois dans les bulles et/ou sur les images, provoquant quelques fois des petits jeux de devinette pour lesquels une loupe est nécessaire.

Tableau 3. Comparaison des toponymes des Marins perdus - roman \& bande dessinée.

\begin{tabular}{|l|c|c|c|c|}
\hline & \multicolumn{2}{|c|}{ Nb. de toponymes } & \multicolumn{2}{c|}{ Nb. d'occurrences } \\
\hline & Roman & $\begin{array}{c}\text { Bande } \\
\text { dessinée }\end{array}$ & Roman & Bande \\
dessinée
\end{tabular}

* et ${ }^{* *}$ : cf. Tab. 2.

Source : Relevés dans Les Marins perdus - roman.

\section{1. À l'échelle de Marseille}

Les cartes construites à partir des relevés exhaustifs des toponymes dans les deux supports le prouvent : nous n'avons pas du tout affaire à la même « géographie ». La mise en parallèle des deux espaces décrits fait immédiatement ressortir la réduction quantitative et la concentration dans la ville. À l'échelle du centre-ville, une seule concentration demeure, celle de l'Opéra.

Pour être tout à fait honnête avec notre analyse, il est utile de modifier le cadrage de ce que l'on a défini comme « centre-ville» pour l'étendre vers le nord car, dans la 
bande dessinée, l'utilisation de l'emprise portuaire s'est déplacée et concentrée au niveau de ce qui s'appelle le Bassin de la Pinède.

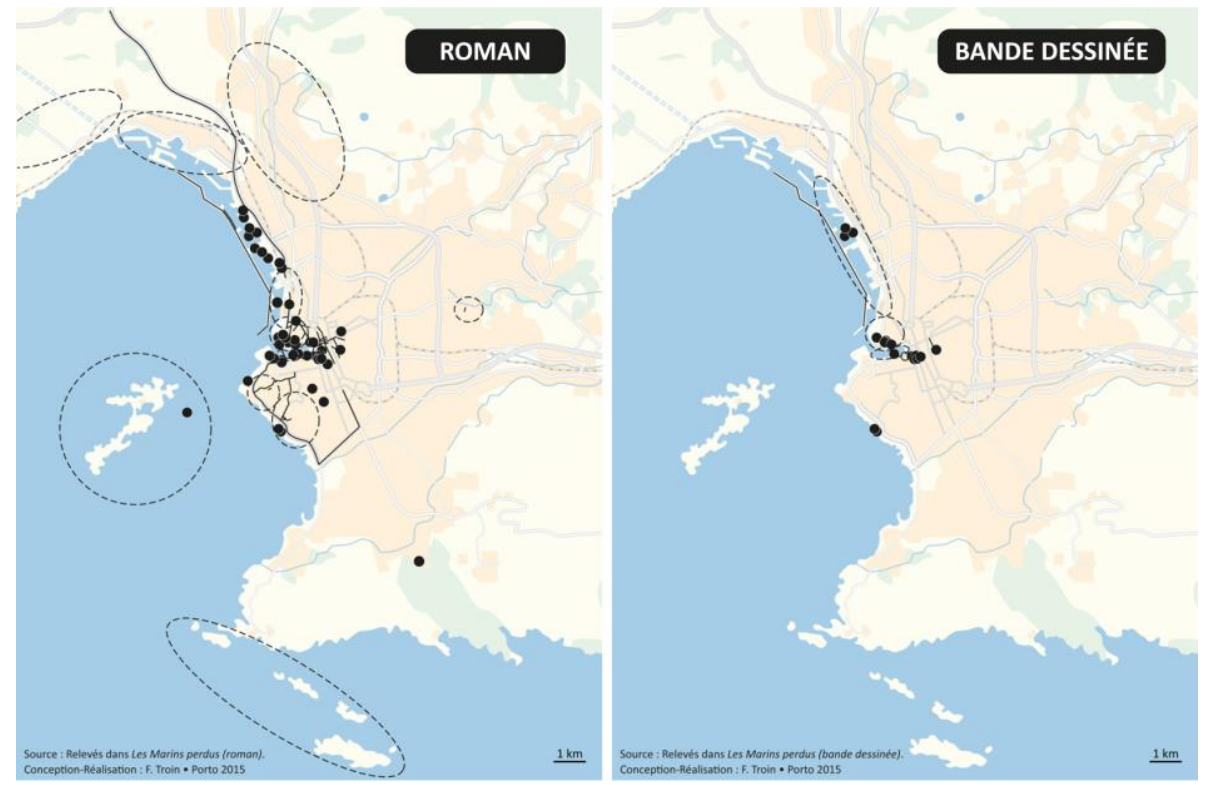

Figure 4. Les toponymes des Marins perdus - roman \& bande dessinée mis en carte(s).

Cartographie : Fl. Troin • CITERES 2015

\section{2. À l'échelle du Monde}

Dans le cas du roman, nous voyageons, grâce aux Marins perdus, vers les cinq continents, même si le rapport de force place l'Europe très largement en tête des continents cités. On constate également, si l'on soustrait le dessin des continents à la carte produite que c'est bien une « géographie » de marins (Fig. 5a) qui nous est donnée à voir, comme en témoignent les côtes de l'Afrique ou celles de l'Amérique du Sud redessinées à près d'un tiers par les toponymes de l'ouvrage. 

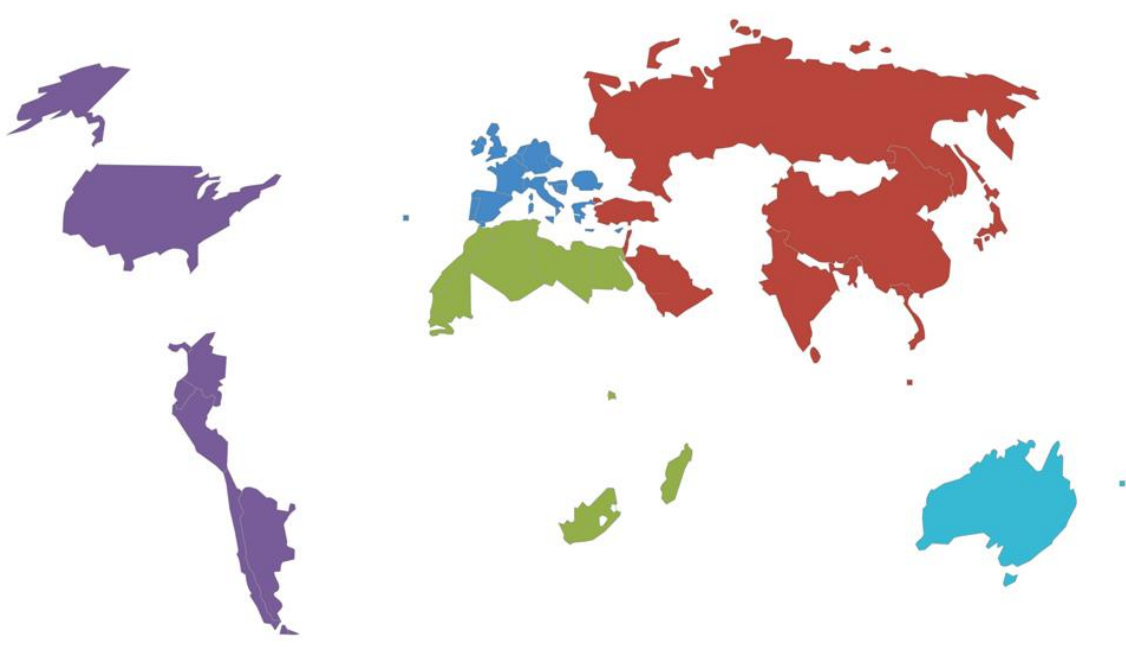

Figure 5a. Les toponymes des Marins perdus - roman : une géographie « de marins ». Cartographie : Fl. Troin • CITERES 2015

La comparaison avec la carte des toponymes de la bande dessinée est encore assez spectaculaire : le planisphère est devenu squelettique, on pourrait même avoir du mal à reconnaître certains continents, certains pays (Fig. 5b).

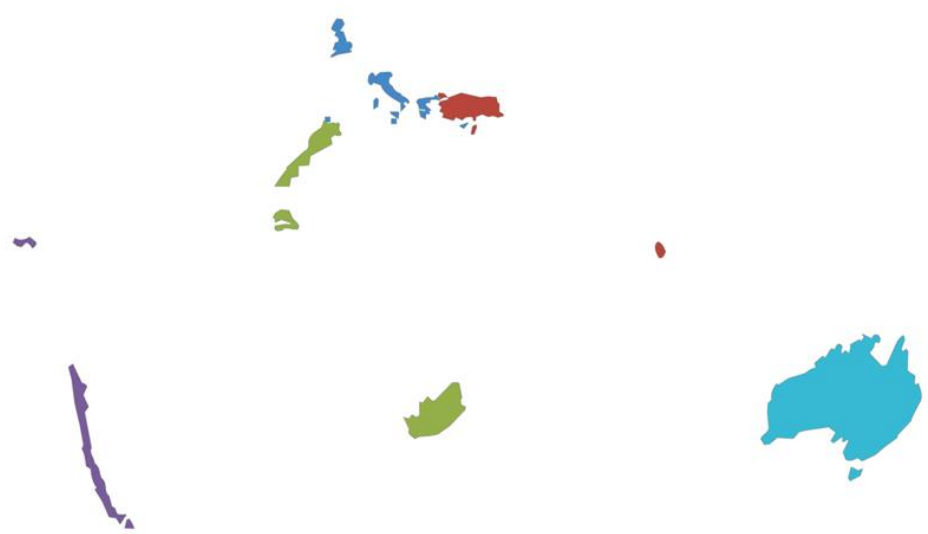

Figure 5b. Les toponymes des Marins perdus - bande dessinée : une géographie « de marins » squelettique.

Cartographie : Fl. Troin • CITERES 2015 
Puisque quantitativement parlant le roman l'« emporte » très largement sur la bande dessinée, il peut être intéressant d'établir la carte des singularités, non pas celles des toponymes présents dans le roman et non dans la bande dessinée (ils sont bien trop nombreux à cette échelle-là $=138$ ), mais l'inverse : la carte du monde des lieux présents dans la bande dessinée seulement (Fig. 6). Elle est forcément un peu «légère », 5 toponymes, qui encadrent l'Afrique mais ne signifient pas grand chose.

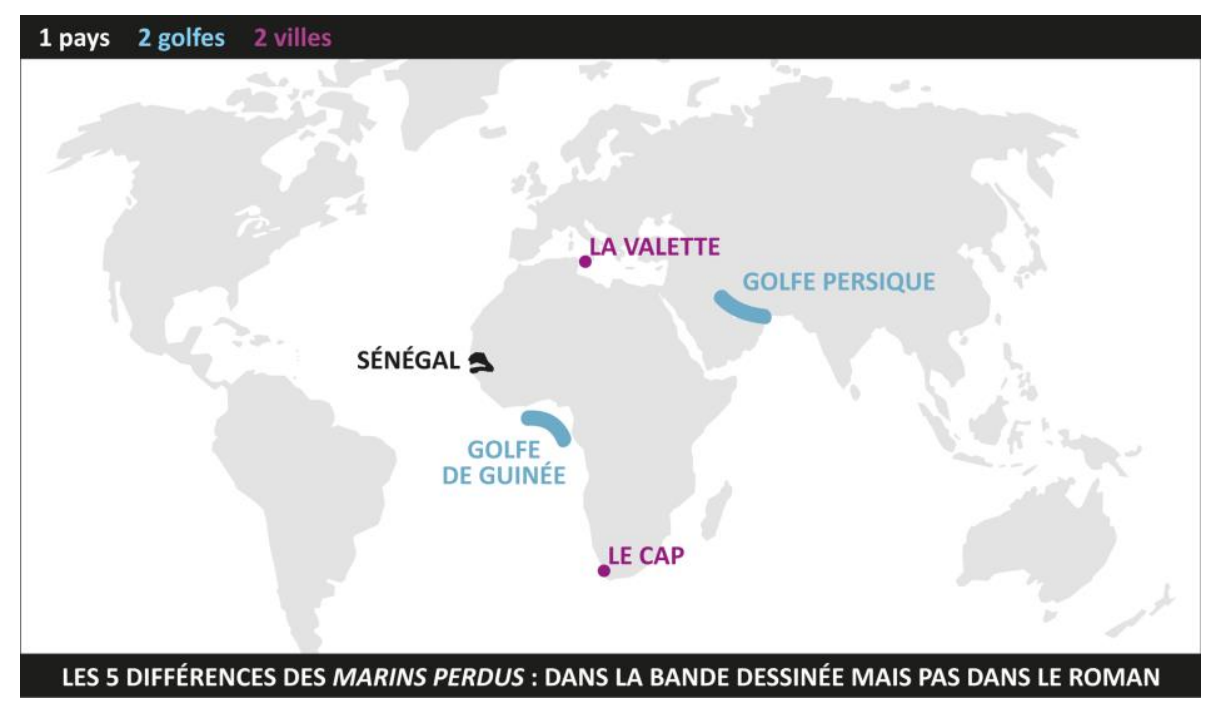

Figure 6. Les toponymes des Marins perdus présents uniquement dans la bande dessinée.

Cartographie : Fl. Troin • CITERES 2015

À l'inverse, la carte des toponymes communs aux deux supports est plus parlante : elle se re-concentre sur la Méditerranée, du Liban à Gibraltar, et mentionne quelques lieux emblématiques des voyages en bateau tels le Panamà, Valparaiso, Colombo ou Port-Adélaïde. 


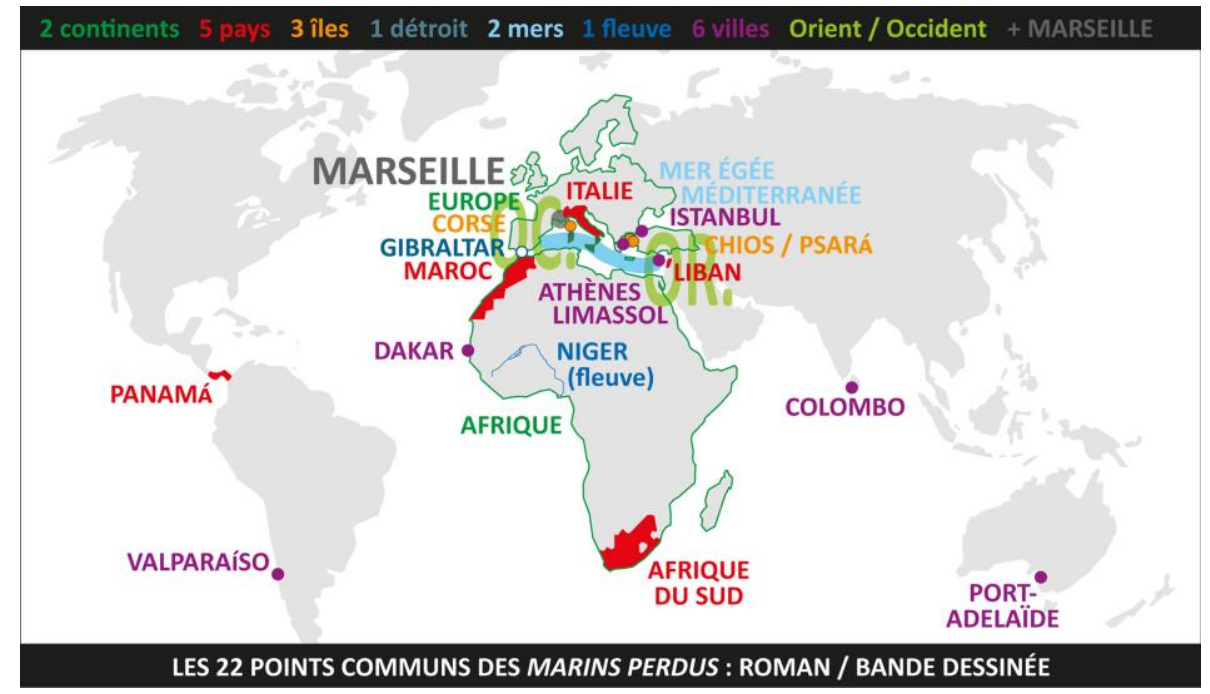

Figure 7. Les toponymes des Marins perdus communs au roman et à la bande dessinée.

Cartographie : Fl. Troin • CITERES 2015

Cette comparaison quantitative et cartographique étant faite, voyons ce qu'elle nous dit, en laissant de côté ce bilan comptable - trop simpliste parce que réducteur pour nous focaliser sur ce que disent les lieux, décrits par des lignes de texte dans le roman et par des images dans la bande dessinée.

\section{APPORTS RESPECTIFS DE CES DEUX ÉCRITURES/LECTURES D'UN ESPACE FICTIONNEL}

\section{En matière de localisation, le roman plaque son espace fictionnel sur un espace} réel, à la différence de la bande dessinée

Ainsi, pas un seul toponyme mentionné dans le roman n'a pu être localisé sur un plan actuel de la ville de Marseille. De la plus grande place au plus petit bar, chaque lieu se repère aisément et, lorsqu'il a disparu de la circulation, l'auteur le signale.

Elle déjeunait, avec une bande de copains, au Cintra, une brasserie sur le Vieux-Port, qui n'existe plus aujourd'hui. (Izzo, 1997 : 95)

Cette rigueur dans la volonté de localiser - qui est un indice du réalisme de l'écrivain (l'illusion référentielle) ${ }^{8}$ - peut même parfois sembler un peu excessive, pour 
ne pas dire «lourde». Mais c'est ainsi qu'Izzo fonctionne, dans Total Khéops ou dans Chourmo comme dans Les Marins perdus ${ }^{9}$.

Pour en revenir à la réalisation de nos cartes de localisation, celles émanant de la bande dessinée ont été plus problématiques, particulièrement en ce qui concerne les bars, restaurants et boîtes de nuit ${ }^{10}$. Il se trouve en effet que ces établissements possèdent des noms ou des adresses au caractère assez approximatif... Nous avons sélectionné les deux exemples de la Bodega et du Nefertiti.

- Dans le cas de la Bodega Don Miguel, que l'on peut aisément trouver à Marseille - même s'il s'agit d'une Bodega Casa Miguelito comme en témoigne une recherche sur linternaute.com -, le dessinateur a pris quelque liberté de positionnement, l'image avec l'Opéra au deuxième plan ne pouvant être « raccord » avec le plan de la ville, à moins de transférer la Bodega sur le trottoir d'en-face.

- À la gauche de cette Bodega, la fameuse boîte Nefertiti, dont on trouve un parent éloigné à Marseille certes, mais du côté de la Joliette, pas tout à fait dans le même quartier donc. Sur les images empruntées à Google, à gauche de la Bodega actuellement en rénovation, un établissement - certes - mais qui répond au doux nom de Pharaon, appellation symbolisée par quelques pyramides ; et au fond de l'image, point d’Opéra comme dans la bande dessinée.

On est ici dans le registre du «détournement» du lieu que s'autorise le dessinateur, pour lequel on peut échafauder plusieurs hypothèses: l'imagination de Clément Belin, sa volonté de s'écarter un peu du roman... ou celle de faire un petit clin d'œil aux fins connaisseurs de Marseille?

\section{Par contre, c'est par le dessin que l'auteur de la bande dessinée montre sa fidélité à l'espace décrit}

Il faut bien admettre que les images dessinées par Clément Belin sont d'une fidélité à la réalité impressionnante, comme en témoigne cet exemple de la rade de Marseille (Fig. 8). D’où l'importance pour nous d'étudier les cases de la bande dessinée significatives de l'espace représenté, et ce même si aucun toponyme n’y figure. 


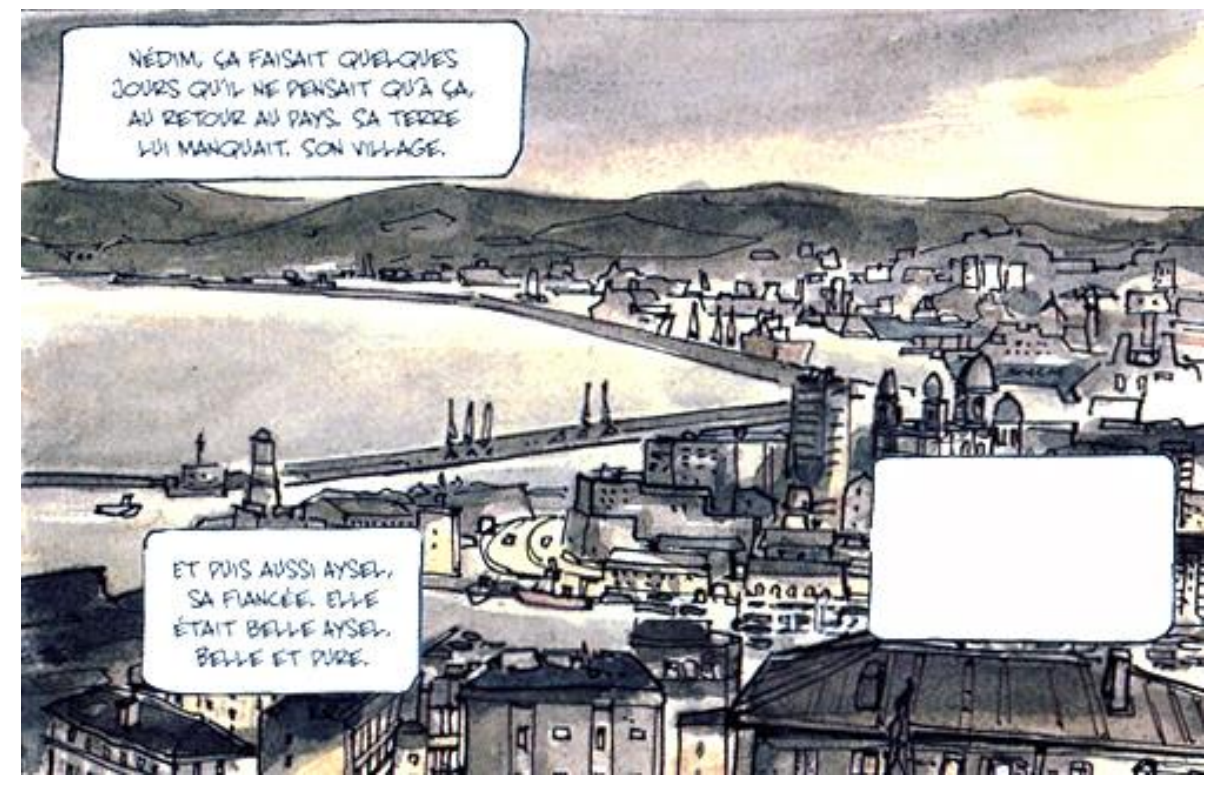

Figure 8. La rade de Marseille telle que dessinée dans la bande dessinée de $C$. Belin.

Extrait des Marins perdus - bande dessinée, Futuropolis, 2008, page 20.

Cet exemple du lieu où réside « Masetto » est assez révélateur du caractère réaliste du dessin (Fig. 9). Pour rendre plausible cet « endroit», on note que l'auteur a mobilisé les éléments qui lui ont semblé indispensables pour le reconnaître : les arches du pont et les petits bateaux de pêche. Sans même connaître l'adresse précise de Masetto (la bande dessinée ne la mentionne pas), il nous a été d'aucune difficulté de retrouver ce lieu dans GoogleMaps.
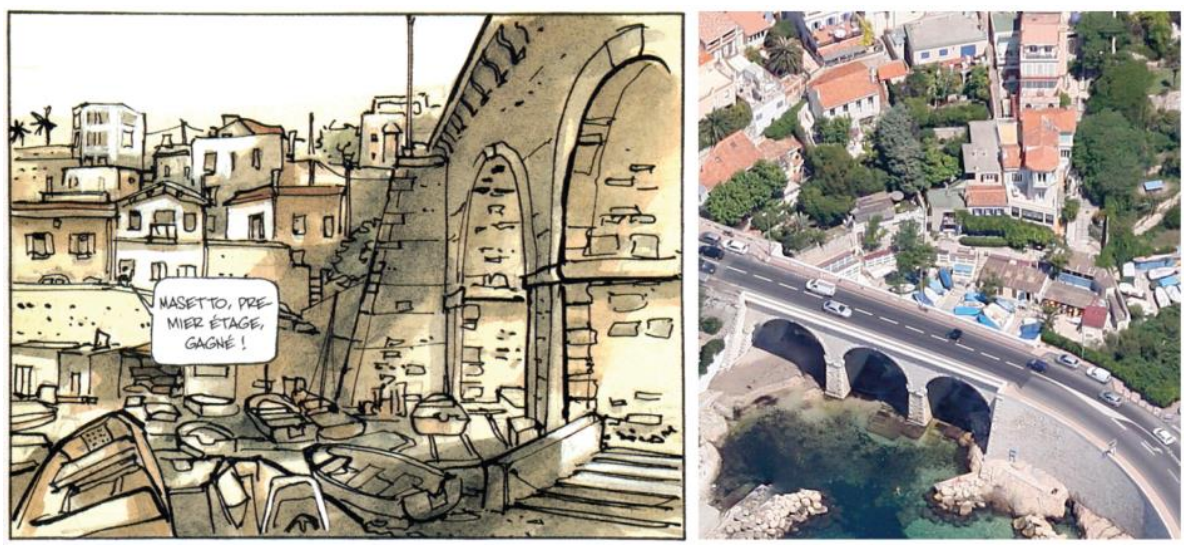

Figure 9. « Chez Masetto », tel que dessiné dans la bande dessinée de C. Belin et retrouvé sur les images de GoogleMaps.

Extrait des Marins perdus - bande dessinée, Futuropolis, 2008, page 23 \& GoogleMaps, 2015. 
Le reproche que l'on pourrait faire alors à la bande dessinée est de ne pas multiplier les images de lieux, celles décrites par un certain nombre de lignes dans le roman.

Mais il faut admettre que le choix du dessinateur - qui a dû s'arracher les cheveux devant le nombre de descriptions narratives d'Izzo - est parfaitement méritoire: effectivement, une seule image pour ces treize lignes de texte (et onze toponymes) (Fig. 10), laquelle donne - selon nous - parfaitement l'idée d'un itinéraire et permet, pour qui connaît un peu Marseille, de se positionner très précisément au point de démarrage de cet itinéraire.

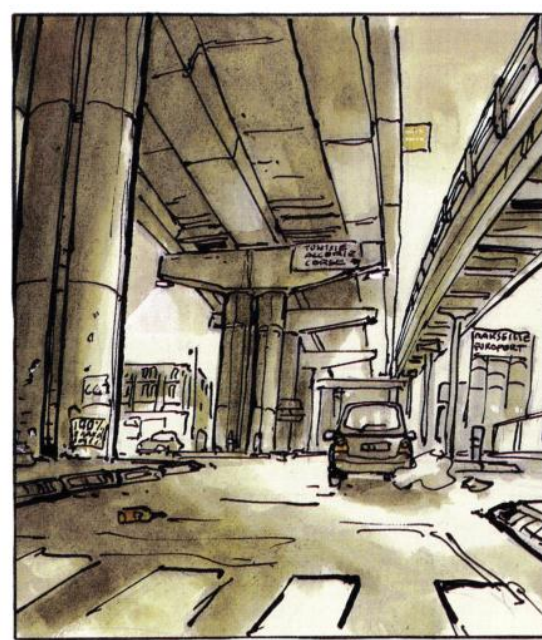

Il roula lentement le long du port désert, prit le tunnel qui traverse le Vieux-Port, ressortit devant l'ancien bassin de carénage, face à la vieille abbaye de Saint-Victor, puis se dirigea vers la Corniche. Jusqu'à la plage du Prophète, il se rappelait. Après.. Dans la boîte à gants, il trouva un plan de Marseille. Au-dessus de la plage, avait précisé Ricardo. La traverse Nicolas. Il la repéra sur la carte. Au milieu d'un dédale de ruelles. Il allait s'y perdre, en voiture. Il se gara en bas du chemin de l'Oriol et grimpa la montée de Roubion. Une volée de marches, la traverse Nicolas était là. Des chiens aboyèrent, ici et là, déchirant le silence du quartier.

Figure 10. Comparaison entre une description « imagée » et une description « romancée ».

Extrait des Marins perdus - bande dessinée, Futuropolis, 2008, page 72 et roman, page 280.

Ainsi, en matière d'apports respectifs du roman et de la bande dessinée par rapport à l'espace, nous pouvons parler de complémentarité de ces deux médias. Pour terminer sur cette thématique, il nous faut parler du « sensible » et, cette fois, sur deux aspects qui opposent fermement les deux auteurs.

\section{La part du « sensible » : un choix de couleurs signifiant}

À la première lecture de la bande dessinée, le choix des tons ocres, présents du début à la fin, interpelle. Surtout quand, de la lecture du roman, on a gardé en tête ces lignes qui parlent de mer, qui parlent de ciel, qui parlent de bleu. 
Il n'eut pas un seul regard pour la mer devant lui. Bleue, à l'image du ciel. Un ciel limpide. Immaculé. Éclatant. (Izzo, 1997 : 281)

Le contraste avec l'image qui s'y rapporte est saisissant : de l'ocre, encore de l'ocre, toujours de l'ocre ${ }^{11}$, à peine un peu plus foncé lorsque la nuit tombe. On l'analysera comme étant le choix délibéré d'un dessinateur qui est pour une fois sorti du cliché de la ville du sud toute de bleue vêtue, pour nous fournir l'image de la ville à la lumière généralement écrasante, baignée par une chaleur souvent épouvantable, sans un souffle d'air... Quoi de mieux alors que ces tons chauds qui nous viennent naturellement à l'esprit lorsque l’on évoque les territoires qui bordent la Méditerranée, aussi bien au nord qu'au sud.

Mais cet emploi systématique d'une même teinte estompe ce que Izzo avait mentionné dans son roman en matière de notations sensorielles de l'espace traversé... Ce travail de cartes sensibles du Marseille d'Izzo n'a pas encore été effectué ; tout au plus pouvons-nous constater qu'il ne sera possible de l'élaborer qu'à partir du roman, beaucoup plus riche dans ce domaine.

\section{Conclusion}

Bien sûr il a été très tentant pour nous d'étudier dans le détail la transposition de ce roman en bande dessinée. L'exercice revient à se poser les mêmes questions que celles que l'on se pose à la sortie d'une pièce de théâtre, lorsqu'on se demande en quoi la pièce a été l'adaptation fidèle du texte d'origine, quels sont les détails qui ont été conservés/supprimés par le metteur en scène, quels sont les éléments qui ont été rajoutés pour rendre la pièce peut-être plus actuelle...?

Et justement, l'exercice pour nous n'est pas terminé puisque Les Marins perdus ont été adaptés au cinéma par Claire Devers en 2003. Nous n'avons pas voulu visionner le film pour rester dans l'imaginaire véhiculé par les lignes du roman et les images de la bande dessinée. Car pour nous, l'intérêt de ces deux médias est qu'ils laissent l'un et l'autre une grande place à l'imaginaire.

En effet, comment ne pas laisser son esprit vagabonder à la lecture de ces lignes... 
Ils pénétraient dans le canal de Panamá. Son premier commandement. L'Éridan. Cap sud, puis cap est, afin de gagner le Pacifique. D'une écluse à l'autre, de balise en balise. Avant de prendre le bateau, il avait étudié le canal comme un lycéen. Les noms des écluses. Gatun Lake. Pedro Miguel. Miraflores. Longueur, largeur, profondeur. Il en avait appris tous les risques. Lu tout ce qui avait été écrit. Et il y était maintenant, devant le canal de Panamá. (Izzo, 1997 : 255)

Ou devant ces images qui parlent de cartes, de cartes et de littérature...

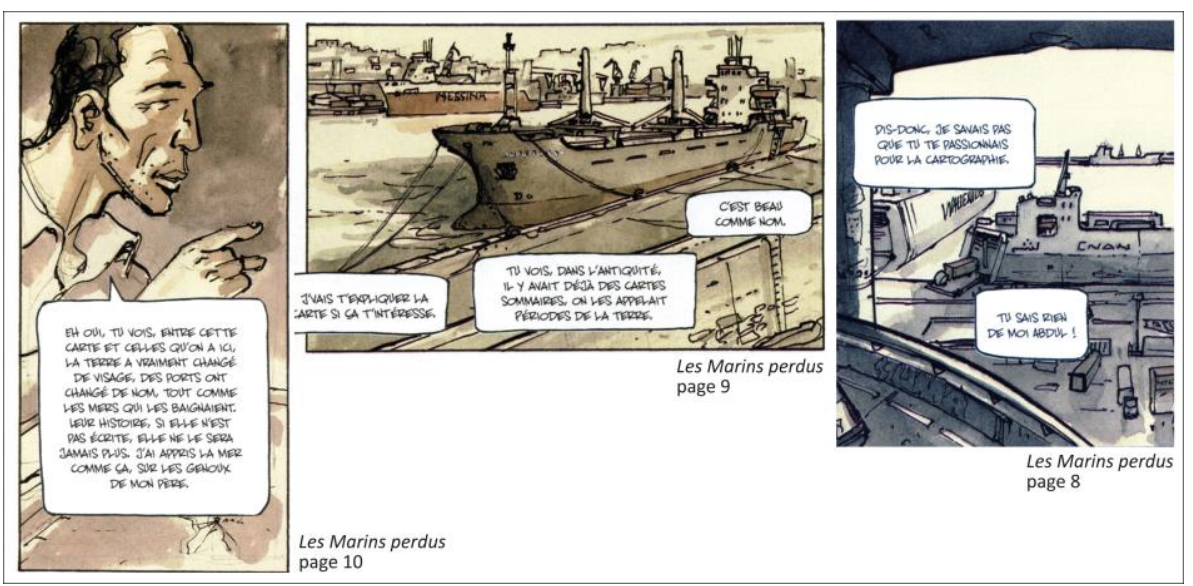

Figure 11. Les cartes et la cartographie dans Les Marins perdus - bande dessinée.

Extraits des Marins perdus - bande dessinée. Futuropolis, 2008. Montage Fl. Troin • CITERES 2015

Ou encore, pour finir, devant ce texte et cette image...

C'est comme ça qu'à douze ans j'avais compris que seule la cartographie pose toutes les questions sur la mer et la terre. C'est-à-dire sur le monde, et notre regard sur le monde. Tu me suis ?

- Ouais, ouais, tout à fait.

- J Je crois que j'aurais aimé ça, être cartographe. Ou géographe.

- $\quad$ Mais t'as pris la mer.

- $\quad$ Je ne me suis pas donné d'autres choix. Mais... Marin, dans le fond, c'est pareil. À chaque voyage, on redessine le monde. (Izzo, $1997: 31$ )

Je serais alors tentée de conclure sur la complémentarité du roman et de la bande dessinée. Certes, le roman en dit beaucoup plus sur la géographie (et l'histoire) de Marseille, ce qui nous a permis de mener à bien notre entreprise qui consiste à vouloir mettre en cartes des œuvres fictionnelles ; mais, dans ces mêmes moments, la bande 
dessinée fait une grande place à l'humain, transpose, donne dans la psychologie des personnages...

Cette dichotomie se trouve parfaitement résumée par les deux images de couverture : celle du roman, couverture bleue dont l'image semble surplomber le port de Marseille, et le nom de l'auteur qui prime sur le titre (Izzo fait vendre à Marseille et pour Marseille)... ; celle de la bande dessinée, toujours le port, bien évidemment ocre, un homme désœuvré et un angle de vue placé à hauteur d'homme, justement...
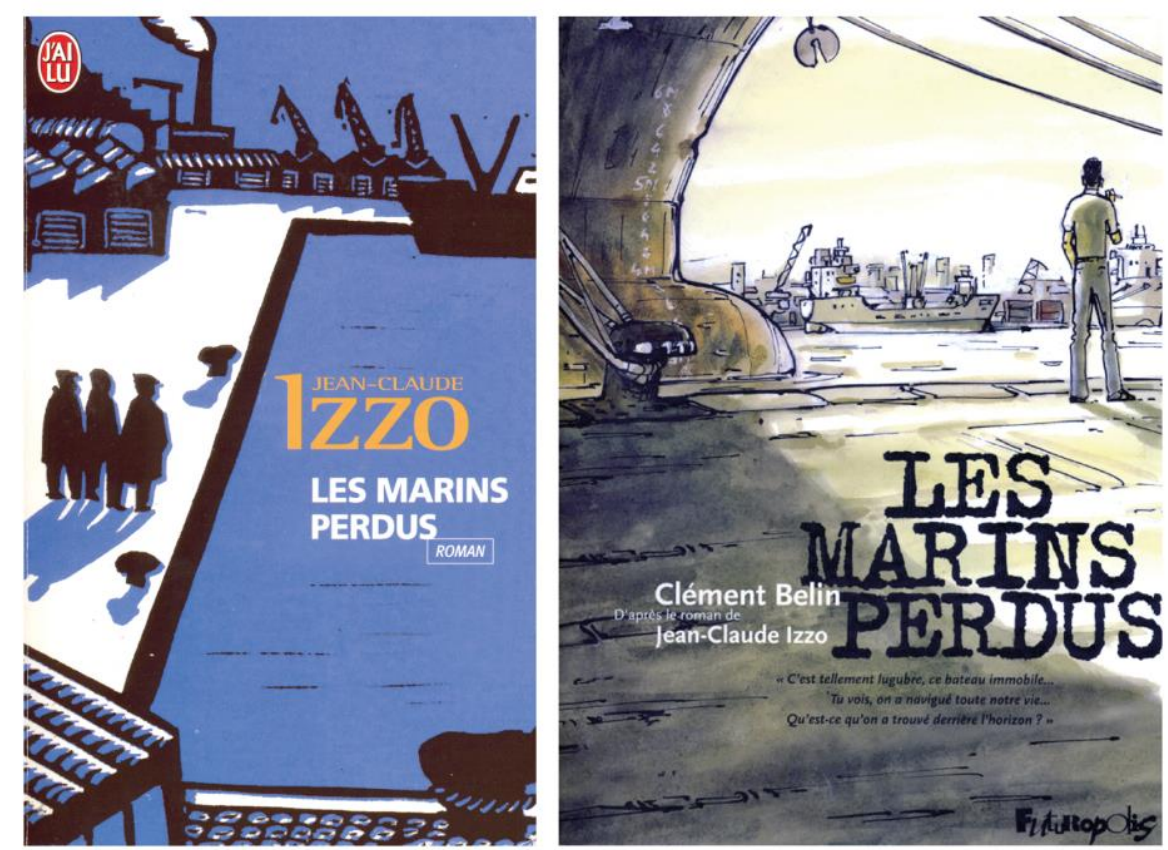

Figure 12. Complémentarité du roman et de la bande dessinée à travers leurs couvertures. Montage Fl. Troin • CITERES 2015 


\section{Bibliographie}

Collot, Michel (2014), Pour une géographie littéraire, Paris, Corti, coll. « Les Essais ». Rosemberg, Muriel (2007), "Les pratiques citadines d'un héros de roman policier», Bulletin de l'Association des Géographes Français, 2007/3 («Géographie et littérature », J.-L. Tissier coord.), pp. 266-273.

Rosemberg, Muriel. Troin, Florence (2015) (à paraître). «Contribution de la cartographie à l'analyse géolittéraire, proposition critique », Mappemonde (en ligne).

Tissier, Jean-Louis (2007), «Géographie et littérature: présentation», Bulletin de l'Association des Géographes Français, 2007/3 («Géographie et littérature », J.-L. Tissier coord.), pp. 243-247.

\section{Ouvrages de référence}

Belin, Clément (2008), Les Marins perdus, d'après le roman de Jean-Claude Izzo, Paris, Futuropolis, $84 \mathrm{p}$.

Izzo, Jean-Claude (1997), Les Marins perdus, Paris, J’ai Lu, coll. « Roman », n 4841, 316 p.

Florence Troin est géographe-cartographe, ingénieure de recherche à CITERES (UMR 7324, CNRS \& Univ. de Tours). Elle collabore depuis plus de quinze ans aux programmes de recherche de l'équipe EMAM (« Monde arabe et Méditerranée »), sur des thématiques variées (gestion des déchets, sauvegarde du patrimoine, transformations des périphéries).

Ouvrage récent, en coll. avec N. Semmoud, B. Florin et O. Legros (dir.) : Marges urbaines et néolibéralisme en Méditerranée, Tours, PUFR, 2014.

En parallèle, elle a investi depuis deux ans le champ des rapports entre la géographie et la littérature en produisant des mises en carte(s) de romans. 
Article récent, en coll. avec N. Semmoud : « La Barcelone de L'Ombre du Vent de C.R. Zafón, héroïne d'une géographie sensible », in A. Madoeuf et R. Cattedra (dir.), Lire les villes. Panoramas du monde urbain contemporain, Tours, PUFR, 2012.

Article à paraître : « Une expérience de cartographie stimulante : révéler des dimensions cachées à l'intérieur des récits policiers. L'Ombre du vent de C.R. Zafón et la Trilogie Fabio Montale de J.-C. Izzo ", in Comment cartographier les récits documentaires et fictionnels?, Journées d'études du LIDO « Des lieux, Des oeuvres », Clermont-Ferrand, PUBP.

\section{Notes}

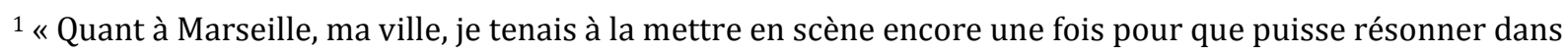
cette histoire les questions les plus actuelles de la Méditerranée.» (Izzo, 1997 : 313). Les paginations données correspondent à l'édition des Marins perdus chez l'éditeur "J'ai Lu », coll. « Roman », n 4841 (1997).

${ }^{2}$ Total Khéops, Chourmo \& Soléa, parus dans la collection Folio Policier, respectivement en 1995, 1996 et 1998.

${ }^{3}$ Il s'agit de Soléa.

${ }^{4}$ « Cet intérêt des géographes pour la littérature reflète une évolution récente de la discipline, qui n'est plus seulement humaine ou humanise, mais culturelle. », M. Collot, 2014, p. 23.

${ }^{5}$ J.-L. Tissier, « Géographie et littérature : présentation », BAGF n 2007/3, p. 243.

${ }^{6} 276$ dans Total Khéops, 223 dans Chourmo et 97 dans Soléa.

${ }^{7}$ Un « roman graphique » peut se définir comme étant une bande dessinée pour adultes, plutôt longue et sérieuse.

${ }^{8}$ M. Rosemberg, «Les pratiques citadines d'un héros de roman policier », BAGF n 2007/3, p. 266.

${ }^{9}$ Exemple de «Chez Toinou » : se situe place de Lenche, en bas du Panier qui est lui-même un «vieux» quartier, et à deux pas du Vieux-Port, soit une juxtaposition de quatre «adresses». Dans la bande dessinée, une image résume cet «endroit», une image qui - ce n'est pas toujours le cas - rend bien compte de la réalité du lieu décrit dans le roman.

10 Lesquels sont - de même que dans le roman - particulièrement nombreux : 8 sur 26 toponymes «marseillais» $(30 \%)$.

11 «Un choix au demeurant esthétique mais qui affadit parfois le dessin», L. Gianati, bedetheque.com, juillet 2008. 



\section{Libretos}

XX ILCML

FCT Fundação para a Ciência e a Tecnologia MINISTÉRIO DA CIÊNCIA, TECNOLOGIA E ENSINO SUPERIOR

UID/ELT/00500/2013
COMPETE 2020 \& 2020

POCI-01-0145-FEDER-007339 